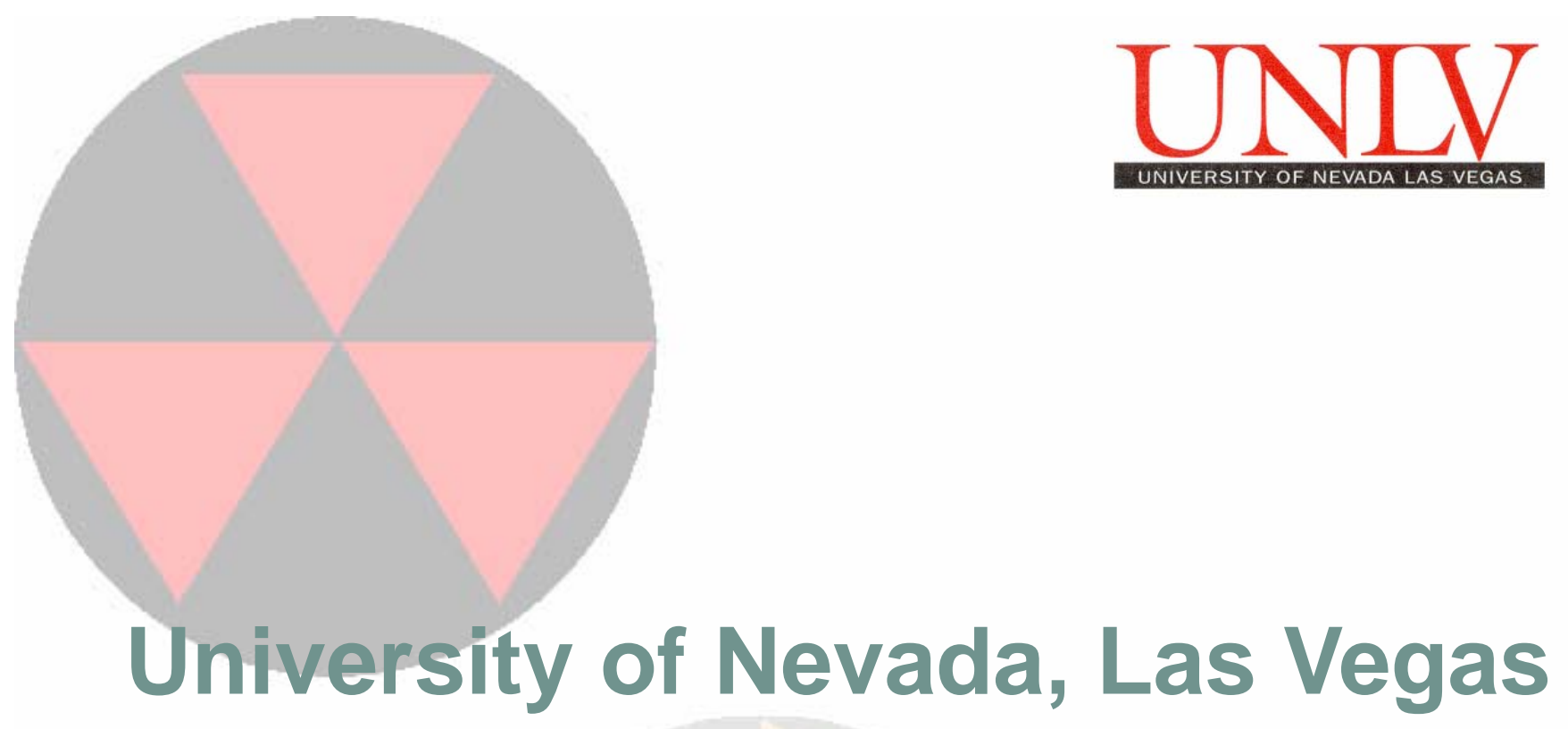

\title{
Advanced Accelerator Applications University Participation Program
} Final Scientific/Technical Report Grant No. DE-FG07-01AL67358
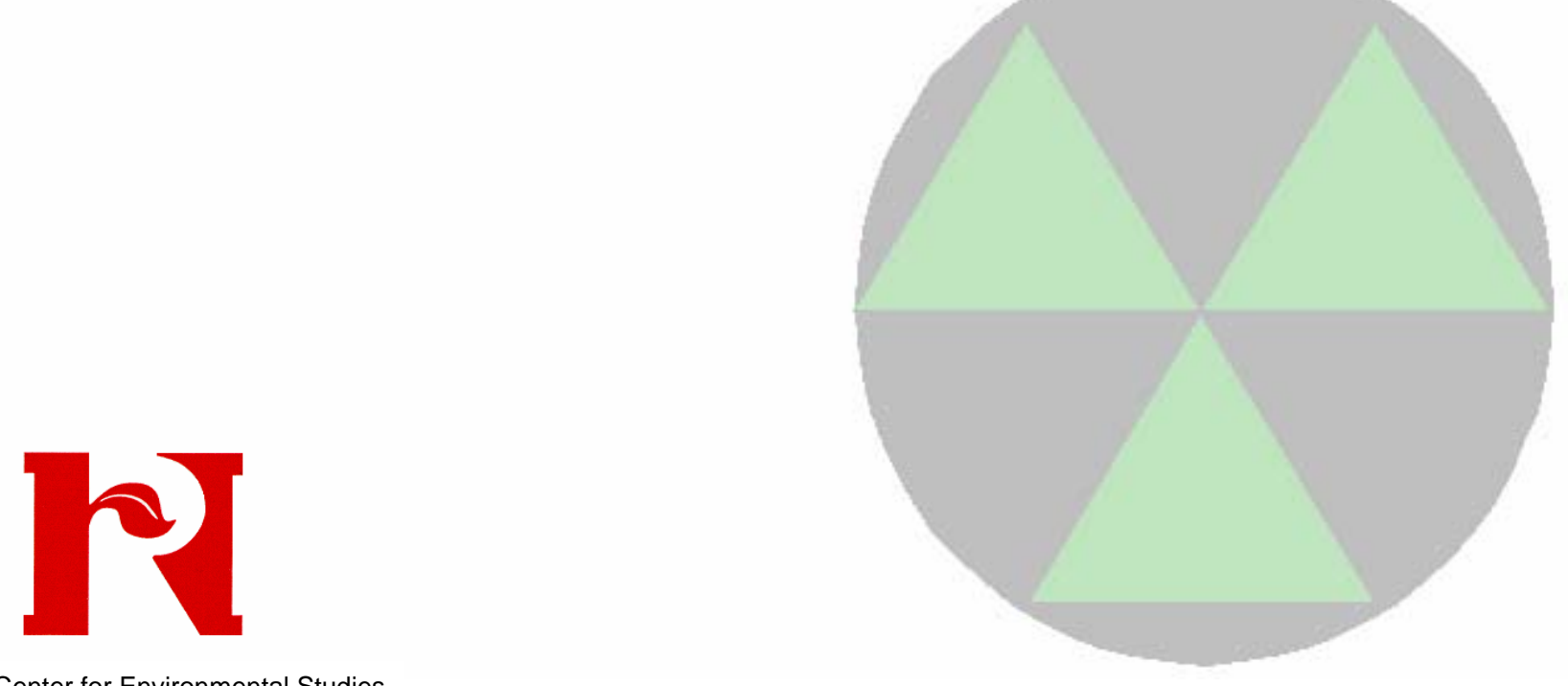


\section{Table of Contents}

Letter from the Director

HTHX

HTHX

TRP Task 1

TRP Task 2

TRP Task 3

TRP Task 4

TRP Task 5

TRP Task 6

TRP Task 7

TRP Task 8

TRP Task 9

TRP Task 10

TRP Task 11

TRP Task 12

TRP Task 13

TRP Task 14

TRP Task 15

TRP Task 16

TRP Task 17

TRP Task 18

TRP Task 19

TRP Task 20

TRP Task 21

TRP Task 22

TRP Task 23

TRP Task 24

TRP Task 25

TRP Task 26

TRP Task 27

TRP Task 28

TRP Task 29

TRP Task 30

Deep Burn
High Temperature Heat Exchanger Project: Design and Testing

High Temperature Heat Exchanger Project: Materials

Design and Analysis of a Process for Melt Casting Metallic Fuel Pins Incorporating Volatile Actinides

Modeling, Fabrication, and Optimization of Niobium Cavities

Corrosion of Steel by Lead Bismuth Eutectic

Environment-Induced Degradation and Crack-Growth Studies of Candidate Target Materials

Modeling Corrosion in Oxygen Controlled LBE Systems with Coupling of Chem. Kinetics and

Hydrodynamics

Neutron Multiplicity Measurements of Target/Blanket Materials

Development of Dose Conversion Coefficients for Radionuclides Produced in Spallation Targets

Development of a Systems Engineering Model of the Chemical Separations Process

Design and Evaluation of Processes for Fuel Fabrication

Development of a Mechanistic Understanding of High-Temperature Deformation of Alloy EP-823 Cycle

Radiation Transport Modeling using Parallel Computational Techniques

Developing a Sensing System for the Measurement of Oxygen Concentration in Liquid Pb-Bi Eutectic 30

Use of Positron Annihilation Spectroscopy for Stress-Strain Measurements

Immobilization of Fission Iodine by Reaction with a Fullerene Containing Carbon Compound and Insoluble 34 Natural Matrix

Evaluation of Fluorapatite as a Waste-Form Material

Interaction between Metal Fission Products and TRISO Coating Materials: A Study of Chemical Bonding and 38 Interdiffusion

Fundamental and Applied Experimental Investigations of Corrosion of Steel by LBE under

Controlled Conditions: Kinetics, Chemistry, Morphology, and Surface Preparation

Dissolution, Reactor, and Environmental Behavior of $\mathrm{ZrO}_{2}-\mathrm{MgO}$ Inert Fuel Matrix

Effect of Silicon Content on the Corrosion Resistance and Radiation-Induced Embrittlement of Materials for Advanced Heavy Liquid Metal Nuclear Systems

Theoretical Modeling of Protective Oxide Layer Growth in Non-isothermal Lead-Alloys Coolant Systems

Design Concepts and Process Analysis for Transmutation Fuel Manufacturing

Development of Nanostructure based Corrosion-Barrier Coatings on Steel for Transmutation

Applications

Development of Integrated Process Simulation System Model for Spent Fuel Treatment Facility Design

Electrochemical Separation of Curium and Americium

Fundamental Chemistry of Uranium and Plutonium in the TBP - Dodecane - Nitric Acid System

Reactor Physics Studies for the AFCI Reactor-Accelerator Coupling Experiments Project

Impact of the Synthesis Process on Structure Properties for AFC Fuel Candidates

Investigation of Optical Spectroscopy Techniques for On-Line Materials Accountability in the Solvent

Extraction Process 


\section{Letter from the Director}

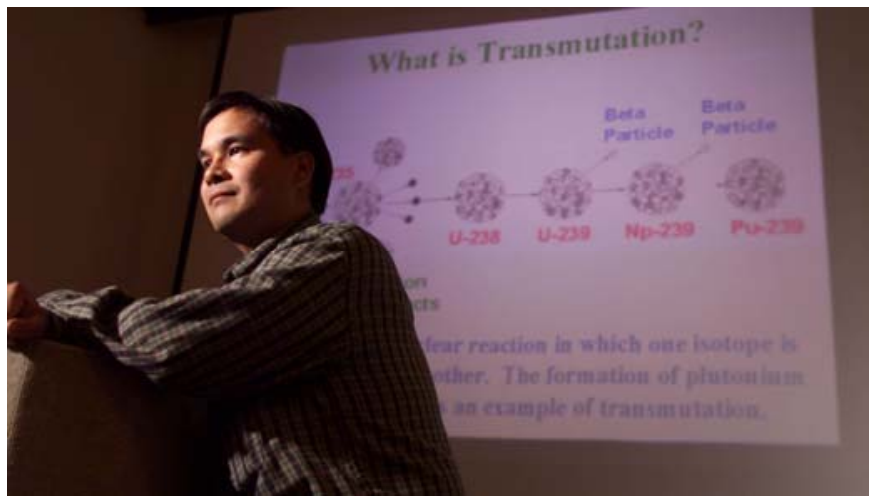

Anthony E. Hechanova, Ph.D.

Director, Nuclear Science and Technology Division

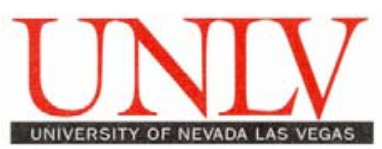

It is my pleasure to present the UNLV Advanced Accelerator Applications University Participation Program's Final Technical Report that highlights the activities of the Transmutation Research Program, the Deep Burn Reactor Program, and the High Temperature Heat Exchanger Program from the fiscal years 2001 to 2007. Supporting this document are the many technical reports and theses that have been generated over the past six years, which can be found on our program's websites at http://aaa.nevada.edu, http://

nstg.nevada.edu/heatexchangers.html, or by request.

In the six years of our program, we saw the evolution of the national transmutation concepts go from the use of accelerators to fast reactors. We also saw an emphasis on gascooled reactors for both high temperature heat and deep burn of nuclear fuel. At the local level, we saw a great birth at UNLV of two new academic programs Fall term of 2004 and the addition of 10 academic and research faculty. The Ph.D. program in Radiochemistry has turned into one of the nation's most visible and successful programs; and, the M.S. program in Materials and Nuclear Engineering initiated Nuclear Engineering academic opportunities which took a long time to come.

Our research tasks span the range of technology areas for transmutation, gas-cooled reactor technology, and high temperature heat exchangers, including separation of actinides from spent nuclear fuel, methods of fuel fabrication, reactor-accelerator coupled experiments, corrosion of materials exposed to lead-bismuth eutectic, and special nuclear materials protection and accountability.

Finally, I believe that through the Transmutation Research Program, the Deep Burn Program, and the High Temperature Heat Exchanger Program, UNLV has established itself as the core university participant in the U.S. Department of Energy, Office of Nuclear Energy research with active collaboration with national laboratories, universities, and international institutions.

Sincerely,

$$
\text { Anthom S. Blechanoox }
$$

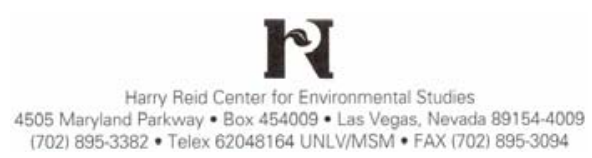




\section{High Temperature Heat Exchangers \\ Design and Testing \\ Y. Chen and A. Hechanova}

\section{BACKGROUND}

Heat exchangers are the key energy conversion components for thermally-driven hydrogen production. Heat exchangers are used in many commercial applications, and numerous types of units can be purchased from a large number of manufacturers. The performance requirements and component designs for these commercial applications are straightforward.

However, commercial units and standard designs will almost certainly be inadequate for the applications anticipated in high temperature nuclear reactor projects. For example, highly reactive and corrosive chemicals at very high temperature, and possibly high pressure, will require specialized materials and fabrication processes to assure safety and durability over long periods and many process cycles for thermochemical processes considered under the Nuclear Hydrogen Initiative.

Although it was decided that much of the research needs still need to be determined and that a working group should be convened to define the baseline High Temperature Heat Exchanger (HTHX) concept, one research task was given the green light: the concept of using an offset strip fin heat exchanger made from liquidsilicon-impregnated carbon-carbon composite that considers helium gas and molten salt as working fluids.

\section{RESEARCH OBJECTIVES AND METHODS}

The HTHX design studies have the following multi-year objectives and scope (note, this report only covers Year 1 of a threeyear project):

- Work with the U.S. Department of Energy Office of Nuclear Energy, Science and Technology nuclear hydrogen research and development program elements on high temperature systems studies for hydrogen production.

- Identify the range of HTHX applications for hydrogen production.

- Develop thermal systems concepts/designs and overall heat/

\section{Total power $=\mathbf{5 0}$}

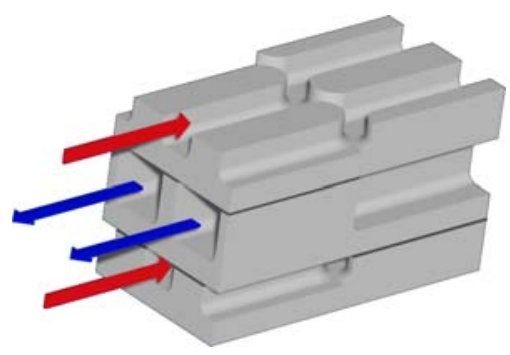

$$
\begin{aligned}
& \text { Hot side } \\
& \text { (helium) } \\
& T_{\text {in }}=1273 \mathrm{~K}
\end{aligned}
$$

Cold side (molten-salt)

$\mathrm{T}_{\text {in }}=835 \mathrm{~K}$

$\mathrm{T}_{\text {out }}=1248 \mathrm{~K}$

$D_{\mathrm{h}}=1.35 \mathrm{~mm}$

$\mathrm{P}=0.1 \mathrm{Mpa}$
Offset strip fin heat exchanger concept and operating conditions.

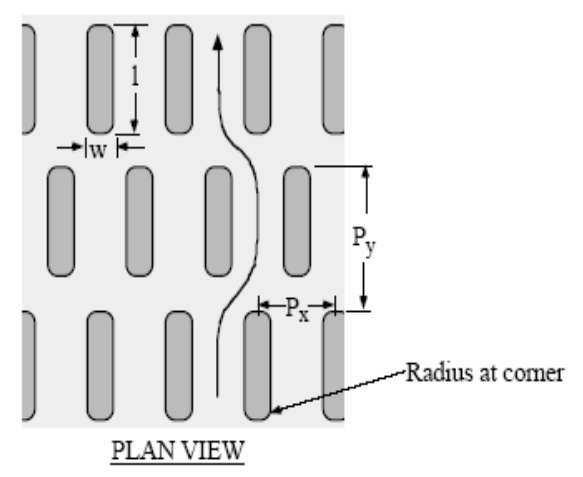

The figure on the right gives the computational domain that takes advantage of symmetry as seen in the plane view on the left.

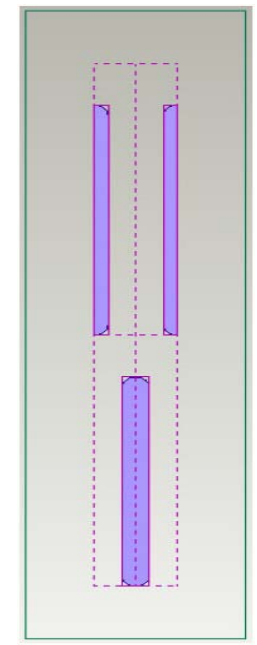

mass balances for the range of power conversion and hydrogen production concepts.

- Develop design specifications for the intermediate heat exchanger and other HTHXs used in the conceptual designs.

- Undertake thermal hydraulic systems numerical modeling to establish and analyze temperature, pressure, and flow rate requirements.

- Perform thermal, thermal hydraulic, and structural analyses for selected advanced HTHX concepts for hydrogen production.

- Deliver detailed design for candidate intermediate heat exchanger concepts and materials for hydrogen production requirements.

\section{RESEARCH ACCOMPLISHMENTS}

The commercial software FLUENT was used to simulate twodimensional fluid flow and heat transfer for the helium side of the heat exchanger. Similarly the boundary conditions used were periodic boundaries in the stream wise direction and a symmetric boundary was used in the span width. When initializing the periodic boundary condition a specified mass flow rate and a specified value of bulk stream temperature is input. The maximum velocity and the average velocity were obtained between the fins. The results were obtained for varied values of Reynolds numbers by specifying different values of mass flow rate. Vortices were observed at the trailing edge of the offset strip-fins at all values of Reynolds numbers over 100 for the helium side which is an expected phenomenon.

It was also observed that the occurrence of vortices at the trailing edge of the fins depend upon the aspect ratio. For the case with a fin thickness of $1 \mathrm{~mm}$ and a length of $10 \mathrm{~mm}$ vortices are observed but were reduced when the fin thickness was reduced. Geometry optimization will require manufacturing issues since dimension are already very small. Attempts should be made to reduce deleterious effects in the stagnation regions. As the vor- 
tices regions are considered to be hot-spots during heat transfer because of the thermal stress on the material. Numerical simulation was performed at different offset distances in the stream-wise direction. It was decided not to reduce the fin thickness any further keeping in mind the manufacturing difficulties.

As expected, the flow obtained between the fins was found to be non-fully developed which adds to heat transfer enhancement. The temperature profiles obtained were found to be relevant considering the constant wall temperature boundary condition as well as the convective heat transfer boundary conditions which were assumed.

Using the convective heat transfer boundary condition the heat transfer coefficient of the external side as well as the external temperature was given as input. In the next step heat transfer from the molten salt channels also needs to be given as input because of the $2 \mathrm{D}$ treatment. It was also observed that the occurrence of vortices at the trailing edge of the fins depend upon the aspect ratio. In our case with a fin thickness of $1 \mathrm{~mm}$ and a length of $8 \mathrm{~mm}$ vortices are observed but were reduced when the fin thickness was reduced so an optimized design will need to consider manufacturability.

The heat transfer coefficient for the offset strip fin design was calculated using a new definition of hydraulic diameter that accounts for differences in the geometry from that used in the correlation of Manglik and Bergles. The physical properties of helium and molten salt are estimated at the average fluid temperatures on the helium side $(\mathrm{T}=1089 \mathrm{~K}, \mathrm{p}=7.06 \mathrm{MPa})$ and molten salt side ( $\mathrm{T}=1041 \mathrm{~K}, \mathrm{p}=0.1 \mathrm{MPa})$.

The results of the calculations give for the Helium side:

$$
\begin{aligned}
& \mathrm{Pr}=0.65923 \\
& \mathrm{Re}=2030.07 \\
& \mathrm{Nu}=14.986 \\
& \mathrm{~h}=3042.75 \mathrm{~kg} /\left(\mathrm{s}^{3} \cdot \mathrm{K}\right)
\end{aligned}
$$
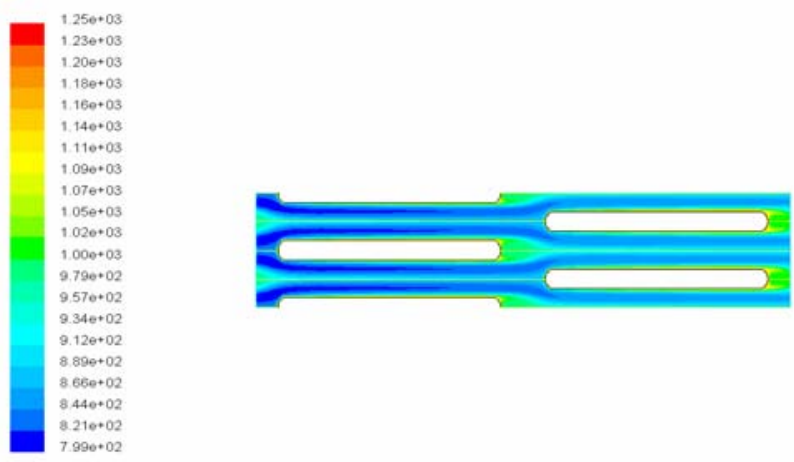

Helium-side temperature contours (units in degrees K).

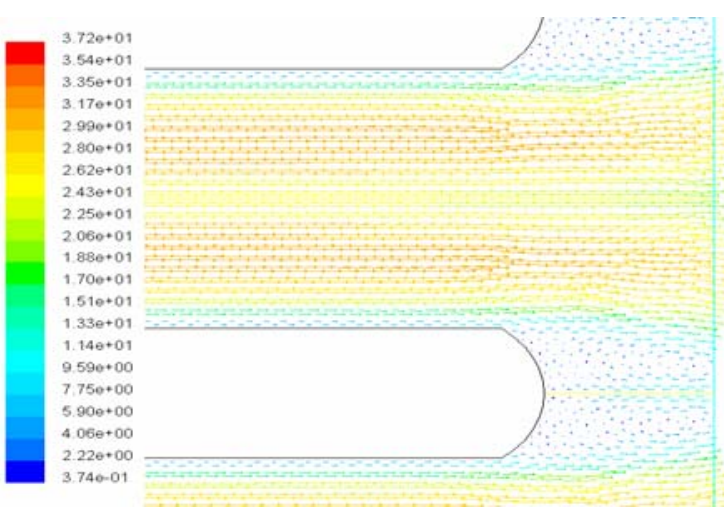

Helium-side velocity vectors on the trailing edge (units in $\mathrm{m} / \mathrm{s}$ ).

The results of the calculations give for the Molten salt side:

$$
\begin{aligned}
& \mathrm{Pr}=11.88353 \\
& \mathrm{Re}=55.3 \\
& \mathrm{Nu}=6.475 \\
& \mathrm{~h}=5426.87 \mathrm{~kg} /\left(\mathrm{s}^{3} \cdot \mathrm{K}\right)
\end{aligned}
$$

It was decided that the concepts of two-dimensional studies of fluid flow and heat transfer on the helium side cannot be applied to the molten salt side due to a low ratio of the channel height to its width (1:1.75). Due to this low ratio, three-dimensional effects on the molten salt side can not be neglected. The other reason for moving to a three-dimensional simulation is interest in calculating local temperatures which requires a three-dimensional simulation between fluids instead of confining the temperature on the wall or specifying the heat flux. The FLUENT software should allow one to determine the temperature distribution on the wall and inside the solid material, and to find locations of hot spots and heat traps needed for the fin designing process. The temperature and local heat transfer coefficient values will then be used for thermal stress analyses.

Before creating a complete three-dimensional model for the offset strip fins, a simplified three-dimensional model will first be created that will consist of several channels of rectangular cross section inside the solid for helium and molten salt, and to observe the temperature distribution in the solid material and local heat transfer coefficient distribution on the surface of the wall. This geometrical simplification is needed for time saving on generating a 3-D mesh. The results of this simplified case will allow one to monitor whether the FLUENT software can accurately solve this class of problems, and to understand the boundary conditions treatment in FLUENT on the solid-fluid interface which is easier to do on a simple three-dimensional geometry.

Research Staff

Yitung Chen, Principal Investigator, Associate Professor, Department of Mechanical Engineering

Anthony Hechanova, Associate Research Professor, Harry Reid Center for Environmental Studies

Roald Akberov, Research Associate, Department of Mechanical Engineering

Students

Sundar Subramanian and Kiran Muramalla, Graduate Students, Department of Mechanical Engineering

Clayton De Losier, Undergraduate Student, Department of Mechanical Engineering 


\section{High Temperature Heat Exchangers \\ Materials \\ A.K. Roy}

\section{BACKGROUND}

Selection of structural metallic materials and alloys for hightemperature heat exchangers to generate hydrogen using nuclear energy poses a major challenge to scientific and engineering communities. These materials must possess excellent resistance to numerous environment-induced degradation and superior hightemperature metallurgical properties.

\section{RESEARCH OBJECTIVES AND METHODS}

The HTHX materials studies have the following multi-year objectives and scope (note, this report only covers Year 1 of a threeyear project):

- Tensile testing at ambient temperature to determine yield strength (YS), ultimate tensile strength (UTS), failure stress $\left(\sigma_{\mathrm{f}}\right)$, percent elongation $(\% \mathrm{El})$ and reduction in area $(\% \mathrm{RA})$.

- Tensile testing at elevated temperatures $\left(100-700^{\circ} \mathrm{C}\right)$ in the presence of nitrogen to determine the tensile properties including ductility parameters as a function of test temperature.

- Metallographic evaluation of specimens before and after tensile testing using optical microscopy.

- Transmission electron microscope (TEM) evaluation of the tested specimens to characterize the deformation mechanism.

- Localized corrosion (pitting/crevice) studies using potentiostats at elevated temperatures to determine the corrosion potential and the critical pitting potential.

- Stress corrosion cracking (SCC) tests using constant-load and slow-strain-rate (SSR) techniques at elevated temperatures with and without controlled cathodic potentials to determine the effect of hydrogen.

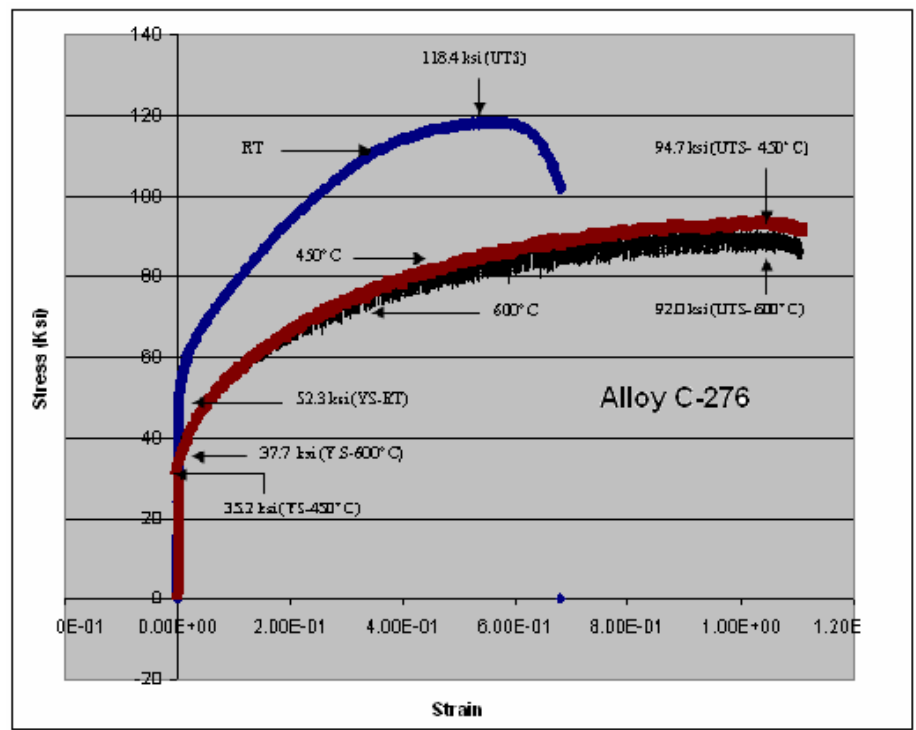

Stress-Strain Diagrams for Alloy C-276 at Different Temperatures.

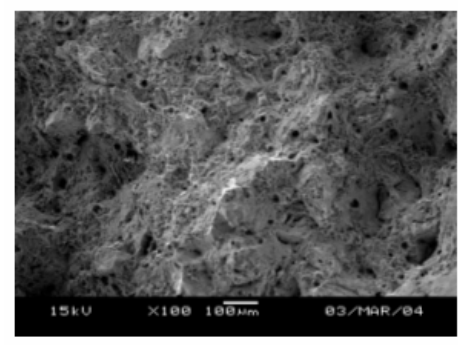

Waspaloy (Room Temperature)

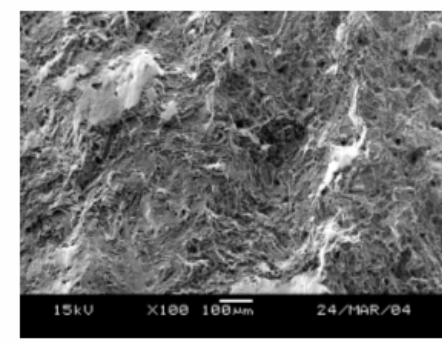

Waspaloy $\left(600^{\circ} \mathrm{C}\right)$
SEM Micrographs of Waspaloy.

- Fractographic evaluation of broken tensile specimens used in SCC testing by scanning electron microscopy (SEM) to determine the extent and morphology of cracking.

- Evaluation of general/localized corrosion test specimens by optical microscopy.

Based on the review of literature gathered from numerous materials-related meetings held at Oak Ridge National Laboratory and UNLV during the past few months, three additional engineering alloys have been identified. They are Incoloy $800 \mathrm{H}$, Incoloy $800 \mathrm{HT}$ and AL 610. Round bars of Incoloy $800 \mathrm{H}$ and $800 \mathrm{HT}$ were ordered to prepare tensile and corrosion testing specimens.

In addition to the work-scope associated with the present investigation, the following two subtasks have been proposed to perform collaborative research with the General Atomics, Inc. (GA) to evaluate prospective structural materials for application in Hydroiodic Acid (HI) decomposition:.

- Corrosion Studies of Candidate Structural Materials in HIx Environment as Functions of Metallurgical Variables

- Crack Growth Studies of Materials in HIx Environment at Elevated Temperatures and Pressures

The materials identified for these two subtasks are $\mathrm{Zr} 702, \mathrm{Zr} 705$, $\mathrm{Nb} 1 \mathrm{Zr}$ and $\mathrm{Ta}-40 \% \mathrm{Nb}$.

\section{RESEARCH ACCOMPLISHMENTS}

Since the inception of this project, preliminary experimental work involving three nickel-base alloys, namely Alloy C-22, Alloy C276 and Waspaloy was initiated. Tensile properties of all three alloys have been determined at ambient temperature, 450 and $600^{\circ} \mathrm{C}$ in the presence of nitrogen using the existing Material Testing System (MTS) machine at UNLV's Mechanical Engineering Department. Further, the evaluation of the stress corrosion cracking susceptibility of all three alloys in an aqueous solution containing sulfuric acid and sodium iodide under a constantloading condition was conducted. Fractographic evaluations of the tested tensile specimens by scanning electron microscopy have also been performed. 


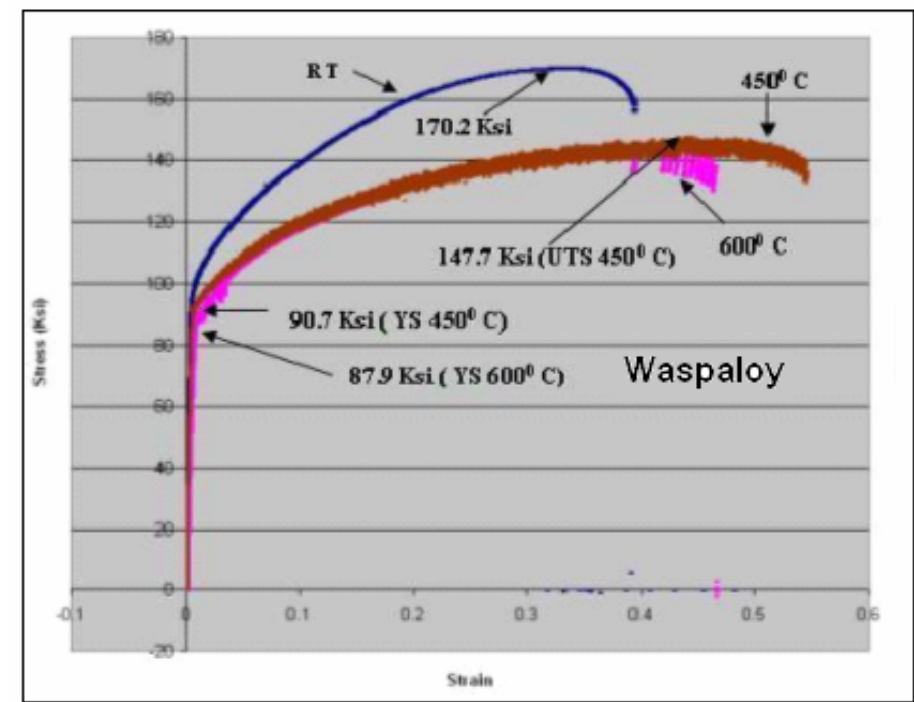

Stress-Strain Diagrams for Waspaloy at Different Temperatures.

The results of tensile testing, shown in the table below, indicate that very little loss in strength in terms of yield strength and ultimate tensile strength was observed in Waspaloy due to a change in testing temperature from ambient to $600^{\circ} \mathrm{C}$. Between 450 and $600^{\circ} \mathrm{C}$, slight reduction in strength was observed for all three alloys. The ductility in terms of percent elongation was significantly enhanced at elevated temperatures for Alloys C-22 and 276 , as expected. The stress versus strain diagrams for all three tested materials are shown.

Fractographic evaluations of the tested tensile specimens by scanning electron microscopy revealed dimpled microstructure, indi-

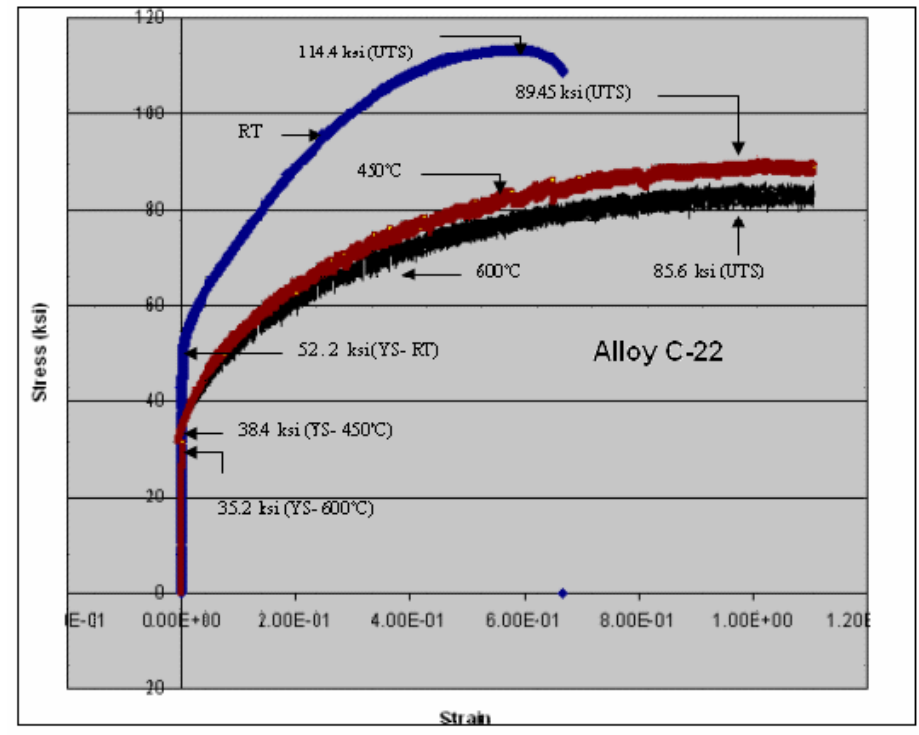

Stress-Strain Diagrams for Alloy C-22 at Different Temperatures.

cating ductile failures at all three testing temperatures.

Stress corrosion cracking testing under constant-loading conditions involving all three alloys was conducted in aqueous environments containing sulfuric acid and sodium iodide at $90^{\circ} \mathrm{C}$. No failures have yet been observed at applied stresses corresponding to 95 percent of the materials' YS values.

Significant interactions took place with research personnel at General Atomics that resulted in two collaborative research proposals to address numerous materials-related issues for successful applications in HTHX.

\section{Results of Tensile Testing.}

\begin{tabular}{|l|c|c|c|c|c|c|c|c|c|}
\hline & \multicolumn{3}{|c|}{ Average YS } & \multicolumn{3}{c|}{ Average UTS } & \multicolumn{3}{c|}{ Average \%El } \\
\hline \multirow{2}{*}{$\begin{array}{c}\text { Mate- } \\
\text { rial }\end{array}$} & RT & $450^{\circ} \mathrm{C}$ & $600^{\circ} \mathrm{C}$ & RT & $450^{\circ} \mathrm{C}$ & $600^{\circ} \mathrm{C}$ & RT & $450^{\circ} \mathrm{C}$ & $600^{\circ} \mathrm{C}$ \\
\hline $\begin{array}{l}\text { Waspa- } \\
\text { loy }\end{array}$ & 100.23 & 89.2 & 84.05 & 167.9 & 145.75 & 143.4 & 40.55 & 49.26 & 43.15 \\
\hline $\begin{array}{l}\text { Alloy } \\
\text { C-22 }\end{array}$ & 52.46 & 36.6 & 34.6 & 113.73 & 89.45 & 84.45 & 66.26 & 80.04 & 79.99 \\
\hline $\begin{array}{l}\text { Alloy } \\
\text { C-276 }\end{array}$ & 53.16 & 37.05 & 36.6 & 116.96 & 94.6 & 90.4 & 66.49 & 80.03 & 80 \\
\hline
\end{tabular}

Research Staff

Ajit K. Roy, Ph.D., Principal Investigator, Professor, Mechanical Engineering Department

\section{Students}

Raghunandan Karamcheti, Narendra Kothapalli, and Lalit Savalia, Graduate Students, Department of Mechanical Engineering 


\title{
Task 1
}

\section{Design and Analysis of a Process for Melt Casting Metallic Fuel Pins} Incorporating Volatile Actinides

\author{
Y. Chen, D.W. Pepper, and R. Clarksean
}

\section{BACKGROUND}

The incorporation of non-fertile actinides into a fuel matrix for a transmuter blanket is of interest to the Advanced Fuel Cycle Initiative. One of three proposed candidate matrices for the transmuter is a metallic alloy fuel matrix. Metallic fuels are an outstanding candidate for a transmutation fuel due to excellent irradiation performance and ease of fabrication. However, incorporating a volatile constituent during fabrication of these or other fuel pins presents a challenge.

Volatile actinides, particularly americium, are susceptible to rapid vaporization during the traditional metal fuel casting processes. The actinide vapors boil off, and flow out of the system into the off-gas recovery system, resulting in only a fraction of the volatile actinide charge being incorporated into the fuel pins. The loss of these actinides from the fuel greatly complicates the task of preparing them for transmutation, requiring additional recovery and fuel fabrication steps to try to incorporate the volatile actinides into the transmuter fuel.

\section{RESEARCH OBJECTIVES AND METHODS}

The goal of this project was to investigate the casting processes for metallic fuels to help design a process that minimizes the loss of the volatile actinide elements from the fuel. The research effort centered on the development of advanced numerical models to assess conditions that significantly impact the transport of volatile actinides during the melt casting process and represents a joint effort between researchers at UNLV and Argonne National Laboratory (ANL). Assessing critical equipment and process variables is required to build a successful system that will operate efficiently.

\section{RESEARCH ACCOMPLISHMENTS}

Development of the induction-heating model: Modeling efforts centered on the development of the governing equations, incorporating these equations into computer codes, setting up a test problem, and making preliminary calculations for the geometry of interest. Detailed analyses were conducted for an Induction Skull Melter (ISM) previously built and tested by ANL.

Modeling of casting process: Efforts continued to improve a model for the casting of fuel pins. Work considered the flow of the melt into the mold and heat transfer into the mold during solidification (after flow has stopped). Results from an energy balance model indicate that the thermal mass would typically be greater than needed to solidify the melt within the mold. The results of this simple model have aided in designing a mold to hold and solidify the fuel pins. Detailed flow and heat transfer models show how the melt flows into the mold and ultimately solidifies.

In order to test the impact of process parameters (temperature, pressure, alloying elements, etc.) on the casting process, parametric studies were carried on different processing parameters. These studies centered around model development and analysis of the impact of mold preheating on heat transfer into the model. Results will assist with determining which process parameters are critical in manufacturing a suitable metallic fuel pin.

Americium Transport Models: A model that analyzes the transport of americium from the melt to the vapor phases above the crucible was also developed. The model considers mass transport in the melt, vaporization at the surface, and transport through the vapor phase. Parametric studies were performed to evaluate the impact of different properties or situations on the transport of americium from the melt.

Develop Prototype Furnace Design: A preliminary furnace design that can be built and tested with surrogate materials is critical in order to assess the viability of metal fuels. A preliminary analysis of potential surrogate materials was completed. Manganese appears to be an acceptable surrogate material. Discussions will be held with Argonne National Laboratory staff members to insure that no health and safety issues prevent manganese from being used.

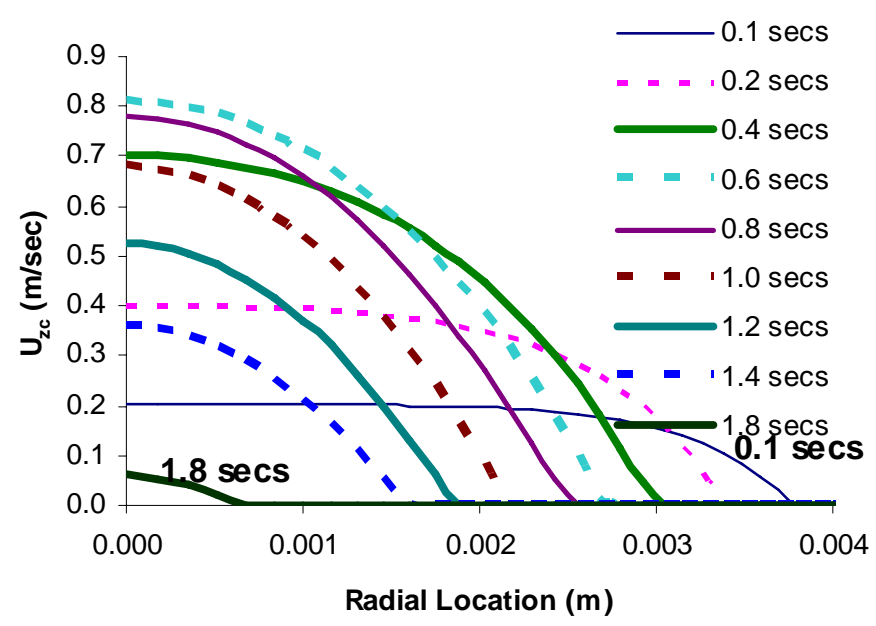

Axial velocity profile for constant inlet pressure of $20 \mathrm{kPa}$ (Mold temperature $=400^{\circ} \mathrm{C}$, initial melt temperature $=1500^{\circ} \mathrm{C}$, interfacial heat transfer coefficient $=2,000 \mathrm{~W} / \mathrm{m}^{2}-K$ ). 


\section{TASK 1 PROFILE}

Start Date: June 2001

Completion Date: June 2004

Theses Generated:

Xiaolong Wu, M.S., Mechanical Engineering, "Design and Analysis for Melt Casting Metallic Fuel Pins Incorporating Volatile Actinides,” August 2002.

Taide Tan, M.S., Mechanical Engineering, "Design and Simulation of an Induction Skull Melting System," May 2004.

Journal Article:

T. Tan, R. Clarksean, Y. Chen, S. Hsieh, and M. Meyer, 2004, "Simulation of the Casting Process for Melt Casting a Metallic Fuel Pin," submitted to Nuclear Engineering and Design.

Conference Proceedings:

T. Tan, R. Clarksean, Y. Chen, S. Hsieh, and M. Meyer, "Analyzing afor Casting Volatile Actinides," 6th International Topical Meeting on Nuclear Reactor Thermal Hydraulics, Operations and Safety, Nara, Japan, October 4-8, 2004.

T. Tan, R. Clarksean, Y. Chen, S. Hsieh, S., and M. Meyer, "Numerical SimulationInduction Heating Processin an Induction Skull Melting Furnace," ICHMT International
Symposium on Advances in Computational Heat Transfer, Norway, April 19-24, 2004.

T. Tan, R. Clarksean, Y. Chen, S. Hsieh, and M. Meyer, "Simulating the Casting Process for Melt Casting a Metallic Fuel Pin," 12th International Conference on Nuclear Engineering (ICONE-12), Arlington, VA, 25-29, 2004.

T. Tan, R. Clarksean, Y. Chen, S. Hsieh, and M. Meyer, "Simulating the Induction Heating Process in an Induction Skull Melter for Casting Metallic Fuel," ICONE-12, Arlington, VA, April 25-29, 2004.

T. Tan, R. Clarksean, Y. Chen, D. Pepper, and M. Meyer, "Simulation and Analysis for Melt Casting a Metallic Fuel Pin Incorporating Volatile Actinides" International Mechanical Engineering Congress and Exposition, Washington, DC, November 16-21, 2003.

X. Wu, R. Clarksean, Y. Chen, D. Pepper, and M.K. Meyer, "An Analysis of the Melt Casting of Metallic Fuel Pins," International Mechanical Engineering Congress and Exposition, New Orleans, LA, November 17-22, 2002.

$\mathrm{X}$. Wu, R. Clarksean, Y. Chen, and D. Pepper, "Design and Analysis for Melt Casting Metallic Fuel Pins Incorporating Volatile Actinides," International Youth Nuclear Congress, Daejeon, Korea, April 16-20, 2002.

X. Wu, R. Clarksean, and Y. Chen, "Design and Analysis for Melt Casting Metallic Fuel Pins Incorporating Volatile Actinides," International Congress on Advanced Nuclear Power Plants, Hollywood, FL, June 9-13, 2002.

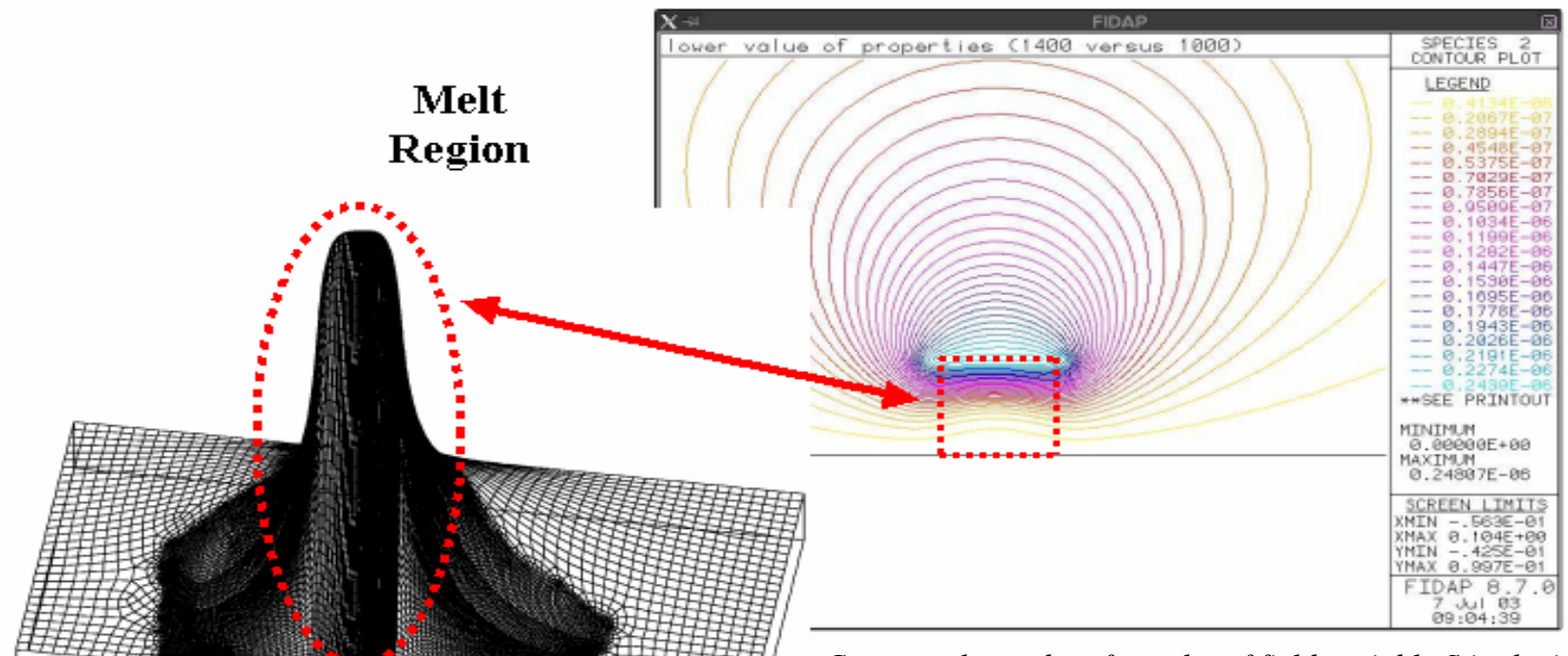

Contour plot and surface plot of field variable $S$ in the induction field. Peak occurs near the top edge of the melt region.

Research Staff

Yitung Chen, Principal Investigator; Associate Professor, Mechanical Engineering Department; Associate Director, NCACM

Darrell W. Pepper, Professor, Mechanical Engineering Department; Director, Nevada Center for Advanced Computational Methods

Randy Clarksean, Adjunct Professor, Mechanical Engineering Department

Students

Taide Tan and Xiaolong Wu, Graduate Students, Mechanical Engineering Department

Yulien Chen and Paul Lawson, Undergraduate Students

Collaborators

Mitchell K. Meyer, Leader of Fabrication Development Group, Nuclear Technology Division, Argonne National Laboratory Steven L. Hayes, Manager of Fuels \& Reactor Materials Section, Nuclear Technology Division, Argonne National Laboratory 


\title{
Task 2 \\ Modeling, Fabrication, and Optimization of Niobium Cavities
}

\author{
R.A. Schill, Jr., M.B. Trabia, and W. Culbreth
}

\section{BACKGROUND}

One of the key technologies for the deployment of acceleratordriven transmutation systems is the accelerator itself. Elliptical superconducting niobium cavities are used to increase the efficiency of the high-power accelerators needed to support the transmutation mission.

One of the major sources of energy loss from a superconducting accelerator cavity is a process known as multiple impacting (or "multipacting") of electrons. This phenomenon limits the maximum amount of energy and power that the niobium cavity can store. As a result, the maximum power available for accelerating the desired charge, as well as the overall performance of the accelerator is reduced. Furthermore, the energy absorbed as a result of multipacting eventually turns into heat. This negatively impacts the performance of both the superconducting cavity and the accelerator.

\section{RESEARCH OBJECTIVES AND METHODS}

This project was tasked with examining the impacts of the design and fabrication technologies for these elliptical niobium cavities on their performance. Niobium was selected primarily due to its behavior at low temperatures.

One objective of this study was to experimentally model the fluid flow resulting in the chemical etching of niobium cavities with the aid of a baffle. Numerical analyses tend to show that the current etching process with a baffle does not uniformly etch the cavity surface. Multiple cavity cell geometries were investigated. Optimization techniques were applied in search of the chemical etching processes, which would lead to cavity walls with near ideal properties.

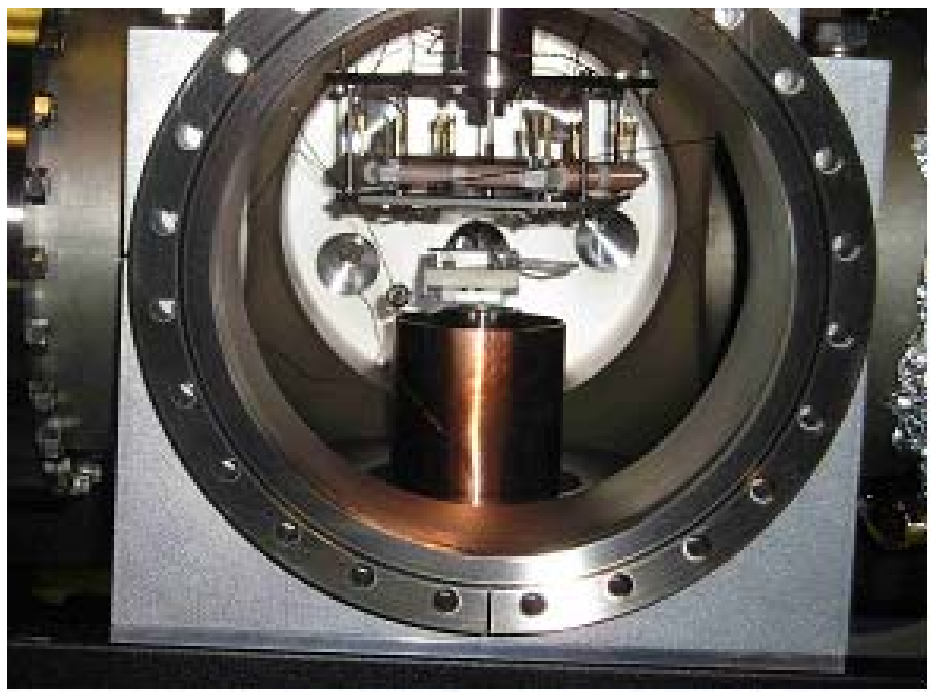

Side view of the secondary electron emission system. The components from top to bottom are: electron gun end, electron beam tube, particle position detector, micro-channel plate stack, business end of the manipulator arm, top of cryostat, and cryostat thermal guard.
A Monte Carlo secondary electron microscopy (SEM) code was modified to provide a statistical study of electron impact from Los Alamos National Laboratory (LANL) cleaned niobium samples at near cryogenic temperatures in a UHV environment. A one-of-a-kind secondary electron emission test stand was developed to study, in part, the dynamics of the emitted particles subjected to an electron beam. Coordinating code studies with experiments offers a wealth of knowledge regarding the surface physics of the material that can enhance modeling codes at LANL.

Modeling codes, optimization techniques, and experimentation provided UNLV researchers with a well-rounded study to examine existing and novel niobium cavity designs and cleaning processes for the superconducting radio frequency high-current accelerator.

\section{RESEARCH ACCOMPLISHMENTS}

Monte Carlo SEE Code Development and Modifications: A Monte Carlo secondary electron emission code based on the "Single Scatter" approach was obtained from Dr. David Joy of both ORNL and the University of Tennessee. The "Single Scatter" approach follows the primary electron and each generation of secondary electron through the entire cascade. The code was modified to allow for surface layer contaminants in the hopes to verify experimental studies. The code only offers approximate results since the inherent mechanisms internal to the code are valid at higher primary beam energies. A SEE code was used to study the initial particle trajectory conditions of the secondary electron released by the primary electron impacted niobium sample. Results were compared with experiments.

SEE (Secondary Electron Emission) Studies: Niobium samples were cleaned both at LANL and Cornell University and used for experimentation. Two types of cleaning procedures have been used: electro-polishing and buffered chemical polishing. In situ pictures of the sample surface were taken with a long-range light microscope for future comparisons.

The experimental setup is unique offering further insights to the SEE process not attained elsewhere. Individual electrons are detected and mapped over the detector surface. With the aid of particle tracking codes, knowledge of the final condition of the electron suggests a family of initial particle trajectory conditions of the emitted electron. Using the Monte Carlo SEE code, the family of initial conditions were evaluated. By March 2004, many of the components of the experimental study reached UNLV with some assembly accomplished. The first secondary electron emission (SEE) measurement was made from the surface of a Faraday cup in September 2004. In December of 2004, the software for the particle positioning detector was finally up and running. The integrity of the code and detector were fine-tuned and initial experiments were completed by April 2005. Experiments on the surface cleaned samples were completed in May of 2005 experimental studies were completed on the 
samples provided by LANL.

Revised Etching Process: The current etching method, which uses a baffle to direct the etching fluid toward the surface of the cavity, partially succeeded in achieving its task. However, flow was restricted to the right half of the cavity with very limited circulation in the left half. An alternative design was proposed and modeled. The exit flow is now parallel to flow inlet. Results show that flow circulation was eliminated. The flow is now closer to the surface of the cavity. Optimization techniques were used to improve this design.

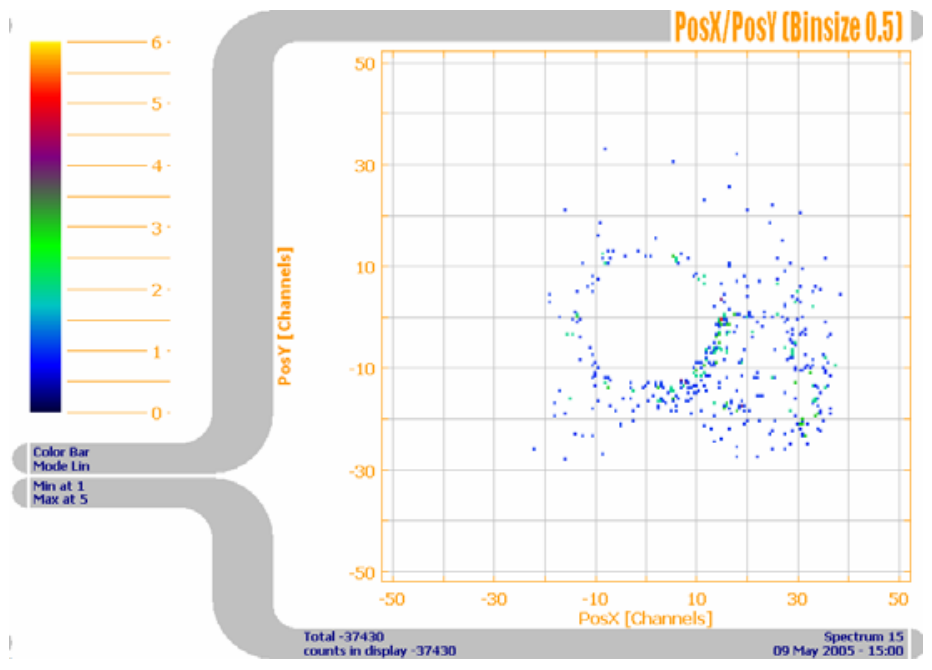

Typical secondary electron emission detected when a $100 \mathrm{~ms}$ pulse, $1 \mathrm{keV}$ electron beam impinges on a 30 degree incline, virgin surface of niobium before in situ sample baking. Each pixel represents a spatial bin on the detector. The color of the pixel corresponds to the number of electrons detected at that position. The sample was buffered chemically polished. Single count events have been removed to enhance the scattering tendency.

Developed Flow Visualization System: To confirm the predictions from the fluid flow models used to analyze the etching process, the UNLV team developed and deployed a flow visualization system. A complete experimental setup, including a computer-controlled $\mathrm{x}-\mathrm{y}$ traverse and digital camera, was assembled. Flow visualization experiments using a plastic prototype of the niobum cavity used dye injection. Dye injection provided quantitative verification that laminar flow exists within the niobium cavities during etching. Additionally, it verified the absence of re-circulation pockets with in the cavities.

\section{TASK 2 PROFILE}

Start Date: June 2001

Completion Date: July 2005

Theses Generated:

Qin Xue, M.S., Mechanical Engineering, "Modeling and Simulation of the Chemical Etching Process in Niobium Cavities,” August 2002.

Satish Sumbramanian, M.S., Mechanical Engineering, "Modeling, Optimization, and Flow Visualization of Chemical Etching Process in Niobium Cavities,” May 2004.

Anoop George, M.S. Electrical and Computer Engineering, "Study of Secondary Electron Emission from Niobium at Cryogenic Temperatures,” August 2005.

Conference Proceedings:

A. George, R.A. Schill, Jr., R. Kant, and S. Goldfarb, "Secondary Electron Emission from Niobium at Cryogenic Temperatures,” International Conference on Plasma Science 2005, Monterey, CA, June 20-24, 2005.

M.B. Trabia, W. Culbreth, S. Subramanian, and T. Tajima, "Optimization of Chemical Etching Process in Niobium Cavities,” Proceedings, ASME 2004 Design Engineering Technical Conferences and Computers and Information in Engineering Conference, Salt Lake City, UT, September 28 October 2, 2004.

M. Holl, M. Trabia, and R.A. Schill, Jr., "Optimization of a FiveCell Niobium Cavity,” Sixth International Topical Meeting on the Nuclear Applications of Accelerator Technology, San Diego, CA, June 1-5, 2003.

Q. Xue, S. Subramanian, M. Trabia, Y.T. Chen, and R.A. Schill, Jr., "Modeling and Optimization of the Chemical Etching Process in Niobium Cavities," International Congress on Advanced Nuclear Power Plants, Hollywood, FL, June 9-13, 2002.

Special Commendation:

A. George and R.A. Schill, "Preparation Studies for Secondary Electron Emission Experiments on Superconducting Niobium,” ANS Student Conference, April 1-4, 2004, Madison, WI. (Outstanding Student Paper Award)

Research Staff

Robert A. Schill, Jr., Co-Principal Investigator, Associate Professor, Department of Electrical and Computer Engineering Mohamed B. Trabia, Co-Principal Investigator, Chair, Mechanical Engineering Department

William Culbreth, Associate Dean for Research, College of Engineering

\section{Students}

Anoop George (Electrical and Computer Engineering) and Satish Subramanian and Qin Xue (Mechanical Engineering), Graduate Students; Myong Holl and Greg Loll, Undergraduate Students 


\title{
Task 3 \\ Corrosion of Steel by Lead Bismuth Eutectic
}

\author{
J.W. Farley, A. Johnson, and D.L. Perry
}

\section{BACKGROUND}

There is an active international interest in lead-bismuth eutectic and similar liquid lead systems because of the relevance to the transmutation of nuclear waste, fast reactors, and spallation neutron sources.

Materials in these systems must be able to tolerate high neutron fluxes, high temperatures, and chemical corrosion. For lead bismuth eutectic (LBE) systems, there is an additional challenge because the corrosive behaviors of materials in LBE are not well understood. Most of the available information on LBE systems has come from the Russians, who have over 80 reactor-years experience with LBE coolant in their Alpha-class submarine reactors. The Russians found that the presence of small amounts of oxygen (on the order of parts per million) in the LBE significantly reduced corrosion. However, a fundamental understanding and verification of its role in the corrosion of steels is incomplete.

\section{RESEARCH OBJECTIVES AND METHODS}

This research program has analyzed various steel samples that have been exposed to lead bismuth eutectic as part of the national program to develop LBE and allied technologies. The goal of this research was to understand the basic science of corrosion in the steel/LBE system. This information will be paramount in developing engineering efforts to control, avoid, and/or minimize the effect of corrosion of steels by LBE in transmuter and LBE systems. Additionally, this program provided UNLV researchers with hands-on experience that will be crucial in developing the UNLV molten metal program.

Investigators performed post-experiment testing and analysis on steel samples that have been exposed to lead bismuth eutectic. Surface analysis techniques were employed that included

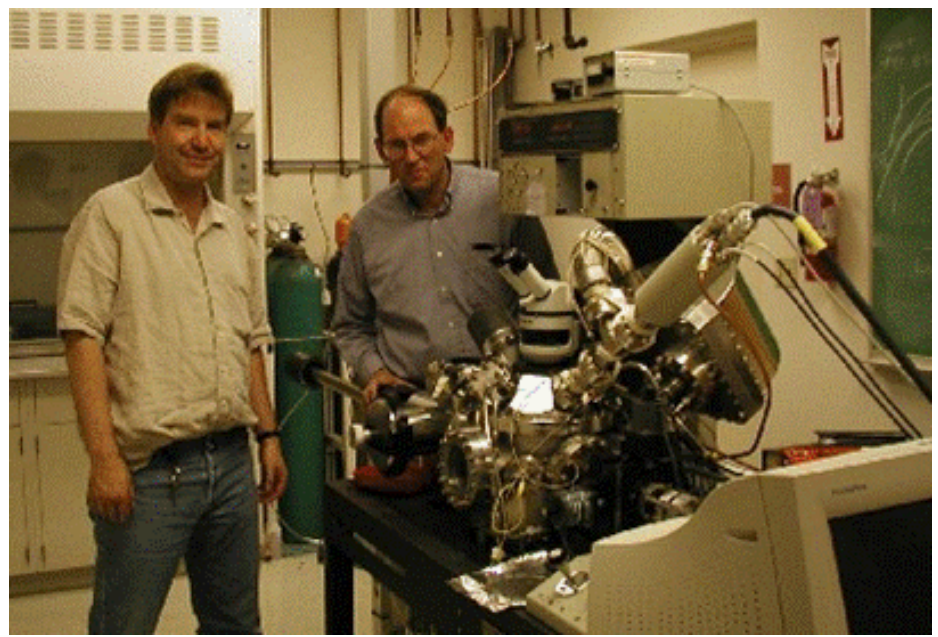

Professors Allen Johnson and John Farley next to an X-ray Photoelectron Spectrometer.
Scanning Electron Microscopy (SEM), Energy Dispersive X-ray (EDAX) spectroscopy, X-ray Photoelectron Spectrometry (XPS), and laser Raman spectrometry.

These techniques, applied to the steel surface, have probed the surface morphology, elemental composition, and oxidation states as a function of position. Chemical alterations and resulting chemical species were studied at the steel surface. Additionally, the experimental facilities at the Advanced Light Source (Lawrence Berkeley National Laboratory) and the Advanced Photon Source (Argonne National Laboratory) were used to characterize the systems. This allowed spectroscopic characterization of the stainless steel before and after interaction with LBE to determine its composition.

\section{RESEARCH ACCOMPLISHMENTS}

Several samples were compared having the same or similar compositions (standard nuclear grade 316/316L) but different surface preparation, including cold-rolled, annealed and a special low-corrosion treatment, "D-9." The cold-rolled sample had an order of magnitude less corrosion (i.e., both lower oxidation and less weight change) than the annealed sample.

Sputter depth profiling of the exposed annealed sample and coldrolled sample showed a marked difference in oxide layer composition between the annealed and cold-rolled sample. The annealed sample showed a complex oxide structure (iron oxide over chromium/iron oxide mixtures) of tens of microns thickness, while the cold-rolled sample was covered with a simple, primarily chromium oxide layer approximately one micron thick. Interestingly, the D-9 material behaved more like the annealed than the more resistant cold-rolled material. In addition to these studies of 316/316L steel, other compositions of steel such as HT9 were also studied. These studies show the importance of surface preparation in resistance to corrosion by LBE.

Another alloy studied in the IPPE series was EP823, an alloy similar to HT9 but with added silicon to improve corrosion resistance. A study of silicon in iron was undertaken to investigate the role of silicon in steels for LBE service. A series of silicon-containing iron samples were examined that were exposed to LBE at INL. Several unique features were observed: at low silicon concentrations in the starting alloy, the silicon was found as a silicate $\left(\mathrm{SiO}_{3}^{--}\right)$. As the concentration of silicon increased in the starting alloy, a layer containing silica $\left(\mathrm{SiO}_{2}\right)$ was found also. Under the oxide layer, the silicon concentration in the metal was found to be decreased by approximately $30 \%$. These were model systems, and the oxide layers that formed were not very protective. In all cases, pockets of LBE were found underneath the oxide layer, potentially corroding the steel. 


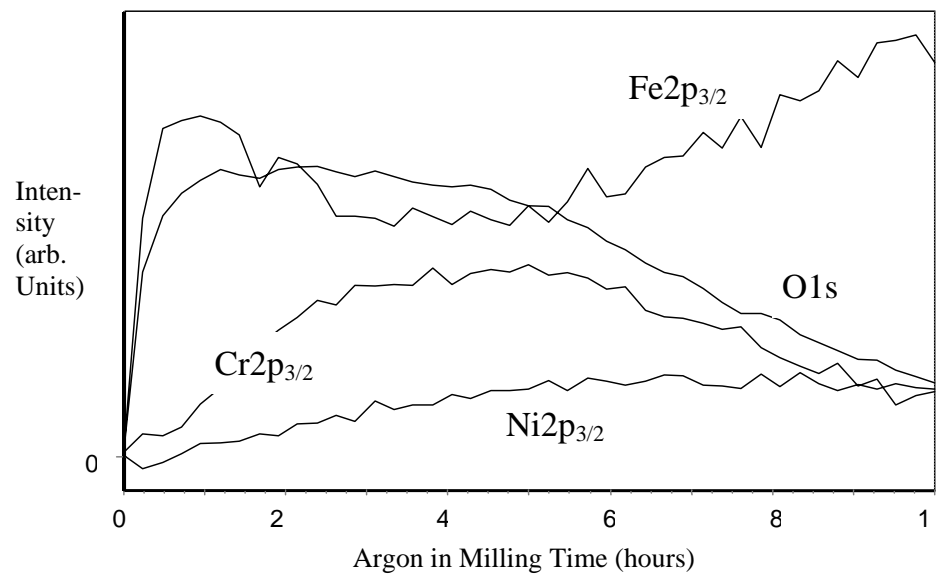

Sputter Depth Profile of annealed 316/316L stainless steel sample. Note iron oxide at the surface.

\section{TASK 3 PROFILE}

Start Date: June 2001

Completion Date: May 2004

(This work continued under Task 18, see pages 40-41.)

\section{Thesis Generated:}

Daniel Koury, M.S., Physics Department, "Investigation of the Corrosion of Steel by Lead-bismuth Eutectic (LBE) Using Scanning Electron Microscopy And X-ray Photoelectron Spectroscopy,” December 2002.

Journal Article:

A.L. Johnson, D. Parsons, J. Manzerova, D.L. Perry, D. Koury, B. Hosterman, and J.W. Farley, "Spectroscopic and Microscopic Investigation of the Corrosion of 316/316L Stainless Steel by Lead-Bismuth Eutectic (LBE) at Elevated Temperatures: Importance of Surface Preparation,” $J$. Nuclear Materials, 328 (2004) 88-96.

\section{Conference Proceedings:}

"Mechanisms of Lead-Bismuth Eutectic Corrosion Chemistry involving Stainless Steels in Nuclear Reactor Cooling Systems," Annual Meeting of the American Chemical

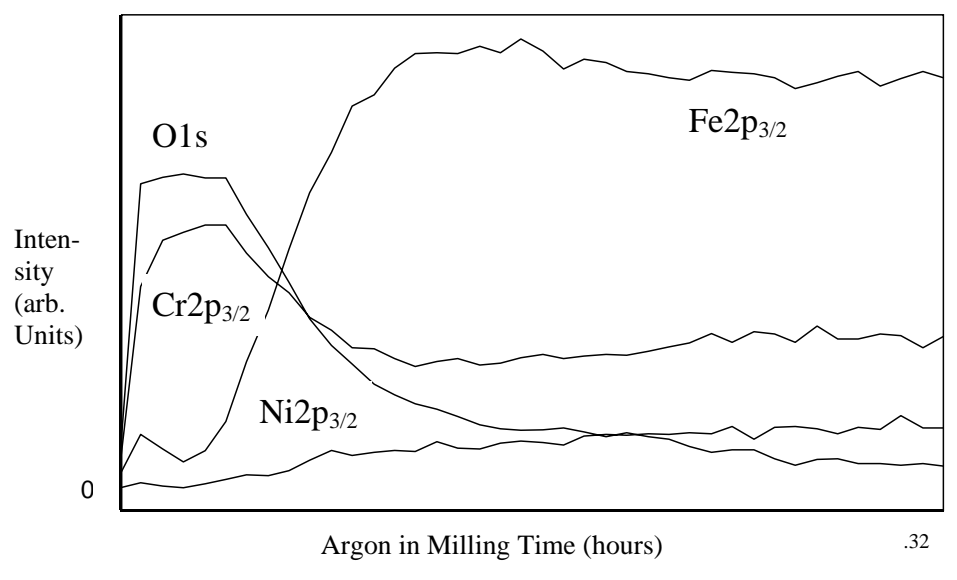

Sputter Depth Profile of cold-rolled 316/316L stainless steel sample. Note chromium oxide at the surface.

Society, Anaheim, CA, March 29-31, 2004.

A. Johnson, D. Parsons, J. Manzerova, D. Koury, B. Hosterman, D.L. Perry, and J.W. Farley, "Surface Studies of the High Temperature Corrosion of Stainless Steel by Oxygen Controlled Lead-Bismuth Eutectic,” American Vacuum Society, Baltimore, MD, Nov. 2-7, 2003.

"Chemical Species Involved in High Temperature Corrosion Resulting from the Interaction Between Stainless Steel and Lead-Bismuth Eutectic," 38th Western Regional Meeting of the American Chemical Society, Long Beach, CA, October 15-18, 2003.

A.L. Johnson, D. Parsons, J. Manzerova, D.L. Perry, D. Koury, B. Hosterman, and J.W. Farley, "Surface Studies of the Corrosion of Stainless Steel by Lead Bismuth Eutectic: Surface Preparation Effects on 316 Stainless Steels," American Nuclear Society Summer Meeting, San Diego, CA, June 1-5, 2003.

D. Koury, A.L. Johnson, D.L. Perry, and J.W. Farley, "Investigation of Corrosion of Steel by Lead Bismuth Eutectic," ANS Topical Mtg. on Accelerator Applications, AccApp/ADTTA01, Reno, NV, Nov. 2001.

Research Staff

John Farley, Principal Investigator, Professor, Department of Physics

Allen Johnson, Assistant Professor, Department of Chemistry

Dale Perry, Lawrence Berkeley National Laboratory; Adjunct Professor, UNLV Department of Physics

Students

Brian Hosterman, Dan Koury, and Umar Younas, Graduate Students, Department of Physics

Thao Trung Ho and Julia Manzerova, Graduate Students, Department of Chemistry

Denise Parsons and Lindsay Wylie, Undergraduate Students, Department of Physics

Stacy Sidle (Rhodes College) and Chris Harland (University of Puget Sound), Visiting Undergraduate Students

\section{Collaborators}

Ning Li, LBE Project Leader, Los Alamos National Laboratory

Eric P. Loewen, Idaho National Laboratory 


\section{BACKGROUND}

The primary objective of this task was to evaluate the effects of environmental and mechanical parameters on environmentinduced degradations of candidate target structural materials for applications in spallation-neutron-target systems. The materials selected for evaluation and characterization were martensitic stainless steels including Alloys HT-9, EP-823, and 422.

Accelerator-driven transmutation systems involve bombarding a target material such as molten lead-bismuth-eutectic (LBE) by a proton beam, thereby producing neutrons. The molten LBE target will be contained in a subsystem structural container made of a suitable material such as Alloys HT-9, EP-823, and 422. During the transmutation process, the target structural material may become susceptible to different types of environmentinduced degradations such as stress corrosion cracking (SCC), hydrogen embrittlement (HE), and localized (pitting and crevice) corrosion. While the performance of these candidate materials in the presence of a molten LBE is yet to be evaluated, substantial work has been performed in this task to evaluate the corrosion behavior of these alloys in aqueous environments of interest. These baseline data can eventually be utilized to compare them to those yet to be generated in the molten LBE environment.

\section{RESEARCH OBJECTIVES AND METHODS}

This investigation was focused on the evaluation of the susceptibility of all three martensitic alloys to SCC, HE, and localized corrosion in neutral and acidic aqueous environments at ambient and elevated temperatures. State-of-the-art experimental techniques including constant-load (CL), slow-strain-rate (SSR), and cyclic potentiodynamic polarization (CPP) were employed to evaluate these corrosion phenomena. The susceptibility of these alloys to HE was evaluated by applying cathodic potential while

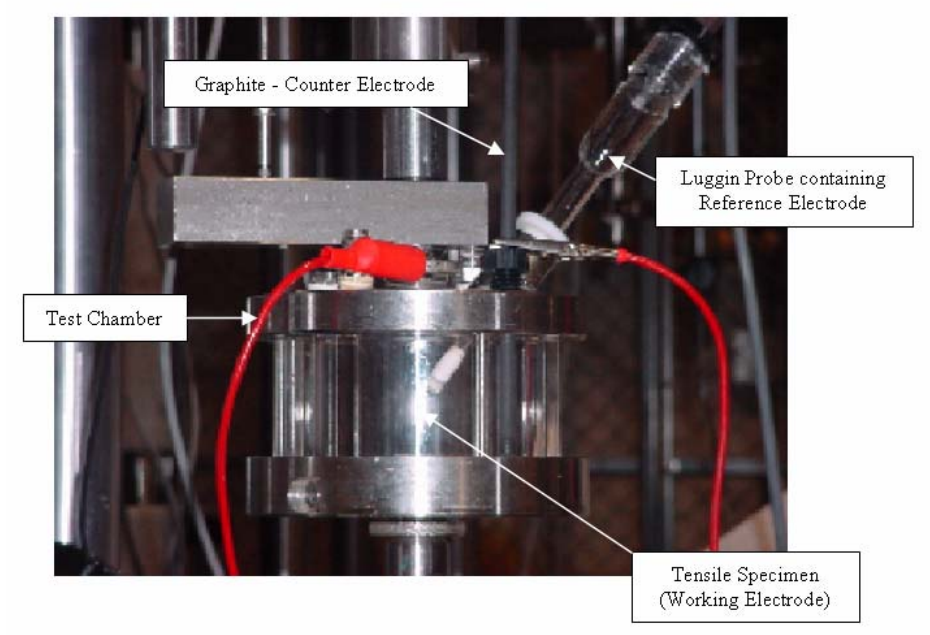

Controlled Potential Test Setup

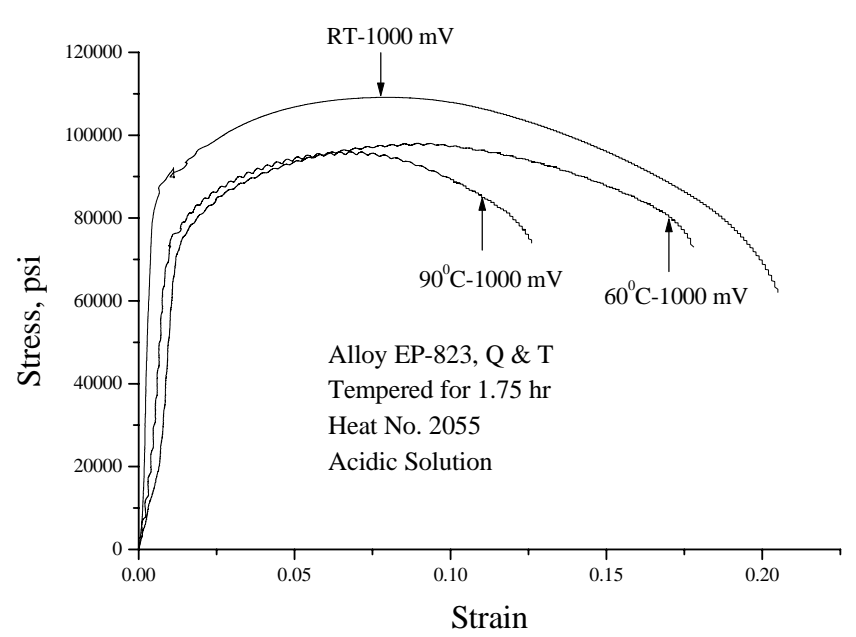

Stress vs Strain under Controlled Potential.

the test specimens were loaded in tension by the SSR method. Optical microscopy and scanning electron microscopy (SEM) were used to analyze the metallurgical microstructures and fractography, respectively of the tested specimens.

\section{RESEARCH ACCOMPLISHMENTS}

The significant results derived from this task are summarized as follows:

- No failures were observed in smooth specimens of Alloys EP823 and 422 in the neutral solution when tested at CL. However, Alloy HT-9 showed failure in the $90^{\circ} \mathrm{C}$ neutral solution at an applied stress $\left(\sigma_{\mathrm{a}}\right)$ of $112 \mathrm{ksi}$.

- All three alloys exhibited failure in the $90^{\circ} \mathrm{C}$ acidic solution at $95 \%$ of their YS values. Alloys HT-9 and 422 also showed failures at $\sigma_{\mathrm{a}}$ of 90 and $85 \%$ of their YS values, but no failure was observed with Alloy EP-823 at stresses below 0.95 YS.

- The magnitudes of the threshold stress $\left(\sigma_{\mathrm{th}}\right)$ for cracking for Alloys EP-823, HT-9 and 422 were 100, 95, and 98 ksi (689, 655 , and $676 \mathrm{MPa}$ ), respectively based on CL testing in the 90 ${ }^{\circ} \mathrm{C}$ acidic solution. The presence of a notch in the test specimen reduced the $\sigma_{\text {th }}$ values in all three alloys.

- The results of SSR testing in the acidic solution involving smooth specimens showed gradual reduction in ductility parameters (percent elongation - \%El and percent reduction in area-\%RA), time-to-failure (TTF), and true failure stress $\left(\sigma_{f}\right)$ with increasing temperature, indicating a synergistic effect of $\mathrm{pH}$ and temperature in enhancing the cracking susceptibility. The presence of a notch in the specimen produced enhanced SCC susceptibility due to the stress concentration. However, the $\sigma_{\mathrm{f}}$ value was increased due to plastic constraint resulting from triaxial stress field at the notch.

- The magnitude of \%El, \%RA, TTF, and $\sigma_{\mathrm{f}}$ was reduced under 
an applied potential of $-1,000 \mathrm{mV}(\mathrm{Ag} / \mathrm{AgCl})$ compared to those obtained without an applied potential.

- The failure mode at the primary fracture face of the specimen tested in the neutral solution, determined by SEM, was characterized by dimpled microstructure, indicating ductile failures. However, intergranular and/or transgranular brittle failures were observed in the acidic environment.

- Secondary cracks with branching were observed by optical microscopy on all three tested materials along the gage section of the specimens tested in the acidic solution.

\section{TASK 4 PROFILE}

Start Date: June 2001

Completion Date: December 2004

\section{Theses Generated:}

Ramprashad Prabhakaran, M.S., "Environment-Induced Degradations in a Target Structural Material for Transmutation Applications,” August 2004.

Sudheer Sama, M.S., "Embrittlement and Localized Corrosion in Alloy HT-9,” August 2004.

Phani P. Gudipati, M.S., "Stress Corrosion Cracking Resistance of Martensitic Stainless Steels for Transmutation Applications,” December 2004.

Mohammad K. Hossain, Ph.D., "Stress Corrosion Cracking and Hydrogen Embrittlement of Martensitic Alloy EP-823," December 2004.

Venkataramakrishnan Selvaraj, M.S., "Environment Assisted Cracking of Target Structural Materials under Different Loading Conditions,” December 2004.

Journal Articles:

A.K. Roy and M. K. Hossain, "Cracking of Martensitic Alloy EP823 under Controlled Potential," Journal of Materials Engineering and Performance, ASM International, (In Review).

A.K. Roy, M. K. Hossain, R. Prabhakaran and S. Sama, "Environment-Assisted Cracking of Structural Materials under Different Loading Conditions," Corrosion, NACE International, April 2005, Vol. 61, No. 4, pp. 364-370.

A.K. Roy, R. Prabhakaran, M. K. Hossain and S. Sama, "Stress Corrosion Cracking of Nuclear Transmutation Structural Materials," Materials Performance, NACE International, September 2004, Vol. 43, No. 9, pp. 52-56.
Conference Proceedings:

A.K. Roy, and M. K. Hossain, "Environment Induced Embrittlement of Martensitic Stainless Steel for Transmutation Applications," Corrosion 2005, NACE International, Houston, TX, April 2005.

A.K. Roy, Phani P. Gudipati, Venkataramakrishnan Selvaraj, "Environment Degradation of Martensitic Stainless Steels for Transmutation Applications,” MS\&T 2004, New Orleans, LA, September 26-29, 2004.

A.K. Roy, R. Prabhakaran, "Stress Corrosion Cracking of Type 422 Stainless Steel for Transmutation Applications," International Youth Nuclear Congress (IYNC) 2004, Toronto, Canada, May 9-13, 2004.

R. Prabhakaran and A.K. Roy, "The Effect of Environmental and Mechanical Variables on Stress Corrosion Cracking of Martensitic Stainless Steels for Transmutation Applications," ICONE-12, Student Paper Competition, Arlington, VA, April 25-29, 2004.

A.K. Roy, M. K. Hossain, R. Prabhakaran, S. Sama, V. Selvaraj, P.P. Gudipati, "Stress Corrosion Cracking of Target Materials for Transmutation Applications," Corrosion 2004, NACE International, New Orleans, LA, March 28-April 1, 2004.

A.K. Roy, R. Prabhakaran, "Characterization of Environment-Induced Degradation in Type 422 Stainless Steel,” TMS 2004, Charlotte, NC, March 14-18, 2004.

A.K. Roy, R. Prabhakaran, M. K. Hossain, S. Sama, V. Selvaraj, P.P. Gudipati, "Effect of Environmental Variables on Cracking of Martensitic Stainless Steels under Different Loading Conditions," ANS Meeting-Global 2003, New Orleans, LA, November 16-20, 2003.

A.K. Roy, R. Prabhakaran, M. K. Hossain, S. Sama, V. Selvaraj, P.P. Gudipati, "Environmental Effects on Materials For Nuclear Applications,” MS\&T 2003, Chicago, IL, November 9-12, 2003.

A.K. Roy, S. Sama, R. Prabhakaran, M. K. Hossain, "Cracking of Martensitic Stainless Steels under Applied Electrochemical Potential," 204 ${ }^{\text {th }}$ Meeting of the Electrochemical Society (ECS), Abstract No. 1255, Orlando, FL, October 12-17, 2003.

A.K. Roy, R. Prabhakaran, M. K. Hossain, S. Sama, B. J. O’Toole, "Environment-Induced Degradation of Spallation Target Materials," ANS Meeting, AccApp’03, San Diego, CA, June 1-5, 2003.

A.K. Roy, M. K. Hossain, B. J. O'Toole, "Stress Corrosion Cracking of Martensitic Stainless Steel For Transmutation Applications," The $10^{\text {th }}$ International High-Level Radioactive Waste Management Conference, Las Vegas, NV, March 30-April 3, 2003.

R. Prabhakaran, "Stress Corrosion Cracking of Type 422 Stainless Steel For Applications in Spallation-Neutron-Target Systems,” Spallation Neutron Source (SNS)-JINS-NICEST 2003, Oak Ridge, TN, March 12, 2003.

A.K. Roy, M.K. Hossain, and B.J. O’Toole, "Stress Corrosion Cracking of Martensitic Stainless Steel for Transmutation Applications," International High-Level Radioactive Waste Management Conference, Las Vegas, NV, Sept. 2002.

Research Staff

Ajit K. Roy, Ph.D., Principal Investigator, Associate Professor, Mechanical Engineering Department

Students

Phani P. Gudipati, Mohammad K. Hossain, Ramprashad Prabhakaran, Sudheer Sama, and Venkataramakrishnan Selvaraj,

Graduate Students, Mechanical Engineering Department

Nikita Agarwal, Undergraduate Student, Electrical Engineering Department

Aaron Tippetts, Undergraduate Student, Mechanical Engineering Department

Ning Li, Ph.D., LBE Project Leader, Los Alamos National Laboratory

Stuart A. Maloy, Ph.D., AFCl Materials Team Leader, Los Alamos National Laboratory 


\section{BACKGROUND}

The corrosion of structural materials is a major concern for the use of lead-bismuth eutectic (LBE) systems for nuclear applications such as in transmuter targets or fast reactors. Corrosion in liquid metal systems can occur through various processes, including, for example, dissolution, formation of inter-metallic compounds at the interface, and penetration of liquid metal along grain boundaries. Predicting the rate of these processes depends on numerous system operational factors: temperature, system geometry, thermal gradients, solid and liquid compositions, and velocity of the liquid metal, to name a few. Corrosion, along with mechanical and/or hydraulic factors, often contributes to component failure.

The goal of this project was to develop a corrosion model that combines the chemical kinetics and hydrodynamics in the system to predict corrosion rates. In this effort, these models were developed for the Delta test loop at Los Alamos National Laboratory (LANL) and a theoretical LBE accelerator target system. The resulting models are predictive tools that can be validated with corrosion test data and used to systematically design tests, interpret the results, and provide guidance for optimization in LBE system designs.

\section{RESEARCH OBJECTIVES AND METHODS}

There were two subtasks to this research. The first subtask developed the necessary tools to predict the levels of oxygen and corrosion products close to the boundary layer using Computational Fluid Dynamics (CFD) modeling. The second subtask predicted the corrosion process kinetics between the LBE and structural materials by incorporating pertinent information from the first subtask.

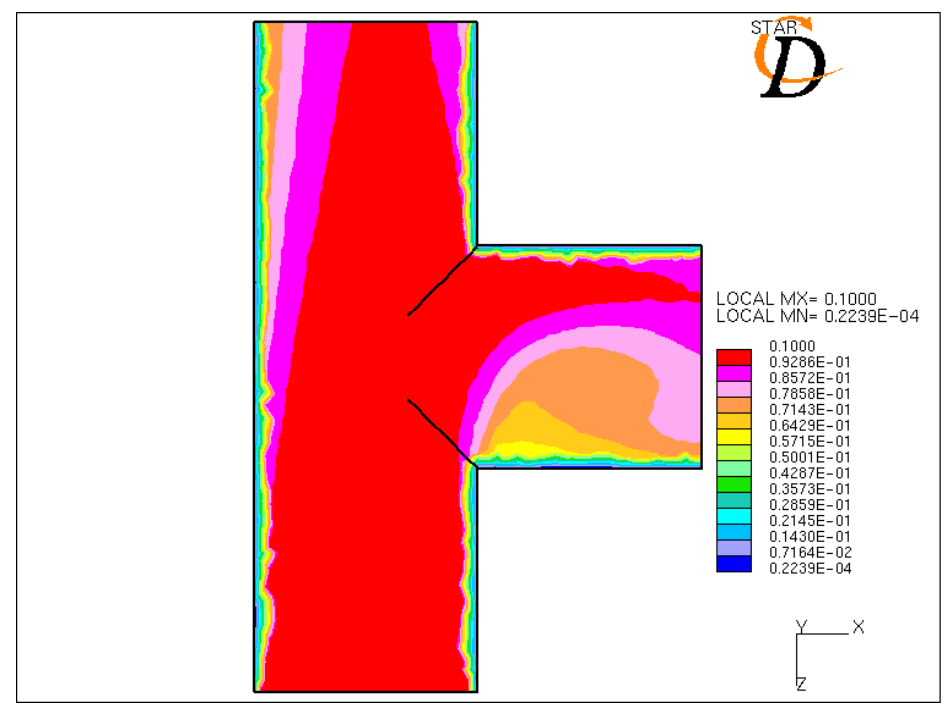

Concentration profile for T-joint at $R e=200,000$.
STAR-CD software was used to model the corrosion and precipitation rates in the LBE loop. This allowed researchers to compare the theoretical analysis with available experimental results. The surface corrosion analysis is being developed as a user supplied subroutine to STAR-CD. The information obtained from this analysis theoretically predicts likely locations for corrosion and precipitation along the axial lengths of the test loop.

The first subtask involved performing a series of parametric runs. Models prepared from the earlier work were used as guides for the parametric studies. Variables investigated included the average eutectic flow velocity, average mean bulk eutectic flow, inlet temperatures, and average inlet oxygen concentrations in the three geometries: a straight flow section, an elbow bend, and a tee section. The thermal-hydraulics study involved using a 3-D CFD code simulation to obtain averaged values of stream-wise velocity, temperatures, and oxygen and corrosion product concentrations at various axial locations close to the walls of several partial loop sections within the LBE loop. The oxygen and corrosion products inside the test loop were simulated to participate in chemical reactions with the eutectic fluid as it diffused towards the walls. Details of the geometry of these loops were obtained from scientists at LANL. These values acted as a set of starting boundary conditions for the second task.

The second subtask focused on the kinetics of the dissolution/ deposition process as a function of temperature, flow velocities, dissolved metal concentrations, oxygen potentials of the system, the kinetics of film formations in the presence of oxygen, and the kinetics of metal transport through the oxidized surface film.

\section{RESEARCH ACCOMPLISHMENTS}

Geometries and flow conditions similar to experimental results in the literature were set up and used to benchmark the models assembled using the STAR-CD software. Test case studies indicated that the outcome from STAR-CD was correct and that numerical modeling is applicable to the research in this problem.

Using these models, concentration flux profiles were obtained for both laminar and turbulent profiles in a straight pipe. This information was then used for the chemical kinetics analysis for corrosion on the inside walls of the LBE loop.

Several CFD runs were made to simulate flow in pipe fittings. These include sudden contraction, sudden expansion and a Tjoint. Testing of a new turbulent model was also performed using the k- $\varepsilon$ Chen model which works better with high Re number flows and predicts some of the peculiar flow features relevant to sudden expansions where eventually vortex generation is expected at the backward step. 
The k- $\varepsilon$ Chen model which works better with high Re number flows and predicts some of the peculiar flow features relevant to sudden expansions where eventually vortex generation is expected at the backward step.

A user subroutine was developed that simulated the corrosion/ precipitation processes and predicted their maximum/minimum location in a typical LBE loop. A chemical reaction subroutine dealt with surface chemistry. The Arrhenius Equation was used to calculate the reactant reaction rate but some constants and coefficients used in calculating chemical reaction rate were updated using some empirical data found in chemical reaction research papers and textbooks.

The location in the loop with the highest concentration occurred in the baffle cell which is adjacent to the iron surface while the area with lowest concentration occurs around the central line of the pipe. It can be inferred that after $\mathrm{Fe}_{3} \mathrm{O}_{4}$ is formed, it diffuses to the fluid area close to the central line of pipe. But, overall, the concentration value was very low.

Similar to the concentration gradient, the area with the highest temperature occurs in the baffle cell which is adjacent to iron surface while the area with lowest temperature occurs around the central line of the pipe. It is obvious, based on the model, that heat was transferred from inner wall to central area of the pipe due to the setting of constant heat flux boundary conditions in the baffle cells.

The chemical reaction model subroutine worked well and this simple CFD model roughly simulated the chemical reaction, diffusion, and heat transfer condition inside the LBE piping. Since the subroutine works well, it can be used in much more complex

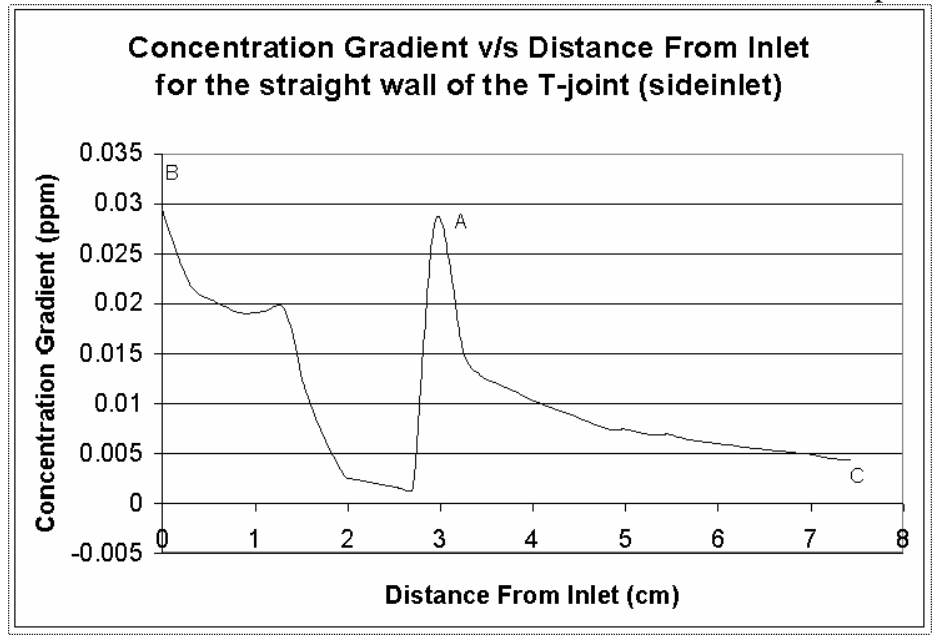

Concentration gradient versus distance from the inlet for the straight wall. modeling.

\section{TASK 5 PROFILE}

Start Date: August 2001

Completion Date: August 2004

\section{Theses Generated:}

Chao Wu, M.S., Mechanical Engineering, "Study of Geometry Effects on Local Corrosion Rates for LBE Loop,” July 2003.

Kanthi Dasika, M.S., Mechanical Engineering, "Chemical Kinetics and Thermal Hydraulics of Lead Bismuth Flow Loops,” December 2003.

Narain Armbya, M.S., Mechanical Engineering, “CFD Analysis of 3-D Thermal Hydraulics Flow Effects on Wall Concentration Gradient Profiles for LBE Loop Fittings,” December 2004.

\section{Conference Proceedings:}

C. Wu, K. Dasika, Y. Chen, S. Moujaes,J. Zhang and N. Li, "Study of Geometry Effects on Local Corrosion Rates for LBE Loop,” ANS National Conference, San Diego, CA, June 1-5, 2003.

S. Moujaes, Y. Chen, K. Dasika, C. Wu, N. Li, and J. Zhang, "Simulation Considerations in Lead-Bismuth Transmutation Loops: Corrosion Concentration, velocity and Temperature Profiles of LBE Loops,” NURETH-10, South Korea Oct. 5-9, 2003.

K. Dasika, C. Wu, S. Moujaes, and Y. Chen, "Modeling of Oxygen Controlled Surface Reaction Kinetics and Hydrodynamics," International Youth Nuclear Congress, Seoul, South Korea, April 2002.

K. Dasika, C. Wu, S. Moujaes, and Y. Chen, "Numerical Modeling of Lead Oxidation in Controlled Lead Bismuth Eutectic Systems: Chemical Kinetics and Hydrodynamic Effects," ICAPP Conference, Hollywood Florida, ANS, June 2002.

Research Staff

Samir Moujaes, Principal Investigator, Associate Professor, Mechanical Engineering Department

Yitung Chen, Associate Professor, Mechanical Engineering Department; Associate Director, NCACM

Students

Narain Armbya, Kanthi Dasika, Guanjun Li, and Chao Wu, Graduate Students, Mechanical Engineering Department 


\section{Task 6 \\ Neutron Multiplicity Measurements of Target/Blanket Materials \\ D. Beller}

\section{BACKGROUND}

The U.S. Advanced Fuel Cycle Initiative (AFCI) is a program to develop economic and environmental methods to reduce the impact of waste from commercial nuclear fuel cycles. One concept for near-complete destruction of waste isotopes from used nuclear fuel is accelerator-driven transmutation. High-power accelerators would be used to produce high-energy charged particles, which then collide with heavy metal targets to create a cascade of neutrons. These neutrons then cause nuclear reactions in subcritical systems.

To design these systems, complex reactor physics computer codes and highly detailed data libraries are used to compute the reactivity of systems, reaction rates, destruction rates, and nuclearinduced damage rates to materials. In this project, a Russian-built detector system was used to make measurements of neutrons generated in a central target by a variety of accelerators.

\section{RESEARCH OBJECTIVES AND METHODS}

A prototype modular Neutron Multiplicity Detector System (NMDS) with $64{ }^{3} \mathrm{He}$ gas counting tubes was developed to measure the neutron multiplicity of scaled lead accelerator targets. Its modularity allows it to be configured for a variety of experiments to measure neutron multiplicity from different sources: protons, electrons, high-energy neutrons, or even cosmic particles such as muons.

This system may be used to measure neutron production in a variety of configurations, on a variety of targets, with a variety of source particles, and over a range of energies (10 to $800 \mathrm{MeV}$ ) to produce a large database that may be used to validate neutron multiplicity predictions. This should enable the quantification of systematic errors in the latest version of MCNPX and its accompanying data libraries. Time-dependent measurements of neutron production in the NMDS should provide a systematic set of precise data that will enable direct comparison with code calculations.

Comparison of results from the NMDS may decrease uncertainties and allow the derivation of relative measurements in the few percent range at the 95 percent confidence level. In addition, discrepancies that are discovered with this system can contribute to the improvement of the codes and data libraries. Improved models of beam line experiments, accelerator targets, and detector designs will result from these code improvements.

\section{RESEARCH ACCOMPLISHMENTS}

Initial work in this project included the development of geometric models of the target-detector assemblies for use with the MCNPX radiation transport code to optimize the design of the NMDS. Radiation transport calculations of neutron detection efficiency were completed and interpreted prior to developing designs of the neutron detection systems needed to perform multiplicity measurements. Following completion of the modeling, a fabrication effort was initiated. A series of MCNPX models were developed at UNLV for a cylindrical target. Another generic model was created to examine response times, collection efficiencies, and escape probabilities. In addition to modeling at UNLV, colleagues at the V.G. Khlopin Radium Institute (KRI) completed preliminary radiation transport modeling using the CONTROL code developed by KRI researchers.

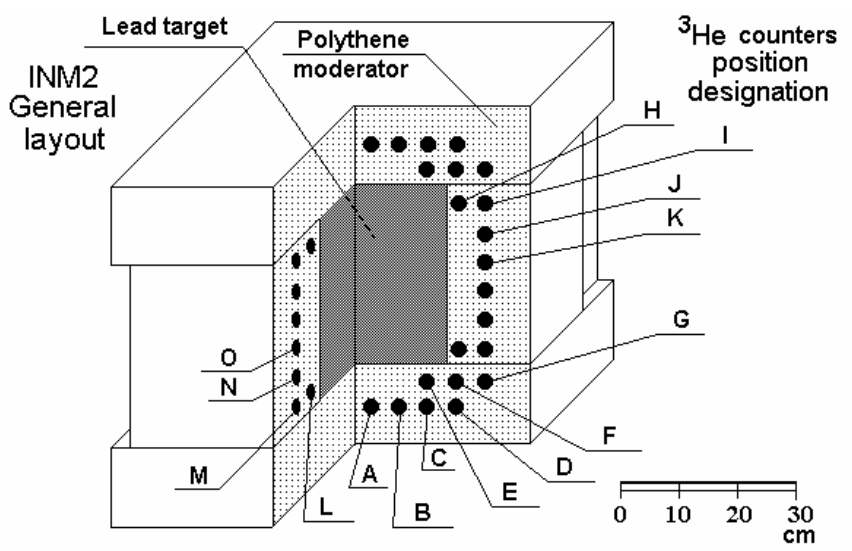

NMDS in the INM2 ("CUBE”) geometry.

The 64-element ${ }^{3}$ He-detector-based NMDS was fabricated by KRI and shipped to UNLV. It was assembled at UNLV in the "CUBE" geometry $(30 \mathrm{~cm}$ x $30 \mathrm{~cm}$ x $30 \mathrm{~cm}$ of lead inside and 8 to 12 detectors on each of the 6 sides of the cube. Detection efficiencies in ${ }^{3} \mathrm{He}$ as well as fractional capture in $\mathrm{Pb}$ and polyethylene were calculated. A ${ }^{252} \mathrm{Cf}$ source was used to calibrate the NMDS. Measured efficiencies were comparable to calculations and measurements were completed at KRI.

\section{ISU-IAC Experiments}

To evaluate its usefulness for measurement of spallation neutrons, the NMDS was transported to the Idaho Accelerator Center at Idaho State University where it was used in conjunction with a linear accelerator to determine its performance.

An americium-beryllium (AmBe) source with a neutron production rate of $2500 \mathrm{n} / \mathrm{s} \pm 10 \%$ was placed against the face of the $\mathrm{Pb}$ in all 5 configurations to measure the overall efficiency of the system. This weak source exceeded the counting capacity of the NMDS, such that its efficiency was reduced to $3.5 \%$ compared to earlier values at UNLV of $20-30 \%$ with source strength of $\sim 600$ $\mathrm{n} / \mathrm{s}$. This was the first indication of a severe count-rate limitation of the NMDS.

To accommodate this limitation, the accelerator was "de-tuned" to reduce the neutron production rate within the boundaries of the 
detectors. All results from the ISU-IAC accelerator-driven experiments were influenced by a count-rate limitation that is inherent in the NMDS hardware and software.

Accelerator-based testing commenced with the electron beam and several parameters and results were examined and compared to radiation transport predictions in these studies. These parameters include the neutron absorption time or lifetime, efficiencies of the systems and individual detectors, and multiplicity distributions.

\section{NTS-RSL Experiments}

In an effort to determine system contributions to deadtime, a deadtime measurement experiment was conducted at the Remote Sensing Laboratory (RSL) of the Nevada Test Site (NTS). Results indicated that the performance of individual detectors depends upon the number of detectors operating as well as the source strength. The individual detectors were determined to have a deadtime coefficient of a few ms, which would indicate a capability of the total system to count several thousand neutrons per second. However, the system has never counted more than $200 \mathrm{n} / \mathrm{s}$, even with strong neutron sources. Each system component contributes to deadtime. In the final analysis, however, these experiments at ISU-IAC and NTS-RSL demonstrated that the performance of the system is critically limited by the Russian hardware and, as a consequence of these experiments, a modern data acquisition system was acquired that will support the maximum performance of each detector and all the detectors combined.

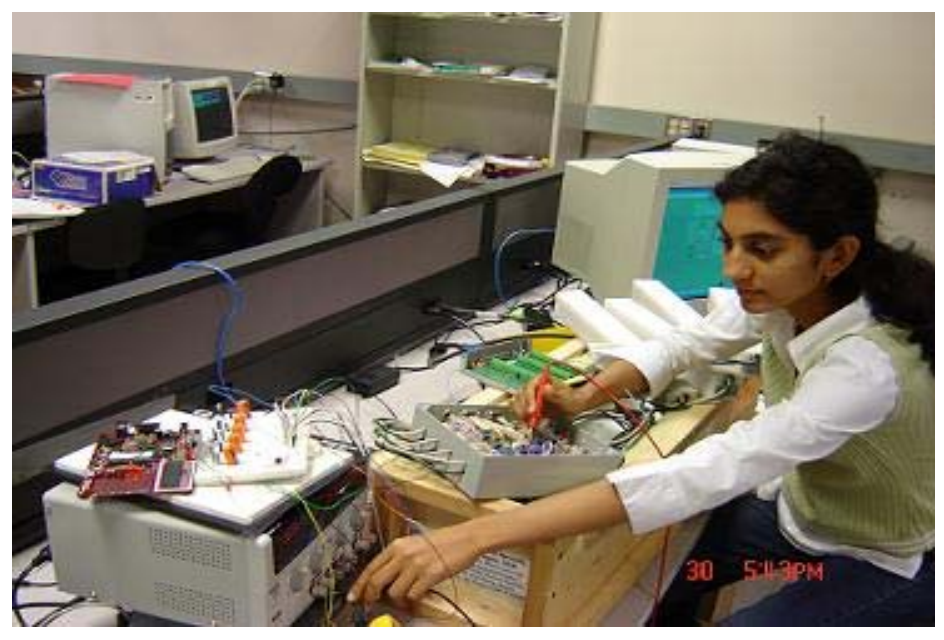

Graduate student Shruti Patil checks signals on one of the 8detector control boxes of the NMDS.

\section{TASK 6 PROFILE}

Start Date: August 2001

Completion Date: December 2005

\section{Conference Proceedings:}

T. Beller, D. Curtis, D. Beller, A. Rimsky-Korsakov, and T. Ward, “The UNLV Neutron Multiplicity Detector System,” Proceedings of the Eighth Information Exchange Meeting on Actinide and Fission Product Partitioning \& Transmutation, OECD/NEA, Paris, France, pp 687-698, 2005.

T. Ward, A. Rimski-Korsakov, N. Kudryashev and D. Beller, "Integral Neutron Multiplicity Measurements from Cosmic Ray Interactions in Lead," Proceedings, XVII Particle and Nuclei International Conference (PANIC05), Santa Fe, New Mexico, October 24-28, 2005.

D. Curtis, D. Beller, C. Hull, A, Rimsky-Korsakov, and T, Ward, "Modeling Neutron Multiplicities in a 60-element ${ }^{3}$ He Detector System," Proc. of the Sixth International Meeting on $\mathrm{Nu}$ clear Applications of Accelerator Technology (AccApp'03), American Nuclear Society, pp. 190-194, 2004.

T. Beller, D. Curtis, D. Beller, A. Rimsky-Korsakov and T. Ward, “The UNLV Neutron Multiplicity Detector System,” Eighth Information Exchange Meeting on Actinide and Fission Product Partitioning \& Transmutation (OECD/NEA), Las Vegas, NV, November 9-11, 2004.

D. Curtis, D. Beller, C. Hull, A. Rimsky-Korsakov, and T. Ward, "Modeling Neutron Multiplicities in a 60-Element 3He Detector System," Sixth International Meeting on Nuclear Applications of Accelerator Technology (AccApp’03), American Nuclear Society, San Diego, CA, June 1-5, 2003. (Awarded Best Overall Poster for AccApp’03)

T. Ward, A. Rimski-Korsakov, M. Todosow, G. Greene, M. Divadeenam, C.L. Snead, Jr., A. Hanson, E. Pitcher, D. Beller, C. Hull, W. Culbreth, A. Hechanova, and G. Cerefice, “Note on the Benchmark and Validation of the LAHET Code System,” ANS Conference, Reno, NV, November 11-15, 2001.

Research Staff

Denis Beller, Principal Investigator, Research Professor, Mechanical Engineering Department

\section{Students}

Mr. Dean Curtis, Undergraduate Student, Electrical and Computer Engineering Deparment

Mr. Steve Curtis, Graduate Student, Health Physics Program

Shruti Patil, Graduate Student, Electrical and Computer Engineering Department

Timothy Beller and Brice Howard, Undergraduate Students, Mechanical Engineering Department

\section{Collaborators}

Eric Pitcher, Nuclear Physics (T-16) Group Leader, Los Alamos National Laboratory

Stephen Wender, Nuclear Physics (LANSCE-3) Group Leader, Los Alamos National Laboratory

Michael Todosow, Nuclear Science \& Technology, Brookhaven National Laboratory

Thomas Ward, AFCI Science Adviser to the U.S. Department of Energy

Alexander Rimsky-Korsakov, Director, V.G. Khlopin Radium Institute 


\title{
Task 7 \\ Development of Dose Coefficients for Radionuclides Produced in Spallation Targets
}

\author{
P.W. Patton and M.J. Rudin
}

\section{BACKGROUND}

Ensuring the safety of workers at accelerator-driven nuclear facilities is paramount before these systems can be deployed for nuclear transmutation or any other mission. Spallation neutron sources produce as many as 660 rare radionuclides in either the target or blanket during the spallation process. No data exists for many of these radionuclides in the current radiation protection guidelines and standards. This research program seeks to address this problem through generating internal and external dose coefficients (DCs) for these "new” isotopes.

Dose coefficients permit simple determination of radiation dose associated with various exposure scenarios, and ultimately permit radiation safety personnel to assess the health risks to workers in a nuclear facility. Specifically, radiation safety personnel use dose coefficients to determine the radiation dose incurred to a tissue or organ system from a given exposure. These parameters are often expressed in terms of Annual Limits on Intake (ALIs) and Derived Air Concentrations (DACs).

\section{RESEARCH OBJECTIVES AND METHODS}

Results from this study will be used to produce ALIs and DACs for these rare radionuclides created by spallation target systems that are not included in Federal Guidance Report (FGR) No. 11. Additionally, DCs developed will augment the radiological data in Publications 68 and 72 of the International Commission on
Radiological Protection (ICRP), contributing to the safe operation of accelerator-driven nuclear systems.

A Dose Coefficient Working Group was established in 2001 (the first year of the project) to direct and oversee consortium activities. Representatives from the Dose Coefficient Working Group developed and verified a methodology to determine internal and external dose for select radionuclides. The first step involved obtaining radiological data from the ENSDF nuclear physics database developed at Brookhaven National Laboratory. Data collected included decay modes, decay energy levels, and radiation energies and intensities.

The DC working group prioritized a list of radionuclides projected to be released via air emissions or in the inventory of a mercury target following a lengthy irradiation period. Only radionuclides with a half-life greater than one minute were considered. These 81 radionuclides were then categorized into three distinct categories, based on half-life, available information, and other technical factors.

All Category 2 radionuclides were investigated to determine which database was most current. However, this task was not straight forward and thus both databases were used to calculate all radionuclides that had complete data. Dose coefficients were then generated for the Category 2 radionuclides using both ENSDF and NUBASE. The results were compared and showed good agreement. Metabolic models and data from ICRP publications

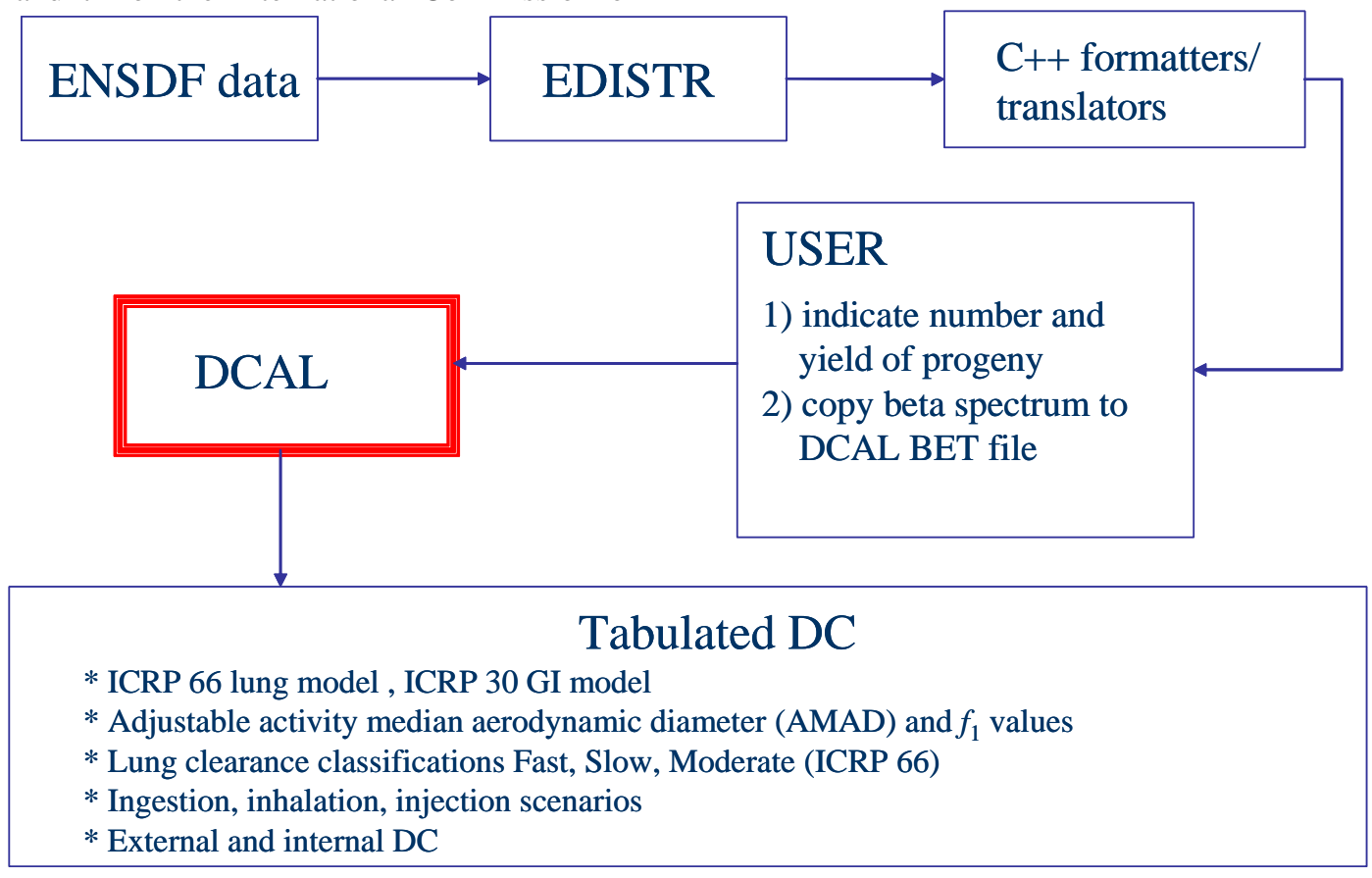

Dose Coefficient Working Group Methodology Flow Sheet. The ENSDF code is used to obtain nuclear physics data. The EDISTR code prepares the data for input into the dose calculation code DCAL. 
(30 and 66) were applied in order to use the best technology available and to maintain consistency with current standards. In accordance with FGR No. 11, dose coefficients were evaluated for an adult male with the target tissues of gonads, breast, lung, red marrow, bone surface (endosteum), thyroid, remainder, and total committed effective dose equivalent (this considers total dose incurred to specific organs or tissues with respect to radiation type over a period of 50 years). Following determination of these variables, values of ALIs and DACs were then calculated for each radionuclide.

The consortium investigated the competing databases to determine the most appropriate one to use for dose coefficient calculations. However, conflicting data made it unclear which was better suited for this task, therefore the previously calculated coefficients were reported. Additionally, time was devoted to trying to acquire missing nuclear data for radionuclides in category three. The consortium believes large scale accelerator driven experiments are needed to accomplish this goal.

\section{RESEARCH ACCOMPLISHMENTS}

The research consortium comprised of representatives from several universities and national laboratories has successfully generated internal and external dose conversion coefficients for twenty radionuclides produced in spallation neutron sources. These dose coefficients fill data gaps exist in Federal Guide Report No. 11 and in Publications 68 and 72 of the International Commission on Radiological Protection (ICRP), and two articles containing the data have been accepted for publication in the Journal of Health Physics. Currently, more nuclear data is needed for the rare radionuclides produced from a mercury target. While attempting to develop a workable plan to acquire this missing data, Q-value discrepancies were investigated and reported. A detailed plan was developed to start a research effort at Idaho State University to produce rare radionuclides. This process will allow for the investigation of the missing nuclear data needed to complete dose coefficients.

\section{TASK PROFILE}

Start Date: June 2002

Completion Date: April 2006

Theses Generated:

John P. Shanahan, M.S., Health Physics Department, “Dose Coef- ficients for Radionuclides Produced in a Spallation Neutron Source,” August 2003.

Yayun Song, M.S., Health Physics Department, "Investigation and Calculations of Dose Coefficients for Radionuclides Produced in a Spallation Neutron Source Using the ENSDF and NUBASE Nuclear Databases,” May 2004.

Publications:

J. Shanahan, K. Eckerman, A. Arndt, C. Gold, P. Patton, M. Rudin, R. Brey, T. Gesell, V. Rusetski, and S. Pagava, "Calculation of Dose Coefficients for Radionuclides Produced in a Spallation Neutron Source Utilizing NUBASE and the Evaluated Nuclear Structure Data File Databases.” Health Phys 90:56-65, 2006.

A. Arndt, J. Shanahan, C. Gold, R. Brey, T. Gesell, P. Patton, M. Rudin, K. Eckerman, V. Rusetski, and S. Pagava "Procedures and Quality Assurance for Calculating Dose Coefficients Using DCAL Software.” Health Phys 90:74-80, 2006.

J. Shanahan, K. Eckerman, A. Arndt, C. Gold, P. Patton, M. Rudin, R. Brey, T. Gesell, V. Rusetski, and S. Pagava, "Calculation of Dose Coefficients for Radionuclides Produced in a Spallation Neutron Source Utilizing NUBASE and the Evaluated Nuclear Structure Data File Databases,” accepted August 16, 2005 for publication in the Health Physics Journal, Health Phys. 89(6), 2005.

A. Arndt, J. Shanahan, C. Gold, R. Brey, T. Gesell, P. Patton, M. Rudin, K. Eckerman, V. Rusetski, and S. Pagava, “The Procedure for Determining and Quality Assurance Program for the Calculation of Dose Coefficients Using DCAL Software," accepted April 2005 for publication in the Health Physics Journal.

J. Shanahan, K. Eckerman, A. Arndt, C. Gold, P. Patton, M. Rudin, R. Brey, T. Gesell, V. Rusetski, and S. Pagava, “An Interdatabase Comparison of Nuclear Decay and Structure Data Utilized in the Calculation of Dose Coefficients for Radionuclides Produced in a Spallation Neutron Source," accepted March 2005 for publication in the Health Physics Journal.

J. Shanahan, A Arndt, C Campbell, R Brey, M Rudin, K Eckerman, and P Patton, "Calculation of Dose Coefficients for Radionuclides Produced in Spallation Neutron Sources," Health Phys. 84 (6S): S252 (2003).

J. Shanahan, P. Patton, and M. Rudin, "Dose Coefficient Methodology Report,” Health Physics Department, University of Nevada, Las Vegas, NV, Aug. 2002.

Research Staff

Phillip W. Patton, Principal Investigator, Associate Professor, Department of Health Physics

Mark Rudin, Associate Professor, Department of Health Physics

Students

John Shanahan, Yayun Song, Tserenpagma Chaoui, Ashley Gann, Sung Yop Kim, Deanna Tuttle, and Jeffrey Wyler, Graduate Students, Department of Health Physics

\section{Collaborators}

Tony Andrade and Brent Boyack, Los Alamos National Laboratory

Keith F. Eckerman, Oak Ridge National Laboratory

Rich Brey, Associate Professor, Idaho State University

Adam Arndt and Chandra Gold, Graduate Students, Idaho State University

Faculty and graduate students from Georgia Institute of Technology, University of Florida, Francis Marion University 


\section{Development of a Systems Engineering Model of the Chemical Separations Process \\ Y. Chen, D.W. Pepper, and S. Hsieh}

\section{BACKGROUND}

The chemical processing of used nuclear fuel is an integral component of any strategy for the transmutation of nuclear waste. Due to the large volume of material that must be handled in this first step of the transmutation process, the efficiency of the separations process is a key factor in the potential economic viability of transmutation strategies. The ability to optimize the chemical separation systems is vital to ensure the feasibility of the transmutation program.

Systems analysis, or total systems modeling, is one of the strongest tools available to researchers for understanding and optimizing complex systems such as chemical separations processes. Systems analyses permit researchers to present decision-makers concise evaluations of system options and their characteristic features. The primary goal of this project was to develop a systems model that can be used to parameterize and optimize chemical separations processes.

\section{RESEARCH OBJECTIVES AND METHODS}

This work includes reviewing and analyzing the AMUSE code structure, examining other possible implementations, defining software activities, developing a verification plan, and modifying and improving the software. This work also involves redefining the graphical user interface (GUI) to increase the utility of the AMUSE code suite as a stand-alone analytical package.

Developing a systems engineering model required discussions with Argonne National Laboratory personnel to identify pertinent

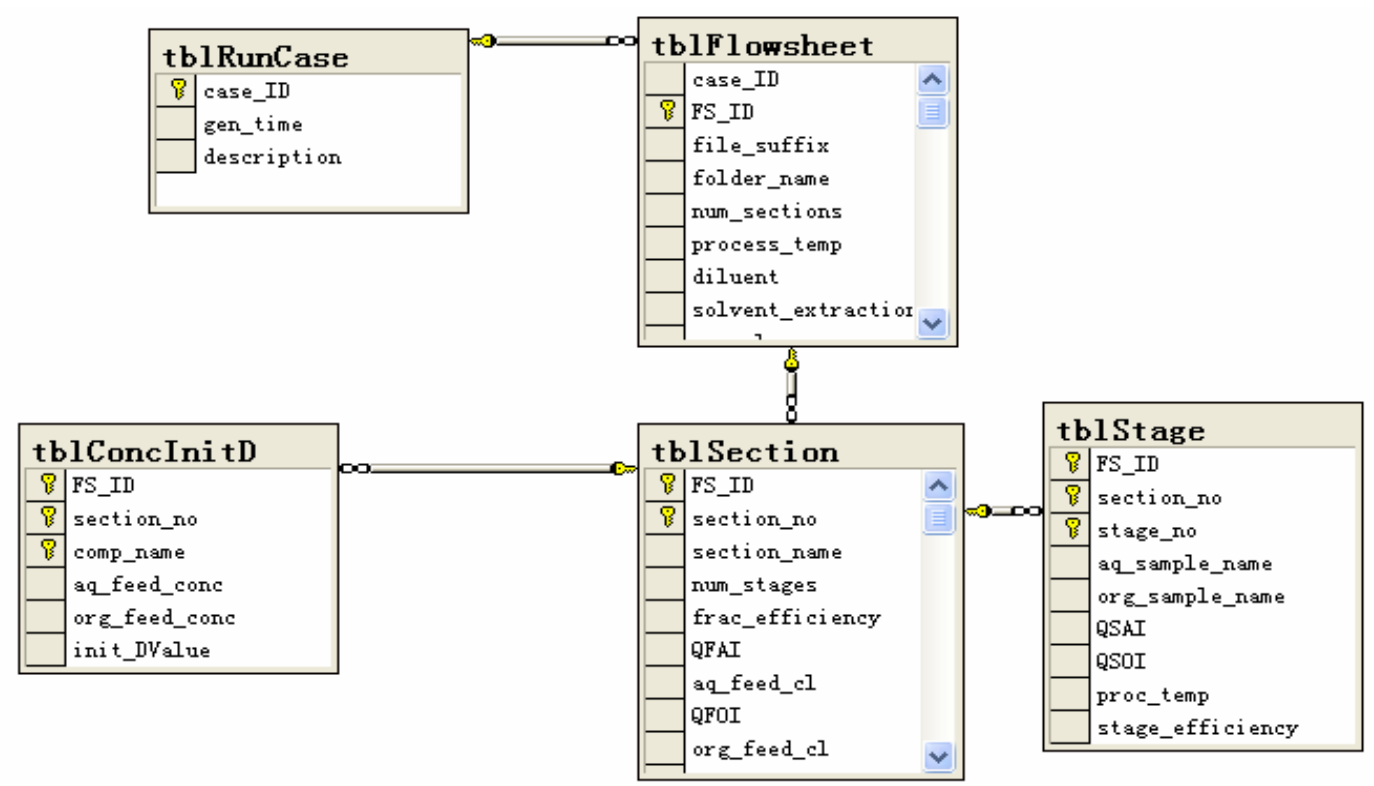

Diagram for the Structure of the Database Design. components of the chemical separations process. Each step required model development to establish its significance with regards to the overall process. Comprehensive model development involved defining the inputs and outputs from individual models and establishing how each connected to the other within in the chemical separations process.

\section{RESEARCH ACCOMPLISHMENTS}

This project developed software for a general-purpose systems engineering model named TRP System Engineering Model Program (TRPSEMPro) that will be used to improve productivity in the design process. The system model also includes various numerical optimization technologies and "Design of Experiments" study technologies.

Object-Oriented Analysis and Design was used for developing and implementing the TRPSEMPro system. A graphical notation, Unified Modeling Language, was employed to express objectoriented designs. Microsoft.Net architecture was used for system development and Visual Basic.NET was the major programming language behind the system. XML (Extensible Markup Language) was used widely to describe data and sets of elements and attributes that can be defined by researchers. XML Schema was used for describing the structure of the system engineering model. XML Database was used to store all the run-time data for the AMUSE module. Since significant experimental data will be generated and require systematic analysis, MS SQL Server 2000 database was selected for housing all run-time parameters and simulation results.

The model is combined with commercial software packages MATLAB OPTIMIZATION toolbox and SIMULINK module from Mathworks.

The system model, TRPSEMPro, considers input simulation modules from multiple disciplines with inconsistent input/output handles. The package with the aid of middleware can communicate with various simulation modules developed by other research groups and create an XMLbased model description file. The critical components for the system engineering modeling include System Manager, Model Integration, Study Plan, and Solution Viewer.

The introduction of the middleware design provides flexibility to interface to other simulation modules without significant program modification. The demonstration code from 
AMUSE macros is kept intact during all system development stages. AMUSESimulator, is the middleware software package which was designed and implemented to serve as a bridge between the AMUSE code, and the systems engineering model, TRPSEMPro. Such an approach can reduce the time-consuming modification on the system model side and keep flexibility on the simulation modules development side.

Further system enhancement allowed the user to select various process types. An interface for conducting multiple runs was created. The GUI included a list of variables, a range for those variables, all of which provide an envelope of end results.

\section{TASK 8 PROFILE}

Start Date: August 2001

Completion Date: August 2004

(This work continued under Task 24, see pages 52-53.)

\section{Thesis Generated:}

Lijian Sun, M.S., Mechanical Engineering, "Development of a Systems Engineering Model for Chemical Separation Process,” December 2003.
Conference Proceedings:

"Development of Systems Engineering Model for Spent Fuel Extraction Process," IMECE 2004, International Mechanical Engineering Congress and Exposition Conference, Anaheim, CA, November 13-19, 2004.

L. Sun, Royyuru, H., Hsieh, S., Chen, Y., Clarksean, R., Vandegrift, G., Copple, J., and Laidle, J., "Development of Systems Engineering Model for Spent Fuel Extraction Process," ICAPP-04, Pittsburgh, PA USA, June 13-17, 2004.

H. Royyuru, Sun, L., Chen, Y., Hsieh, S., Clarksean, R., Pepper, D., Vandegrift, G., Copple, J., and Laidle, J., "Development of Systems Engineering Model For UREX Process,” ASME International Mechanical Engineering Congress and Exposition, Washington, DC, November 16-21, 2003.

H. Royyuru, Sun, L., Chen, Y., Hsieh, S., Clarksean, R., Pepper, D., Vandegrift, G., Copple, J., and Laidle, J., "Development of Systems Engineering Model For UREX Process," AccApp'03: Accelerator Applications in a Nuclear Renaissance, San Diego, CA, June 1-5, 2003.

L. Sun, Chen, Y., Clarksean, R., and Laidler, J., “The Development of a Systems Engineering

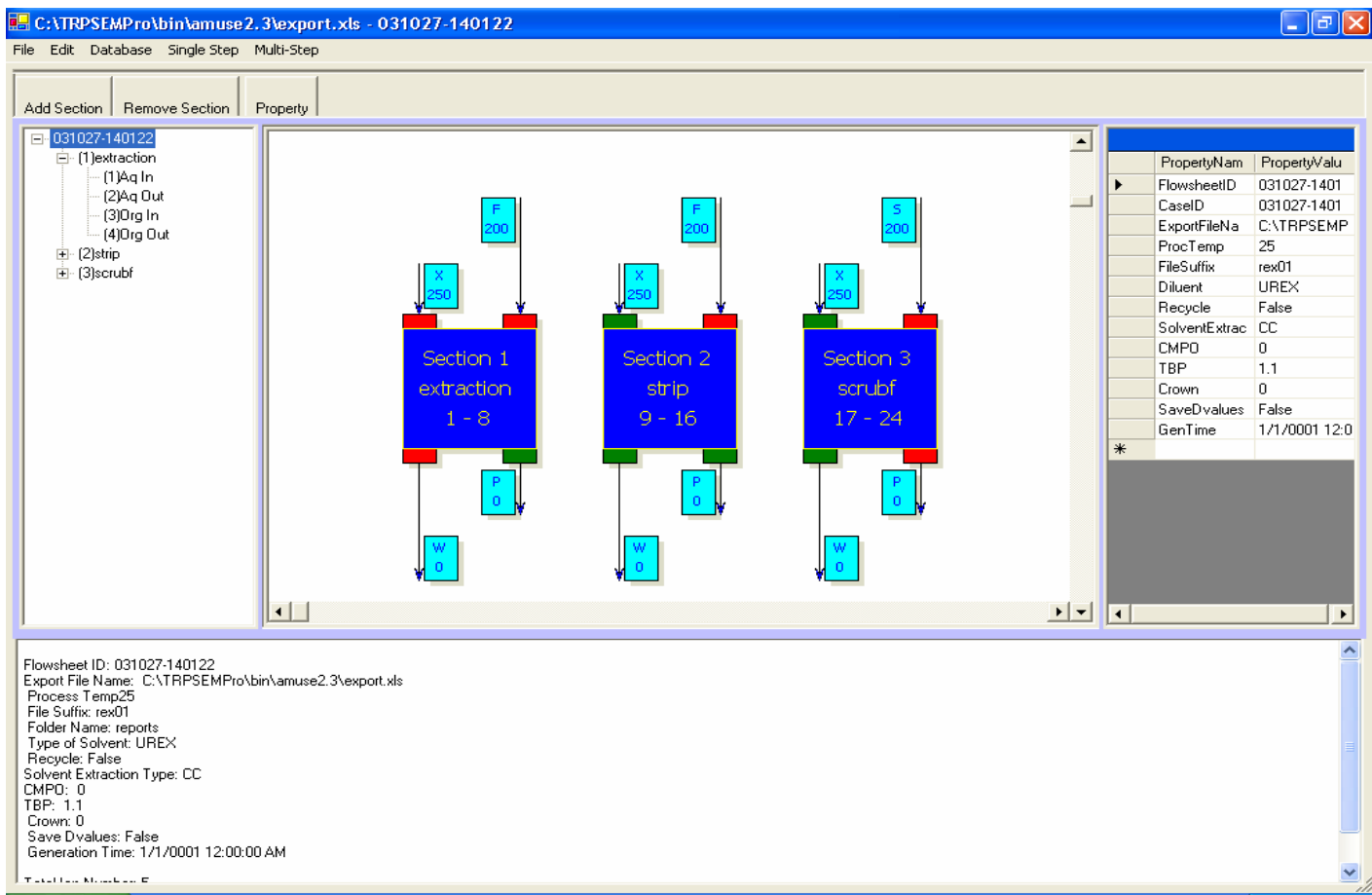
Model for the DOE Advanced AcInternational Congress on Advanced Nuclear Power Plants, embedded topical meeting at the ANS Summer Meeting, Hollywood, Florida, June 9-13, 2002.

The main GUI for AMUSESimulator includes five parts as shown here. Menu and toolbar (Top Part) where user can invoke all the available commands. Flowsheet contents displayed in tree view format (Left Part) - where user can select different section, stream. Flowsheet contents displayed in way of drawing blocks (Middle Part) - where user can select different sections, streams by clicking mouse at corresponding area.

Research Staff

Yitung Chen, Principal Investigator; Associate Professor, Mechanical Engineering Department; Associate Director, NCACM

Darrell W. Pepper, Professor, Mechanical Engineering Department; Director, Nevada Center for Advanced Computational Methods Sean Hsieh, Research Assistant Professor, Mechanical Engineering Department, Nevada Center for Advanced Computational Methods

Students

Sushma Gujjula, Jianhong Li, Haritha Royyuru, Sridhar Munaga, and Lijian Sun, Graduate Students, Mechanical Engineering Department 


\title{
Task 9 \\ Design and Evaluation of Processes for Fuel Fabrication
}

\author{
G. Mauer
}

\section{BACKGROUND}

The safe and effective manufacturing of actinide-bearing fuels for any transmutation strategy requires that the entire manufacturing process be contained within a shielded hot cell environment. To ensure that the fabrication process is feasible, the entire process must be designed for remote operation. The equipment must be reliable enough to perform over several decades, and also easy to maintain or repair remotely. The facility must also be designed to facilitate its own decontamination and decommissioning. In addition to these design factors, the potential viability of any fuel fabrication process will also be impacted by a number of variables, such as the current state of technology, potential problem areas, deployment scaling, facility safety, and cost.

\section{RESEARCH OBJECTIVES AND METHODS}

The goal of this research project was to provide technical support to process designers working on the development of the fuel cycles for transmutation applications. Detailed process models were developed to better define the impact of fuel choice on the transmuter fuel cycle, including relative process losses, waste generation, and plant capital cost. These process models provide insight regarding required plant size and number of plants needed to mesh with the fuel recycling line. They also determine requirements for automation.

Manufacturing models for large-scale production in a hot cell environment were also developed. Combined, these two models allow the assessment of plant layout, and provide the framework for estimation of plant capital and operating cost estimates, and for feasibility in general. The need for development in the areas of robotic and sensor technology was assessed. The manufacturing technology developed for hot cell applications was also applicable to other, more general uses, where occupational hazards

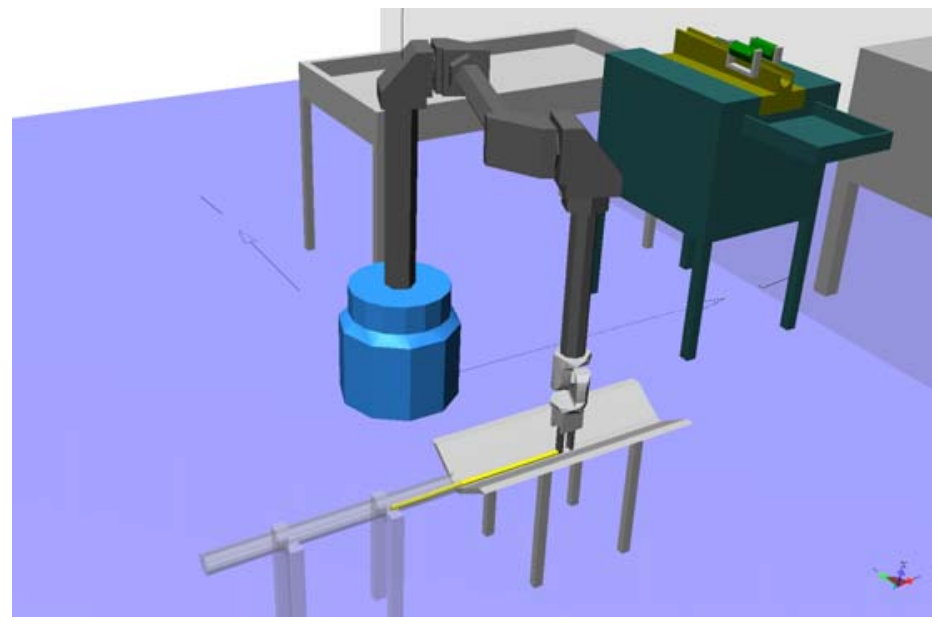

The Wäelischmiller robot inserts the fuel pins in the cladding tube.

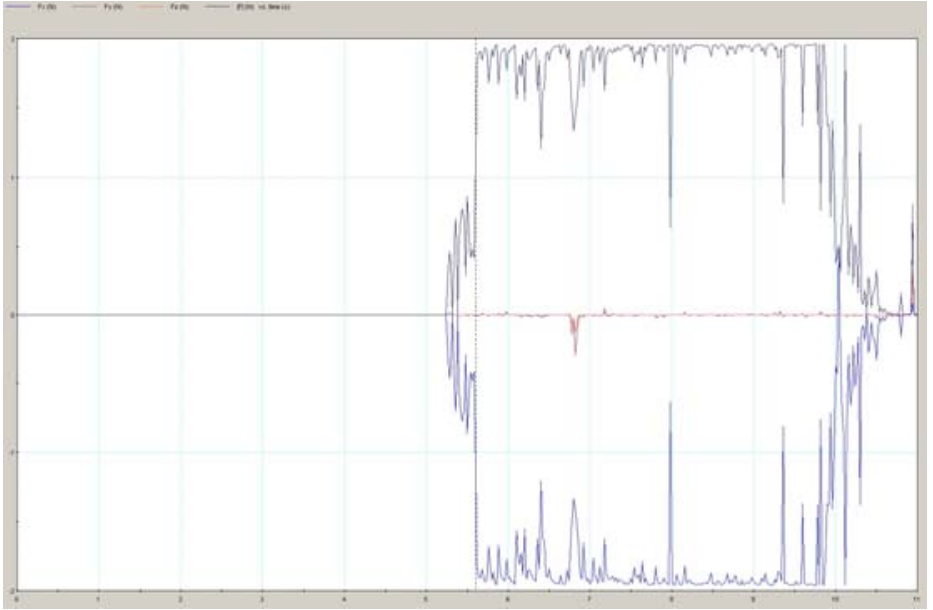

Friction Force (N) between Second Pin and Cladding Tube vs. Time (sec) during Insertion.

prevent human presence near processes.

The research work was divided into several tasks and subtasks:

Methods and Processes - A literature survey and detailed analysis of the research and development pertaining to candidate processes for transmuter fuel manufacture was performed. Industry standards were used to refine equipment, instrumentation, and control specifications, and assessed the reliability and safety of operations.

Simulations - This task modeled manufacturing processes to generate a realistic assessment of plant layout, size, feasibility, and technology development required for large-scale remote fabrication of fuel. Modeling of the candidate fuel manufacturing processes was conducted using the MSC.visualNastran and ProEngineer simulation software tools. The modeling of powderprocessed fuels was completed, and the modeling of other fuel types (metallic, TRISO etc.) was initiated.

Process and Equipment for Autonomous Manufacturing - This task developed an understanding of the cost and capability of current generation remotely operated equipment suitable for use in radiation environments. Monitoring of the market for equipment and components with regard to suitability for automated manufacturing under hot cell conditions was conducted.

Sensors, Controls, and Operational Safety - This task determined the adequacy of current technology and the need for suitable sensor technology development for deployment in hard radiation environments. A means to identify the precise location and spatial orientation of all parts in the robot's work envelope were implemented. The ability to position and handle materials along with trouble shooting techniques were evaluated. Radiation hardened vision systems appear to be promising technologies. 


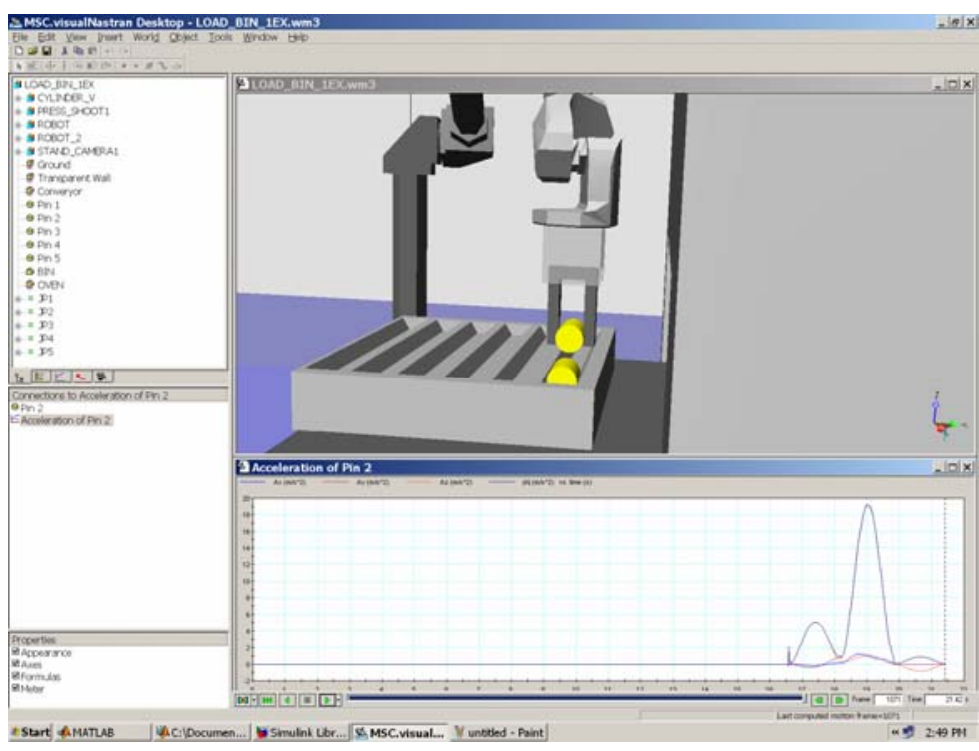

Visual Nastran Analysis of Pellet accelerations. The simulation verified that pellet's acceleration did not exceed a specified maximum of $20 \mathrm{~m} / \mathrm{s}^{2}$.

Cost, Feasibility, and Large Scale Deployment - This task developed the database necessary to provide cost estimates and differential cost for various fuel manufacturing options. Efforts were initiated to tabulate and quantify estimates regarding projected cost, reliability, and plant life.

\section{RESEARCH ACCOMPLISHMENTS}

A special simulation model with a Waelischmiller hot cell robot was developed and coupled with MatLab control software. Matlab provides the interface with the robot and is used to control the system. This renders a realistic simulation of the forces and torques present during robot motion. A 3-D manufacturing process simulation using CAD models and the Newtonian dynamics of the moving components was developed.

Results exist in the form of movies, data sets, and images. Simulations for several robot types were developed and their proper kinematic configuration was verified. The simulations permit the detailed analysis of forces and torques in any modeled part or component.

While the simulation process generally worked flawlessly, the simulation time rose considerably as more details were added to the simulation. The speed of the simulation has been increased about 100 -fold by moving to fast dual-processor computers.
Efforts to develop a vision-based methodology for locating and identifying objects within the robot's workspace were conducted using the Artificial Intelligence (AI) algorithm for object identification.

Another accomplishment involved the development of algorithms for knowledge based pattern recognition using IF (a set of conditions is satisfied) THEN (a set of consequences can be executed) routines. Other simulation variables established included pattern matching using clustered indexing vectors containing information about an object and feature vector indexing, where a 3-D object is segmented into a set of simple geometric features. Each feature is stored with its vector segmentation and geometry information (magnitude, inner angle, etc.).

\section{TASK 9 PROFILE}

Start Date: August 2001

Completion Date: August 2004

(This work continued under Task 22, see pages 48-49.)

\section{Thesis Generated:}

Jae-Kyu Lee, Ph.D., Department of Mechanical Engineering, "Three Dimensional Pattern Recognition using Feature-based Indexing and Rule-based Search,” December 2003.

Journal Article:

J.K. Lee and G. Mauer, "Feature-Based Pattern Recognition and Object Identification for Telerobotics," submitted to IEEE/ ASME Journal of Mechatronics in August 2004.

\section{Conference Proceedings:}

G.F. Mauer and J. Renno, "Virtual Testing of Robotic Assembly Processes for Hot Cells," Proceedings, 10th International Conference on Robotics \& Remote Systems for Hazardous Environments, March 2004.

G.F. Mauer and J. Renno, "Design and Analysis of Robotic Manufacturing Processes," Proceedings, American Nuclear Society Winter Annual Meeting, New Orleans, LA, November 2003.

G.F. Mauer, "Design and Evaluation of Processes for Transmuter Fuel Fabrication," Proceedings, American Nuclear Society Winter Annual Meeting, November 2002.

G.F. Mauer, "Object Recognition Over An Expanded Range Of Viewing Angles Using Indexing Methods," Proceedings, CAINE 2002 conference, San Diego, CA, November 2002.

Research Staff

Georg Mauer, Principal Investigator, Professor, Mechanical Engineering Department

Caroline Wiejak, Visiting Scholar, Ecole Supérieure d'Ingénieurs en Electronique et Electrotechnique, Noisy-le-Grand, France

\section{Students}

Jae-Kyu Lee, Jamil Renno, and Richard Silva, Graduate Students, Mechanical Engineering Department 


\section{BACKGROUND}

During the transmutation process, a significant amount of heat can be generated in a molten lead-bismuth-eutectic (LBE) target, which will be contained in a subsystem structural container made of a suitable martensitic iron-chromium-molbdenum (Fe-Cr-Mo) stainless steel such as Alloys EP-823, HT-9 and 422. These materials will be subjected to high tensile stresses while they are in contact with the molten LBE at temperatures ranging between 400 and $600^{\circ} \mathrm{C}$. Therefore, a research program was conducted to evaluate the deformation characteristics of all three alloys in properly heat-treated conditions at temperatures relevant to the operating conditions.

\section{RESEARCH OBJECTIVES AND METHODS}

Experimental heats of Alloys EP-823, HT-9 and 422 were vacuum-induction-melted, followed by forging and hot rolling. The hot-rolled bars were subsequently thermally treated to produce a fully tempered and fine-grained martensitic microstructure without any retained austenite. They were austenitized at $1010^{\circ} \mathrm{C}$, oilquenched, and tempered at $621^{\circ} \mathrm{C}$. The tempering operation was performed for $1.25,1.75$, and 2.25 hours, respectively, to study the effect of tempering time on the tensile properties. The hardness of all materials, before and after tempering, was measured using the Rockwell hardness scale. The tensile properties were determined at temperatures ranging from ambient to $600^{\circ} \mathrm{C}$ using smooth cylindrical specimens at a strain rate of $10^{-3} \mathrm{sec}^{-1}$ accord- ing to the ASTM Designation E 8. A minimum of two specimens were tested under each condition, with the average value recorded. The metallurgical microstructures of the tested specimens were evaluated by optical microscopy. The primary fracture surface of the tensile specimens was analyzed by scanning electron microscopy (SEM) to determine the extent and morphology of failure. The resultant data include the percentage elongation $(\% \mathrm{El})$, percentage reduction in area (\%RA), yield strength (YS), and ultimate tensile strength (UTS) as functions of the testing temperature and thermal-treatments. At least two specimens per material were tested under each of the three metallurgical conditions at the desired temperatures.

\section{RESEARCH ACCOMPLISHMENTS}

The significant conclusions drawn from this investigation are summarized below:

- The hardness of all three austenitized and quenched alloys were significantly reduced due to tempering, showing a gradual reduction with increasing tempering time.

- The magnitude of the yield, ultimate and failure stress were gradually reduced with increasing temperature, showing significant reductions at temperatures above $400^{\circ} \mathrm{C}$.

- The extent of ductility in terms of \%El and \%RA was reduced to some extent in the temperature regime of ambient to $300^{\circ} \mathrm{C}$ due to strain hardening. However, beyond $300^{\circ} \mathrm{C}$, the magnitude of these parameters was enhanced due to increased plastic flow.

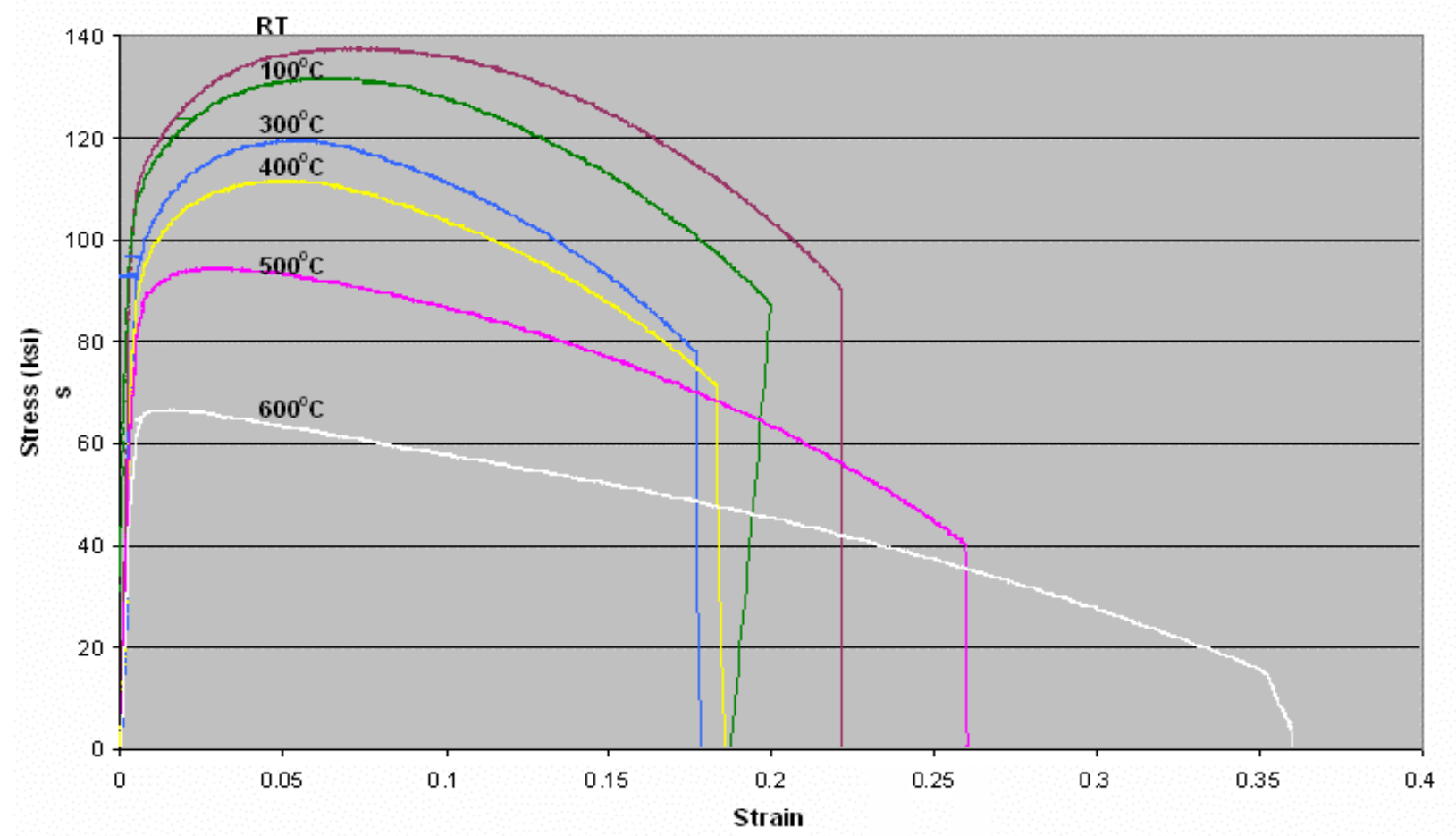

Stress-strain curves for Alloy HT-9 at different temperatures. 


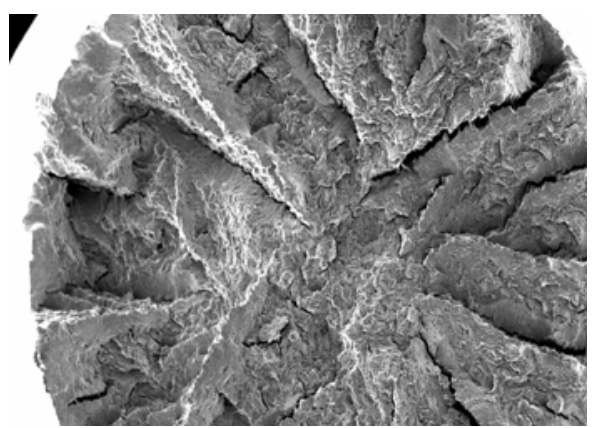

Room Temperature

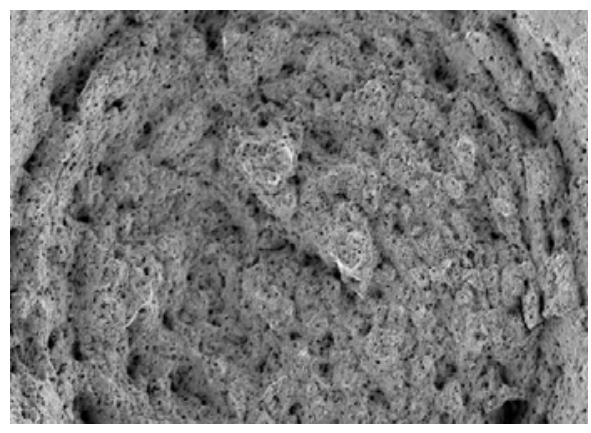

$300^{\circ} \mathrm{C}$

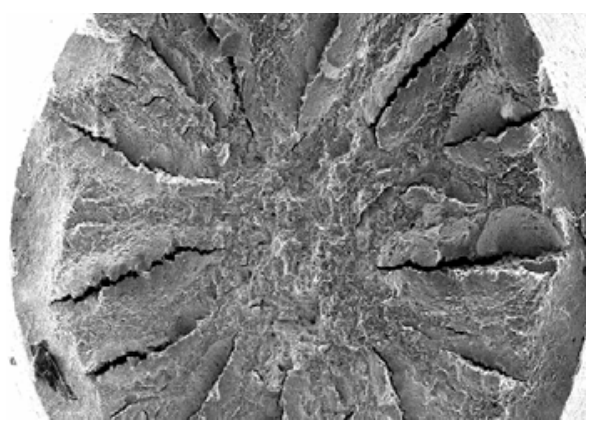

$100^{\circ} \mathrm{C}$

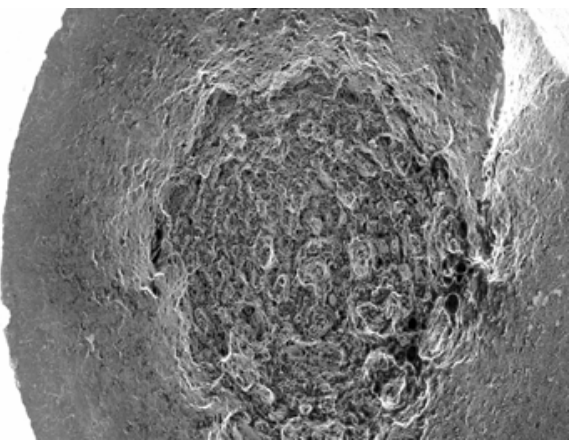

$600^{\circ} \mathrm{C}$

Scanning Electron Microscope micrographs of Alloy HT-9 at various temperatures (35X).

- The morphology of failure was characterized by increased plastic deformation at elevated temperatures. Reduced cracking and dimpled microstructures were observed on the fracture surfaces indicating improved ductility at higher temperatures.

- The tempering time did not influence the metallurgical microstructure and the resultant tensile properties to any great extent irrespective of the testing temperature.

\section{TASK 10 PROFILE}

Start Date: August 2001

Completion Date: August 2004

\section{Theses Generated:}

Srinivasa R. Kukatla, M.S., Department of Mechanical Engineering, "Corrosion and High-Temperature Deformation Characteristics of a Target Structural Material for Transmutation Applications,” June 2004.

Venkata Nagarjuna Potluri, M.S., Department of Mechanical Engineering, "Effect of Heat Treatment on Deformation and Corrosion Behavior of Type 422 Stainless Steel,” August 2004.
Bhagath Yarlagadda, M.S., Department of Mechanical Engineering, "Elevated Temperature Mechanical Properties and Corrosion Characteristics Evaluation of Alloy HT-9,” August 2004.

\section{Journal Article:}

A.K. Roy, S. R. Kukatla, B. Yarlagadda, V. N. Potluri, M. Lewis, M. Jones and B. J. O'Toole, "Tensile Properties of Martensitic Stainless Steels at Elevated Temperatures," Journal of Materials Engineering and Performance, ASM International, April 2005, Vol. 14, No. 2, pp. 212-218.

Conference Proceedings:

A.K. Roy, S.R. Kukatla, and B. Yarlagadda, "High Temperature Deformation Characteristics of Martensitic Stainless Steels," Society for the Advancement of Material and Process Engineering (SAMPE) International Technical Conference, Long Beach, CA, May 16-20, 2004.

M. Lewis, M. Jones, A.K. Roy, and B.J. O’Toole, "HighTemperature Deformation of Alloy EP-823 for Transmutation Applications,” American Nuclear Society Conference, San Diego, CA, June 1-5, 2003.

Research Staff

Ajit K. Roy, Principal Investigator, Associate Professor, Mechanical Engineering Department

Brendan J. O'Toole, Associate Professor, Mechanical Engineering Department

\section{Students}

Mark Jones, Prad Koppula, Raymond Kozak, Srinivasa Kukatla, Martin Lewis, Venkata Potluri, and Bhagath Yarlagadda, Graduate

Students, Mechanical Engineering Department

John Motaka, Undergraduate Student, Mechanical Engineering Department

Stuart A. Maloy, AFCI Materials Team Leader, Los Alamos National Laboratory 


\title{
Task 11 \\ Nuclear Criticality, Shielding, and Thermal Analyses of Separations Processes for the Transmutation Fuel Cycle
}

\author{
W. Culbreth and D. Beller
}

\section{BACKGROUND}

The first step in any transmutation strategy is the separation of radionuclides in used nuclear fuel. The current separation strategy supporting the Advanced Fuel Cycle Initiative (AFCI) program is based on the use of a solvent extraction separation process to separate the actinides, fission products, and uranium from used commercial nuclear fuel, and on the use of pyrochemical separation technologies to process used transmuter fuels. To separate the fission products and transuranic elements from the uranium in used fuel, the national program is developing a new solvent extraction process, the Uranium Extraction Plus, or UREX+, process based on the traditional solvent extraction reprocessing technologies.

Preparing fuel for possible burn up in light water reactors, fast reactors, or accelerator-driven systems involves various chemical processes to partition the transuranics (neptunium, americium, plutonium, and curium) from the fission products. This results in waste streams that are highly radioactive and require radiation shielding for safety. These transuranic elements pose varied criticality, thermal, and radiation risks during storage and handling. Additionally, the radioactive decay of strontium and cesium waste products of the UREX+ technique produce roughly half of the thermal products and gamma radiation emissions in spent fuel. These radioisotopes require storage for approximately 300 years before heat and radiation hazards decrease to a safe level.

As the volume of waste requiring treatment increases, a higher probability exists that fissionable isotopes of plutonium, neptunium, and curium can accumulate and form a critical mass. Criticality concerns warrant an assessment of the effective neutron multiplication factor, or $\mathrm{k}_{\text {eff, }}$, to prevent a possible sustained fission reaction. Maintaining $\mathrm{k}_{\mathrm{eff}}$ below a safe level $(<0.95)$ prevents criticality events. This parameter can be computed for any combination of fuel and geometry using Monte Carlo neutron transport codes. Monte Carlo simulations establish the best means of examining the criticality safety of the proposed separation processes, and allow engineers to develop proper safety measures for the reprocessing and fabrication of actinide fuels.

Candidate storage containers also require analysis to assess the need for radiation shielding. Since minor actinides generate significant amounts of heat through radioactive decay, proposed containment measures must be designed to avoid excessive temperatures. Radioactive decay also generates heat that can lead to melting of the fuel during storage and handling.

\section{RESEARCH OBJECTIVES AND METHODS}

The primary goal of this research program was to provide the nuclear and thermal modeling support for the development of this new separation process. The assessments of nuclear criticality, radiation for shielding, and thermal analyses of wastes in the Cs/ $\mathrm{Sr}, \mathrm{Pu} / \mathrm{Np}$, and $\mathrm{Cm} / \mathrm{Am}$ waste streams will assist in designing the UREX+ process. This project was identified as a critical R\&D need of the Chemical Technology Division (CTD) at the Argonne National Laboratory (ANL) as safety concerns associated with criticality, shielding, and heat buildup must be addressed prior to further development of the UREX+ process.

UNLV students used nuclear analysis codes to perform assessments of $\mathrm{k}_{\mathrm{eff}}$ at different points in the separation processes that have been identified by the project collaborators at ANLCTD. They also worked on problems to assess the need for radiation shielding and to develop software to assess the possibility of excessive temperatures due to radioactive decay in separated wastes. ANL-CTD has provided sample fuel process geometries and compositions for calculation of $\mathrm{k}_{\mathrm{eff}}$ as a function of the relative concentrations of process salt, transuranics, and fission products.

\section{RESEARCH ACCOMPLISHMENTS}

An investigation and analysis of criticality and thermal effects for the safe storage of curium was completed. The assessment involved determining $\mathrm{k}_{\text {eff }}$ as a function of fuel burnup, initial enrichment, and time since irradiation. Additionally, since curium generates a substantial quantity of decay heat, an analysis was completed to determine the mass of curium that will lead to temperatures high enough to melt the metal. A spherical geometry was

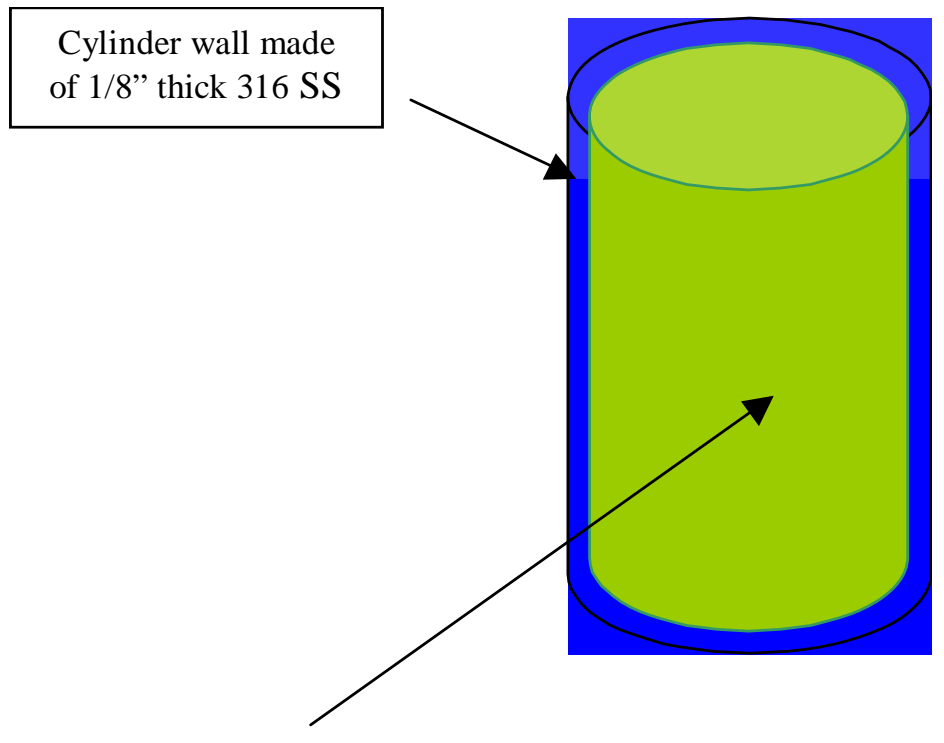

$$
\begin{aligned}
& \text { Interior filled with homogeneous } \\
& \text { mix of TRU, Process Salt, and } \\
& \text { Fission Products }
\end{aligned}
$$

Cylindrical problem with TRU, process salt, and fission products. 
used in the analysis. Heat removal from the sphere was assumed to be a combination of natural convection and radiation heat transfer. This heat transfer analysis was also modified and resulted in an analysis that utilized a more sophisticated and suitable cylindrical container. A report developed for Dr. Laidler at ANL described the in-depth investigation regarding the criticality and thermal properties of curium. The heat transfer spreadsheet was used for other combinations of minor actinides as indicated by ANL.

Investigators also investigated the properties of the other minor actinides, including plutonium and americium. A study was conducted on the values of $\mathrm{k}_{\mathrm{eff}}$ and ultimate temperature for varying combinations of plutonium, americium, and the remaining minor actinides.

UNLV students used nuclear analysis codes SCALE 4.4 and/or MCNPX to perform assessments of $\mathrm{k}_{\mathrm{eff}}$ at different points in separation processes that have been identified by ANL-CTD. They also worked on problems to assess the needs for radiation shielding and develop software to assess the possibility of excessive temperatures due to radioactive decay in separated wastes. ANLCTD has provided sample fuel process geometry and composition for calculation of $k_{\text {eff }}$ as a function of the relative concentrations of process salt, TRU actinides, and fission products. The research team analyzed the cesium/strontium waste stream, the plutonium/ neptunium waste stream, and the americium/curium waste stream.

\begin{tabular}{|c|c|c|c|c|c|}
\hline \multicolumn{2}{|c|}{ Cm Metal C ylinder } & \multicolumn{2}{|l|}{ Criticality } & \multicolumn{2}{|l|}{ Heat Transfer } \\
\hline & & $\operatorname{rad}(\mathrm{cm})$ & mass (kg) & $\operatorname{rad}(\mathrm{cm})$ & mass (kg) \\
\hline & bare & 4.6 & 82.52 & 1.1 & 1.129 \\
\hline & water & 2.7 & 16.69 & 3.3 & 30.48 \\
\hline \multicolumn{2}{|c|}{$\mathrm{Cm}_{2} \mathrm{O}_{3}$ Cylinder } & Criticality & & Heat Transfer & \\
\hline & & $\operatorname{rad}(\mathrm{cm})$ & mass (kg) & $\operatorname{rad}(\mathrm{cm})$ & mass (kg) \\
\hline & bare & 5.4 & 125.59 & 1.55 & 2.74 \\
\hline & water & 3 & 21.53 & 2.25 & 8.37 \\
\hline \multicolumn{2}{|c|}{$\mathrm{Am}_{2} \mathrm{O}_{3}$ Cylinder } & Criticality & & Heat Transfer & \\
\hline & & $\operatorname{rad}(\mathrm{cm})$ & mass (kg) & $\operatorname{rad}(\mathrm{cm})$ & mass (kg) \\
\hline & bare & 11.2 & 1032.28 & 1.6 & 3.01 \\
\hline & water & 10.5 & 850.58 & 1.9 & 5.04 \\
\hline \multicolumn{2}{|c|}{$\mathrm{Am}_{2} \mathrm{O}_{3}+\mathrm{Cm}_{2} \mathrm{O}_{3}$} & $\overline{\text { Criticality }}$ & & Heat Transfer & \\
\hline \multirow[t]{3}{*}{ Cylinder } & & $\operatorname{rad}(\mathrm{cm})$ & mass (kg) & $\operatorname{rad}(\mathrm{cm})$ & mass (kg) \\
\hline & bare & 10 & 737.9 & 1.4 & 2.02 \\
\hline & water & 9.3 & 593.54 & 2 & 5.88 \\
\hline
\end{tabular}

Recommendations for Cm and Am oxide inventories based on criticality and melting temperature.

\section{TASK 11 PROFILE}

Start Date: August 2001

Completion Date: August 2004

Thesis Generated:

Elizabeth Bakker, M.S., Mechanical Engineering Department, "Criticality and Thermal Analysis of Separated Actinides in Transmutation,” November 2003.

\section{Reports:}

B. Culbreth, E. Bakker, and J. Viggato, "The Fission Properties of Curium Separated from Spent Nuclear Fuel,” Department of Mechanical Engineering, University of Nevada, Las Vegas, April 2002.

B. Culbreth, D. Lowe, and J. Viggato, “Assessment of Criticality Safety for Cylindrical Containers to be Used In the Processing of Spent Fuel,” Department of Mechanical Engineering, University of Nevada, Las Vegas, October 28, 2001.

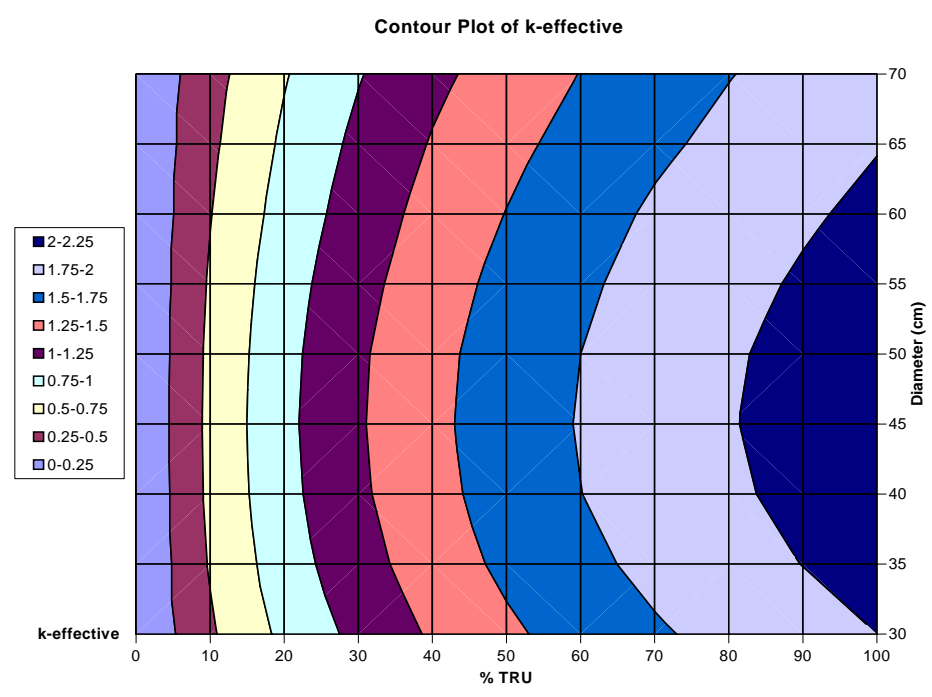

Contour Plot of the Effective Neutron Multiplication Factor as a function of cylinder diameter and \% TRU in the mixture.

Research Staff

William Culbreth, Principal Investigator, Associate Dean for Research, College of Engineering

Denis Beller, Research Professor, Mechanical Engineering Department

Students

Elizabeth Bakker, Robin Jenkins, Maurice Moore, and Jason Viggato, Graduate Students, Mechanical Engineering Department Daniel Lowe and Robert O'Brien, Undergraduate Students, Mechanical Engineering Department

James J. Laidler, Senior Scientist, Chemical Technology Division, Argonne National Laboratory

George F. Vandergrift, III, Senior Scientist, Chemical Technology Division, Argonne National Laboratory 


\title{
Task 12 \\ Radiation Transport Modeling using Parallel Computational Techniques
}

\author{
W. Culbreth and D. Beller
}

\section{BACKGROUND}

One of the most significant tools available for the design and analysis of accelerator-driven systems, such as the systems proposed for transmutation, is the high-energy particle transport code MCNPX. The MCNPX code suite, developed by the national laboratories, allows researchers and engineers to model the complex interactions of high-energy particles with the target and related systems, including the spallation reaction and subsequent neutron multiplication expected in the accelerator targets.

The next stage in the development of the MCNPX code suite is to validate the code by comparing the theoretical predictions from the models with experimental observations. Additionally, the nuclear database, particularly the cross sections (i.e., reaction probabilities) for high-energy particle interactions, needs to be revisited to reduce the uncertainties associated with key nuclear properties.

The Department of Energy, through its national laboratories, has initiated several experiments geared towards removing uncertainties in the MCNPX libraries, with more in the planning stages. These experiments utilize the proton and neutron beam lines at the LANSCE proton accelerator at the Los Alamos National Laboratory to irradiate a target, producing a pulse of neutrons which are observed by the experimenters. The results of these experiments are then compared against the predictions from the MCNPX models of the system. By comparing the predicted system behavior to the data acquired from the experiments, the experimenters will be able to validate the MCNPX code and its nuclear data libraries.

Through this project, UNLV researchers were involved in support of these experiments by developing the system models in MCNPX and benchmarking/validating the models against the experimental results. UNLV students were also involved in conducting experiments at LANL and in assisting researchers in designing new experiments.

\section{RESEARCH OBJECTIVES AND METHODS}

This project involved modeling several aspects of the LANCSE beam experiments:

- Modeling targets of varying diameter in air, in a vacuum, and in the presence of humid air;

- Modeling various proton beam profiles;

- Modeling the effects of off-axis proton beam impingement on the target;

- Modeling the asymmetry introduced by the steel table below the target;

- Modeling the effect of varying ratios of $\mathrm{Pb}$ to $\mathrm{Bi}$ and the effect of impurities; and

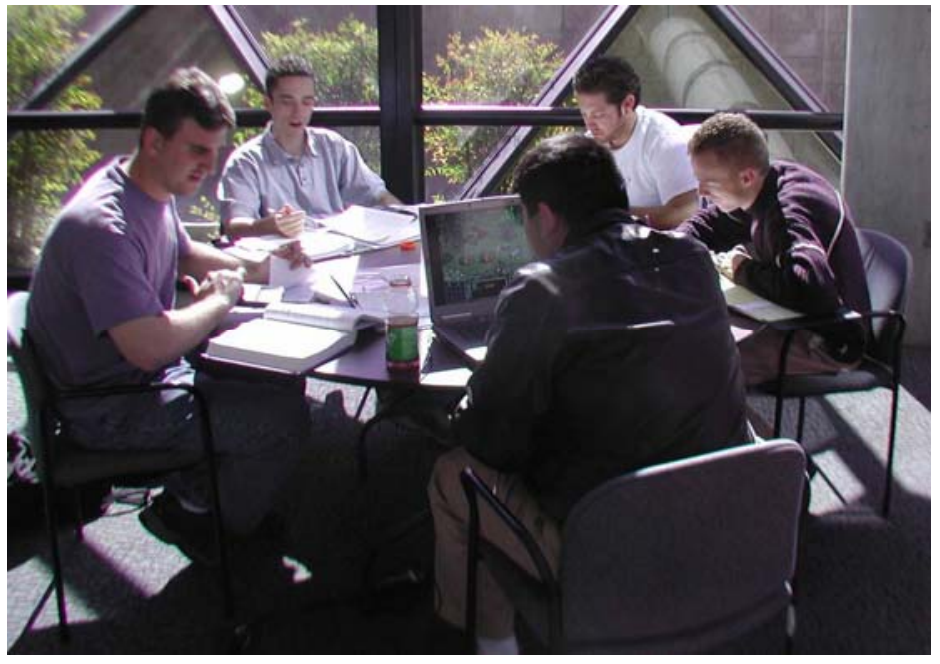

Robert O'Brien (left of center) and Daniel Lowe (far right) areboth undergraduate Mechanical Engineering students working on the project.

- Modeling the system, including other structures within the test room.

With the experience gained through modeling these systems, the UNLV researchers developed, with the assistance of their national laboratory collaborators, a benchmark program for the neutron leakage tests and other tests related to transmuter development. A comprehensive three-dimensional computer-aided design (CAD) image of the LANSCE experiments was prepared using ProEngineer to help benchmark the experiments and provide accurate geometric data for MCNPX modeling.

\section{RESEARCH ACCOMPLISHMENTS}

Undergraduate student Daniel Lowe worked on neutron spallation tests at the LANSCE facility (Summer 2002). He performed MCNPX runs and worked on calculations for initial benchmarking data. His early MCNPX calculations helped the experimenters determine where foil packets should go and what types of neutron flux to expect from these foils. He also prepared foils to determine neutron flux from the experiment and assisted in radiation counting of the foils. Mr. Lowe completed Solid Works CAD models of the Blue Room at LANSCE and conducted MCNPX simulations of the summer experiments when he returned back to UNLV. His MCNPX runs included estimations of the effect of the proton beam striking the target at positions slightly off of the centerline. He also estimated the neutron energy spectra expected from the time-of-flight neutron detectors.

Through MCNPX simulations of the neutron leakage from leadbismuth targets, the UNLV team was able to assist in the design of the experimental configurations for the LANCSE experiments. 
These models were also used to predict the results for the experiments, and assist in positioning detectors for measuring the leaking. Similar computational support was also provided for proton activation experiments in sodium coolant.

Extensive studies on how MCNPX performs with respect to MPI (Message Pass Interface) and PVM (Parallel Virtual Machine) have been run. PVM was no longer supported by the LANL team after 2005, hence more emphasis was placed on how MCNPX runs with MPI on a Beowulf system.

Parallelization of MCNPX for a Parallel Virtual Machine was completed. Message Passing Interface (MPI) bugs and compiling problems were resolved.

Analysis of linearization characteristics on a Beowulf cluster was completed. Work was then focused on characteristics of the Supercomputing Center and the linearization of criticality studies.

Benchmarking and optimization of MCNPX to run on multiple platforms was performed. This insured that the user will not be limited to a specific system type when running simulations. In addition, the MCNPX simulations of experiments was performed.

User guides were developed for future users. These will describe how to implement an optimized version of MCNPX on a heterogeneous cluster using a Message Passing Interface. Efforts to increase the speed of MCNPX on parallel clusters of computers was conducted and a preliminary graphical user interface (GUI) for MCNPX using open source code and tools was developed. The GUI interface is written in Visual Basic allowing easy integration into Excel codes that contain databases of results from criticality and heat transfer studies of waste storage containers.

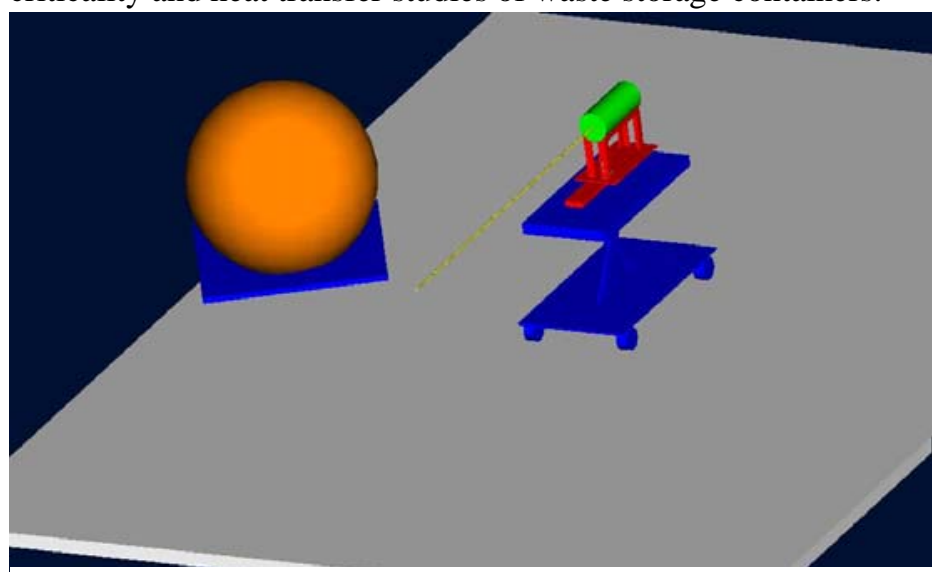

Schematic of the experimental facility at LANSCE used for modeling.
With the help of Trevor Wilcox, a doctoral student in mechanical engineering, the MCNPX software was ported to a Beowulf cluster located in the Tiberti Laboratory at UNLV. The cluster has between 32 and 50 processors available to run a single MCNPX job.

\section{TASK 12 PROFILE}

Start Date: August 2001

Completion Date: August 2004

Thesis Generated:

Suresh B. Sadineni, M.S., Mechanical Engineering Department, "Benchmarking Photoneutron Production of MCNPX Simulations with Experimental Results,” December 2002.

Conference Proceedings:

M.A. Reda, J.F. Harmon, and S.B. Sadineni, "Properties of Photo-Neutron Sources for Accelerator Driven Sub-Critical Systems," American Nuclear Society Conference, June 1-5, 2003, San Diego, CA.

M.R. James, R.T. Klann, G.L. Morgan, E.J. Pitcher, M.A. Paciotti, J.M. Oostens, J.E. Platte, and D.R. Lowe, "Measurements from Activation Foils of a Proton Irradiated Lead-Bismuth Target,” American Nuclear Society Conference, June 1-5, 2003, San Diego, CA .

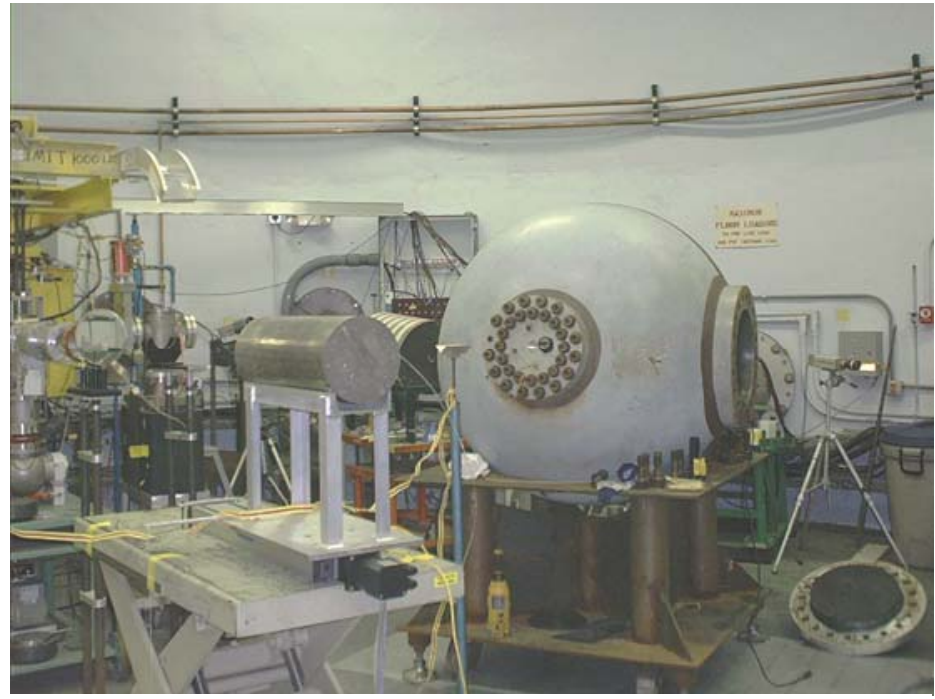

Experimental facility at LANSCE, Los Alamos, NM.

Research Staff

William Culbreth, Principal Investigator, Associate Dean for Research, College of Engineering

Denis Beller, Research Professor, Mechanical Engineering Department

Students

Ashraf Kaboud, Suresh Sadineni and Trevor Wilcox, Graduate Students, Mechanical Engineering Department Daniel Lowe and Robert O'Brien, Undergraduate Students, Mechanical Engineering Department

Laurie S. Waters, Los Alamos National Laboratory 


\section{Task 13}

\section{Developing a Sensing System for the Measurement of Oxygen Concentration in Liquid Pb-Bi Eutectic \\ Y. Jiang and B. Fu}

\section{BACKGROUND}

Although liquid lead-bismuth eutectic (LBE) is a good candidate for the coolant that can be employed in a subcritical transmutation blanket, it is known to be very corrosive to stainless steel, the material used in the containment structure. To mitigate this problem, trace levels of oxygen can be introduced into the system, causing the formation of a protective oxide layer at the interface between the LBE and steel. The proper formation of this oxide layer largely depends on the accurate measurement and subsequent control of the oxygen concentration in liquid LBE.

Yttria Stabilized Zirconia (YSZ) oxygen sensors, using molten bismuth saturated with oxygen as the reference, have been utilized to accurately measure the concentration of oxygen dissolved in LBE. By measuring the voltage difference across the YSZ sensor, the oxygen concentration in test solutions can be determined relative to that in the reference solutions (the potentiometric method). The theoretical model for calculating oxygen concentration based on voltage measurements from YSZ sensors in static conditions is well understood. The real world performance of these systems, however, is less predictable.

\section{RESEARCH OBJECTIVES AND METHODS}

The research objectives of this project were as follows:

- To generate calibration curves of voltage versus oxygen concentration for the YSZ oxygen sensor system under various temperatures in liquid LBE.

- To determine the sensor characteristics of the YSZ sensor system.

- To determine oxygen dissolving rates in LBE under different temperatures in vitro.

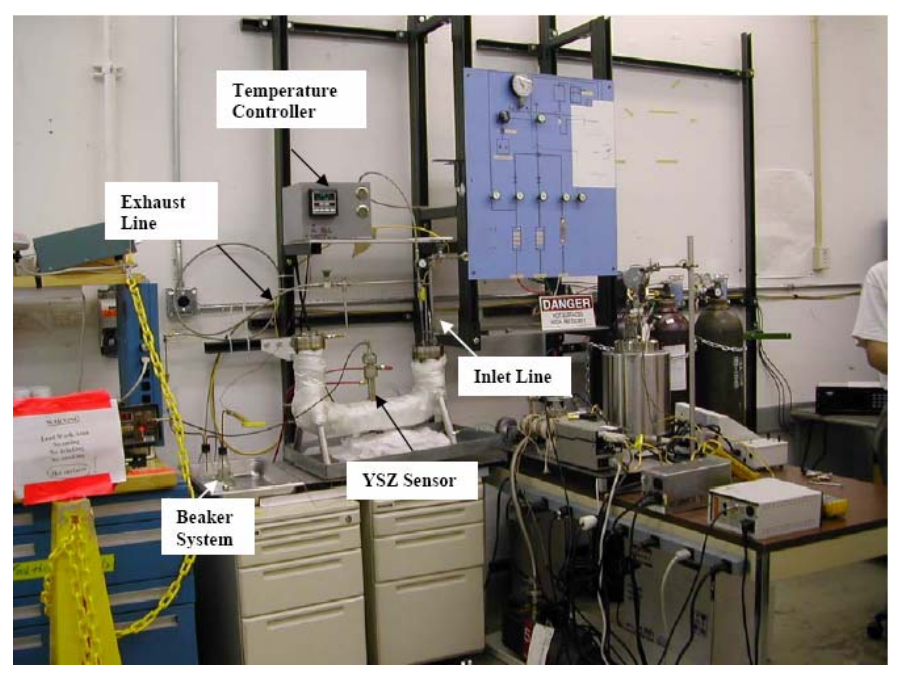

The first sensor calibration experimental setup.
- To study the effects of unwanted electrical conductivity, contributed by the mobility of the electrons at high temperatures, for more accurate oxygen measurement.

- To study alternative and promising oxygen measuring methods.

\section{RESEARCH ACCOMPLISHMENTS}

The first experimental set up consisted of a temperature controlled U-shape container, gas supplies and exhaust, a residual gas analyzer (RGA), a high-impedance electrometer, and a PC for data acquisition. The container is tightly sealed from the outside atmosphere using a conflat flange except for gas inlet and outlet, and openings for insertion of thermocouple or RGA signal wire. Flexible heating tapes around the container heated the liquid metal to the required temperature under the control of a temperature controller. Meanwhile, the thermally insulated container is placed on a rocker to provide fluid motion that promotes mixing and homogenization of oxygen concentration in LBE.

Although some calibration results were obtained using this setup, it had several shortcomings. For instance, it was impossible to heat the system to reach the desired high temperature (up to 750 ${ }^{\circ} \mathrm{C}$ ). In addition, direct injection of $\mathrm{O}_{2} / \mathrm{H}_{2}$ method adopted in this system is unlikely to produce a required extremely low oxygen level (ppm to tens of ppb) in liquid LBE. These problems in part were solved by developing a new apparatus. Some noticeable features of this apparatus were:

- Instead of using a steel tube, this apparatus incorporates a cylindrical crucible made of Magnesia Stabilized Zirconia (MSZ), and the liquid LBE is contained in this MSZ crucible. MSZ was chosen because of its desirable material properties.

- The MSZ crucible sits on a stainless steel beaker. The beaker acts as a pressure boundary, and it can distribute the weight

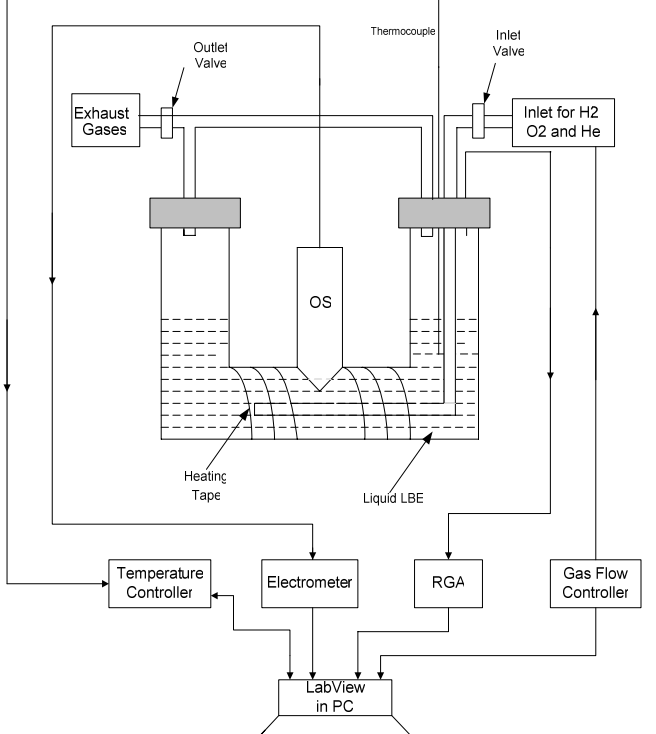
of the molten metal and crucible to the outer support. Back-up materials are used to fill the gap between the inner crucible and beaker.

- The crucible is tightly sealed with a metallic flange, with only a few openings left for gas inlets and outlets.

- A stirring unit is employed in order to mix the gases with the molten metal. The stirrer is made of Silicon Nitride (Si3N4) ceramic. Silicon Nitride has high temperature strength, creep resistance, 
oxidation resistance, and it is not wetted by any molten metal. On top of those, compared to many other ceramic materials, $\mathrm{Si}_{3} \mathrm{~N}_{4}$ has good mechanical strength.

\section{$\underline{\text { Oxygen Sensor Calibration Results }}$}

Calibration curves were obtained from two oxygen sensors. After some initial transients, voltage-temperature curves first follow constant oxygen concentration lines according to the Nernst equation, and then turn to the concentration saturation line.

The slopes of experimental and theoretical curves are almost identical, ranging from 0.33 to 0.5 . This indicates that the YSZ sensors are of high sensing quality. Overlapping of the calibration curves for the two sensors indicates consistency in the sensors of the same design.

Experimental results show that tantalum oxidizes at high temperature around $480^{\circ} \mathrm{C}$ after running for a certain amount of time. This directly causes tantalum wires to lose electrical conductivity, and consequently, the sensor fails to provide meaningful signal output. This effect was demonstrated. In the first trial experiment cycle, molybdenum, stainless steel (SS) and tungsten were tested for this purpose. When introducing hydrogen and helium mixture into the system to clean excessive oxygen in the LBE container, it was found that Mo responds a little faster than SS.

It had been suspected that different combinations of $\mathrm{Bi}$ or $\mathrm{Bi}_{2} \mathrm{O}_{3}$ may have affected the sensor response. During Phase III of this project, several experiments were performed and it was determined that there are no evident effects on the sensor response. Experiment results further confirmed that even a small amount of residual oxygen inside sensor tubes will be sufficient for $\mathrm{Bi}$ to be

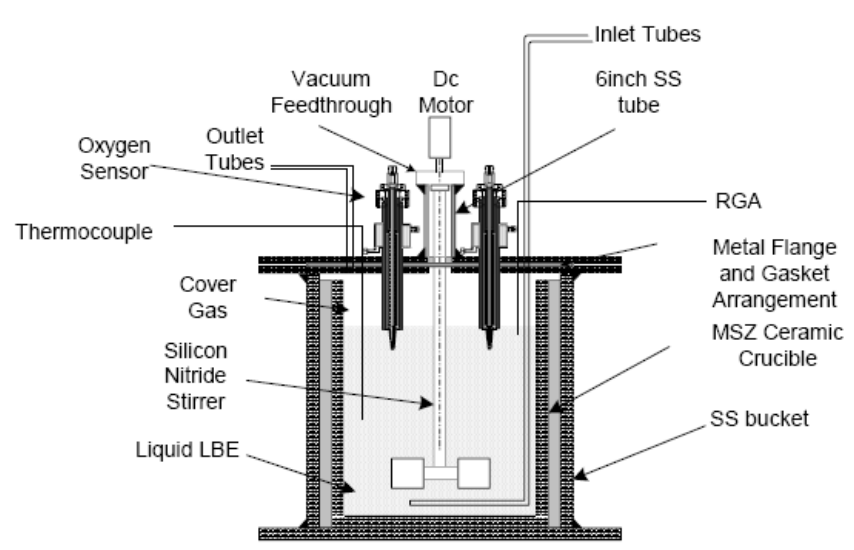

Schematic of the second sensor calibration experimental setup. oxidized.

Commercial FEM (finite element method) software, FEMLAB was used to simulate the oxygen dissolving process and the distribution in liquid LBE for the new system under three different boundary conditions. Simulation results show that the oxygen concentration distributes evenly in the whole flow field due to the strong convection flow in LBE. These simulation results with the experimental measurements help to not only determine the oxygen dissolving rate and the diffusion coefficient under different temperatures, but also provide suggestions for better experimental design.

\section{TASK 13 PROFILE}

Start Date: May 2002

Completion Date: May 2005

Theses Generated:

Ramkumar Sivaraman, M.S., Department of Electrical and Computer Engineering, "Calibration of YSZ Sensor for the Measurement of Oxygen Concentration in Liquid LBE,” December 2003.

Xiaolong Wu, M.S., Department of Electrical and Computer Engineering, "Instrumentation of YSZ Oxygen Sensor Calibration in Lead-Bismuth Eutectic,” December 2004.

Journal Article:

J. Ma, P. Guo, J. Zhang, N. Li, B. Fu, "Enhancement of Oxygen Transfer in Liquid Lead and Lead-Bismuth Eutectic by Natural Convection" International Journal of Heat and Mass Transfer, Vol. 48 (13), p. 2601-2612, January 2005.

Conference Proceedings:

X. Wu, J. Ma, Y. Jiang, B. M. Fu, W. Hang, J. S Zhang, and N. Li, "Instrumentation of YSZ Oxygen Sensor Calibration in Liquid Lead-Bismuth Eutectic," Proc. of 2005 IEEE International Symposium on Circuits and Systems, May, 2005.

X. Wu, R. Sivaraman, N. Li, W. Hang, T. W. Darling, Y. Jiang, W. Yim, B. M. Fu, "Design of an Oxygen Sensor Calibration/ Measurement Apparatus for the Liquid Lead-Bismuth Eutectic System," Proc. of 2003 Annual Meeting, San Diego, CA, June 1-5, 2003.

X. Wu, R. Sivaraman, N. Li, W. Hang, T. W. Darling, Y. Jiang, W. Yim, B. M. Fu, "Calibration of YSZ Sensors for the Measurement of Oxygen Concentration in Liquid Pb-Bi Eutectic," Proc. of 10th International High-Level Waste Management Conference, Las Vegas, March 30-April 3, 2003.

Research Staff

Yingtao Jiang, Principal Investigator, Assistant Professor, Department of Electrical and Computer Engineering

Bingmei Fu, Assistant Professor, and Woosoon Yim, Professor, Department of Mechanical Engineering

Jian Ma and Peng Guo, Post Doctoral Research Associates, Department of Mechanical Engineering

\section{Students}

Xiaolong Wu, Ramkumar Bhavani Sivaraman and Yi Lu, Graduate Students, Department of Electrical and Computer Engineering

Shahidur Rahman and Bin Chen, Graduate Students, Department of Mechanical Engineering

Ning Li, LBE Project Leader, and Wei Hang, Research Scientist, Los Alamos National Laboratory 


\title{
Use of Positron Annihilation Spectroscopy for Stress-Strain Measurements
}

\author{
A. K. Roy
}

\section{BACKGROUND}

Engineering metals and alloys, when subjected to tensile loading beyond a limiting value, undergo plastic deformation resulting in lattice defects such as voids and dislocations. These imperfections interact with the crystal lattice, producing a higher state of internal stress, also known as residual stress, which can be associated with reduced ductility. Residual stresses are also generated in welded structures due to rapid solidification and resultant dissimilar metallurgical microstructures between the weld and the base metals. Development of these internal stresses is often influenced by incompatible permanent strain resulting from thermal and mechanical operations associated with welding and plastic deformation. These types of operations can cause premature failures in structural materials unless these stresses are relieved by thermal treatments, which are commonly known as stress-relief operations.

During the past academic year, this project was focused on the characterization of residual stress in welded specimens consisting of austenitic and martensitic stainless steels using an activation technique based on the Positron Annihilation Spectroscopic (PAS) method. The extent of residual stress was expressed in terms of three line-shape parameters (S-, W- and T-). Further, efforts were made to characterize linear lattice defects such as dislocations in the vicinity of Fusion-Line (FL), Heat-AffectedZone (HAZ), and the base material of the welded specimens using Transmission Electron Microscopy (TEM). The metallurgical microstructures at these three regions have also been evaluated by optical microscopy.

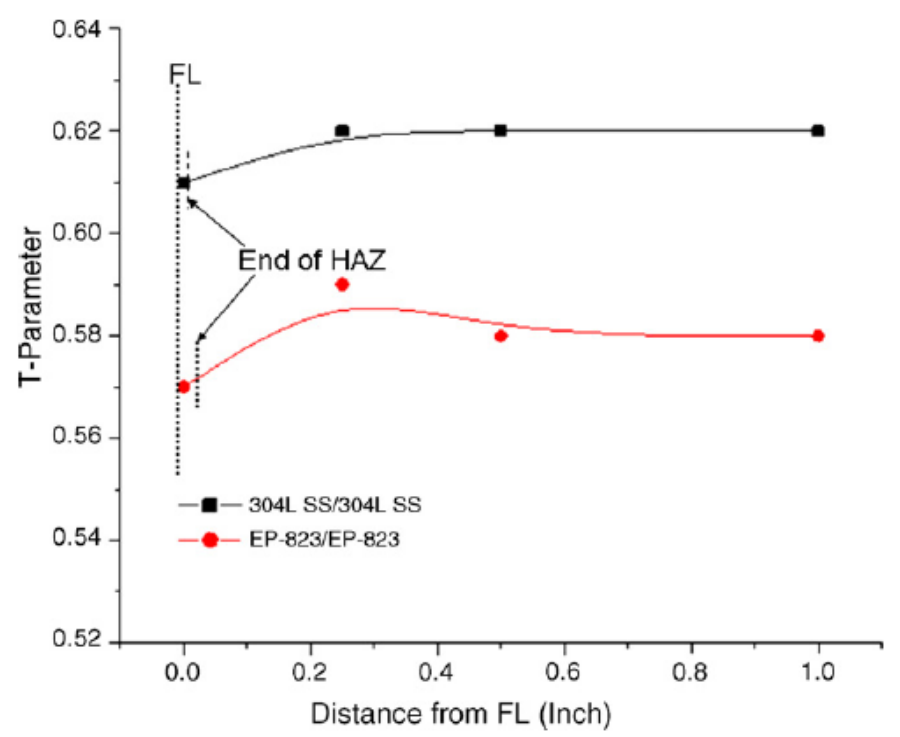

T-Parameter versus Distance from FL for Welded Specimens of Similar Materials

\section{RESEARCH OBJECTIVES AND METHODS}

The primary objective of this task was to evaluate the feasibility of the characterization of residual stresses in plastically-deformed and welded structural materials using a new nondestructive technique based on PAS. The residual stresses measured by a modified PAS method have been compared to those measured by three other techniques, namely the Ring-Core (destructive), X-Ray Diffraction (non-destructive), and Neutron Diffraction (nondestructive).

All four techniques have been used to evaluate residual stresses in cold-worked, plastically deformed and welded specimens of austenitic Type 304L Stainless Steel (SS), and martensitic Alloys EP-823 and HT-9. Alloy EP-823 is a leading target structural material to contain the molten lead-bismuth eutectic nuclear coolant needed for fast spectrum operations of an Accelerator-Driven Transmutation System. Type 304L SS is a universally-known corrosion resistant low-carbon iron-nickel-chrome alloy having optimum formability and weldability. Alloy HT-9 is known for its superior high temperature tensile properties. The metallurgical microstructures and the nature of defects have been analyzed by optical microscopy, scanning electron microscopy, and TEM.

\section{RESEARCH ACCOMPLISHMENTS}

The significant results obtained from this investigation during the past academic year are summarized below.

- For welded specimens consisting of similar materials on both sides, the residual stress in terms of the S-, W-, and Tparameters was maximum at the FL. A gradual drop in residual stress was observed with these specimens at locations away from the FL.

- The extent of residual stress was higher in martensitic Alloy EP-823 compared to that of austenitic Type 304L SS, irrespective of the weld configuration.

- Compressive residual stresses were observed in Alloy EP823 , when welded to Type 304L SS.

- The magnitude of dislocation density $(\rho)$ was substantially higher at the HAZ compared to that of the base material of the welded specimens consisting of similar materials (Type 304L SS or Alloy EP-823) on both sides.

- In the case of the welded specimen of dissimilar materials (Type 304L SS and Alloy EP-823) on the opposite side, the concentration of dislocation in terms of $\rho$ was greater at the HAZ on the Alloy EP-823 side of the weld.

- The enhanced value of $\rho$ at the HAZ on the Alloy EP-823 side of the weld may be attributed to the faster rate of solidification of this alloy compared to that of the austenitic SS.

- The sizes of the HAZ on the Alloy EP-823 sides of the welded specimens were relatively larger, irrespective of the weld configuration. 


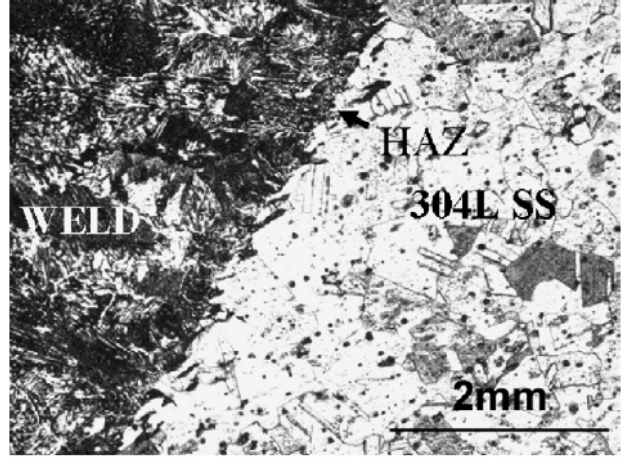

(a)

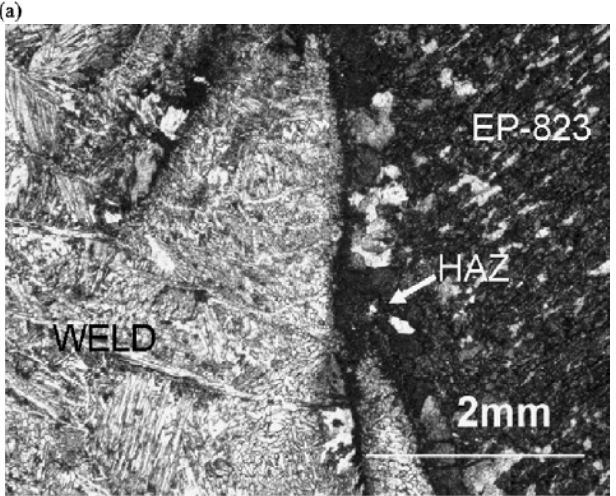

(b)

Optical micrographs of welded specimens of similar materials. (a) Type 304L SS/Type 304L SS, $\mathrm{HNO}_{3}+\mathrm{CH}_{3} \mathrm{COOH}+\mathrm{C}_{3} \mathrm{H}_{5}(\mathrm{OH})_{3}$; (b) Alloy EP-823/Alloy EP-823, Fry's reagent.

\section{TASK 14 PROFILE}

Start Date: May 2002

Completion Date: December 2006

\section{Theses Generated}

Srinivas Chanda, M.S., Mechanical Engineering, "Characterization of Residual Stress and Defects in Welded Specimens," December 2006.

Silpa B. Suresh, M.S., Mechanical Engineering, "Use of Neutron Diffraction and Microscopy for Characterization of Residual Stresses and Defects," December 2005.

Subhra Bandyopadhyay, M.S., Mechanical Engineering, "Residual Stress Characterization and Defects Analyses by Microscopy," December 2005.

Anand Venkatesh, M.S., Mechanical Engineering, "Comparative Analyses of Residual Stresses in Target Sub-System Materials," August 2004.

Vikram Marthandam, M.S., Mechanical Engineering, "Metallurgical Characterization and Residual Stress Measurements of Target Structural Materials," August 2004.
Satish B. Dronavalli, M.S., Mechanical Engineering, "Residual Stress Measurements and Analyses by Destructive and Nondestructive Techniques," August 2004.

Journal Articles

A.K. Roy, S. Chanda, A. Ghosh, P. Kumar, and L. Ma , "Defects Characterization of Welded Specimens by Transmission Electron Microscopy," Materials Science and Engineering A, Elsevier Science, Vol. 464/1-2, pp. 274-280, 2007.

A.K. Roy, S. Chanda, D.P. Wells, A. Ghosh, and C.K. Mukhopadhyay, "Residual Stress Characterization of Welded Specimens by Nondestructive Activation Technique," Materials Science and Engineering A, Elsevier Science, Vol. 464/1-2, pp. 281-287, 2007.

D.P. Wells, et al., "Gamma-induced Positron Annihilation Spectroscopy and Application to Radiation-damaged Alloys," $\mathrm{Nu}$ clear Instruments and Methods in Physics Research A, Elsevier Science, Vol. 562, pp. 688-691, 2006.

A.K. Roy, et al., "Comparison of Residual Stress in Martensitic Alloys by Nondestructive Techniques," Materials Science and Engineering A, Elsevier Science, Vol. 419, pp. 372-380, 2006.

A.K. Roy, et al., "Relationship of Residual Stress to Dislocation Density in Cold-Worked Martensitic Alloy," Materials Science and Engineering A, Elsevier Science, Vol. 416 , pp. 134-138, 2006.

A.K. Roy, et al., "Residual Stress Measurements in Welded and Plastically Deformed Target Structural Materials," Journal of ASTM International, Vol. 2, No. 6, pp. 1-13, June 2005.

A.K. Roy, et al., "Residual Stress Characterization in Structural Materials by Destructive and Nondestructive Techniques," Journal of Materials Engineering and Performance, ASM International, Vol. 14, No. 2, pp. 203-211, April 2005.

F.A. Selim, et al., "Stress Analysis using Bremsstrahlung Radiation," Advances in X-ray Analysis, Joint Committee on Powder Diffraction Standards, Vol. 46, pp. 106-111, 2003.

Conference Proceedings

Ten conference papers were also published. See TRP website at http://aaa.nevada.edu for more information.

Dislocation density $(\rho)$ in welded specimens of different configurations

\begin{tabular}{lll}
\hline Weld configuration & $\rho\left(\right.$ no. $\left./ \mathrm{m}^{2}\right)$ \\
\cline { 2 - 3 } & Base material & HAZ \\
\hline 304L SS/304L SS & $5.1 \times 10^{13}$ & $2.4 \times 10^{14}$ \\
EP-823/EP-823 & $7.6 \times 10^{13}$ & $1.3 \times 10^{14}$ \\
304L SS side of 304L SS/EP-823 & $1.7 \times 10^{13}$ & $3.2 \times 10^{13}$ \\
EP-823 side of 304L SS/EP-823 & $6.5 \times 10^{13}$ & $2.2 \times 10^{14}$ \\
\hline
\end{tabular}

Research Staff

Ajit K. Roy, Ph.D., Principal Investigator, Professor, Mechanical Engineering Department

Students

Srinivas Chanda, Subhra Bandyopadhyay, Silpa Suresh, Satish Dronavalli, Vikram Marthandam, Anand Venkatesh, Bhagath Yarlagadda, and Raghunandan Karamcheti Graduate Students, Mechanical Engineering Department

\section{Collaborators}

Stuart A. Maloy, Ph.D., AFCI Materials Team Leader, Los Alamos National Laboratory

J. Frank Harmon, Ph.D., Director, Idaho Accelerator Center, Idaho State University

Doug Wells, Ph.D., Associate Professor, Department of Physics, Idaho State University

Farida Selim, Ph.D., Post Doctoral Researcher, Idaho Accelerator Center, Idaho State University 


\title{
Task 15
}

\section{Immobilization of Fission Iodine by Reaction with a Fullerene Containing Carbon Compound and Insoluble Natural Matrix}

\author{
S.M. Steinberg, G.S. Cerefice, and D.W. Emerson
}

\section{BACKGROUND}

The recovery of iodine released during the processing of used nuclear fuel poses a significant challenge to the transmutation of nuclear waste. Iodine-129, a long-lived fission product formed by both commercial nuclear power generation and nuclear weapons production, is released when reprocessing nuclear fuel. Since iodine can be concentrated in the human thyroid, any uncontrolled release of iodine may result in an increased rate of thyroid cancer in the exposed population. For this reason, recovery of iodine is important for implementing any nuclear transmutation strategy.

The first step in any transmutation strategy is the processing of the used nuclear fuel. This step involves separating the used fuel into its constituent elemental components, allowing the recovery of the uranium, transuranic actinides, long-lived fission products, and other components, depending on the strategy and processes involved.

When used fuel rods are dissolved in concentrated nitric acid in preparation for actinide recovery, iodine is released from the fuel. A significant fraction of the iodine is lost to the vapor phase during this process, where it may potentially become a fugitive emission and be released from the plant. To avoid this, specialized filtration systems are used to try to trap and sequester the released iodine (and other fission product gases).

The primary goal of this research is to capture and immobilize the iodine released from these processes in a form that can easily be converted to a suitable target for neutron-induced transmutation. The investigators believe that iodine released during fuel reprocessing can be immobilized in a Fullerene Containing Carbon (FCC) compound or a Natural Organic Matter (NOM) matrix.

Natural organic matter (such as spaghnum moss, peat or brown coal) is an inexpensive and a renewable resource. Further processing of the trapped iodine using simple desorption or combustion processes should be able to produce iodine in a form suitable for transmutation. Furthermore, collaborators at the Khlopin Radium Institute (KRI) have proposed that the iodine-loaded FCC material, when combined with ceramics, is stable enough for use as a long-term storage form, and may be usable as a transmuter target matrix.

\section{RESEARCH OBJECTIVES AND METHODS}

The stability of the association of iodine with FCC and NOM products were studied. Product distributions for the various matrices under various reaction conditions were examined in order to maximize the binding of iodine. The recovery of the iodine from the sequestration matrices was also examined, along with the conversion of the iodine to matrices more suitable for geological storage and/or use as transmutation targets. lodide Sequestration at $\mathrm{pH} 4$

Continous Flow method

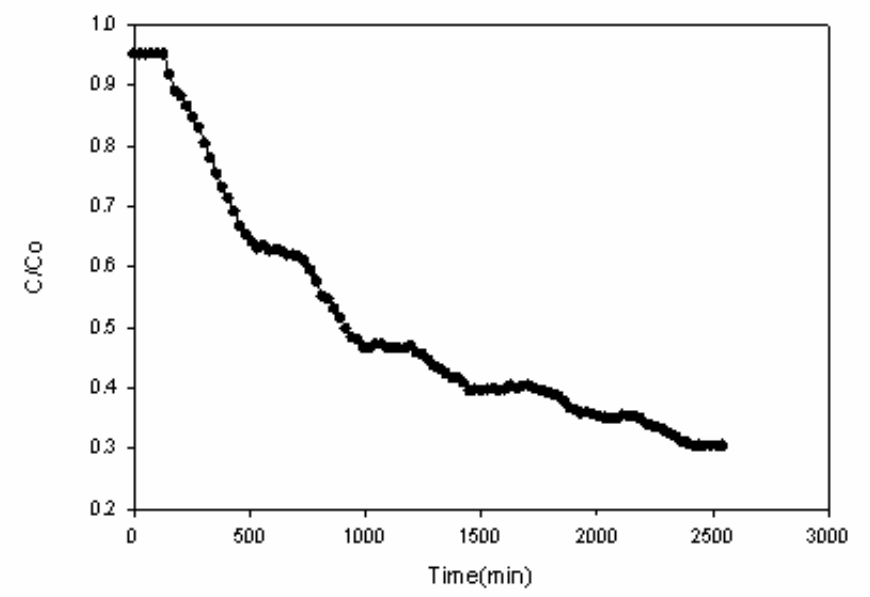

Sequestration of iodide $\left(10^{-4} \mathrm{M}\right)$ in the presence of sphagnum peat and $\mathrm{MnO}_{2}$. The solution was circulated through a column at $5 \mathrm{~mL} / \mathrm{min}$.

The following are the specific research objectives and goals:

- Develop bench-scale experimental set-up and procedures for simulating plutonium extraction process (PUREX) head-end vapor phase.

- Develop experimental procedures for evaluating iodine sequestering methods using bench-scale procedures.

- Develop FCC bearing material as potential iodine sequestration matrix.

- Determine binding of iodine to FCC and NOM.

- Examine alternate iodine sequestration matrices using techniques developed for FCC and NOM studies.

- Examine the effect of reaction conditions on binding.

- Elucidate the nature of the reaction products (volatile, hydrophobic, soluble, insoluble).

- Develop methodology and host matrix for converting sequestered iodine to solid matrix for evaluation as transmutation target and/or disposal matrix.

- Examine recovery of iodine from sequestration matrices.

The FCC compounds were developed and prepared by the KRI Research Industrial Enterprise (KIRSI). The KRI-KIRSI team researched the impacts of process parameters on sorption of iodine, and examined the material properties, such as how iodine attaches to the FCC compounds. The KRI-KIRSI team also examined the conversion of the iodine loaded FCC compound to a stabilized matrix (similar to ceramic) for potential use as a disposal form, acceptable transportation material, or potential target material. 


\section{RESEARCH ACCOMPLISHMENTS}

Observations related to the oxidation of iodide to iodine $\left(\mathrm{I}_{2}\right)$ or hypoiodic acid (HIO) by $\mathrm{MnO}_{2}$ were continued. During this study, a number of synthetic (nano-particle) manganese (III, IV) oxide preparations have been shown to be capable of oxidizing iodide to iodine (or $\mathrm{IOH}$ ) at $\mathrm{pH}$ as high as 5 . Various synthetic preparations of $\mathrm{MnO}_{2}$ were examined. These various nanoparticle manganese oxides have been characterized by transmission electron microscopy, scanning electron microscopy, and atomic force microscopy. In addition, surface areas, average manganese oxidation states and the kinetics of iodide oxidation by these materials have been measured. The rate of iodide oxidation by various manganese oxide preparations varies significantly. The oxidation rate appears to have some relationship to the average oxidation state of the manganese.

The incorporation of iodine into NOM was demonstrated in batch mixtures of $\mathrm{MnO}_{2}$ and alkali lignin or sphagnum peat. The sequestration of iodine by NOM is illustrated to the left.

In another facet of this project, iodine distributions in salt impacted soils from the Virgin River, Nevada were examined. This study indicates that organic iodine was the most abundant form of iodine in the soil samples and that the content of organic iodine was correlated to total organic matter and to the lignin content (as measured by chemolysis) of the samples. These observations are consistent with the notion of the formation of organic iodine resulting from the cycling of iodine between iodide and iodate, with organic iodine resulting from the iodine or hypoiodic acid $\left(\mathrm{I}_{2}\right.$ and HIO) intermediate reacting with phenolic moeties in sedimentary and soil organic mater.

\section{ACADEMIC YEAR HIGHLIGHTS}

- S.M. Steinberg and G. Kimble, "Immobilization of Fission Iodine By Reaction with Insoluble Natural Organic Matter," Journal of Radioanalytical and Nuclear Chemistry, (in press).

- S.M. Steinberg, G.M. Kimble, G.T. Schmett, and D.W. Emerson, "Abiotic Reaction of Iodate with Spahgnum Peat and Other Natural Organic Matter," Journal of Radioanalytical and Nuclear Chemistry, (in press).

- M.A. Cheney, N.R. Birkner, L. Ma, T. Hartmann, P.K. Bhowmik, V.F. Hodge, and S.M. Steinberg, "Synthesis and characterization of inorganic double helices of cryptomelane nanomaterials," Colloids and Surfaces A: Physicochemical Engineering Aspects 289, pp 185-192, 2006.

- S.M. Steinberg, B. Buck, J. Morton, and J. Dorman, "Speciation of iodine in the salt-impacted Black Butte soil series along the Virgin River, NV," accepted, 234 ${ }^{\text {th }}$ American Chemical Society National Meeting, Boston, MA, August 19-23, 2007.

- S.M. Steinberg and N.R. Birkner, "Formation of organic iodine in soil and sediment by reaction of manganese oxide with iodide," accepted, $234^{\text {th }}$ American Chemical Society National Meeting, Boston, MA, August 19-23, 2007.

\section{FUTURE WORK}

The oxidation of iodide with $\mathrm{MnO}_{2}$ will continue to be investigated using remaining funds under a no cost extension. $\mathrm{MnO}_{2}$ preparations will continue to be characterized. Presently, surface acidity of the various materials is being examined.

\begin{tabular}{lrrrrrrr}
\hline Combined Data & $\begin{array}{r}\text { Depth } \\
\text { 1.000 }\end{array}$ & Org Iodide & Lignin & $\% \mathrm{C}$ & $\%$ Clay & $\mathrm{I}$ & $\mathrm{IO}_{3}$ \\
Avg depth & 0.458 & 1.000 & & & & & \\
Org Iodide & 0.519 & 0.623 & 1.000 & & & & \\
Lignin $/$ mg & 0.407 & 0.394 & 0.608 & 1.000 & & & \\
$\%$ C & 0.186 & 0.388 & 0.130 & 0.535 & 1.000 & & \\
$\%$ Clay & 0.339 & 0.303 & 0.030 & 0.023 & 0.084 & 1.000 & \\
$\mathrm{I}$ & 0.260 & 0.223 & -0.065 & 0.175 & 0.334 & 0.684 & 1.000 \\
$\mathrm{IO}_{3}{ }^{-}$ & & & & & & &
\end{tabular}

Correlation analysis for Black Butte soils

Research Staff

Spencer M. Steinberg, Principal Investigator, Professor, Chemistry Department

Gary S. Cerefice, Research Scientist, Harry Reid Center for Environmental Studies

David W. Emerson, Emeritus Professor, Chemistry Department

Students

Ginger Kimble, Nancy Birkner and James Dorman, Graduate Students, Chemistry Department

\section{Collaborators}

James J. Laidler, Senior Scientist, Chemical Technology Division, Argonne National Laboratory

George F. Vandergrift, III, Senior Scientist, Chemical Technology Division, Argonne National Laboratory

Michael Savopulo, V. G. Khlopin Radium Institute-Research-Industrial Enterprise, St. Petersburg, Russia

Boris E. Burakov, Head of Mineralogical Group, V.G. Khlopin Radium Institute-Research-Industrial Enterprise, St. Petersburg, Russia 


\section{D.W. Lindle, O. Hemmers and D.L. Perry}

\section{BACKGROUND}

High Temperature Gas-Cooled Reactor (HTGR) systems are currently being designed and evaluated as part of the Advanced Fuel Cycle Initiative, both as a future nuclear reactor type (in the Generation IV reactor program) and as a potential system for burning plutonium in a dual-tier transmutation strategy. HTGR designs use a TRISO-coated fuel (a silicon-carbide and pyrocarbon composite coating) to provide much of the passive containment for radionuclides.

Although this fuel form is quite stable and comprises one of the key components in the safety performance of these reactor systems, TRISO-coated fuel is comparatively difficult to recycle. If HTGR systems are to be used as part of either the first tier of a transmutation strategy or as primary power reactors, the plutonium and other actinides in the used TRISO fuel must be processed to recycle plutonium and permit recovery of minor actinides and other fission products produced.

Argonne National Laboratory has proposed a new extraction procedure to handle TRISO-coated fuels, the Fluoride Extraction Process, or FLEX. The FLEX process is designed to separate the uranium in the fuel from the actinides and most fission products by taking advantage of the unique properties of uranium hexafluoride $\left(\mathrm{UF}_{6}\right)$. In the FLEX process, the used TRISO fuel is reacted with zirconium fluoride salt, forming $\mathrm{UF}_{6}$ and the fluoride salts of the actinides and fission products. At process temperatures, the $\mathrm{UF}_{6}$ volatizes into a gas, and is released from the molten salt mixture. This leaves behind the actinides and most fission products in a fluoride salt, which is subsequently processed using pyrochemical techniques to recover the actinides and other longlived fission products for transmutation. The $\mathrm{UF}_{6}$ is then cooled, causing it to sublime into solid form, which is then further processed for disposal or reuse.

The primary waste stream from the FLEX process is the fission products from the fuel, which are in a zirconium fluoride salt at the end of the process. Due to the fluorine in this waste stream, the fluoride salts are unsuitable for conversion into the traditional

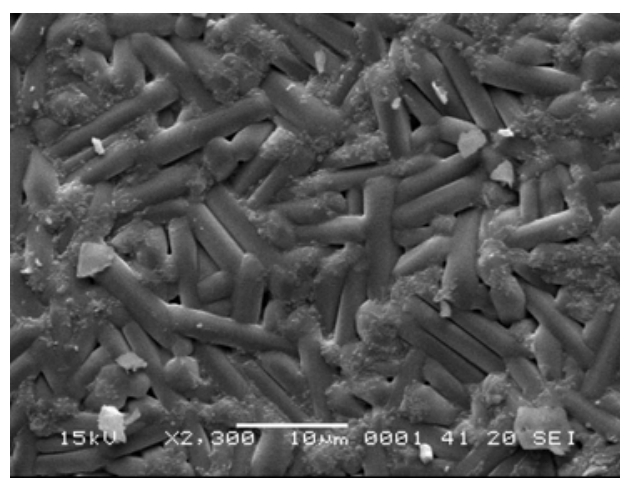

SEM micrograph of $\mathrm{Ca}_{4} \mathrm{SrFap}$ (annealed sample). borosilicate waste glass. Therefore, without a suitable disposal form, this process can not be deployed.

This research attempts to develop a waste form for disposing of the zirconium fluoride fission product waste stream. Fluorapatite, a naturally-occurring fluorinated calcium phosphate, has been identified as a potential matrix for the entombment of this waste stream. If the efficacy of fluorapatite-based waste-storage can be demonstrated, then new and potentially more efficient options for handling and separating high-level wastes, based on fluoride-salt extraction, will become feasible.

\section{RESEARCH OBJECTIVES AND METHODS}

The following are the specific research objectives:

- To develop a waste matrix for the disposal of the fission product waste stream from the FLEX process;

- To develop a process to make synthetic fluorapatite that incorporates the FP-bearing $\mathrm{ZrF}_{4}$ salt;

- To develop a fundamental understanding of the chemistry of this new waste form in order to better predict its long term behavior in a repository environment;

- To develop a fundamental understanding of natural, fluoride-bearing mineral phases to use as natural analogs to bound the predicted behavior of the FLEX fission product waste stream.

Originally, the research effort had been divided along two parallel paths: the Fabrication Path, led by collaborators at the Khlopin Radium Institute (KRI) in St. Petersburg, Russia; and the Characterization Path, led by researchers from UNLV.

The Fabrication Path is focused on examining and evaluating various techniques for fabricating synthetic fluorapatite; synthesizing synthetic fluorapatite; and examining the impacts of waste loading and other fabrication process factors on the performance of the synthetic fluorapatite as a potential waste form.

The Characterization Path is focused on adapting and refining the $\mathrm{X}$-ray spectroscopy techniques currently used to characterize borosilicate glass for use in examining the fluorapatite system. This path also encompassed the examination of the ceramic and synthetic mineral waste forms created at KRI, with subsequent examination of these techniques to develop a molecular-level understanding of natural fluorapatite and other fluorine-bearing natural phases as natural analogs for the waste form. These techniques will also be used to examine the changes in surface chemistry caused by environmental degradation of these materials.

Waste form development at KRI involves the formulation, synthesis, and examination of ceramic samples to investigate the impact of processing parameters and composition on material properties (e.g. homogeneity) and performance (via leach testing). The 


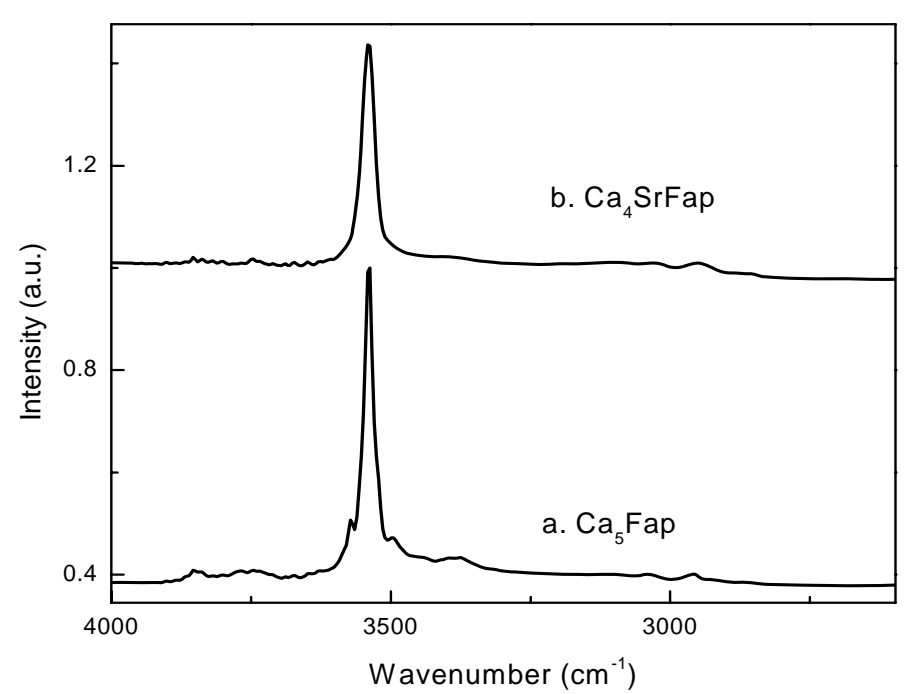

IR spectra of $\mathrm{Ca}_{5}$ Fap and $\mathrm{Ca}_{4}$ SrFap after annealing.

most promising fabrication process developed will be used to synthesize the ceramic in varying compositions to examine the impact of process parameters, ceramic formulation, and waste loading on the final ceramic phase. Based on these experiments, a baseline composition and fabrication process will be established. Finally, alternate fabrication processes, compositions, and potential alternate waste matrices will be examined and compared against the baseline composition.

Waste form characterization carried out at UNLV employs state of the art techniques that characterize the molecular structure of both natural fluorapatite and fluoride-bearing minerals and the fluorapatite-based ceramic waste form. Changes in the surface/ interfacial chemistry of these materials as they undergo reactions with species in the environment will also be examined to help develop a basis for understanding the corrosion chemistry that the waste form and its natural analogs may experience under repository conditions. The UNLV researchers also synthesized several surrogate samples with help of the KRI collaborators in order to study their properties.

\section{RESEARCH ACCOMPLISHMENTS}

Research highlights for the third year of the project can be summarized as follows:

- Applying x-ray spectroscopy and more-conventional characterization techniques (e.g., Fourier Transform Infrared Spec-

\section{ACADEMIC YEAR HIGHLIGHTS}

- G. Silva presented a paper "Characterization of the Thermal Stability of Zinc Containing Fluorapatite" at the American Nuclear Society Student Conference, Columbus, OH, April 14-16, 2005.

- C. Rodrigo presented a paper "Characterization of Fluorapatite as a Waste Form Material" at the American Nuclear Society Student Conference, Columbus, OH, April 14-16, 2005.

troscopy, SEM, XRD, Raman Spectroscopy) to synthesized samples of apatite and fluorapatite doped with surrogates and compared those with baseline measurements of "pure" materials.

- Chemically prepared several samples in which some of the calcium in apatite materials is substituted by non radioactive actinide surrogates $(\mathrm{Zn}, \mathrm{Sr}, \mathrm{Yt}, \mathrm{Cs}, \mathrm{Cu}, \mathrm{Ni}, \mathrm{Zr}$ ) or elements produced by decay of actinides.

- Chemically prepared apatite samples containing different Ca:Surrogate weight ratios and studying the physical properties of these apatites with different calcium to phosphorous molar ratios.

- Studied metal-containing apatites and fluorapatites with the same cadre of characterization techniques noted above to assess the degree of incorporation and any changes in the physical and chemical structure of the materials.

\section{FUTURE WORK}

The work is completing its third and final year of the project with the two graduate students finishing their Masters degree. The Characterization Path, led by the UNLV team, has been performing baseline spectroscopic studies of natural and pristine (no artificially added impurities) apatite materials as well as of surrogate loaded samples. The studies found that it is possible to load surrogates successfully into apatites and that it is important to control the by-products such as metal phosphates and metal fluorites that weaken and/or destroying the crystal structure. The amounts of surrogates that can be loaded strongly depend on the type of surrogate and these amounts still need to be determined. The ultimate goal is to use these techniques to achieve a molecular-level understanding of fluorapatite and other fluorine-bearing phases as natural analogs for waste-form materials. These techniques will also be used to examine changes in surface chemistry caused by environmental degradation.

Research Staff

Dennis W. Lindle, Principal Investigator, Professor, Chemistry Department

Oliver Hemmers, Assistant Research Professor, Chemistry Department

Dale L. Perry, Lawrence Berkeley National Laboratory, Adjunct Professor, UNLV Department of Physics

Students

Chirantha Rodrigo and Chinthaka Silva, Graduate Students, Chemistry Department

\section{Collaborators}

James J. Laidler, Senior Scientist, Chemical Technology Division, Argonne National Laboratory

Alexander A. Rimsky-Korsakov, Director General, V.G. Khlopin Radium Institute, St. Petersburg, Russia

Evgeniy B. Anderson and Boris E. Burakov, V.G. Khlopin Radium Institute, St. Petersburg, Russia 


\section{Task 17 \\ Interaction between Metal Fission Products \\ and TRISO Coating Materials}

C. Heske

\section{BACKGROUND}

This project focuses on the chemical bonding and interface formation of metal fission products with the coating materials used in TRISO fuel particles. By combining surface- and bulksensitive spectroscopic methods, intermediate chemical phases at the interface, intermixing/diffusion behavior, and the electronic interface structure as a function of material (metal and coating materials) and temperature are examined.

In detail, the project studies the interface formation of Pd, Cs, and Ag with $\mathrm{SiC}$ and pyrolytic carbon. Using $\mathrm{SiC}$ single crystals as substrates, interfaces are prepared under controlled conditions in an ultra-high vacuum environment and are studied with a combination of experimental methods, including Photoelectron Spectroscopy, Auger Electron Spectroscopy, Inverse Photoemission, $\mathrm{X}$-Ray Emission Spectroscopy, and X-Ray Absorption Spectroscopy. Furthermore, microscopic techniques (Transmission Electron Microscopy, Scanning Tunneling Microscopy, Atomic Force Microscopy) and local scanning tunneling spectroscopy are being employed.

\section{RESEARCH OBJECTIVES AND METHODS}

By combining results for the electronic and chemical structure of the fission product/TRISO layer interfaces, the research results

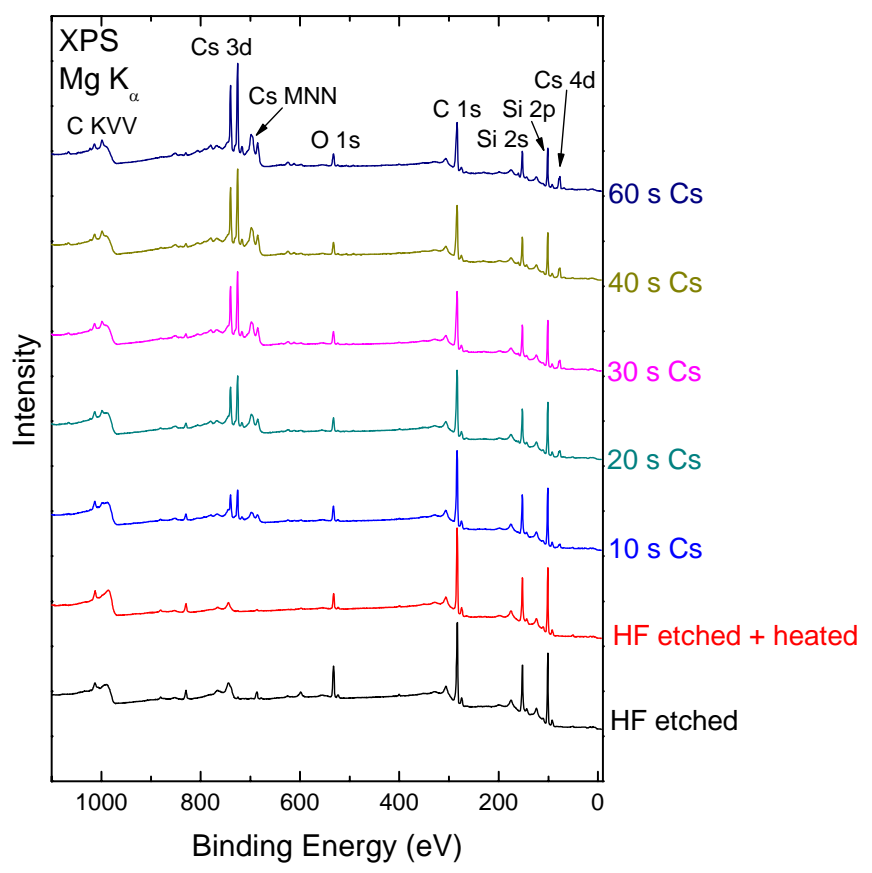

XPS survey spectra of an HF-etched SiC single crystal surface, after heat treatment at approximately $400^{\circ} \mathrm{C}$, and after various deposition steps of Cs (given is the deposition time in seconds). give information about failure mechanisms of TRISO particles and fission product transport.

Furthermore, they can be used to derive strategies to tailor the interface properties for an optimization of TRISO particles in terms of, e.g., chemical and long-term stability.

The experiments use two different experimental set-ups. First, a multi-chamber ultra-high vacuum system at UNLV (see photo in the AY 2005 Annual Report) houses the majority of surfacesensitive methods. Second, the SXF endstation at Beamline 8.0 at the Advanced Light Source, Lawrence Berkeley National Lab is used to perform X-ray absorption and emission spectroscopy. The apparatus at UNLV consists of a surface spectroscopy chamber, a preparation chamber, and a ultra-high vacuum scanning probe microscope. Samples can be introduced into the machine through a glove box with integrated load-lock and then transferred to each of the chambers via a distribution chamber. The analysis chamber is equipped with a state-of-the-art electron analyzer, an X-ray source, a UV-source, and an inverse photoemission setup consisting of a low-energy high-flux electron gun and a UV detector. The preparation chamber is used for cleaning samples with an ion source and for the deposition of metal films with an evaporator.

\section{RESEARCH ACCOMPLISHMENTS}

In the past year, emphasis was placed on a detailed analysis and description of the $\mathrm{Cs} / \mathrm{SiC}$ interface formation process.

Great care was taken to prepare a clean $\mathrm{SiC}$ surface. It was found that the purchased SiC single crystals exhibit strong surface contaminations with oxygen. Based on an in-depth literature research, two different cleaning routes were investigated. The first route is an $\mathrm{HF}$ etch of the SiC surface, which is reported to result in a clean, C-terminated SiC surface. The second route is a sputtercleaning of the surface with $\mathrm{Ar}+$ ions. It was found that it was not possible to entirely remove the $\mathrm{O}$ with either of the techniques, showing that the crystals were significantly oxidized into the bulk. As a consequence of this investigation, a new vendor was identified and new SiC crystals were ordered.

For the deposition of Cs films on the $\mathrm{SiC}$ substrate, a Cs evaporator was designed and constructed. Cs films of different thickness were deposited on SiC substrates (exhibiting some degree of surface oxidation, as discussed above). Exemplarily, the survey spectra of films with different Cs thicknesses are shown (left). These spectra illustrate the stepwise increase in Cs intensity after subsequent deposition steps, indicating an increase in the Cs film thickness. In parallel, the Si and C intensities decrease due to attenuation by the Cs film. A careful quantitative analysis shows that this attenuation is weaker than expected, suggesting either an inhomogeneous growth of the Cs film or an intermixing at the interface. 
To gain further insight into this question, and to learn more about the detailed chemical environment at the $\mathrm{Cs} / \mathrm{SiC}$ interface, detailed core level XPS spectra were recorded. As an example, a series of $C 1$ s core levels as a function of sample preparation and Cs deposition time (below right). As is evident in the figure, a second carbon species at higher binding energies emerges, which is directly indicative of the chemical interaction between Cs and SiC. Interestingly, no changes are observed in the Si core levels, suggesting that the chemical attack of $\mathrm{SiC}$ by $\mathrm{Cs}$ is initiated at the C sites.

The X-ray photoemission experiments were supplemented by UV photoemission data (not shown), which gives detailed information about the valence electrons. The students in the project have learned about the chemical and electronic information that can be exerted from such spectra, and a detailed analysis of the $\mathrm{Cs} / \mathrm{SiC}$ dataset is currently ongoing. In the previously investigated case of $\mathrm{Pd} / \mathrm{SiC}$, similar data could be used to draw the picture of the formation of a Schottky barrier at the $\mathrm{Pd} / \mathrm{SiC}$ interface.

Finally, selected $\mathrm{Cs} / \mathrm{SiC}$ interfaces were also investigated at the Advanced Light Source using X-ray emission spectroscopy of the Si L2,3 and the C K edge, giving additional insight into the intermixing behavior at the interface between Cs and SiC.

\section{FUTURE WORK}

The experiments on $\mathrm{Cs} / \mathrm{SiC}$ will be continued including the deposition on differently prepared substrates. In addition, the interaction between Cs and pyrolytic graphite surfaces will be studied. The focus will be on single crystalline surfaces and also on rough surfaces, which will be prepared by $\mathrm{Ar}+$ ion bombardment. This will allow an investigation of the influence of substrate roughness on the chemical Cs-SiC and Cs-C interactions.

Furthermore, the substrate temperature will be varied during deposition, up to approximately $1200 \mathrm{C}$. Both experiments will help to correlate the results to the real case of a TRISO particle with microscopically rough interfaces involving the SiC diffusion barrier and the pyrocarbon layers. In addition, the experiments will simulate the "natural" high temperature environment present in the nuclear reactor.

\section{ACADEMIC YEAR HIGHLIGHTS}

- Participation of all graduate and undergraduate students in experimental campaigns at the Advanced Light Source, Lawrence Berkeley National Laboratory, Berkeley, CA (October 2006 and March 2007).

- C. Heske, "How to reveal the chemical and electronic properties of interfaces, buried layers, and liquids with soft X-ray spectroscopy,” Physics Department, Boston University, December 8, 2006.

- C. Heske, "The surface and interface analysis 'tool chest' at UNLV,” Group seminar Prof. T. Moustakas, Boston University, November 17, 2006.

- C. Heske, "How to reveal the chemical and electronic properties of interfaces, buried layers, and liquids with soft X-ray spectroscopy,” Materials Science and Engineering Department, Stanford University, August 31, 2006.

- C. Heske, "Surface and Interface Analysis in Las Vegas," Seminar Experimentelle Physik II, University of Würzburg, Germany, July 20, 2006.

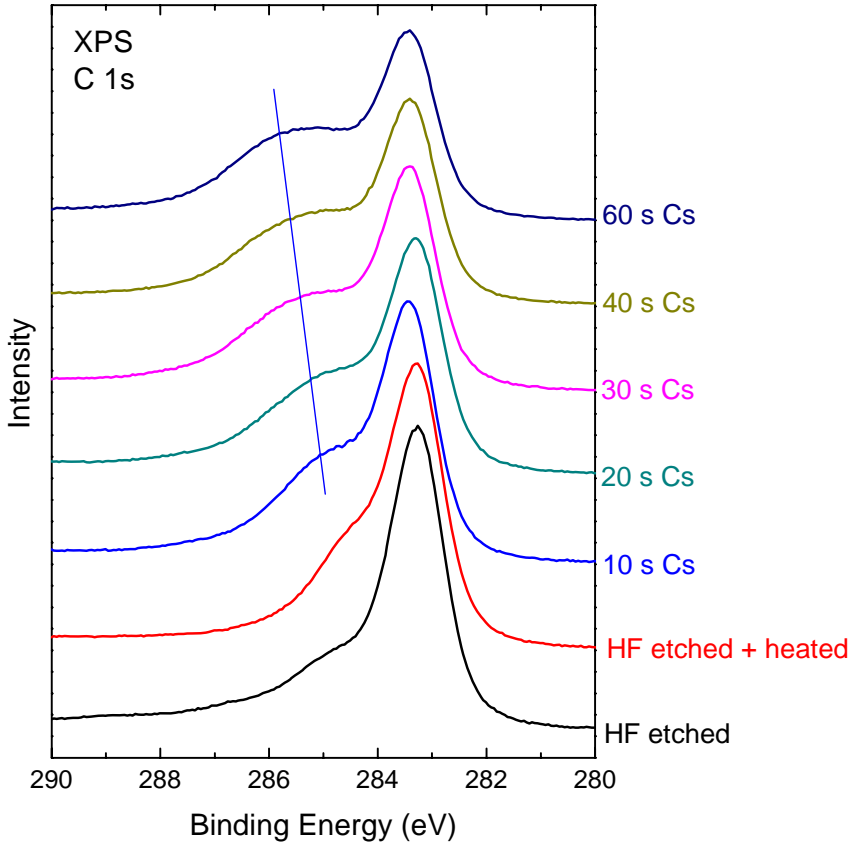

XPS detail spectra of the $C 1$ s core level, indicating the presence of a second, reacted $C$ species after deposition of the Cs films (indicated by the blue slanted line).

Research Staff

Clemens Heske, Principal Investigator, Associate Professor, Department of Chemistry

Lothar Winhardt, Post-Doctoral Fellow, Department of Chemistry

Students

Sharath Sudarshanam, Timo Hofmann, Roberto Felix, and Ich Tran, Graduate Students, Department of Chemistry

Alessio Luinetti, Sunil Subramanyam, and Kyle George, Undergraduate Students, Department of Chemistry 


\title{
Task 18
}

\section{Fundamental and Applied Experimental Investigations of Corrosion of Steel by LBE under Controlled Conditions: Kinetics, Chemistry Morphology, and Surface Preparation}

\author{
J.W. Farley, A. L. Johnson, and D.L. Perry
}

\section{BACKGROUND}

Advanced nuclear processes and facilities (e.g., transmutation of nuclear waste, fast reactors, and spallation neutron sources) impose special demands on materials, which must withstand high temperatures, high radiation fields, and chemical corrosion. Proposed schemes for transmuting nuclear waste require a nonmoderating coolant such as lead-bismuth eutectic (LBE). While LBE corrodes most steels, small amounts of oxygen in the LBE greatly reduces the corrosion rate, and could ideally re-grow a damaged oxide layer in-situ. The protective oxide layer would thus be self-healing. However, the fundamental understanding of the role of oxygen and passivating oxide layers is presently incomplete.

\section{RESEARCH OBJECTIVES AND METHODS}

Steel samples have been characterized before and after exposure to LBE using different types of surface microscopy, including Scanning Electron Microscopy (SEM), Energy Dispersive X-ray analysis (EDX), Wavelength Dispersed X-ray, X-ray Photoelectron Spectrometry (XPS), and Sputter Depth Profiling. In past work, steel samples exposed to LBE at the Institute for Physics and Power Engineering in Obninsk, Russia, were examined using SEM and EDX. Samples with the same chemical composition but different surface treatments were compared, and cold-rolled samples were more corrosion resistant than annealed samples. Increased corrosion resistance was associated with changes in oxide layer thickness, morphology, and composition. These past results were published in the Journal of Nuclear Materials.

During the present reporting period, gas-phase experiments were conducted, in which steel samples were oxidized in glass capsules at elevated temperatures in a tube furnace. Corroded steel samples were analyzed from a variety of sources, including the Delta loop at LANL and samples corroded at UNLV in the gas phase experiments.

\section{RESEARCH ACCOMPLISHMENTS}

An analysis of the role of silicon in conferring corrosion resistance was published during the present reporting period. Silicon and its various oxides were found in the oxides of siliconcontaining steels after exposure to $\mathrm{LBE}$, with $\mathrm{SiO}_{2}$ found near the oxide/metal interface, consistent with the formation of a layer between the metal and the oxide. Results were published in the Journal of Nuclear Materials.

A model was developed and presented at the AFCI materials working group March 2006 in Santa Fe. This model and supporting experimental results indicate that the conversion of the oxide

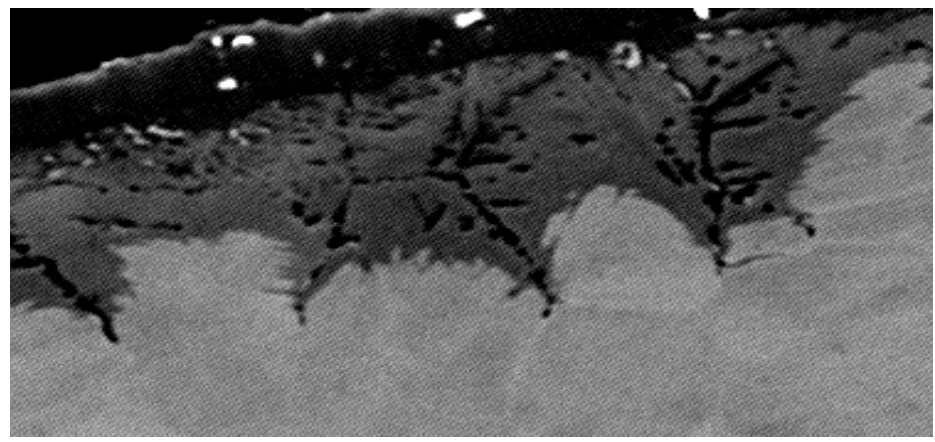

Atom probe image of etched D-9. Note the high etch rate along grain boundaries and elsewhere. Also note the evidence of oxidation along the crystal planes in the metal.

layer on the austenitic steels from an initial compact thin layer to a porous thick multilayer occurs at localized failures of the thin oxide, with the formation of diffusion channels in the thick oxide. At the May 2007 Heavy Liquid Metals (HLM) Workshop in Rome, Italy, other researchers supported this model. Currently, a paper is being prepared on the application of the defect generated diffusion channel model to austenitic and ferritic/martensitic steels for nuclear applications.

\section{Gas phase experimental results}

The gas phase oxidation of steels has been examined at oxygen concentrations approximating those in LBE. This study determines the unique aspects of oxidation in LBE. For example, in the gas phase experiments on these steels, tin was sometimes observed at the surface. Tin has been implicated in temper embrittlement. In LBE, tin does not accumulate due to the solubility of tin in LBE. Conversely, nickel is depleted from the oxide layer that forms on the austenitic steels. In LBE, this nickel can dissolve. In the gas phase, Ni depletion was also observed, indicating that nickel must dissolve into the bulk metal in this case.

After $100 \mathrm{~h}$ of oxidation up to 10 microns of oxide is formed, which indicates a flux of oxygen onto the metal surface that is much higher than the oxygen control mechanism $(\mathrm{CuO} / \mathrm{Cu}$ couple) would allow, suggesting that some other oxygen containing species is active. Of course water is a likely suspect, and experiments have been initiated to determine the role of water as an oxygen containing/transport agent in LBE. In summary, gas phase experiments have directed the project towards studies expected to give insight into the mechanisms of LBE corrosion of steel.

\section{Facility development}

After the renovation of room $112 \mathrm{C}$ in the Chemistry building (CHE), the first experimental data came from an experiment in gas phase corrosion using a tube furnace. Steel samples were corroded by contact with controlled amounts of oxygen at elevated 
temperatures. The gas phase facility has produced valuable data for comparison with corrosion of steel by liquid metal. A clean bench has been installed in CHE 112C for handling liquid lead safely. A small liquid metal experiment is being assembled, and the lower section is now finished.

\section{Analytical Techniques}

In the last year, a laser Raman microscope was successfully developed, capable of performing Raman spectroscopy of sample surfaces with lateral resolution of a few microns, allowing detection of chemical species on the surface, whereas other analytical techniques (e.g., XPS or EDX) only provide elemental/oxidation state information. The laser Raman microscope can easily distinguish between the two oxides of iron, hematite $\left(\mathrm{Fe}_{2} \mathrm{O}_{3}\right)$ and magnetite $\left(\mathrm{Fe}_{3} \mathrm{O}_{4}\right)$, and was used in Hosterman's 2006 masters degree.

\section{FUTURE WORK}

Plans for Summer 2007 and later consist of continuation of work specified in previous work packages. The small liquid metal exposure facility will be completed, and physical, chemical, and corrosion LBE characterization will begin. Gas phase experiments will be continued with the use of the Oxygen Control System. These experiments are planned for completion in Fall 2007. They test the specifics of LBE corrosion verses standard gas corrosion of steel, and allow a clear indication of the differences induced by the LBE. Isotope labeling experiments turned out to be more difficult than planned. ${ }^{18} \mathrm{O}$ labeling studies following the experiments of Martinelli et al. (recently mentioned at the HLM conference in Rome) will be done on D9 and 316, and training on the required TOF-SIMS technique at the NESAC-BIO workshop will happen in August 2007. A joint paper has been planned using task work as well as investigations by the LANL and French groups to expand the model to include a broad array of structure steel corrosion phenomena in LBE.

D-9 shows failure of the thin oxide and formation of duplex oxide in localized patches. The iron moves outside the original metal surface to form $\mathrm{Fe}_{3} \mathrm{O}_{4}$ (as shown by Raman Spectroscopy) and the chromium stays in place to form an iron/ chromium oxide which undercuts the thin oxide.

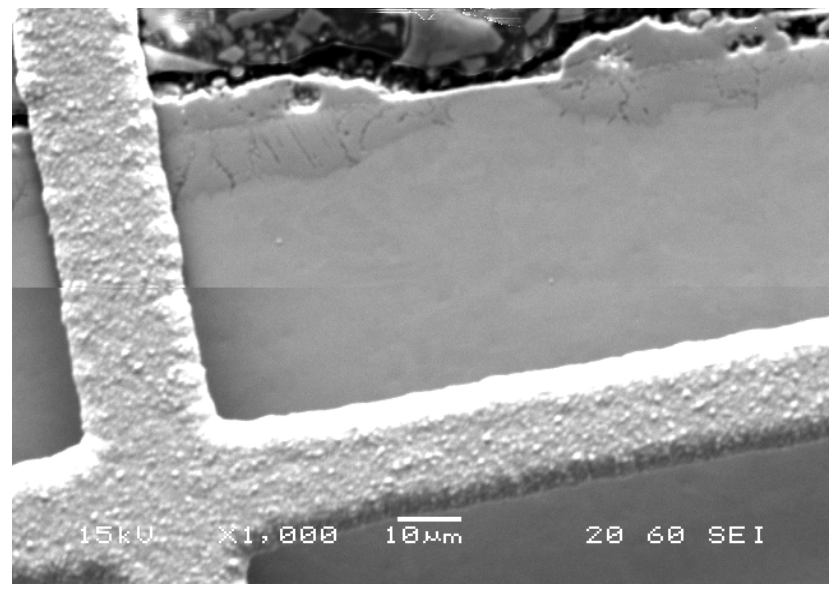

\section{ACADEMIC YEAR HIGHLIGHTS}

- Brian Hosterman, M.S. thesis, UNLV Physics Department, "Micro-Raman Spectroscopic Studies of Corrosion of Steel by Lead-Bismuth Eutectic,” December 2006.

- A. L. Johnson, J. W. Farley, D. Koury, B. Hosterman, J. Welch, T. Ho, L. Ma, and U. Younas; "Protective Oxide Layers on Austenitic Stainless Steel (316L and D9) in Molten Lead Service: Formation and Reformation, Structure and Dynamics,” poster, Annual Meeting of the American Vacuum Society, San Francisco, CA, November 12-17, 2006.

- A.L. Johnson, J.W. Farley, L. Ma, O. Tschauner, D. Koury, T. Ho, B. Hosterman, and J. Welch, "HLM efforts at UNLV, USA: LBE Corrosion of D9 and Other 316-Group Steels,” oral presentation, IV Workshop on Materials for HLM Cooled Reactors and Related Technologies, Rome, Italy, May 21-23, 2007.

- A.L. Johnson, D. Koury, J. Welch, T. Ho, S. Sidle, C. Harland, B. Hosterman, U. Younas, L. Ma, and J.W. Farley, "Spectroscopic and microscopic investigation of the corrosion of D-9 stainless steel by lead-bismuth eutectic (LBE) at elevated temperatures: Initiation of duplex oxide formation," submitted, Journal of Nuclear Materials.

- T.D. Lane, C. Carr, J.W. Farley, A.L. Johnson, J.S. Welch, T. Ho, and D. Koury, "Formation of Oxide Layers in an Oxygen Controlled System,” poster, Summer Undergraduate Research Experience, UNLV, Las Vegas, NV, August 11, 2006.

- P. Shafe, J. Farley, A. Johnson, D. Koury, and J. Welch, "Lead Bismuth Eutectic Corrosion Chamber Prototype," poster, Summer Undergraduate Research Experience, UNLV, Las Vegas, NV, August 11, 2006.

\section{Faculty}

Allen Johnson, Principal Investigator, Assistant Professor, Department of Chemistry

John Farley, Professor, Department of Physics

\section{Students}

Thao Trung Ho, Graduate Student, Department of Chemistry

Dan Koury and Brian Hosterman, Graduate Students, Department of Physics and Astronomy

Jenny Welch and Tim Lane, Undergraduate Students, Department of Physics and Astronomy

Peter Shafe (University of Wisconsin, Eau Claire) and Crystal Carr (Dine College, AZ), Summer 2006 Undergraduate Students

(supported by NSF Research Experience for Undergraduates grant, not DOE TRP)

\section{Collaborators}

Ning Li, LBE Project Leader, Los Alamos National Laboratory

Peter Hosemann, Visiting Scientist, Los Alamos National Laboratory

Eric P. Loewen, Idaho National Engineering and Environmental Laboratory 


\section{BACKGROUND}

There has been a recent resurgence of interest in different oxide fuel types (e.g., Th, inert matrix, and Pu fuels) as potential advanced fuels that can be operated to relatively high burnups at lower costs than current $\mathrm{UO}_{2}$ fuels. These fuels can also be formed to incorporate transuranics elements in the matrix. Inert fuel matrices have the advantage of burning $\mathrm{Pu}$ and other transuranic elements from the fuel cycle without the production of other actinide elements. Of the possible materials for use in an inert matrix, $\mathrm{ZrO}_{2}$ has been examined. The inclusion of $\mathrm{ZrO}_{2}$ is expected to increase chemical stability and radiation resistance. The natural analogue of zirconia, baddeleyite $\left((\mathrm{Zr}, \mathrm{M}) \mathrm{O}_{2}\right)$, where $\mathrm{M}$ is a tetravalent ion such as hafnium), contains up to $3000 \mathrm{ppm}$ $\mathrm{U}$ or Th. This supports the durability of inert matrix fuels using $\mathrm{ZrO}_{2}$ in reactor conditions and repository conditions. However, fuels appropriate for the advanced fuel cycle applications should have desirable reprocessing properties, namely ease of dissolution for separations. An additional oxide which is somewhat soluble may need to be added to the $\mathrm{ZrO}_{2}$ matrix to achieve desirable reprocessing properties. A candidate oxide is $\mathrm{MgO}$.

\section{RESEARCH OBJECTIVES AND METHODS}

This project will examine inert fuels containing $\mathrm{ZrO}_{2}$ and $\mathrm{MgO}$ as the inert matrix. Ceramics with this inert matrix, Ce, $U$ and eventually Pu will be synthesized and examined. While the Advanced Fuel Cycle Initiative focus is on inert fuels with $\mathrm{Pu}$ as the fissile component, this task will perform initial laboratory experiments with Ce and $U$. The initial work with Ce will be performed early in the project with results used as a basis for $U$ studies. Reactor physics calculations will be used to examine suitable quantities of burnable poisons from the candidate elements Gd, Er, or Hf. Most fuels use Gd or Er, but the chemical properties of Hf lend themselves to formation of solid solutions with $\mathrm{Zr}$ and the tetravalent actinides and will therefore be investigated. This project will provide the necessary data for evaluating the performance, reprocessing, and waste behavior of the $\mathrm{MgO}-\mathrm{ZrO}_{2}$ fuels from a quantified, chemical perspective.

Reactor physics calculations are used to examine suitable quantities of burnable poisons from the candidate elements Gd, Er, or

\begin{tabular}{ccccc}
\hline Sample \# & $\mathrm{Zr} \%$ & $\mathrm{Mg} \%$ & $\mathrm{U} \%$ & Er \% \\
\hline 1 & 92.5 & 0 & 5 & 2.5 \\
2 & 87.5 & 5 & 5 & 2.5 \\
3 & 82.5 & 10 & 5 & 2.5 \\
4 & 77.5 & 15 & 5 & 2.5 \\
5 & 72.5 & 20 & 5 & 2.5 \\
6 & 62.5 & 30 & 5 & 2.5 \\
7 & 47.5 & 45 & 5 & 2.5 \\
8 & 32.5 & 60 & 5 & 2.5 \\
9 & 17.5 & 75 & 5 & 2.5 \\
10 & 0 & 92.5 & 5 & 2.5 \\
\hline
\end{tabular}

Metal Concentrations for Uranium Containing Ceramics
Hf with reactor grade Pu providing the fissile component, with up to $10 \%$ of ${ }^{239} \mathrm{Pu}$. Ceramics are synthesized and characterized based on the reactor physics results. The solubility of the fuel ceramics, in reactor conditions, reprocessing conditions, and repository conditions, are investigated in a manner to provide thermodynamic data necessary for modeling.

The research objectives of this project are as follows:

- To examine the neutronic behavior of $\mathrm{MgO}-\mathrm{ZrO}_{2}$ inert fuels. Variation of $\mathrm{MgO}$ and $\mathrm{ZrO}_{2}$ composition ranges from $30 \%$ to $70 \% \mathrm{MgO}$ in $\mathrm{ZrO}_{2}$. Analysis of Gd, Er, and Hf for reactivity control ranging from 5-10\% lanthanides. Analysis of reactor grade $\mathrm{Pu}$ as fissile component ranging from $5-10 \% \mathrm{Pu}$. Results will be used as parameters for fuel composition.

- To synthesize and characterize $\mathrm{MgO}-\mathrm{ZrO}_{2}$ ceramics containing burnable poison and fissile composition. Synthesis is based on a precipitation method. Range of $\mathrm{MgO}$ in $\mathrm{ZrO}_{2}$, fissile component concentration, and burnable poison concentration based on results of neutronic calculations. Characterization of ceramics will include density, X-ray diffraction (XRD), surface area analysis, X-ray absorption fine structure, and chemical composition. Results will be applied to behavior in high temperature water, acid, and environmental conditions.

- To describe the chemical behavior of synthesized ceramics. Chemical thermodynamic and kinetic analysis will use equilibrium data, kinetic data, and surface area normalized dissolution. Different conditions will include reactor conditions (high temperature and high pressure water) and reprocessing conditions (nitric acid and elevated temperature). Environmental conditions will be near neutral solution conditions.

- To utilize project data in kinetic and thermodynamic modeling codes to evaluate the speciation of the elements in the ceramics under reactor, reprocessing, and repository conditions.

\section{RESEARCH ACCOMPLISHMENTS}

\section{Development of XRF characterization method}

A reliable method for X-ray fluorescence (XRF) was developed involving ashing the individual oxides, then preparing standards through the dry synthesis route. It was believed that the samples that showed heterogeneous Ce distribution were due to insufficient sintering times. Therefore, one such sample was removed from resin, resintered, and elemental mapping was performed a second time. This second mapping showed a homogenous distribution of cerium demonstrating the suitability of the method.

\section{Synthesis and characterization of U-containing ceramics}

Ceramics were synthesized using $\mathrm{MgO}-\mathrm{ZrO}_{2}$ as the inert matrix and $\mathrm{Er}_{2} \mathrm{O}_{3}$ as a burnable poison as in previous studies; however, $\mathrm{UO}_{2}$ is now being used as a more accurate $\mathrm{PuO}_{2}$ analog than the previous $\mathrm{CeO}_{2}$ containing ceramics. 
A soxhlet experiment was initiated to determine the corrosion resistance of the ceramics. The results demonstrated the corrosion resistance enhancement from the inclusion of $\mathrm{ZrO}_{2}$. A thermogravimetry and differential scanning calorimetry scan was performed on the precipitated material to examine calcining and sintering behavior. The material appears to change from the oxyhydroxide precipitate to the oxide at the same temperature as the Ce-containing ceramics $\left(260^{\circ} \mathrm{C}\right)$. The phase change also starts at the same temperature $\left(510^{\circ} \mathrm{C}\right)$, but it does not proceed as quickly and therefore shows a broader peak.

XRD patterns were taken of all samples under investigation to qualitatively determine the phases present within the sintered sample. With no $\mathrm{MgO}$ present the $\mathrm{UO}_{2}$ and $\mathrm{Er}_{2} \mathrm{O}_{3}$ only partially stabilizes the $\mathrm{ZrO}_{2}$ resulting in a mixture of monoclinic and tetragonal $\mathrm{Zr}$ oxide phases. With as little as $5 \% \mathrm{wt} / \mathrm{wt} \mathrm{MgO}$, the material fully stabilizes to form a pure cubic zirconium phase. Over $10 \% \mathrm{MgO}$ results in a $\mathrm{MgO}$ phase, in addition to the cubic zirconia. This pure $\mathrm{MgO}$ phase increases with total $\mathrm{MgO}$ content. When there is no longer $\mathrm{ZrO}_{2}$ in the sample a $\mathrm{MgO}$ phase dominates, while there is a minor cubic uranium erbium oxide phase. Quantitative analysis will be performed once TOPAZ software is obtained.

Scanning Electron Microscopy and optical microscopy were used to image the material and identify the nature of the phase mixing within the sample. The $\mathrm{MgO}$ phase appears darker than the $\mathrm{ZrO}_{2}$ phase due to lower mass number. The color images show large areas of various colors, but higher magnification in greyscale shows a high degree of mixing the two phases. Microprobe was also used to sweep large areas of the sample to determine where each element is concentrated. This shows that $\mathrm{Zr}$, Er, and $\mathrm{U}$ are all within the same area (phase), while $\mathrm{Mg}$ is contained within its own phase. This compliments the XRD findings well. In the U and Er map the brightness and contrast were enhanced because of the low concentrations of those elements.

Dissolution studies with nitric acid have shown a linear dissolution rate for $\mathrm{U}$; however, improvements are needed for consistent kinetic constants. Also, $\mathrm{U}$ leaching in nitric acid is only possible at high $\mathrm{Mg}$ concentrations. This is due to the greater surface area of the exposed zirconia phase once the magnesia is dissolved, and the higher $U$ concentration within the zirconia phase in these samples. Dissolution in supercritical water was extended to 3 weeks with the same results. Only Mg is found in solution.

Oxide waste forms based on project results

$\mathrm{UY}_{6} \mathrm{O}_{12}$ pellets were synthesized for Los Alamos National Laboratory for initial waste form studies complementary to the inert fuel research. Composition was confirmed to be delta phase by XRD.

\section{ACADEMIC YEAR HIGHLIGHTS}

- Ken Czerwinski (PI) was the U.S. delegate to the International Atomic Energy Agency Minor Actinide Inert Fuel Matrices working committee from May 2004 to present.

- K. Holliday, T. Hartmann, and K. Czerwinski, "Characterization of zirconium-magnesium ceramics for inert matrix fuel,” 2006 Inert Matrix Fuel Workshop, Park City, UT, October 2006.

- K. Holliday, T. Hartmann, and K. Czerwinski, "Characterization and dissolution of Zr-Mg ceramics for inert matrix fuel,” Advanced Fuel Cycle Topics, American Chemical Society Regional Meeting, Boise, ID, June 2007.

\section{FUTURE WORK}

Further synthesis and characterization of $\mathrm{MgO}-\mathrm{ZrO}_{2}$ ceramics will be performed with the use of Pu containing material obtained from Idaho National Laboratory. The project will be the basis of further fuel studies on the oxygen to metal ratio and research into the development of oxide waste forms for Tc.
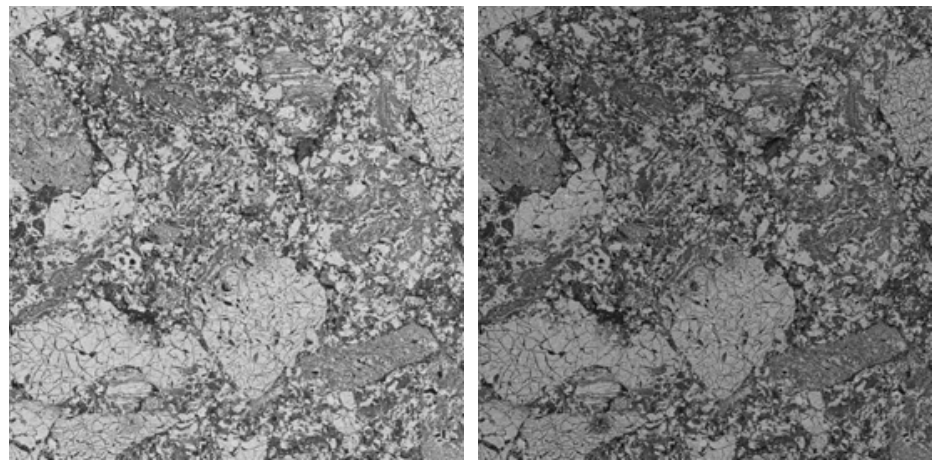

Sample 6 (3 x 3 mm U map)

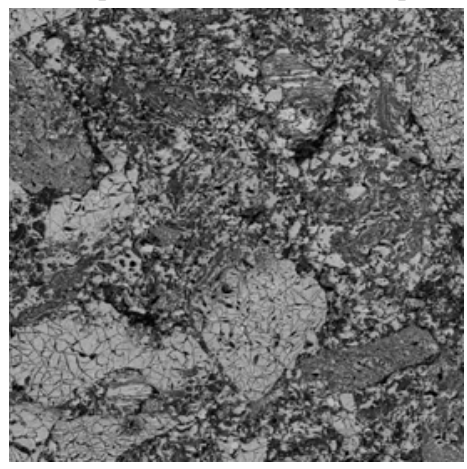

Sample 6 (3 $x 3$ mm Zr map)

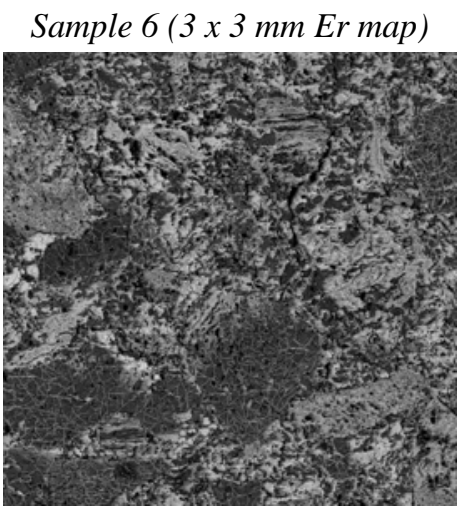

Sample 6 (3 $\times 3 \mathrm{~mm} \mathrm{Mg} \mathrm{map)}$

Elemental Scanning by Microprobe

Research Staff

Ken Czerwinski, Principal Investigator, Associate Professor, Department of Chemistry

Thomas Hartmann, Staff Scientist, Harry Reid Center

Frederic Poineau, Post-Doctoral Researcher, Harry Reid Center

Students

Kiel Holliday, Graduate Student, Department of Chemistry (Radiochemistry Ph.D. Program)

Mitchell Meyer, Idaho National Laboratory 


\title{
Task 20
}

\section{Effect of Silicon Content on the Corrosion Resistance and Radiation- Induced Embrittlement of Materials for Advanced Heavy Liquid Metal Nuclear Systems}

\author{
A.K. Roy
}

\section{BACKGROUND}

This task is focused on the evaluation of the effects of silicon content on both the corrosion behavior and radiation-inducedembrittlement of martensitic stainless steels having compositions similar to that of modified 9Cr-1Mo steel, also known as T91 grade steel. T91 grade steel was selected to be a candidate structural material to contain molten lead-bismuth eutectic (LBE), which can act both as a target material and a coolant during the spallation process. The operating temperature during this process may range from $420-550{ }^{\circ} \mathrm{C}$. Thus, moderate tensile strength of the containment material (T91) is a major requirement.

The beneficial effects of Si on both the metallurgical and corrosion properties of chromium-molybdenum (Cr-Mo) steels have previously been demonstrated at UNLV. Therefore, additions of Si ranging from 0.5-2.0 weight percent (wt\%) was attempted in this investigation to explore Si effect on both the high temperature tensile properties and corrosion behavior of T91 grade steel. Corrosion studies in the presence of molten LBE could not be performed due to a lack of proper experimental facilities at UNLV. Therefore, detailed corrosion studies involving Sicontaining T91 grade steels were performed in an aggressive aqueous solution of acidic pH. Further, significant efforts have

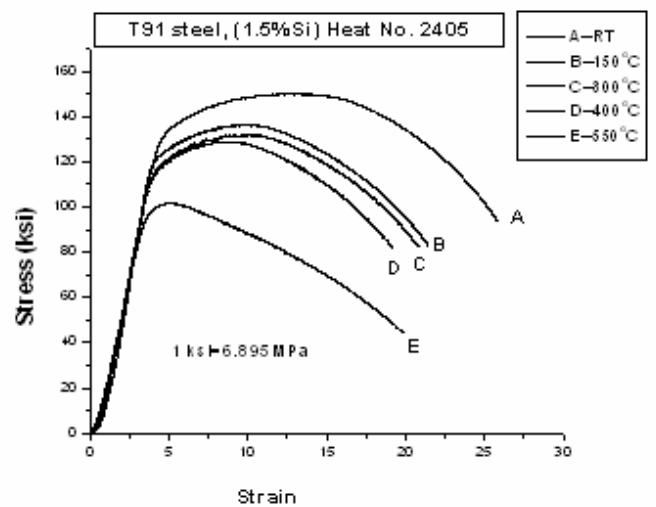

Stress-Strain

Diagrams of $T 91$

Steel with 1.5 $w t \% \mathrm{Si}$

Dislocation Density vs. Temperature $\left({ }^{\circ} \mathrm{C}\right)$

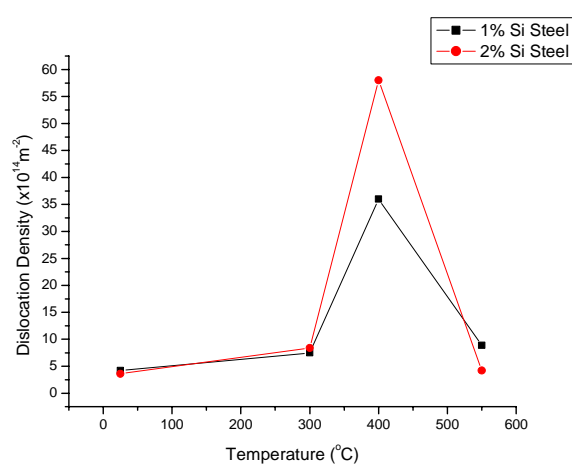

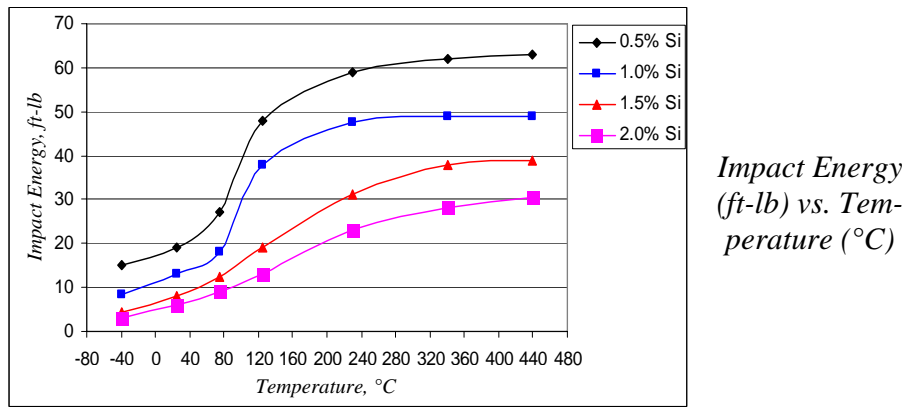

been made to determine both the impact and fracture toughness of the tested materials as a function of Si content.

\section{RESEARCH OBJECTIVES AND METHODS}

Four heats of T91 grade steel having Si levels of 0.5, 1.0, 1.5 and $2.0 \mathrm{wt} \%$ were custom-melted by a vacuum-induction-melting practice. They were subsequently processed and thermallytreated to achieve fully-tempered martensitic microstructures. These materials were then machined to fabricate desired types of specimens for evaluation of tensile properties, impact toughness, fracture toughness, resistance to localized corrosion, stress corrosion cracking (SCC), and crack propagation behavior. Limited tensile testing was also performed on T91 grade steels under different levels of radiation. Numerous state-of-the-art experimental techniques were employed to evaluate the desired properties. The relevant experimental techniques have been described in previous annual reports. The significant results obtained during the past fiscal year are summarized below.

\section{RESEARCH ACCOMPLISHMENTS}

- The results of tensile testing indicate that the magnitude of failure strain $\left(e_{f}\right)$ was gradually reduced with increasing temperature within a susceptible temperature range, irrespective of the Si content. Simultaneously, serrations were also noted in the engineering stress vs. strain diagrams.

- The reduced $e_{f}$ values and the occurrence of serrations within a specific temperature regime can be attributed to a metallurgical phenomenon known as Dynamic Strain Ageing (DSA). Irrespective of the Si content, the susceptibility to DSA was predominant at temperatures ranging from ambient to $400^{\circ} \mathrm{C}$.

- The DSA phenomenon, as seen in this investigation, is commonly associated with the diffusion of solute elements into the matrix of the material at elevated temperatures, thus impeding the movement of dislocations through the matrix and grain boundaries. Such reduction in dislocation mobilities can significantly impair the plastic deformation, which is manifested by reduced $e_{f}$ values, as seen in this study. 


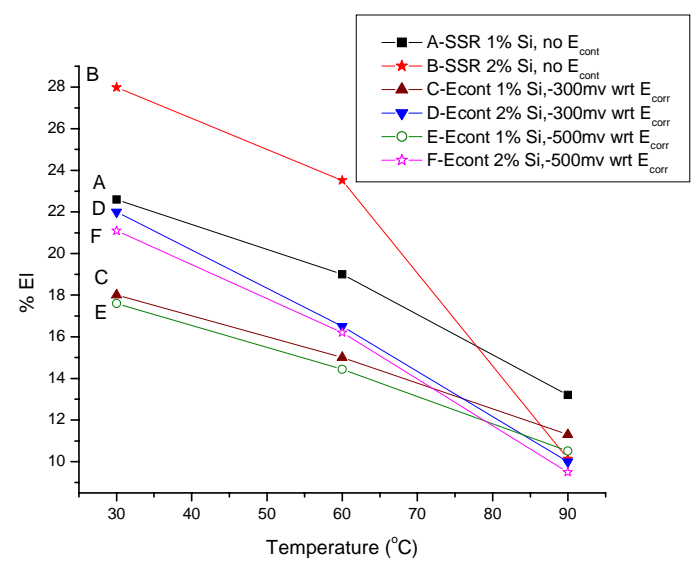

Variation of \%El with temperature for steels (1 and $2 \mathrm{wt} \% \mathrm{Si}$ ), with and without cathodic $E_{\text {cont }}$.

- A maximum dislocation density $(\rho)$, determined from the transmission electron micrographs, was seen at $400^{\circ} \mathrm{C}$, irrespective of Si content.

- The work hardening index (n) and activation energy for diffusion are two key parameters influencing the DSA behavior of engineering materials. Simultaneously, both temperature and strain rate can influence the DSA behavior. The variation of $\mathrm{n}$ with temperature at a strain rate of $5 \times 10^{-4} \mathrm{sec}^{-1}$ is shown in the table below. A gradual increase in the $\mathrm{n}$ value was observed at temperatures up to $400^{\circ} \mathrm{C}$, as expected.

- A longer activation time using an electron beam resulted in reduced ductility in terms of $\mathrm{e}_{\mathrm{f}}$.

- The presence of higher Si content in T91 grade steel resulted in reduced impact energy and higher ductile-brittle transition temperature, indicating reduced impact resistance.

- The susceptibility to SCC was enhanced at more cathodic (active) controlled potentials $\left(\mathrm{E}_{\text {cont }}\right)$ and higher testing temperature, implying a synergistic effect of cathodic potential and temperature on SCC.

- The morphology of failure in double-cantilever-beam specimen used in SCC testing was characterized by a combination of striations (fatigue), SCC (intergranular/transgranular), and fast fracture (dimples).

Variation of $n$ with Temperature (RT: Room Temperature)

\begin{tabular}{|c|c|c|c|c|c|}
\hline Heat no. / Temp. $\left({ }^{\circ} \mathrm{C}\right)$ & RT & 150 & 300 & 400 & 550 \\
\hline $2403(0.5 \% \mathrm{Si})$ & 0.1643 & 0.1698 & 0.1784 & 0.1984 & 0.1432 \\
\hline $2404(1.0 \% \mathrm{Si})$ & 0.1716 & 0.1794 & 0.1945 & 0.2143 & 0.1564 \\
\hline $2405(1.5 \% \mathrm{Si})$ & 0.1586 & 0.1702 & 0.1794 & 0.1802 & 0.1642 \\
\hline $2406(2.0 \% \mathrm{Si})$ & 0.1669 & 0.1709 & 0.1772 & 0.1997 & 0.0994 \\
\hline
\end{tabular}

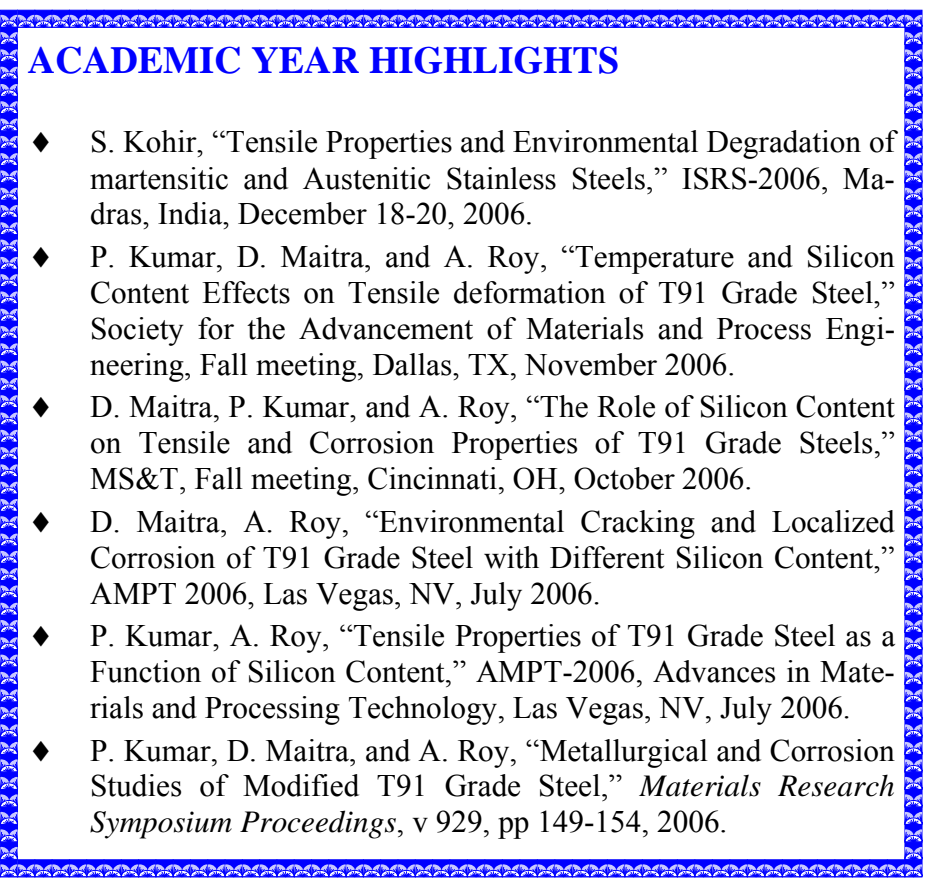

\section{FUTURE WORK}

Stress corrosion cracking will be evaluated under anodic $\mathrm{E}_{\text {cont }}$, dynamic strain ageing will be characterized by transmission electron microscopy, and fracture toughness will be evaluated.

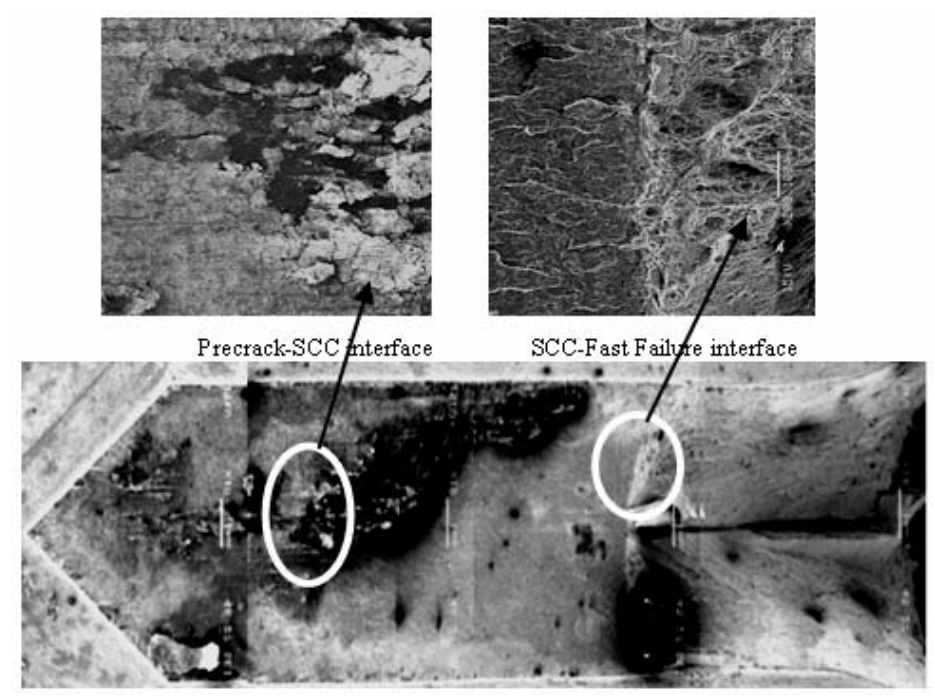

SEM micrographs of DCB specimens with $0.5 \mathrm{wt} \%$ Si subjected to SCC testing at $100^{\circ} \mathrm{C}$ in acidic solution for 30 days

Research Staff

Ajit K. Roy, Ph.D., Principal Investigator, Professor, Mechanical Engineering Department

Arindam Ghosh, Ph.D., Research Scholar, Mechanical Engineering Department

\section{Students}

Debajyoti Maitra and Pakaj Kumar, Ph.D. Students, Mechanical Engineering Department

Srinivas Kohir, M.S. Student, Mechanical Engineering Department

\section{Collaborators}

Stuart A. Maloy, Ph.D., AFCI Materials Team Leader, Los Alamos National Laboratory

Ning Li, Ph.D., LBE Technology Development, AFCl, Los Alamos National Laboratory

Doug Wells, Ph.D., Associate Professor and Chair, Department of Physics, Idaho State University 


\title{
Theoretical Modeling of Protective Oxide Layer Growth in Non-isothermal Lead Alloy Coolant Systems
}

\author{
Y. Chen, J. Zhang, H. Chen, J. Li
}

\section{BACKGROUND}

In advanced nuclear energy systems, lead-alloys (e.g., lead, leadbismuth eutectic) emerge as strong candidates for transmutation and advanced reactor systems as nuclear coolants and high-power spallation neutron targets. However, it is widely recognized that corrosion of materials caused by lead-alloys presents a critical barrier to their industrial use. A few experimental research and development projects have been set up by different groups such as LANL to study the corrosion phenomena in their test facilities and to develop mitigation techniques and materials. One of the central or main techniques in lead-alloys coolant technology under development is to use active control of oxygen thermodynamic activity (OTA) to provide protective oxide layers.

Setting OTA in flowing lead-alloys makes corrosion highly dependent upon the oxygen concentration and the oxidation processes at materials surfaces. The active oxygen control technique exploits the fact that lead and bismuth are chemically less active than the major components of steels, such as Fe, Ni, and $\mathrm{Cr}$. By carefully controlling the oxygen concentration in LBE, it is possible to maintain an iron and chrome based oxide film on the surfaces of structural steels, while keeping lead and bismuth from excessive oxidization that can lead to precipitation contamination. Thermal analysis has given an ideal oxygen level range in a nonisothermal lead-alloy coolant system. However, in a practical coolant loop, the proper oxygen level depends not only on thermal factors but also on hydraulic factors (temperature profile, flow velocity, etc.). In addition, the oxygen distribution in a nonisothermal lead-alloy coolant system is still unclear. The optimal oxygen levels still need to be investigated.

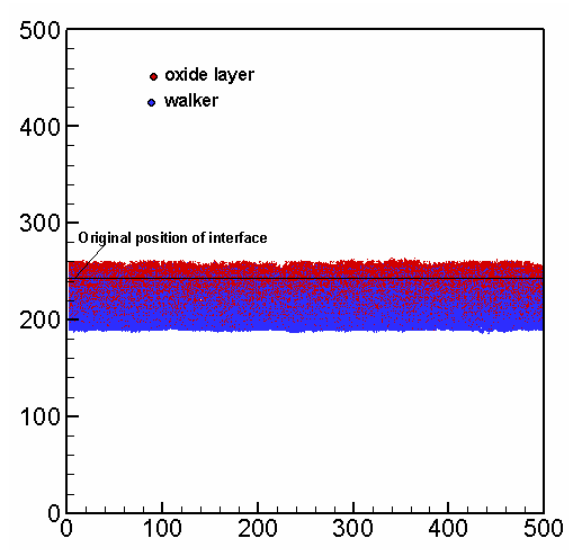

(a) time step $=1 \times 10^{4}$

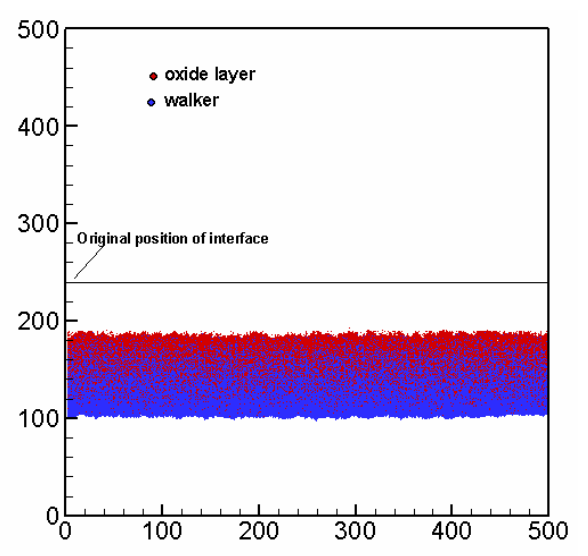

(b) time step $=5 \times 10^{4}$
Snapshots of the simulated layer in the presence of corrosion with scale removal. They correspond to $2.5 \times 10^{4}$ time step. The red dot is the oxide site; The blue dot is the walker site; The upper side of the layer is filled with solvent; The lower side of the oxide layer is pure metal. The corrosion probability of metal is taken as 0.5 . The possibility of scale removal of the oxide site close to solvent is 0.004 .
The goal of the proposed research project is to provide basic understanding of the protective oxide layer behaviors and to develop oxide layer growth models of steels in non-isothermal lead-alloys (lead or lead-bismuth eutectic) coolant systems. Precise studies and simulations of all hydrodynamics with thermal conditions encountered in practical coolant loop systems by use of different flowing conditions in the laboratory are difficult and expensive, if not impossible. Therefore it is important and necessary to develop theoretical models to predict the protective oxide layer behaviors at the design stage of a practical lead-alloy coolant system, to properly interpret and apply experimental results from test loops, and to provide guidance for optimization in lead-alloy nuclear coolant systems. The research project, therefore, is aimed at understanding protective oxide layer growth and the optimal oxygen concentration level before lead-alloy nuclear coolants are ready for programmatic implementations and industrial applications.

\section{RESEARCH OBJECTIVES AND METHODS}

- To elucidate the mechanism of the protective oxide layer growth of steels in static, non-isothermal flowing lead-alloy coolant systems with oxygen concentration level control.

- To elucidate the mechanism of mass transport of oxygen and corrosion products in the multi-phase system.

- To develop oxidation growth models of steels in lead-alloy coolant systems.

- To clarify the dependence of oxidation processes on thermal hydraulic factors (system operating temperature, temperature profile, flow velocity, etc.) and the oxygen concentration distribution and level.

- $\quad$ To clarify the optimal oxygen concentration levels in practical coolant system scales.

- To interpret the experimental results from test loops and to apply them to the design of practical nuclear coolant systems.

\section{RESEARCH ACCOMPLISHMENTS}

Cellular automata modeling of oxide layer growth with scale removal: To simulate the scale removal effect on oxide layer growth, the previous cellular automata model of oxide layer growth has been improved to consider the scale removal effect. In this model, the scale removal rate was taken to be linear. It is assumed that the oxide layer sites which are close to the oxidant site have a probability to move away. The global random walker model is still used to simulate the solid state diffusion of the ionic metal site in the oxide layer. The phenomena of oxide growth which obeyed Tedmon theory was found. 
Stochastic modeling with cellular automata method on the surface growth and internal oxidation: The quantitative cellular automata model on the inward oxidation mechanism was developed. The stochastic rule to the population of particles is based on the exclusion principle. Considering the exclusion principle, which permits at most one particle per site, a particle moves to its targeted site if this site is free and simply does not move if the site it targeted was already occupied. To avoid the confliction between particles competing for a single free site, the following rule was adopted. When more than one particle attempts to move to a single open site, only one of the competing particles, which will be chosen randomly from among them, is allowed to move to this open site and the others do not move. A benchmark with the theoretical solution was made, and a good agreement was obtained.

Numerical modeling on the diffusion controlling oxidation model with scale removal: A numerical diffusion-controlling oxidation model with scale removal was developed in oxygen-containing liquid flow. Scale removal effect was considered and the formation mechanism of duplex oxide layer structure was analyzed and employed in the model. The volume expansion effect caused by density difference during the oxidation is coupled with the consideration of increasing weight of reacted oxygen. To solve the diffusion equations with an advection term caused by the moving boundaries, a coordinate transform technique was employed. The governing equations were analogized with the Stefan problem in heat transfer with phase change in the enthalpy formulation and then solved numerically by finite difference method.

Cellular automaton model on the oxide growth coupled with inward oxygen diffusion: To simulate the oxide layer growth of steel in liquid lead alloy environment, a cellular automaton model

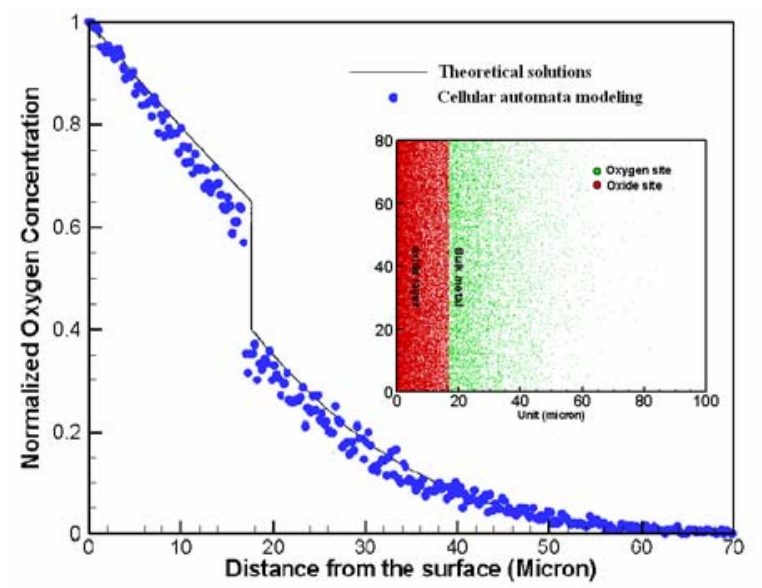

Distribution of oxygen concentration at 0.5 hour. Application of quantitative cellular automata modeling of oxidation in metal matrix composite.

\section{ACADEMIC YEAR HIGHLIGHTS}

- Y. Chen, H. Chen, and J. Zhang. "Enhancement of oxygen transfer by forced convection in lead alloy system," International Journal of Heat and Mass Transfer, 2007, 50 (12): 2139-2147.

- H. Chen, Y. Chen, and H.T. Hsieh. "Stochastic modeling on oxide layer growth with scale removal effect in liquid metal environment," $15^{\text {th }}$ International Conference on Nuclear Engineering (ICONE 15), April 22-26, 2007, Nagoya, Japan.

- H. Chen and Y. Chen, "Cellular automaton modeling on the corrosion/oxidation mechanism of steel in liquid metal environment," $2^{\text {nd }}$ COE-INES International Symposium on Innovative Nuclear Energy Systems, November 26-30, 2006, Yokohama, Japan.

- X. Tan, Y. Chen, H. Chen, T. Tan, and H.T. Hsieh, "Numerical analysis of natural convection induced oxygen transport in liquid lead bismuth eutectic;” T. Tan, Y. Chen, H. Chen, and H.T. Hsieh, "Corrosion precipitation in nonisothermal lead alloy coolant systems;” and, H. Chen, Y. Chen, and H.T. Hsieh, "A stochastic model of oxidation mechanism on high temperature corrosion of stainless steel," 2006 ASME International Engineering Congress and Exposition, Chicago, IL, November 5-10, 2006.

was developed that considered inward oxygen diffusion. In this model, the lattice sites are occupied by metal, oxide, or lead alloy, while the interstitial sites are route ways for oxygen to occupy and diffuse. The benchmark of cellular automata model for pure oxygen diffusion has been made and a good agreement has been obtained.

\section{FUTURE WORK}

The next phase of the project involves accomplishing the following tasks:

- Structure stability analysis on oxide layer under liquid metal environment for different operating conditions.

- Model the erosion-corrosion process mechanisms in oxygencontrolled lead-alloy systems.

- Identify the protective oxide layer growth under corrosion and oxidation mechanisms using stochastic methods.

- Clarify the dependence of the oxidation process on the hydraulics factors (system operating temperature, temperature profile, flow velocity, etc.) and the oxygen concentration distribution and level.

- Predict the optimal oxygen concentration levels in practical coolant system scales.

Research Staff

Yitung Chen, Principal Investigator, Associate Professor, Department of Mechanical Engineering

Huajun Chen, Postdoctoral Researcher, Department of Mechanical Engineering

Jichun Li, Assistant Professor, Department of Mathematics

Students

Taide Tan and Chaiyod Soontrapa, Graduate Students, Department of Mechanical Engineering

Ning Li, LBE Team Leader and Jinsuo Zhang, Los Alamos National Laboratory 


\section{Task 22 \\ Design Concepts and Process Analysis for Transmuter Fuel Manufacturing}

G. Mauer

\section{BACKGROUND}

The safe and effective manufacturing of actinide-bearing fuels for any transmutation strategy requires that the entire manufacturing process be contained within a shielded hot cell environment. To ensure that the fabrication process is feasible, the entire process must be designed for remote operation. The equipment must be reliable enough to perform over several decades, and also easy to maintain or repair remotely. The facility must also be designed to facilitate its own decontamination and decommissioning. In addition to these design factors, the potential viability of any fuel fabrication process will also be impacted by a number of variables, such as the current state of technology, potential problem areas, deployment scaling, facility safety, and cost.

\section{RESEARCH OBJECTIVES AND METHODS}

The goal of this research project is to provide technical support to process designers working on the development of the fuel cycles for transmutation applications. Detailed process models have been developed to better define the impact of fuel choice on the transmuter fuel cycle, including relative process losses, waste generation, and plant capital cost. These process models provide insight regarding required plant size and number of plants needed to mesh with the fuel recycling line. They also determine requirements for automation.

Manufacturing models for large-scale production in a hot cell environment have also been developed. Combined, these two models allow the assessment of plant layout, and provide the framework for estimation of plant capital and operating cost estimates, and for feasibility in general. The operations of robotic equipment and the sensor technology required for safe ad reliable robot control have been evaluated through simulations in threedimensional space. The manufacturing technology developed for hot cell applications is also applicable to other, more general uses, where occupational hazards prevent human presence near processes.

The research work performed during the reporting period was divided into several tasks:

Simulations: This task modeled manufacturing processes to generate a realistic assessment of plant layout, size, feasibility, and
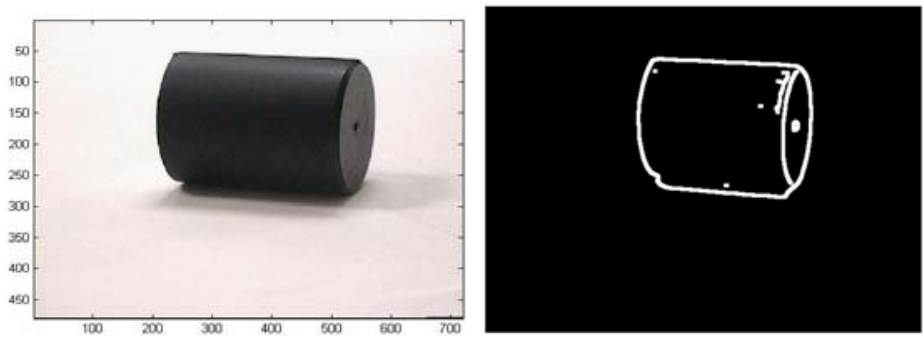

CCD image (left), and Contour (right) of a cylinder

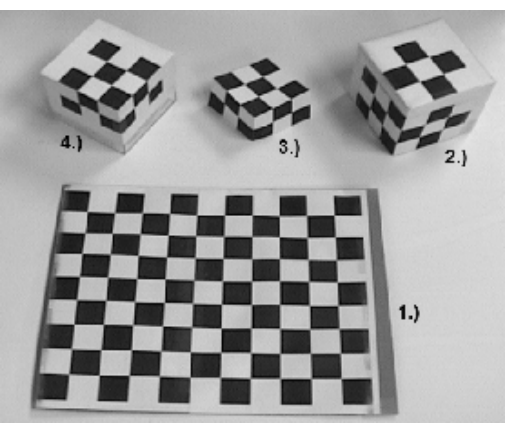

technology development required for large-scale remote fabrication of fuel. Modeling of the candidate fuel manufacturing processes was performed using the MSC.visualNastran and ProEngineer simulation software tools. To date, the modeling of dispersion and TRISO fuels has been completed. A parametric study to determine the process reliability and possible reliability improvements for various fuel types and equipment configurations is in progress.

Cost, Feasibility, and Large Scale Deployment: This task will develop the database necessary to provide cost estimates and differential cost for various fuel manufacturing options. Cost estimates regarding projected capital cost, reliability, and plant life have been developed and are being refined as additional knowledge is developed.

Automated Vision-Based Image Acquisition and Robot Control: This task explores and demonstrates strategies for the reliable and flexible control of the material handling robots inside the hot cell by means of automated vision systems. Since the cameras can be positioned outside the hot cell, such systems would have significant advantages over sensors inside the hot cell, resulting in potentially reduced system maintenance and increased system reliability.

\section{RESEARCH ACCOMPLISHMENTS}

Research during the past year focused on vision-based recognition and spatial location of fuel pellets inside a hot cell.

Recognition of Cylindrical Fuel Pellets by the CCD Camera: The images of cylinders that are captured by the camera have properties which make the recognition of the cylinder more difficult. The real time cylinder pictures contain shadows as well as reflections (specularity) caused by lighting conditions. This project seeks to detect the cylinders' contours in order to identify and classify it correctly. Changes of lighting conditions can make the correct identification difficult at times.

Camera Calibration and Dimensional Measurements using the CCD Camera

Calibration objects: Calibrating a camera requires several corre- 


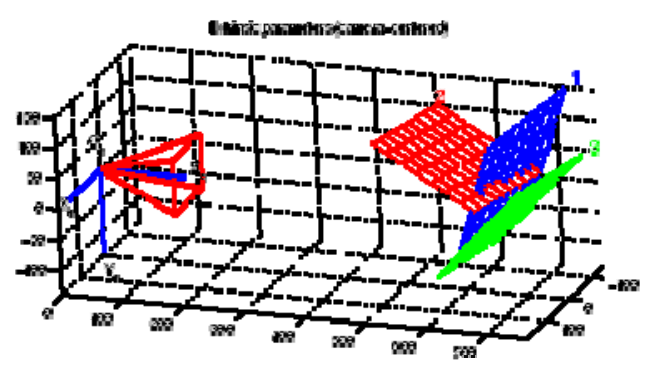

Estimated 3D Structure of a calibration plane

sponding 3D and 2D points. Calibration objects are mostly planes or cubes (two or three orthogonal planes) with special markings. Here, those markings are chess board patterns with equidistant corners distributed accurately over the object surface. The corners define the known points in the world coordinate system and can be easily identified in the image from edge detection algorithms. This step provides the opportunity to estimate the projection matrix. Another method of calibrating is self-calibration. This technique obtains correspondences from the camera movement in a static scene using image information alone.

Estimation of the projection matrix: The camera calibration algorithm was programmed in Matlab. The regions of interest were defined for every single image by selecting the 4 outmost corners of the chess pattern. The Matlab software identifies and saves the positions of the individual black square's corners for processing. The optimization method of Levenberg-Marquardt is applied which also includes the adaptive correction of the lens distortion.

Two-View Triangulation: Triangulation is the process of finding the position of a point in space given its position in a stereo image pair. This task is essential for vision-based robot pick and place operations. The Linear-Eigenmethod is the simple triangulation method that is used for extracting the $3 \mathrm{D}$ points.

Optimal Triangulation: Suppose there are two point correspondences $\mathrm{x}$ and $\mathrm{x}$ ' from two images, and the goal is to reconstruct the 3D point $\mathrm{X}$. If the correspondences are accurate (which cannot usually be expected) the rays of $\mathrm{x}$ and $\mathrm{x}$ ' will lie in the same plane and thus will intersect in X. In the presence of noise, accurate point coordinates cannot be expected. It follows that $\mathrm{x}$ and $\mathrm{x}$ ' may not lie in a plane, which means that there is no intersection. A method for correcting the existing point correspondences such that the corresponding rays will lie in the same plane consists in finding a global minimum of a cost function. For this approach, it is assumed that the fundamental matrix is well defined.

Recognizing calibration cubes: Until now a disadvantage of the calibration process has been the need to determine the point correspondences of the calibration object and a given 3D model manu-

\section{ACADEMIC YEAR HIGHLIGHTS}

- G.F. Mauer, "Equipment Redundancy and Plant Reliability in Robotic Hot Cells for Fuel Fabrication,” Proceedings, American Nuclear Society Winter Annual Meeting, November 2006.

ally. A desirable feature would be the automatic mapping from calibration cube points to the 3D locations of a 3 plane model. This would allow estimating the projective matrix automatically. For the experimental validation, several calibration objects were arranged on a paper grid in order to cover multiple points in the 3D space.

For the tests, 50 points were used to estimate the fundamental matrix. The same points have been reapplied as control points. The triangulation error was around 0.2 inches at a distance to the calibration points of 10 inches. In the proximity of the calibration points the error was below 0.1 inch. The errors are attributed by the following effects:

- Quality deficiencies of the camera device

- Inaccurate calibration objects (perpendicularity)

- $\quad$ Linearity of the algorithm

\section{FUTURE WORK}

Vision-based control of hot cell robots: Images of scenes inside a hot cell, such as fuel pellets, will be acquired in real time under varying lighting conditions and in increasingly complex environments. The development of algorithms for reliable object identification, for validation and measurement of the object geometry, location, and orientation, and for camera calibration, will continue.

Vision-based robot servoing: Using a Fanuc M-16iB industrial robot, the stereo vision system will be installed in lab TBE-B 162, and the task will proceed to test the visual servoing algorithms under more realistic conditions.

Tests of the camera system in noisy environments will continue for the vision system's ability to discern fuel pellets from other objects present.

The conceptual design plant layout, and cost estimates for possible Transmuter Fuel fabrication plants will continue for various fuel types. (Simulations of oxide, metallic, and dispersion fuels have been completed.)

Capital and operations cost estimates will be developed for various fuel options. Target Plant capacity approximately 100 metric tons annually.

Research Staff

Georg Mauer, Principal Investigator, Professor, Mechanical Engineering Department

Students

Tobias Kotthäuser, Undergraduate Student, Mechanical Engineering Department, University of Duisburg, Germany

Kyle Gohres, Undergraduate Student, School of Computer Science, UNLV

Koushik Damera, and Prathima Sajja, Graduate Students, School of Computer Science, UNLV

Mitchell K. Meyer, Group Leader, Fabrication Development Group, Nuclear Technology Division, Argonne National Laboratory 


\section{BACKGROUND}

Advanced transmutation systems require structural materials that are able to withstand high neutron fluxes, high thermal cycling, and high resistance to chemical corrosion. The current candidate materials for such structures are ferritic and ferritic-martensitic steels due to their strong resistance to swelling, good microstructural stability under irradiation, and the retention of adequate ductility at typical reactor operating temperatures.

In parallel, lead bismuth eutectic (LBE) has emerged as a potential spallation target material for efficient production of neutrons, as well as a coolant in the accelerator system. While LBE has excellent properties as a nuclear coolant, it is also highly corrosive to stainless steel. The corrosion is due to relatively high solubilities of the base and major alloying components of steel, such as $\mathrm{Ni}, \mathrm{Fe}, \mathrm{Cr}$, etc. in LBE at elevated temperatures. Without some protection, the steel structures rapidly corrode in LBE through dissolution and leaching of these materials.

Thus, for long term reliability of the structures, it is necessary to provide some protection of the steel surface from corrosion, without affecting the bulk properties of the steel. One such technique that has been well investigated is the use of oxygen control at the surface of the steel, which maintains a coating of oxide layer that protects the steel surface. The protective layer forms due to the higher affinities of the steel alloying components to oxygen compared to lead and bismuth. However, once a continuous film of oxide is formed, a competing process takes place; the oxide layer interacts with the LBE causing reduction of the oxide layer at higher temperatures. It is thus critical to maintain an optimum flow of oxygen at the LBE/steel interface, which is made challenging by the non-uniform temperature distribution in the transmutation systems. In addition, while the oxygen control technique works effectively at lower temperatures, it is not appropriate for higher operational temperatures $\left(500-600^{\circ} \mathrm{C}\right)$, which is becoming increasingly important. Thus, it is necessary to develop alternative techniques for corrosion protection of steel that will perform reliably at elevated temperatures and under thermal cycling in LBE.

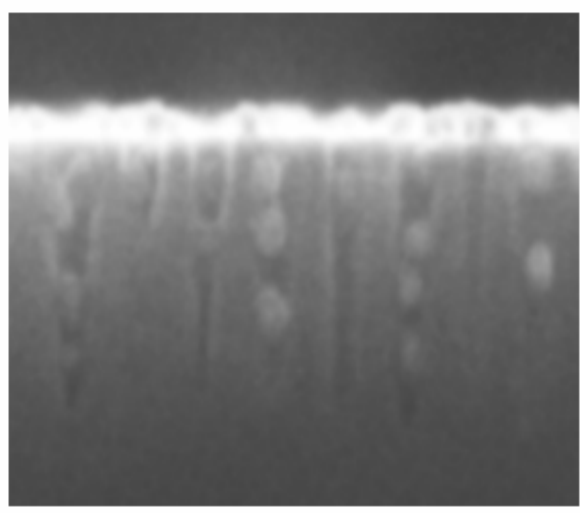

of electro-phoretically deposited nanoparticles inside nanoporous alumina

\section{RESEARCH OBJECTIVES AND METHODS}

The objective of this project is to develop a novel nanostructure based coating technology that will provide significantly improved corrosion resistance for steel in LBE at elevated temperatures $\left(500-600{ }^{\circ} \mathrm{C}\right)$, as well as provide long-term reliability under thermal cycling. The nanostructure based coatings will consist of a layer of nanoporous alumina with the pores filled with an oxidizing metal such as $\mathrm{Cr}$, followed by a capping layer of alumina. Alumina, which is a robust anti-corrosion material, provides corrosion resistance at elevated temperatures. The $\mathrm{Cr}$ serves two purposes: (1) it acts as a solid filler material for the pores in the alumina, enhancing its mechanical and chemical integrity, and (2) it acts as a second layer of defense against corrosion by providing a replenishable source of $\mathrm{Cr}$ (for the formation of a chromium oxide protective layer) in case the alumina layer is compromised. The innovation of this project is the use of a nanoporous alumina layer for the coating, which is mechanically flexible and can expand and contract with the underneath steel surface. As a result, the mechanical integrity of the coating is preserved under thermal cycling. In addition to their usefulness at higher temperatures, the proposed coatings can also provide increased reliability at lower temperatures by complementing the oxygen control technique. The nanostructure based coatings developed in this project will significantly enhance the long-term reliability of steel structures in LBE at elevated temperatures and under thermal cycling.

Working with the DOE collaborator, the stainless steel alloys HT9 and EP-823 were chosen as the candidate materials for investigation at this time. The above project objective will be achieved in three phases; each phase will be carried out over a one-year period.

Phase I will develop the fabrication technology for the coatings on steel, and study their structural integrity at elevated temperatures and under thermal cycling.

Phase II will perform corrosion studies of the structures in LBE at elevated temperatures.

Phase III will use the data from Phases I and II to develop an optimized coating technology for improved structural integrity under thermal cycling, and improved corrosion resistance in LBE at elevated temperatures. If necessary, multiple layers of such coating structures will be used for increased resistance to corrosion.
During Year 3 of the project (2006-2007), extensive investigation was carried out on the deposition of longer and improved quality metal nanowires inside the pores using a new technique as well as the establishment of the experimental setup for characterization of the coatings. 


\section{RESEARCH ACCOMPLISHMENTS}

As reported previously, during Phases I \& II of the project, a significant problem was encountered with the synthesis of $\mathrm{Cr}$ nanowires inside the alumina pores, the uniformity of coverage was very poor. As a result, alternative metals to form nanowires were looked into and nickel was selected primarily due to its established electrochemical synthesis procedure.

A number of recipes were investigated for their suitability for synthesis inside nanoscale pores, and the process parameters were experimentally optimized for the synthesis of nanowires. The deposition of the Ni nanowire was performed in a two-electrode arrangement with a mixture of $\mathrm{NiSO}_{4}{ }_{6} \mathrm{H}_{2} \mathrm{O}, \mathrm{NiCl}_{2}{ }_{6} \mathrm{H}_{2} \mathrm{O}$ and $\mathrm{H}_{3} \mathrm{BO}_{3}$ as the source of Ni. The wires were deposited at a potential difference of $1 \mathrm{~V}$ between the anode and the cathode and at ambient temperatures. The Ni nanowire samples were characterized by Field Emission Scanning Electron Microscopy (SEM), which showed excellent uniformity and coverage. However, while Ni can provide very good structural integrity to the porous alumina, one potential problem is its higher dissolution rate in LBE.

In addition, it was noted that the heights of the Ni nanowires were limited, and even with extended deposition times, the heights were limited to a few tenths of a micron. This limited height was believed to be arising due to the dynamics of fluid flow inside the nanoporous alumina.

To address the above issues, two different approaches were taken, A systematic study was continued during the past year to improve the deposition uniformity of the $\mathrm{Cr}$ nanowires, and some improvement was achieved. The uniformity of coverage showed improvement and experimental optimization of process parameters was continued for further improvement of the coverage uniformity. In addition, a new and promising approach was initiated for the deposition of metal nanowires inside the nanoporous alumina as described below.

During the past year, a new technique was initiated and investigated for the deposition of metal nanowires inside the nanoporous alumina. This technique involves the electro-phoretic deposition of nanoparticles inside the pores followed by recrystallization into nanowires. The major advantage of this technique is that the chemistry of nanoparticle synthesis is separated from the formation of nanowires, as a result it has the potential to eliminate the limitations encountered in nanowire synthesis. Nanowire deposition inside the alumina pores is made challenging by the nanoscale fluid flow and chemical reactions inside the nanoscale volume of nanoporous alumina pores. In this new technique, nanoparticles of the desired metal are first synthesized by an es-

\section{ACADEMIC YEAR HIGHLIGHTS}

- B. Das, “Nonlithographic Nanoscale Devices,” International Conference on MEMS and Semiconductor Nanotechnology, Kharagpur, India, December, 2006 (invited paper).

tablished technique in an emulsion form, which are then incorporated inside the nanoporous alumina pores. Since nanoparticles are relatively less complex to incorporate inside pores, it provides an excellent means for the synthesis of nanowires of good uniformity and desired heights. The nanoparticles can be synthesized using an established technique such as sol gel technique. The nanoparticles can be then annealed to form the nanowires or sonication can be used during electro-phoretic incorporation to form the nanowires.

Deposition of $\mathrm{Cr}$ nanowires on steel substrates will be achieved by using the following procedure. A new batch of steel samples will be coated with metallic aluminum which will be anodized using constant current anodization. Since it is not possible to obtain cross-sectional images of the structures on steel samples, the voltage-time characteristics will be measured to monitor the quality of the anodized alumina structures. A typical voltage-time characteristic obtained during the anodization of aluminum on steel samples, when compared to data from silicon samples, confirms the good quality of the nanoporous alumina. Cr nanoparticles will be synthesized using the sol-gel technique and will be then electro-phoretically incorporated inside the nanoporous alumina. Sonication will be used during deposition to fuse the nanoparticles to form nanowires. A sonication apparatus was obtained for this purpose. This will be followed by the deposition of a thick film of dense alumina, the process technology for which has already been developed during the previous phase of the research.

\section{FUTURE WORK}

The next phase of the project is to characterize the samples fabricated using the new technique, including structural integrity of the coatings with $\mathrm{Cr}$ at elevated temperatures and under thermal cycling. The samples will then be characterized by SEM and also scratch tested to evaluate the structural integrity and adhesion properties of the coatings for thermal cycling at different temperatures. A programmable furnace had been acquired and a specialized sample holder fabricated to perform automated thermal cycling of the coatings developed on steel samples. However, the functions of the programmable furnace were delayed due to facility issues. To address this, a smaller furnace was acquired and installed for the characterization of the samples.

Research Staff

Biswajit Das, Principal Investigator, Professor of Electrical and Computer Engineering, Director of Nevada Nanotechnology Center

Arghya Banerjee, Post-Doctoral Researcher, Electrical and Computer Engineering

Nilanjan Halder, Post-Doctoral Researcher, Electrical and Computer Engineering

Kishire Sreenivasan, Post-Doctoral Researcher, Electrical and Computer Engineering

Students

Rani Krishna, Graduate Student, Electrical and Computer Engineering

Lillian Ratliff and Tan Wu, Undergraduate Students, Electrical and Computer Engineering

Stuart Maloy, AFCI Fuels \& Materials Project Leader, Los Alamos National Laboratory 


\section{Task 24 \\ Development of Integrated Process Simulation System Model for Spent Fuel Treatment Facility (SFTF) Design

\author{
Y. Chen and S. Hsieh
}

\section{BACKGROUND}

The UNLV Transmutation Research Program is developing technology for the transmutation of nuclear waste to address longterm disposal issues. Integrating and enhancing the Argonne Model for Universal Solvent Extraction (AMUSE) code that contains a great part of chemical separations processing, is the major part of a previous 3-year project. Simulating the Light Water Reactor (LWR) Spent Fuel Treatment Facility (SFTF) processes is the major focus for this three-year project. The approach is to combine commercial process simulation software, ASPEN-Plus, with the chemical separation calculation from the AMUSE code. Based on the current Integrated System Optimization Program, ISOPro, developed by UNLV, the project objective is to create a system framework that interacts with both programs and provides analyzed results useful for SFTF design that provides the functionality of receiving, temporarily storing, and preparing spent nuclear fuel for leaching.

The spent fuel treatment facility has many individual processes that make up the overall separations processes. As illustrated in the overall process flow sheet below, each block represents a unique process that carries out an individual chemical separation. Each individual process block contains numerous operations that are responsible for the chemical separation. By removing the primary constituent, $U$, from spent fuel enables more waste to be stored at geologic repositories. The Uranium Extraction Process (UREX) is often the first removal process in the overall scheme of spent fuel recycling. After extracting $U$ and Tc from the spent fuel, the washed and rinsed effluents (Cs/Sr raffinate) move on to the next separation process.

A key concept in the SFTF plant design is the recycling of nitric acid. The purpose of the nitric acid recycle system is to concentrate the spent nitric acid to a desired molarity that in turn can be recycled back into the process. The spent nitric acid streams from many processes are collected and sent to a distillation column where it is separated from the impurities collected in the various separation processes. The feed to the separation column contains acetic acid and water as well as the desired nitric acid.

\section{RESEARCH OBJECTIVES AND METHODS}

The major objectives described below will lead to a creation of framework that combines all the strengths of AMUSE's complicated calculations, well-established commercial system process package and ISOPro's flexible parameter optimization modules. Development of the process simulation code can be done using the solvent extraction process at Argonne National Laboratory in collaboration with the research team from Mechanical
Engineering Department at UNLV. The objectives of this project are:

- To develop a framework for simulating the Spent Fuel Treatment Facility process using the AMUSE code, ASPEN-Plus commercial process package and ISOPro system engineering model.

- To develop middleware interfaces that can communicate between the AMUSE code and ASPEN-Plus packages.

- To extend the existing system engineering model for the optimization process that includes process simulation results.

- To include a scenario-based database system that efficiently reports required information as chart output using web-based programming, and Microsoft Visual Basic (MS VB).

\section{RESEARCH ACCOMPLISHMENTS}

- Integrated the ASPEN-Plus process model with the ISOPro system engineering modeling package, developed by the UNLV team.

- Tested the simplified system process integration using the ISOPro package.

- Generated complete version of the ISOPro package user manual and tutorial.

- Made an interface to interact with ASPEN-Plus through the ISOPRO Package

To interact with both the AMUSE and ISOPro packages, the middleware interface based on the ISOPro should provide the capability of interacting with external programs, converting input and

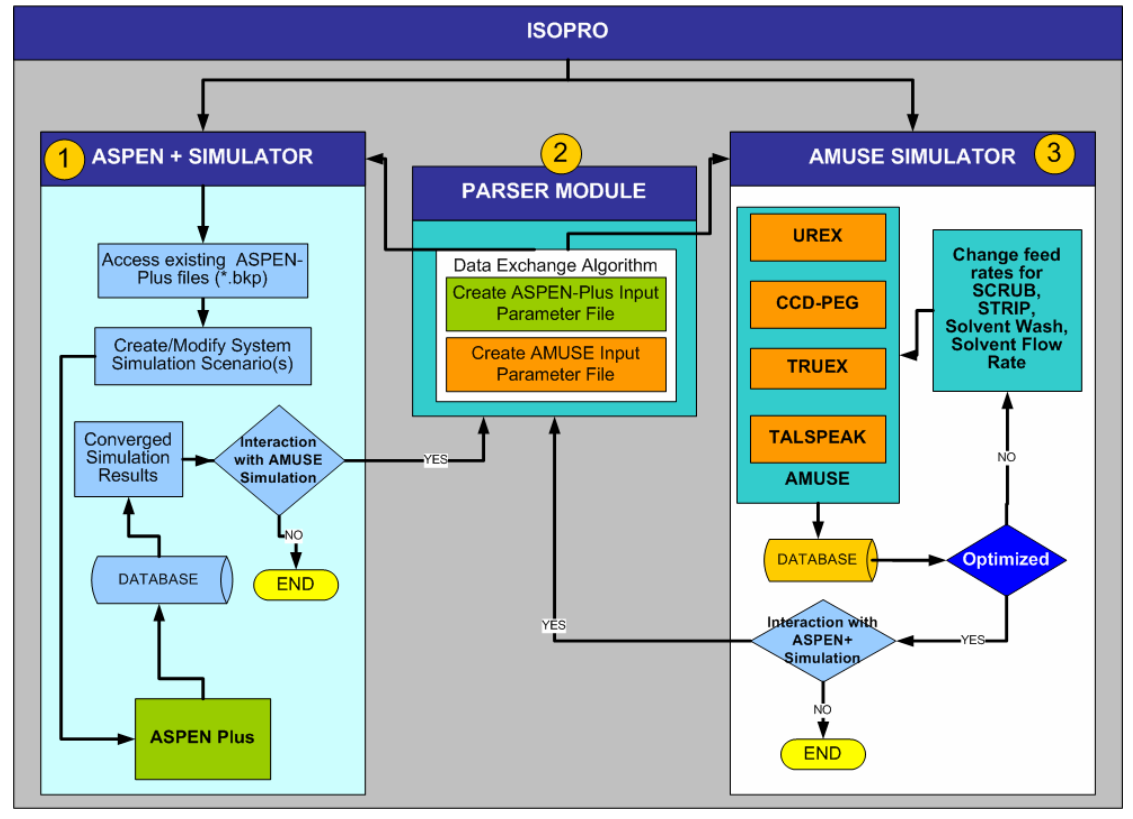

Modified TRPSEMPro system architecture 
output data and managing process results. The major task for the year was to complete the interface to the ASPEN-Plus program through the developed ISOPro package. The data communication and result presentation from these two programs are valuable for the SFTF's process design task. The internal MS Access database was developed for storing intermediate and final simulation results from both programs. However, input and output data files originally generated from each individual program are kept intact and are used to populate the initial data sheet within each middleware interface. Although the program integration was completed, the final SFTF's system optimization work is not included in this report due the export control nature of the AMUSE code. The optimization can be completed by the ANL research team by plugging the full AMUSE program into the ISOPro package. The accomplishments for the year are summarized as follows:

- The framework design was revised to improve the performance of the system. It defines the data flow from ASPEN-plus to AMUSE with the data set "parser module" in the middle. Based on the discussion with ANL staff, the UREX+1a process simulation flow chart was updated based on the input and output natures defined in the database storage.

- The middleware for the ASPEN-Plus interacts with the ASPEN-Plus and populates data into a user friendly, tabulated format. It displays the information from streams and its elements. The user can modify the input values and directly run the simulation through the interface. There are sets of standard menu items listed to provide faster access. A "Tree"

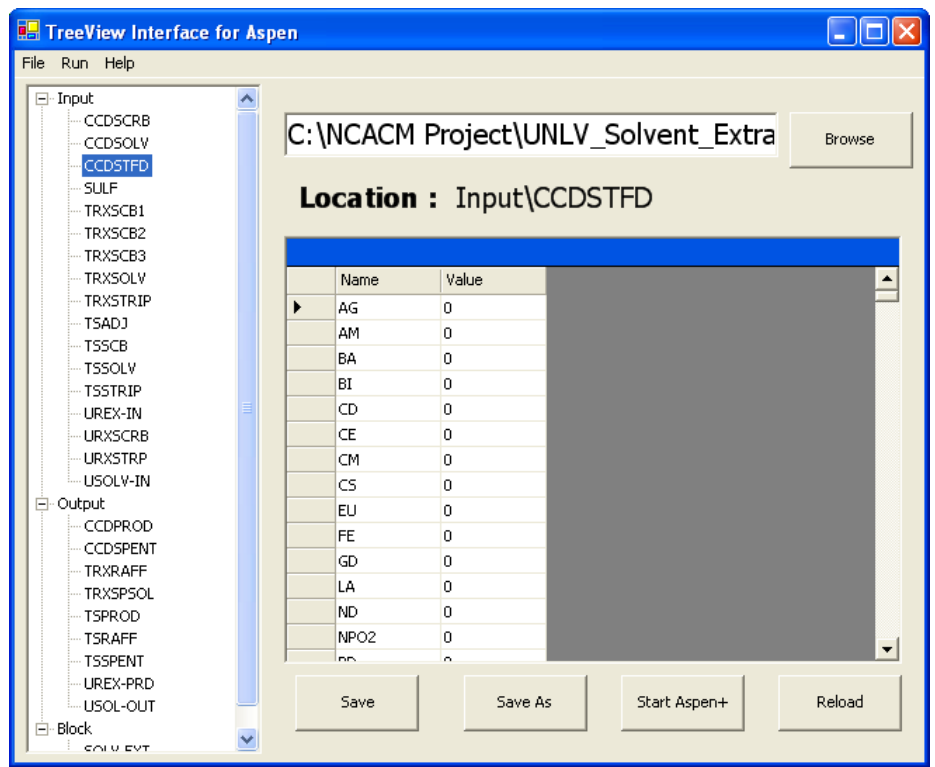

\section{ACADEMIC YEAR HIGHLIGHTS}

- M. Cheng, M. Hodges, K. Kwan, H.T. Hsieh, and Y. Chen (UNLV); G. Vandegrift, J. Copple and J. Laidler (ANL), “An Object-oriented Systems Engineering Modeling Design for Integrating Spent Fuel Treatment Facility and Chemical Separation Processes," 2006 ASME International Mechanical Engineering Congress, Chicago, IL, November 5-10, 2006.

view of the streams is organized into "Input" and "Output" based on the "Blocks" definition retrieved from the Aspen "bkp" file. After each simulation run from the ASPEN-plus, input/output information is updated into the interface. The selected programming algorithm can significantly impact the $\mathrm{read} /$ write efficiency of the code, especially loading a large and complicated "bkp" file. A "nested hash" programming technique was used. To accelerate data access, ASPEN-Plus information was stored in two hashes, one for Input streams and one for Output streams.

\section{FUTURE WORK}

Future work will include optimization of the system and chemical separation processes using the ISOPro system engineering modeling package developed by the UNLV team.

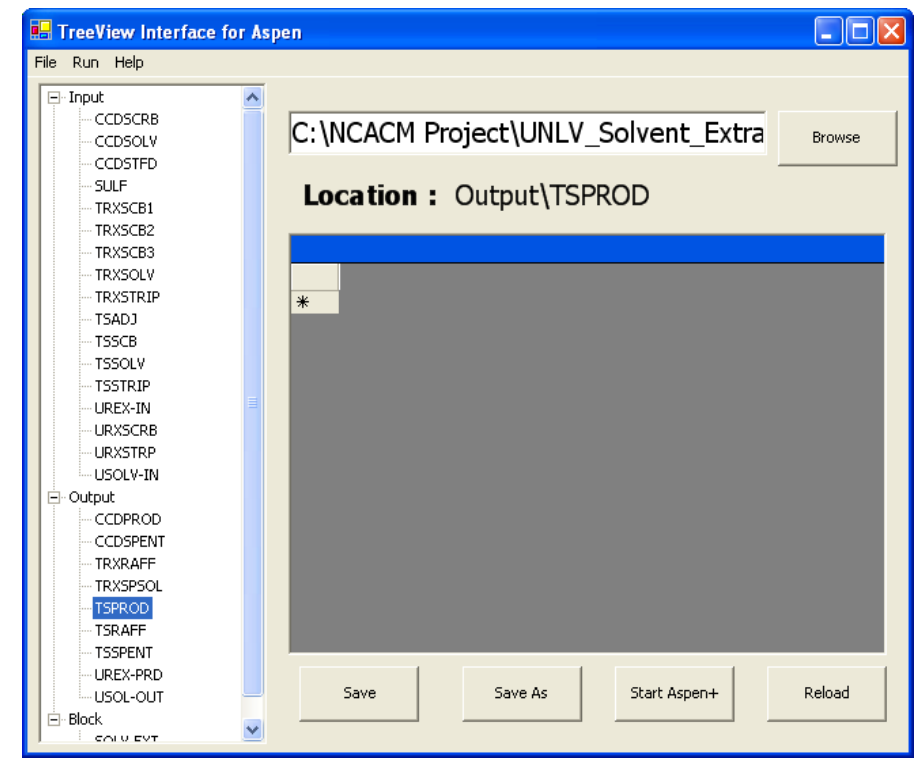

Screenshots of the newly updated ISOPRO interface to the ASPEN-Plus; (left) input stream; (right) output stream

Research Staff

Yitung Chen, Principal Investigator; Associate Professor, Mechanical Engineering Department; Associate Director, NCACM

Sean Hsieh, Research Assistant Professor, Mechanical Engineering Department; Nevada Center for Advanced Computational Methods

Students

Matthew Hodges, Graduate Student, Mechanical Engineering Department

Ming Chang, Roulong Li and Ling Kwan, Graduate Students, Computer Science Department 


\section{D.W. Hatchett and K. Czerwinski}

\section{BACKGROUND}

In the Transmutation Research Program the separation of the trivalent actinides $\mathrm{Am}$ and $\mathrm{Cm}$ from the trivalent lanthanides, and even each other, has been identified as an area of particular interest. The removal of lanthanides from trivalent actinides is necessitated for the neutron economy of a fuel containing Am and Cm. Furthermore, a fuel containing only Am would ease the demands on a reactor for transmutation. The destruction rate of $\mathrm{Cm}$ isotopes in a reactor is comparable to their decay rate. Separation and storage of the $\mathrm{Cm}$, and reintroduction into the fuel of the $\mathrm{Pu}$ daughters, is a transmutation option that can be explored if a suitable method for the separation of $\mathrm{Cm}$ from Am is obtained. Furthermore, removal of Cm would reduce difficulties in fuel fabrication.

Electrochemical methods can be used to effectively separate actinide and lanthanide species from complex mixtures. This is based on the unique electrochemical properties of each specific target species. In studies it has been found that with the exception of $\mathrm{Ce}$, aqueous solutions provide unsuitable electrochemical windows to effectively evaluate the thermodynamic properties that are useful for chemical separation. Therefore a more novel approach was examined which eliminated the aqueous solution with a Room Temperature Ionic Liquid (TRIL) solution. RTIL solutions do not suffer from the side reactions that are prominent in aqueous environments. In addition the potential window is much larger for the RTIL solutions. The RTIL solutions are a new starting point for the electrochemical separation of individual species from a mixture.

\section{RESEARCH OBJECTIVES AND METHODS}

The objectives of this project are to use electrochemical tech-

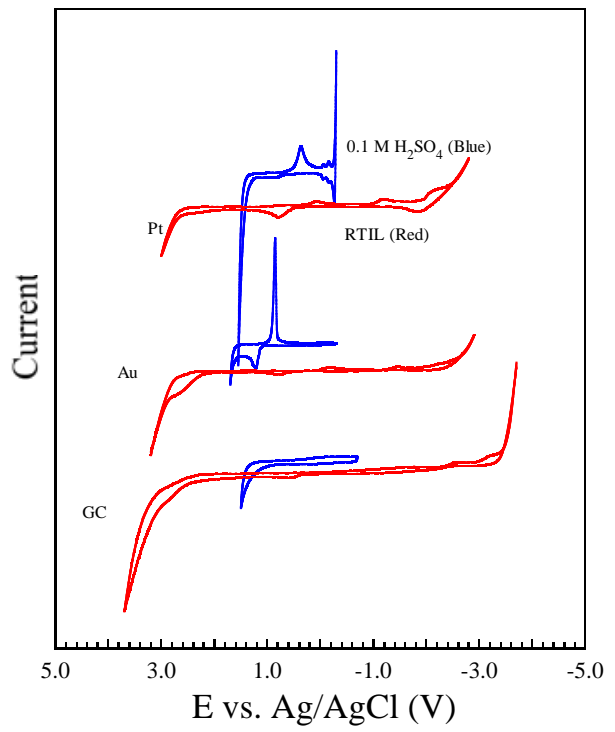

Electrochemistry of GC, $A u$, and Pt electrodes in TRIL ([MeBu3N][NTf2]), (Red) and 0.1 M H2SO4, (Blue).

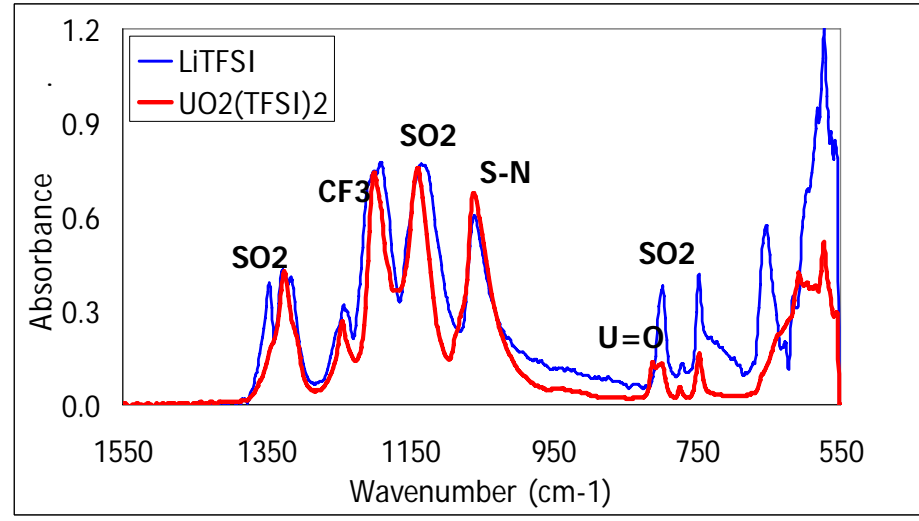

The IR spectra show the typical RTIL anion Li(TFSI) (blue), and $\mathrm{UO}_{2}$ complexed to TFSI (red). The shift of the $\mathrm{SO}_{2}$ peak at $1350 \mathrm{~cm}^{-1}$ indicates TFSI complexation, and the peak around $810 \mathrm{~cm}^{-1}$ indicates the presence of a $U=O$ bond.

niques to develop a thermodynamic understanding of actinide and lanthanide species in RTIL solution, and to use this data to effectively separate species with very similar chemical properties. In consultation with a DOE collaborator, electrochemical methods and materials will be evaluated and used to exploit the thermodynamic differences between similar chemical species, enhancing the ability to selectively target and sequester individual species from mixtures. This project is in its third year and has successfully completed phases 1 and 2 . Phase 3 has been partially completed. The tasks have been expanded to include a fourth phase.

Phase 1

Evaluate thermodynamic oxidation/reduction properties of $\mathrm{Ce}$ using electrochemical methods.

\section{Phase 2}

Evaluate the thermodynamic properties of chelated Ce, Sm, and $\mathrm{Eu}$ at carbon, platinum and gold electrodes.

\section{Phase 3}

Examine the use of conductive polymer membranes for the uptake and expulsion of complexed and uncomplexed actinide and lanthanide species.

This phase still needs to examine the uptake, selective adsorption and separation of individual actinide and lanthanide species, including the isolation of $\mathrm{Cm}$ from Am, using conductive polymer/ metal composite membranes containing bound chelates.

\section{Phase 4}

Prepare and characterize RTIL solutions. Examine the electrochemical window and evaluate the electrochemical properties of lanthanide and actinide species in the non-aqueous ionic environment.

The following were specific goals for this year:

- To prepare RTIL solutions. 


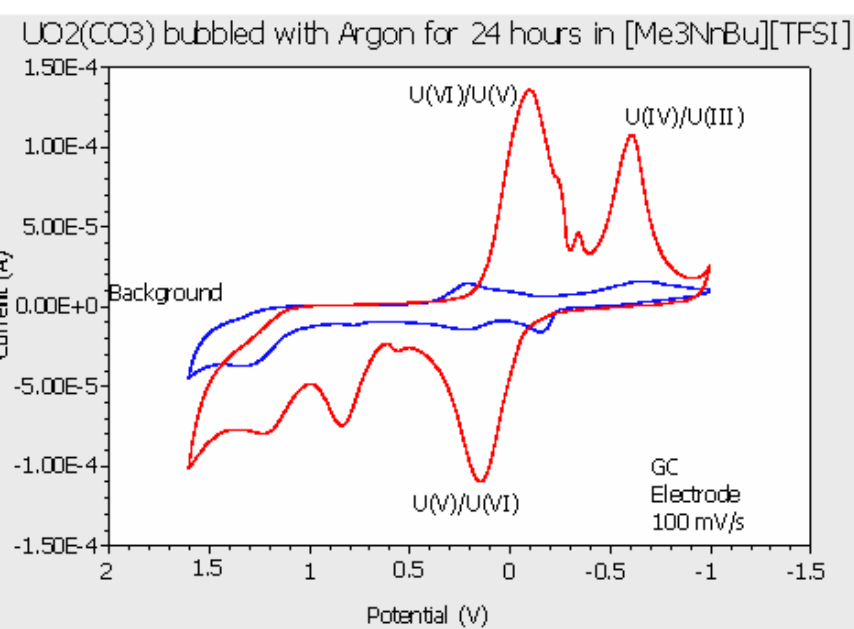

$\mathrm{CV}$ of $\mathrm{UO}_{2}$-TFSI complex formed by added $\mathrm{UO}_{2}\left(\mathrm{CO}_{3}\right)$ directly to the RTIL and using Argon to remove the carbonate from the system.

- To evaluate the potential window of RTIL solutions.

- To develop a fundamental understanding of the thermodynamic properties of actinide and lanthanide species (such as $\mathrm{Cm}, \mathrm{Am}, \mathrm{Ce}, \mathrm{Nd}, \mathrm{Eu}$, and Sm) in RTIL solutions.

\section{RESEARCH ACCOMPLISHMENTS}

The electrochemical window for RTIL systems is based primarily on the reduction of the cation and oxidation of the anion used to make the solution. The potential window is significantly larger for RTILs ranging from approximately 4.5 to $6 \mathrm{~V}$ when compared to aqueous environments. The figure to the left illustrates the potential windows obtained in aqueous solutions of $0.1 \mathrm{M} \mathrm{H}_{2} \mathrm{SO}_{4}$ (blue line) and the RTIL, tri-n-butylmethylammonium bis (trifluoromethylsulfonyl)imide ([ $\left.\mathrm{MeBu}_{3} \mathrm{~N}\right]\left[\mathrm{NTf}_{2}\right]$, red line) at GC, $\mathrm{Au}$, and Pt electrodes. For each electrode the positive and negative potential limits provide an absolute potential window of approximately $4.5 \mathrm{~V}$ for $\mathrm{Pt}, 5.0 \mathrm{~V}$ for $\mathrm{Au}$, and $6.0 \mathrm{~V}$ for GC.

The advantage to eliminating aqueous side reactions and expanding the potential window is that previously inaccessible electrochemical reactions may be observed. These systems provide a huge potential window for the observation of oxidation and reduction of lanthanides and actinides. In addition, the potential mediated deposition of f-elements is possible - indicating that the controlled separation of chemical species is thermodynamically feasible. For example, the reduction of $\mathrm{Pu}^{3+}, \mathrm{Am}^{2+}, \mathrm{Am}^{3+}, \mathrm{Cm}^{3+}$, and $\mathrm{U}^{3+}$ all occur before $\mathrm{E}=-1.90 \mathrm{~V}$ vs. $\mathrm{Ag} / \mathrm{AgCl}$, well within the negative potential limit for the RTIL at platinum $(-2.6 \mathrm{~V}$ vs. Ag/ $\mathrm{AgCl})$, gold (-2.2 V vs. Ag/AgCl), and glassy carbon electrode ($3.4 \mathrm{~V}$ vs. $\mathrm{Ag} / \mathrm{AgCl}$ ) in the RTIL solutions shown in the before mentioned figure. The preliminary electrochemical characteriza-

\section{ACADEMIC YEAR HIGHLIGHTS}

- Sandra Elkouz, M.S. thesis, UNLV Chemistry Department, "Complexation and Electrode Effects on the Electrochemical Behavior of the Cerium(IV)/Cerium(III) Redox Couple,” April 2007.

- S. Elkouz, P. Houlihan, K. Czerwinski, and D.W. Hatchett, "The influence of electrode composition, $\mathrm{pH}$, and ionic strength on the redox properties of Ce(IV)/Ce(III)," Submitted to Electrochimica Acta, April 2007 (Ms. Ref. No.: EA-S-07-00835).

tion of Eu in RTIL is shown in the figure below.

Through using IR and UV-Vis spectra, it was observed that the uranyl did complex to the anion of the RTIL. However, a more interesting way to complex the uranyl to the RTIL is by adding uranyl carbonate directly to the RTIL and then using Argon gas to remove the carbonate. The results yielded a soluble $\mathrm{UO}_{2}$-bis (trifluoromethylsulfonyl)amide (TFSI) complex that produced reversible electrochemical reactions with Uranium including the $\mathrm{U}(\mathrm{VI}) / \mathrm{U}(\mathrm{V})$ couple. The Cyclic Voltammogram (CV) also yielded the $\mathrm{U}(\mathrm{IV}) / \mathrm{U}(\mathrm{III})$ couple. This method could prove to be very useful in observing the electrochemistry of any metalcarbonate species.

\section{FUTURE WORK}

Future work will focus on the development of RTIL solutions suitable for the potential mediated oxidation/reduction and deposition of lanthanide and actinide species. The ultimate goal is to separate individual species using the electrochemical potential of species.

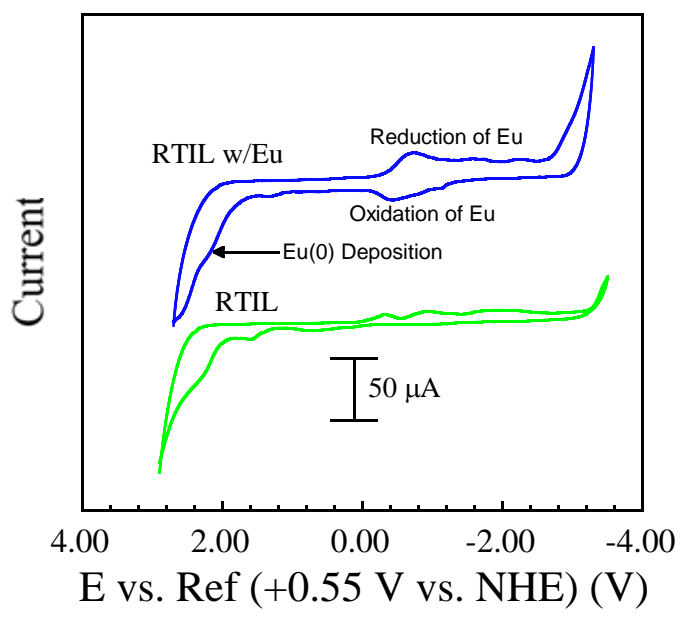

Electrochemistry of Eu at a Pt electrode in RTIL $\left(\left[\mathrm{MeBu}_{3} \mathrm{~N}\right]\right.$ $\left.\left[\mathrm{NTf}_{2}\right]\right)$

Research Staff

David W. Hatchett, Principal Investigator, Assistant Professor, Department of Chemistry

Ken Czerwinski, Associate Professor, Department of Chemistry

Students

Sandra Elkouz and Wendy Pemberton, Graduate Students, Department of Chemistry

Collaborators

George F. Vandegrift, Associate Division Director for Nuclear Fuel Cycle Programs, Chemical Engineering Division, Argonne National Laboratory 


\section{Fundamental Chemistry of $U$ and Pu in the TBP-Dodecane-Nitric Acid System}

\section{K. Czerwinski}

\section{BACKGROUND}

The extraction of tetravalent $\mathrm{Pu}$ and hexavalent uranyl in nitric acid solution by tributylphosphate (TBP), based on the formation of organic phase neutral complexes such as $\mathrm{Pu}\left(\mathrm{NO}_{3}\right)_{4} \cdot 2 \mathrm{TBP}$ and $\mathrm{UO}_{2}\left(\mathrm{NO}_{3}\right)_{2} \cdot 2 \mathrm{TBP}$, has been the foundation of actinide purification for a number of decades. Upon reduction of $\mathrm{Pu}(\mathrm{IV}), \mathrm{Pu}(\mathrm{III})$ is back extracted into an aqueous phase. However, the data needed for detailed modeling of Pu extraction is not available for all conditions of concern to the Advanced Fuel Cycle Initiative (AFCI). This proposal was developed with Dr. George Vandegrift of Argonne National Laboratory to obtain the necessary data for $\mathrm{Pu}$ extraction modeling.

Understanding the role of nitrate in actinide speciation is important for determining the necessary data for extraction modeling. Difficulties in modeling Pu extraction under some nitrate conditions may be due to ill-defined constants of formation for the dinitrate and trinitrate species of $\mathrm{U}$ and Pu. The influence of pertechnetate on the speciation of $\mathrm{U}$ and $\mathrm{Pu}$ in the TBP-dodecane-nitric acid system is still poorly understood. Since pertechnetate is capable of reoxidizing reduced Pu species, it may have a profound impact on the extraction of $\mathrm{Pu}$.

In the uranium extraction process, acetohydroxamic acid (AHA) is expected to be used. AHA can complex and reduce $\mathrm{Pu}$, decreasing its extraction into the organic phase; the effect of uranyl-

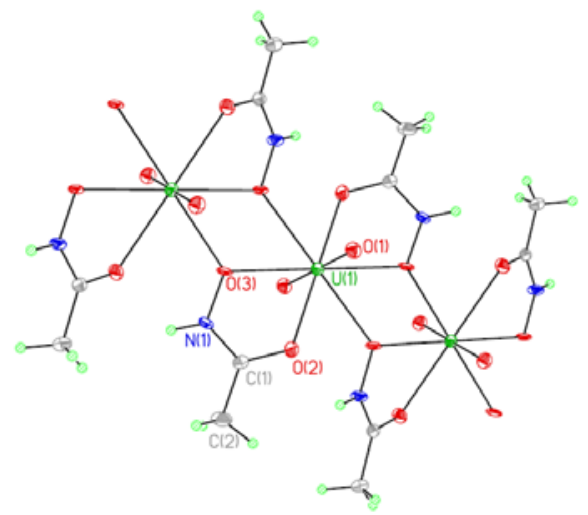

Crystal Structure of Uranyl-AHA

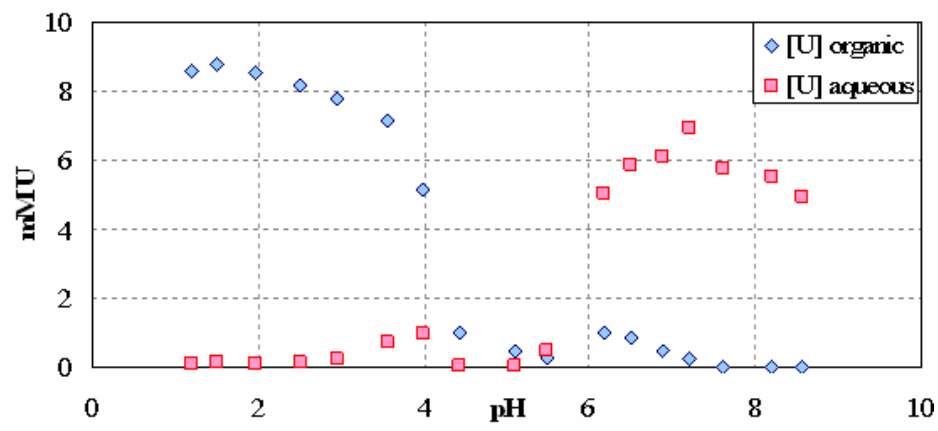

The measured concentrations in the organic and aqueous phases of $10 \mathrm{mM}$ uranyl, $100 \mathrm{mM}$ AHA extracted with TBP.

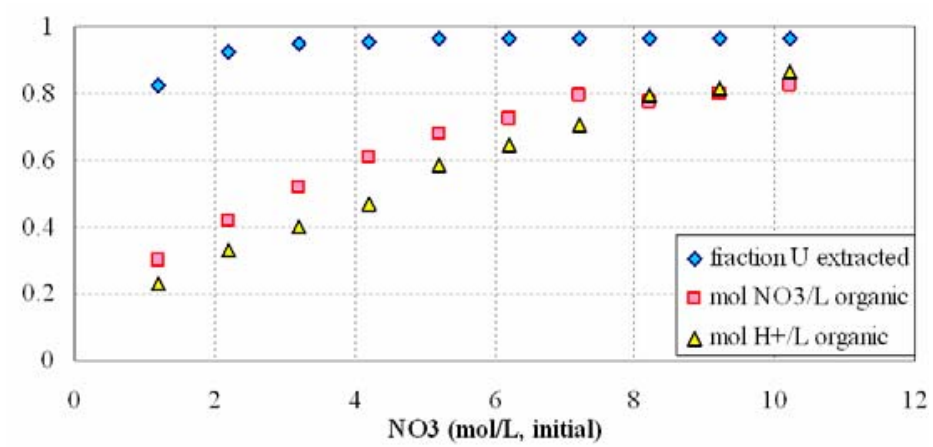

The measured concentrations of uranyl, nitrate, and acid in the organic phase extracted from $0.02 \mathrm{M} \mathrm{U}, 1.0 \mathrm{M} \mathrm{HNO}_{3}$, and varied initial nitrate.

AHA on U extraction has not been quantified. AHA can reduce pertechnetate as well, initiating a redox cycle with both $\mathrm{U}$ and $\mathrm{Pu}$. In a solvent extraction system using AHA, it is necessary to determine the complexation kinetics, redox reactions, and thermodynamics of AHA interactions with these elements.

\section{RESEARCH OBJECTIVES AND METHODS}

The research objective is to experimentally evaluate the fundamental speciation of $\mathrm{Pu}$ and $\mathrm{U}$ in the TBP-dodecane-nitric acidAHA system and the effect of pertechnetate, specifically:

- To determine the influence of nitrate on the speciation of $U$ and $\mathrm{Pu}$ in the TBP-dodecane-nitric acid system. The aqueous and organic speciation of $\mathrm{U}$ and $\mathrm{Pu}$ are examined as a function of the nitric acid concentration, nitrate concentration, actinide ion concentration, temperature, and time.

- To determine the speciation of $U$ and Pu with AHA in the presence and absence of TBP-dodecane organic phase. The aqueous and organic speciation of $\mathrm{U}$ and $\mathrm{Pu}$ are evaluated as a function of AHA concentration, metal ion concentration, metal ion redox state, $\mathrm{pH}$, and temperature.

- To determine the interaction of AHA with pertechnetate, and the effect on the interaction of AHA and pertechnetate with $\mathrm{U}$ and Pu.

- To incorporate thermodynamic and kinetic data into existing modeling codes.

All of the initial experiments were performed with uranyl, $\mathrm{UO}_{2}{ }^{2+}$. The results obtained from $U$ are the basis for further experiments with $\mathrm{Pu}$. In extraction experiments, the aqueous and organic phases are contacted in equal volumes from 0.3 to $5.0 \mathrm{~mL}$.

\section{RESEARCH ACCOMPLISHMENTS}

Uranyl Nitrate. The complexation of uranyl $(0.01$ to $0.1 \mathrm{M})$ with nitrate was studied at $1 \mathrm{M} \mathrm{HNO}_{3}$ with excess nitrate (from Li$\mathrm{NO}_{3}$ ) varied from 0 to $10 \mathrm{M}$. It was found that at higher nitrate 
concentrations, more uranyl was present in the organic phase, and, in the absence of uranyl, more $\mathrm{HNO}_{3}$ extracted.

Uranyl-AHA. The complexation of uranyl with AHA and its effect on U extraction into TBP-dodecane was studied via ultraviolet-visible spectroscopy (UV-vis), nuclear magnetic resonance (NMR), and Inductively Coupled Plasma-Atomic Emission Spectroscopy in perchlorate and nitrate media. The concentrations of uranyl (0.1 to $10 \mathrm{mM}$ ) and AHA (1 to $700 \mathrm{mM}$ ) and the $\mathrm{pH}$ (1 to 10) were systematically varied. It was determined via NMR that there are at least two species of uranyl-AHA, that the species formed is $\mathrm{pH}$-dependent, and that there is little hydrolysis at 25 times or higher molar excess AHA. The low-pH species extracts from perchlorate media as well as free uranyl, and the high-pH species remains in aqueous solution. In nitrate media, the nitrate competes with and oxidizes the AHA under acidic conditions; the exact interactions remain to be explored.

In addition, methods for synthesis of the uranyl-AHA solid were developed; the solid was characterized by UV-vis, Fourier Transform Infrared spectroscopy, NMR, laser fluorescence, melting point, and X-ray Absorption Fine-structure Spectroscopy (XAFS), and a crystal structure was obtained. The uranyl-AHA is present as a highly symmetrical polymer, in which each equatorial atom is exactly $180^{\circ}$ from its opposite and the ligand planes are twisted within and between unit cells.

Technetium-AHA. Previous work failed to observe pertechnetate reduction by AHA; however, in the presence of catalytic acid (0.5 to $4 \mathrm{M} \mathrm{HNO}_{3}$ or $\mathrm{HClO}_{4}$ ) and a large excess of AHA (0.5 to $\left.4 \mathrm{M}\right)$, pertechnetate ( 0.1 to $20 \mathrm{mM})$ will be reduced to the $\mathrm{Tc}^{\mathrm{II}} \mathrm{NO}$ (AHA $)_{2}$ species in aqueous media. This species is highly water soluble and does not extract into 30\% TBP. The presence of uranyl has no effect on the formation or extraction of this species, and up to hundredfold excess $\mathrm{UO}_{2}{ }^{2+}$ does not affect the rate of formation. There is significant evidence that the reaction is in-

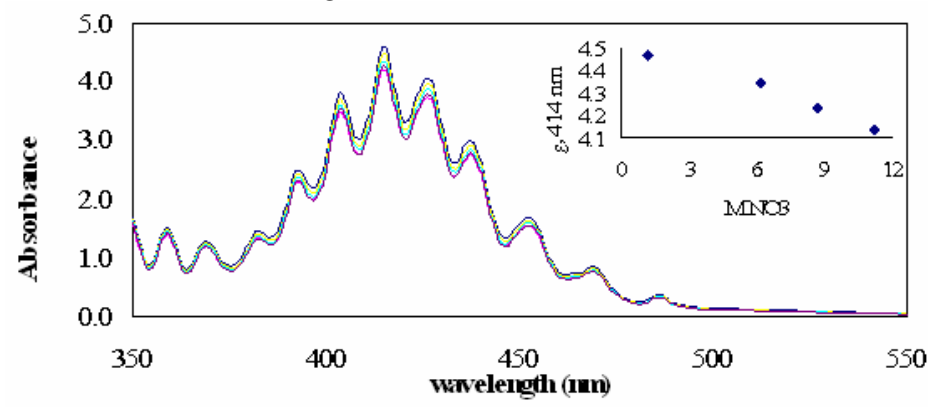

$-1.2 \mathrm{MNO}-3.7 \mathrm{MNO} 3-6.2 \mathrm{MNO} 3-8.7 \mathrm{MNO} 3-11.2 \mathrm{MNO} 3$

The UV-vis spectrum of uranyl nitrate in $30 \%$ TBP varies with nitrate concentration.

\section{ACADEMIC YEAR HIGHLIGHTS}

- C. Gong, F. Poineau, and K. Czerwinski, "Synthesis and characterization of the solid uranium(VI) dioxo-diacetohydroxamate complex,” Radiochim. Acta 95(8), 439-450 (2007).

- A. Wright and K. Czerwinski, "Nitrate effects on uranium and plutonium extractions," 233rd ACS National Meeting, Chicago, IL, March 2007.

- C. Gong, F. Poineau, and K. Czerwinski, "Synthesis and characterization of the solid uranyl-acetohydroxamic acid complex," 233rd ACS National Meeting, Chicago, IL, March 2007.

- K. Czerwinski, A. Wright, N. Smith, L. Wright, and G. Cerefice, "Fundamental Chemistry of Uranium in Extraction for use in Enhanced Separations and Proliferation Resistance," MRS Scientific Basis for Nuclear Waste Management XXX, Boston, MA, November-December 2006.

- A. Wright, N. Smith, F. Poineau, and K. Czerwinski, "Nitrate effects on uranium and plutonium extractions in the tributylphophate-dodecane system," 232nd ACS National Meeting, San Francisco, CA, September 2006

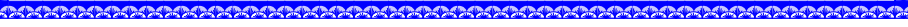

stantaneous and the change in the Tc-AHA UV-vis spectrum is due to the increasing $\mathrm{pH}$ as AHA hydrolyzes to acetic acid. However, the mechanism of formation is yet to be elucidated.

\section{FUTURE WORK}

The stability constants of the higher nitrado species of uranyl have yet to be determined; preliminary UV-vis and laser fluorescence studies have been performed. The stability constant of the uranyl-AHA species is also unknown; UV-vis and NMR studies are underway. The mechanism of Tc-AHA formation and its effect on Pu redox and extraction will be explored.

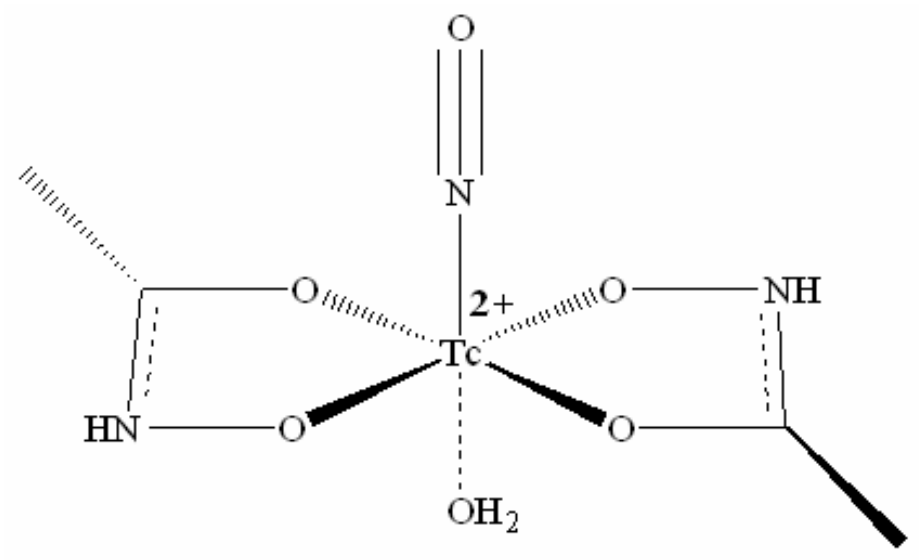

XAFS Structure of Technetium(II)-nitrosyl-AHA.

Research Staff

Ken Czerwinski, Principal Investigator, Associate Professor, Department of Chemistry

Cynthia Gong and Frederic Poineau, Post-Doctoral Researchers, Harry Reid Center

\section{Students}

Amber Wright, Wendy Pemberton, and Jeanette Daniels, Graduate Students, Department of Chemistry (Radiochemistry Ph.D. Program) Jeremy Maute and Trent Ohman, Undergraduate Students, Department of Chemistry

\section{Collaborators}

George Vandegrift, Argonne National Laboratory

Thomas Albrecht-Schmitt, Auburn University 


\section{Task 27 \\ Reactor Physics Studies for the AFCl \\ Reactor-Accelerator Coupling Experiments (RACE) Project \\ D. Beller}

\section{BACKGROUND}

In the RACE Project of the U.S. Advanced Fuel Cycle Initiative (AFCI), a series of accelerator-driven subcritical systems (ADSS) experiments have been conducted at the Idaho State University's Idaho Accelerator Center (ISU-IAC) and at the University of Texas (UT) at Austin. In these experiments, electron accelerators are used to induce Bremsstrahlung photon-neutron reactions in heavy-metal targets. They produce a neutron source of 0.8 to 1.0 $x 10^{12} \mathrm{n} / \mathrm{s}$ per $\mathrm{kW}$ of electron beam, which will then initiate fission reactions in the subcritical systems. These subcritical systems include a compact, transportable assembly at ISU and a TRIGA reactor at UT-Austin. A variety of fuel and assembly geometries are being studied: at ISU 150 flat plates of $20 \%$-enriched uranium-aluminum alloy plated with aluminum are used; and at UT-Austin $20 \%$-enriched UZr-H fuel are used. A third phase at Texas A\&M using 70\%-enriched UZr-H "FLIP" fuel has been put on hold. The use of compact accelerators and a small target allow the target to be placed in various positions in or adjacent to these subcritical assemblies to "map" the coupling of driven neutron sources; measuring core coupling and mapping adjoint flux.

The RACE Project is an important intermediate step between the recent European program MUSE and a future near full-scale demo. For MUSE, which was conducted by the CEA at Cadarache, France, the driving neutron source was produced by D-D or D-T reactions which produced a nearly mono-energetic source of 2.45 or $14.1 \mathrm{MeV}$ and a maximum strength of $\sim 10^{10} \mathrm{n} / \mathrm{s}$. For design of full scale ADSS, a complete knowledge of the effects of the driving neutron source is essential. This will ultimately require spectral, temporal, directional, and intensity fidelity in prototype experiments. In the absence of this fidelity, simulated sources should match some of the characteristics of projected driving sources to build confidence in the predicting performance of these systems, and codes and methods must be validated. The RACE Project will provide experience in a higher energy range (above $14.1 \mathrm{MeV}$ ) and with a stronger and more isotropic source than the MUSE experiments. In addition, a high-power RACE phase could provide valuable information on thermal feedback effects in TRIGA reactors. This combination of attributes of the RACE Project will provide highly valuable information in advance of the prototype or demonstration programs.

\section{RESEARCH OBJECTIVES AND METHODS}

The specific research objective of this three-year project is to design and conduct accelerator driven experiments, which will help demonstrate in the U.S. the ability to design, compute, and conduct ADSS experiments and to predict and measure source importance, coupling efficiency, sub-critical reactor kinetics and source-driven transients. In addition, databases will be created for both steady state and transient ADSS experiments for the nuclear community to develop and test new computational codes and methods, and the importance of a driving neutron source in various regions of different subcritical assemblies will be mapped. Experiments will be conducted and compared to calculations with radiation transport and thermal-hydraulics codes such as MCNPX and RELAP.

\section{RESEARCH ACCOMPLISHMENTS}

ISU RACE Experiments: UNLV collaborated with ISU and CEA in a series of ADSS experiments at the Idaho Accelerator Center. This series of ADSS experiments was conducted with a lowpower, $20-\mathrm{MeV}$ electron accelerator coupled to the Subcritical Assembly (SCA) with a tungsten-copper neutron generating target. Dozens of individual experiments were conducted to measure a variety of parameters and ADSS responses, including breakpoint frequency, flux stability, a long-duration reference pulsedneutron-source experiment, a beam trip experiment, and a variable criticality experiment, which was conducted by observing the neutron response while water was drained from the SCA. The last series of these experiments were completed in October, 2006.

Since the conclusion of the ISU RACE Project experiments, results were compared from ISU RACE experiments conducted at ISU in October with Monte Carlo radiation transport modeling to analyze effective delayed neutron fraction $\left(\beta_{\text {eff }}\right)$ in these far-

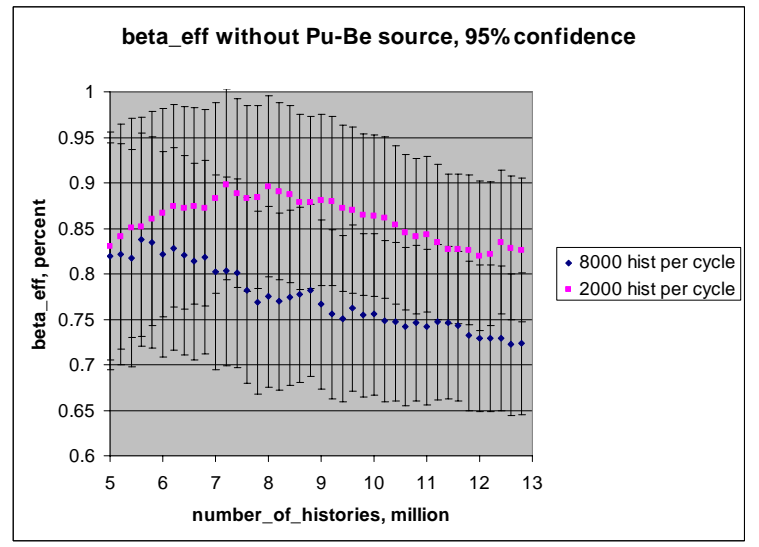

Calculated effective delayed neutron fraction for a subcritical (left side) versus a critical (right side); without a PuBe source.

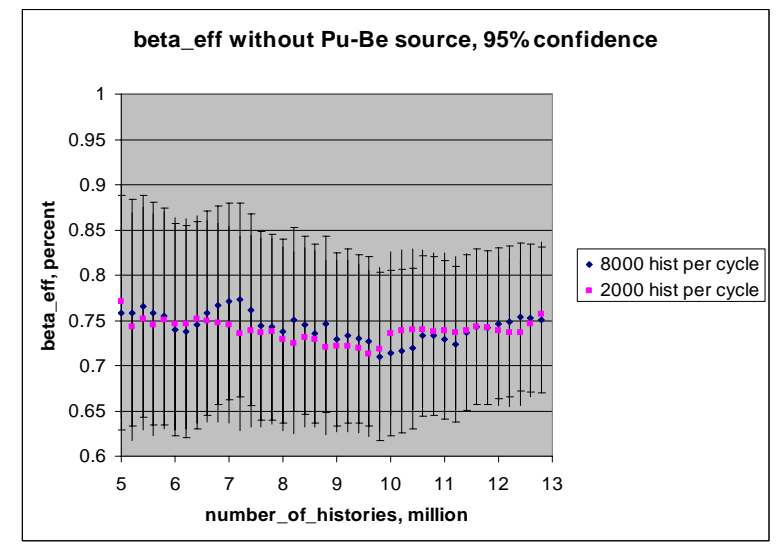




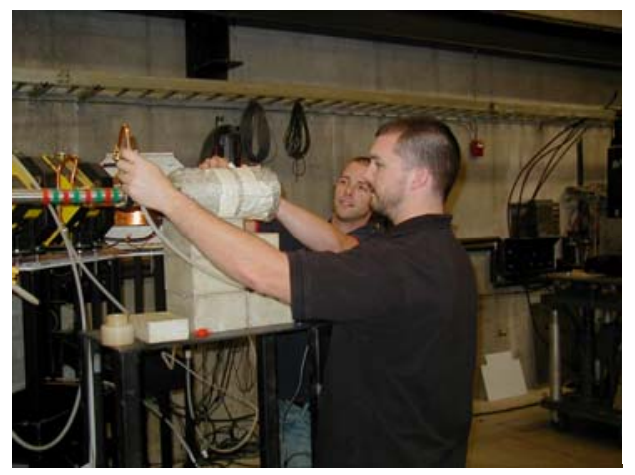

UNLV graduate students Timothy Beller and Ryan LeCounte couple the UNLV High-Power RACE Target to a linear electron accelerator at the Idaho Accelerator Center.

subcritical, under-moderated systems using MCNP. The simplest approach based on $2 \mathrm{k}$-eigenvalue predictions with and without accounting for delayed neutrons gave unsatisfactory results due to the lack of convergence. Calculations have been completed with and without a plutonium-beryllium neutron source, which, although it was small, did affect the results. Two more-suitable techniques based on different weighting functions are currently under investigation.

The statistical behavior of calculated effective delayed neutron fraction based on two independent calculations (with and without delayed neutrons) for a critical system was more stable than for the subcritical case. Again, calculations have been completed with and without a plutonium-beryllium neutron source. Two moresuitable techniques based on different weighting functions are currently under investigation. The importance function is being used as an approximation of an adjoint weighting of the spaceand velocity-dependent neutron population to calculate the effective neutron lifetime. Use of the value of a particle leaving a collision is being compared to that of a particle entering an event. Another computational approach that is based on a power iterations method (KCODE) to directly assess the efficiency of delayed neutrons is under development. The shape function for the steadystate problem, which will be used as a weighting function, was calculated and the relative efficiency of neutrons causing fission was determined.

High-power Target Design: The High-power RACE Target was transported to ISU's IAC in August 2006 for further tests to measure neutron generation and heat transfer while coupled to an electron linac. An accelerator-driven neutron production experiment was conducted and temperatures were recorded at several points. Since completing the experiments, experimental results are being evaluated. The Target is being modeled using Gambit and the CFD code FLUENT for comparison with experiments. During this reporting period, the potential complexity of the CFD modeling was upgraded with a parallel processing system. Refinement was continued of the MCNPX transport model to reduce statistical uncertainty and to perform parametric studies to study

\section{ACADEMIC YEAR HIGHLIGHTS}

- C.O. Maidana, A.W. Hunt, D. Beller, and K. Folkman, "Design, Modeling and Simulations in the RACE Project: First Study for the Development of a Transport Line," Nuclear Instruments and Methods-A, 562, 2, pp. 892-895 (2006).

- D. Beller, F. Harmon, E. Stankovskiy, T. Ward, and F. Goldner, "Reactor Accelerator Coupling Experiments (RACE) Project," poster, International Conference on Research Reactors in the 21st Century (RR-XXI), Moscow, Russia, June 20-23, 2006.

- D. Beller, "Update on the Reactor-Accelerator Coupling Experiments (RACE) Project;" T. Beller, R. LeCounte, and D. Beller, "Analysis of Neutron Production in the High-Powered RACE Target;" and, R. LeCounte, T. Beller, and D. Beller, "Thermal Analysis of Neutron Production in the High-Powered RACE Target," Winter Meeting of the ANS, Albuquerque, NM, November 12-16, 2006.

- E. Stankovskiy, "The Experimental Results and Computational Analysis of the RACE-ISU," American Nuclear Society Student Conference, Corvallis, OR, March 29-31, 2007.

impacts of accelerator performance and characteristics, such as beam spread in energy or position.

RACE Project Management: In his role as national RACE Project Director, the PI began to conclude the RACE Project with several universities and several European organizations. These organizations have contributed to several aspects of the RACE Project, including target design and analysis for High-Power RACE. Contracts supporting RACE Project work at the University of Michigan, Texas A\&M University, and University of Texas at Austin ended during the summer, the Idaho participation was terminated in December, and the UNLV portion of the RACE Project will end summer 2007. EUROTRANS participants may continue to evaluate experimental data.

UNLV hosted, and students and faculty attended, an Advanced MCNPX Workshop at UNLV. As a result, the group was able to greatly improve statistical results of calculations of electronphoton-neutron transport.

\section{FUTURE WORK}

During the summer of 2007, graduate student Evgeny Stankovskiy will complete his doctoral dissertation, which will be the final research within the RACE Project. In addition, the PI will be the General Chair of the Fifth Workshop on Accelerator-Driven Subcritical Systems Experiments will be conducted at the Idaho State University as part of the Eighth International Topical Meeting on Applications and Utilization of Accelerators (AccApp'07).

Research Staff

Denis Beller, Principal Investigator, Research Professor, Department of Mechanical Engineering

Students

Evgeny Stankovskiy, Graduate Student, Department of Mechanical Engineering

Timothy Beller, and Ryan LeCounte, Graduate Students, Department of Mechanical Engineering

\section{Collaborators}

George Imel, Argonne National Laboratory; John Bennion and Alan Hunt, Idaho State University; William Charlton, Texas A\&M University; Sean O'Kelly, University of Texas at Austin; and, John C. Lee, University of Michigan 


\title{
Impact of the Synthesis Process on Structure Properties for AFCI Fuel Candidates
}

\author{
K. Czerwinski
}

\section{BACKGROUND}

Synthesis of actinium mononitrides using carbothermic reduction of the corresponding oxides has a few outstanding issues, including the formation of secondary phases such as oxides and carbides and low densities of the final product. Furthermore the requirement of a high process temperature at $1700^{\circ} \mathrm{C}$, for more than 12 hours is also a drawback particularly for Americium-bearing samples. Therefore, it is important to explore the use of other possible routes to synthesize actinide mononitrides.

A low temperature process is used in this research to produce actinide mononitrides using a fluoride route in which the first step is to mix the actinide oxide with $\mathrm{NH}_{4} \mathrm{HF}_{2}$. The second step involves the heat-treatment of the resulting ammonium actinide fluoride salts in ammonia atmosphere. Using different analytical techniques available, the experimental conditions can be studied and optimized to synthesize the required materials with high phase purity. Such available techniques are X-ray Powder Diffraction (XRD), Thermogravimetry and Differential Scanning Calorimetry (TG/DSC), and microscopic techniques such as Scanning Electron Microscopy (SEM) and Transmission Electron Microscopy (TEM). Once the experimental conditions are studied and optimized, a number of actinide nitride systems (uranium, thorium, and neptunium) will be synthesized and characterized to provide knowledge on the chemistry of the systems. Characterization of these nitride systems will include chemical phase identification, lattice parameter refinements, morphological studies, microstructural verifications, thermal behavior, reaction mechanism, and reaction kinetics.

\section{RESEARCH OBJECTIVES AND METHODS}

The research objectives are:

- To explore a low-temperature fluoride route to synthesize actinide nitrides.

- To characterize actinide nitrides structurally and thermally.

- To use high resolution TEM techniques to explore the microstructure of the radioactive samples.

\section{RESEARCH ACCOMPLISHMENTS}

\section{Uranium based nitride synthesis and characterization}

The fluoride route was successfully used to synthesize three uranium nitride samples with different stoichiometry $\left(\mathrm{UN}_{2}, \mathrm{U}_{2} \mathrm{~N}_{3}\right.$, and UN). Experimental conditions were optimized to synthesize high phase purity UN (97 wt.\%). Thermal decomposition of $\mathrm{UN}_{2}$ under different atmospheric conditions was also studied, and ultra high purity argon could successfully be used to reduce the sample completely to $\mathrm{UN}$ at $1100^{\circ} \mathrm{C}$, see graph on the opposite page. $\mathrm{UN}_{2}$ and $\mathrm{U}_{2} \mathrm{~N}_{3}$ decomposition kinetics into $\mathrm{UN}$ were studied under argon at three different temperatures $\left(1000,1050\right.$, and $\left.1100^{\circ} \mathrm{C}\right)$.

Optical microscopy and SEM were used to explore the morphology of uranium nitride samples. Bright Field Transmission Electron Microscopy was also used to confirm the morphological observations. Microstructural studies of the samples were carried out using high resolution (HR) TEM with the help of selected area diffraction (SAD) patterns. X-ray energy dispersive spectrometry of TEM was utilized to characterize the elemental distribution and to verify the phase purity of the samples. Powder XRD patterns of the as-synthesized uranium nitrides, $\mathrm{UN}_{2}, \mathrm{U}_{2} \mathrm{~N}_{3}$, and UN were collected and analyzed. Optical microscopic studies showed that the particle sizes of these uranium nitride samples range from 100 to $5000 \mathrm{~nm}$. The microstructure of the UN sample shows the presence of $\mathrm{UO}_{2}$ as a secondary phase on the surface of the sample. In this region, the lattice fringes correspond to the (222) interplanar $d$-spacing of $\mathrm{UO}_{2}$. X-ray Energy Dispersive
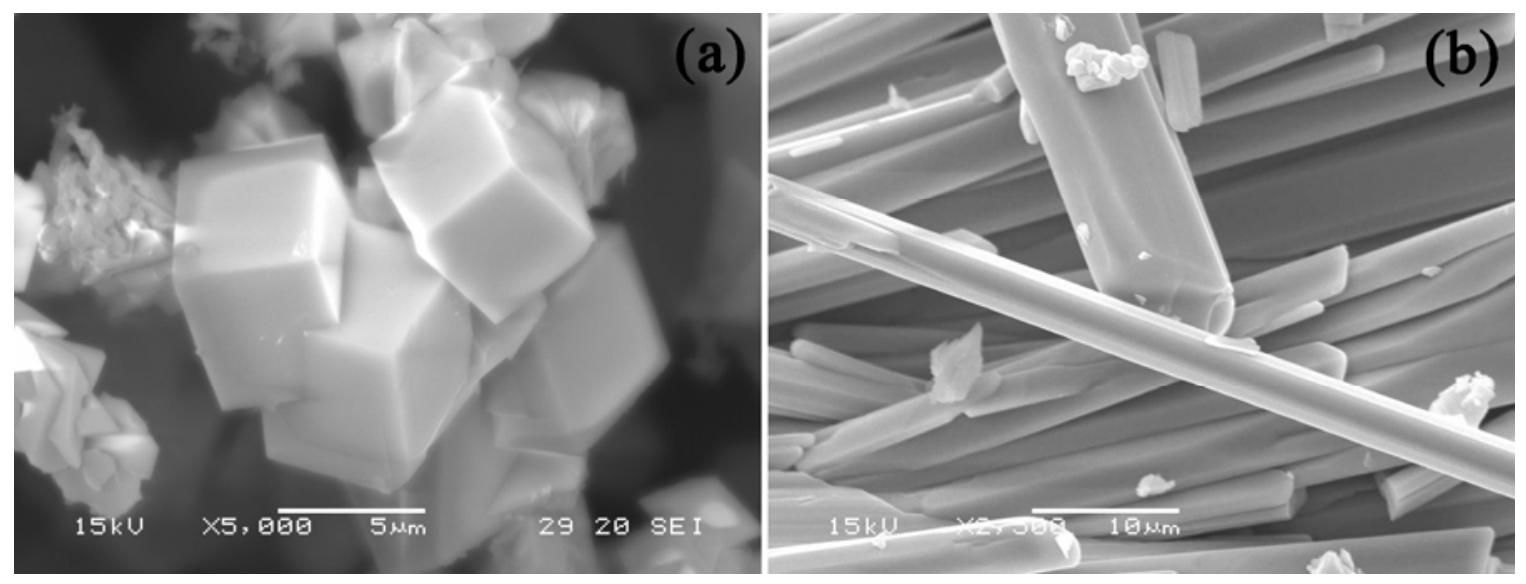

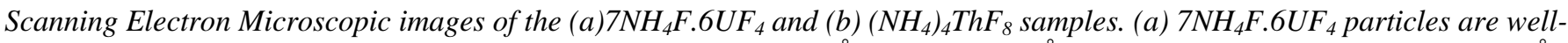
crystallized (hexagonal unit cell with a rhomb-centered, $a(b)=15.40 \AA$ and $c=10.49 \AA$ and $U N_{2}$ is cubic (fcc) with $\left.a=5.310 \AA\right)(b)$ Well-crystallized $\left(\mathrm{NH}_{4}\right)_{4} \mathrm{ThF}_{8}$ acicular-shaped particles (triclinic unit cell with lattice parameters $a=8.477, b=8.364$, and $c=7.308 \AA$ ). 


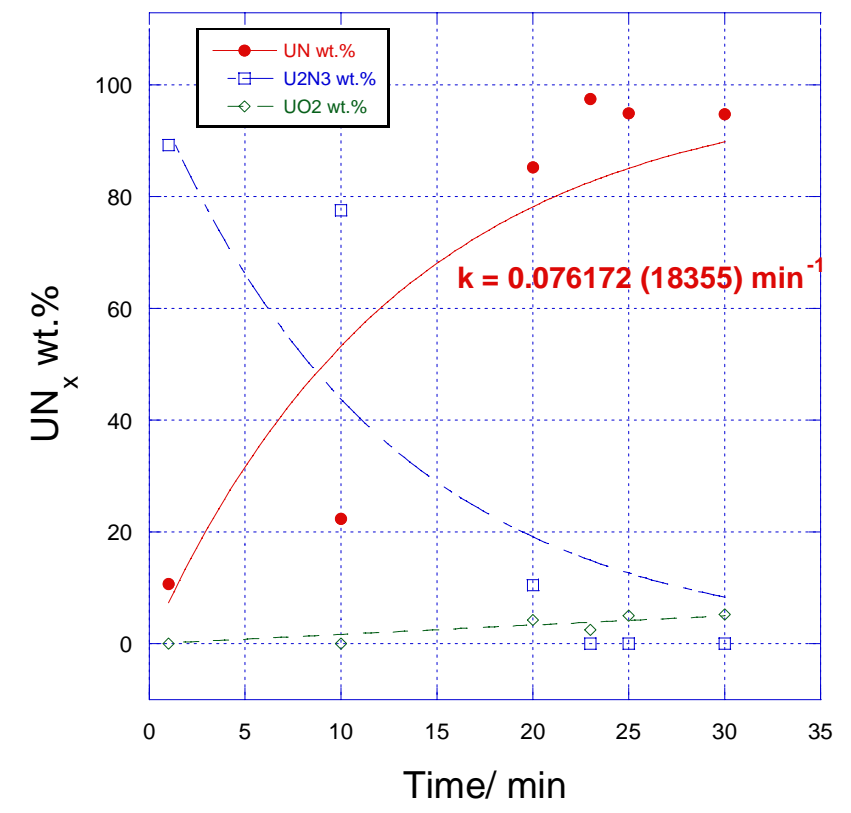

Pseudo-first-order kinetics of $\mathrm{UN}_{2}$ denitriding at $1100^{\circ} \mathrm{C}$.

Spectrometry (XEDS) demonstrated that U was prominent, but it is difficult to identify the presence of $\mathrm{N}$ due to overlaps with peaks from $\mathrm{O}$ and $\mathrm{C}$. However, the magnified EDS spectra verifies the presence of $\mathrm{N}$ in samples, and this figure also displays the presence of $\mathrm{O}$ only in the UN sample. Thus, the XEDS verifies the phase purity of the synthesized sample.

Thorium based nitride synthesis and characterization Use of the fluoride route was successful only up to the formation of ThNF. The removal of fluorine, which should have lead to the formation of thorium nitrides was unsuccessful at different experimental conditions. However, the characterization of ammonium thorium fluoride and ThNF was done using the above mentioned techniques.
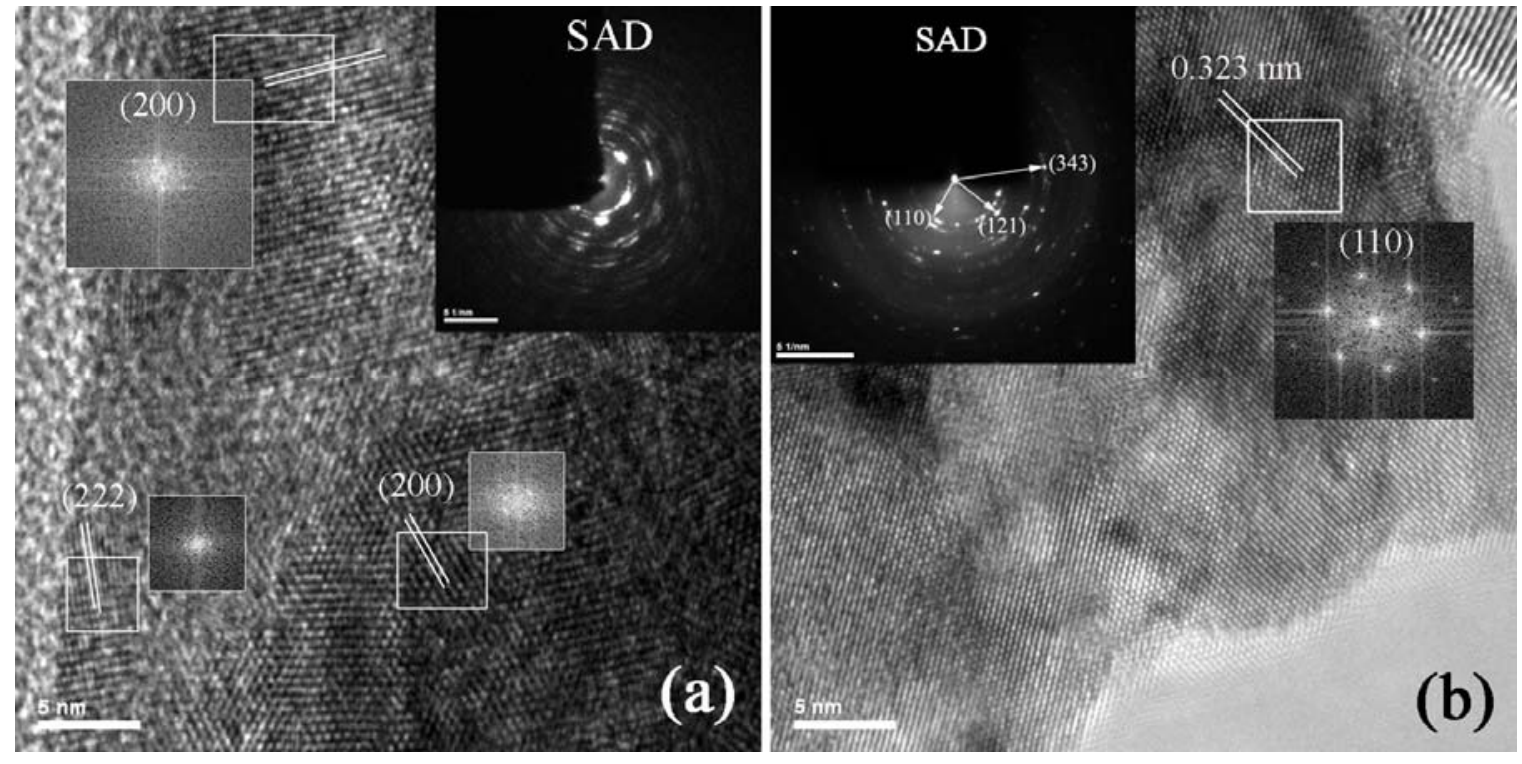

High resolution TEM images of (a) UN and (b) ThNF samples. (a) Crystallography of UN was confirmed using the lattice fringes of HRTEM image, and the secondary oxide phase was only identified at the surface of the particle edge. (b) ThNF crystal structure which is determined using XRD was confirmed by the HRTEM and SAD pattern.

Research Staff

Ken Czerwinski, Principal Investigator, Associate Professor, Department of Chemistry

Gary Cerefice, Assistant Research Professor, Harry Reid Center for Environmental Studies

Students

Chinthaka Silva, Graduate Student, Department of Chemistry

Charles Yeamans, Graduate Student, University of California, Berkeley

Al Sattelberger, Argonne National Laboratory 


\title{
Investigation of Optical Spectroscopy Techniques for On-Line Materials Accountability in the Solvent Extraction Process
}

\author{
G. Cerefice and K. Czerwinski
}

\section{BACKGROUND}

Increasing the proliferation resistance of the nuclear fuel cycle is one of the stated goals for both the advanced fuel cycle initiative (AFCI) and the global nuclear energy partnership program. From a proliferation aspect, the greatest challenge to closing the nuclear fuel cycle is ensuring that nuclear material is not diverted during the recycling processes. As part of the safeguards-by-design concept, new separations facilities will incorporate integral systems capable of providing materials accountability for the actinide elements to minimize the potential for undetected diversion of material. The goal of this project is to evaluate technologies to meet this need. Optical spectroscopic techniques, such as UltravioletVisible Spectroscopy (UV/Vis) and Laser Fluorescence Spectroscopy (LFS), are quantitative analytical techniques that have been used for measuring the concentration of the actinides under laboratory conditions.

In UV/Vis spectroscopy, the sample is illuminated by a continuous spectrum (from the UV through the Visible wavelengths). The transmitted light is measured, allowing the determination of the absorbance of the light as a function of wavelength. The wavelength of the absorbance is dependant on the electronic structure of the absorbing atom, and is proportional to the concentration of the absorbing element in the sample. For LFS, the sample is illuminated at a single wavelength, which is absorbed by the target atoms in the sample. The energy absorbed is re-emitted through fluorescence. The wavelength of the absorbance, and the fluorescence-response, is again dependant on the electronic structure of the absorbing atom, and is proportional to the concentration of the absorbing element in the sample.

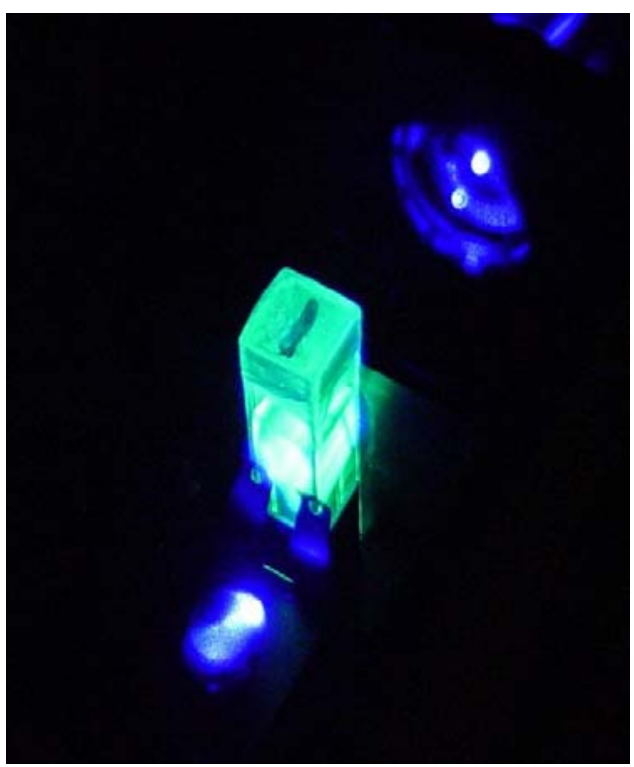

Laser induced fluorescence of a uranium sample in nitric acid

ured, providing a tool for not only the determination of material concentrations for mass balances, but also providing inspectors and plant operators with a tool to examine the process chemistry itself. As optical techniques, both of these methods can be adapted for fiber optics, allowing the instrumentation to be placed in shielded areas of the plant to minimize the impact of the radiation fields on the detectors and increase the accessibility of the systems for maintenance and inspection.

\section{RESEARCH OBJECTIVES AND METHODS}

The goal of this project is to evaluate the application of these analytical techniques to the on-line, real-time measurement of the actinide elements in the process streams of a solvent extraction process, with particular attention to the UREX+ and PUREX processes. Based on the experience gained through this effort, engineers will have the information necessary to decide if these technologies should be advanced to the prototype stage and tested at the pilot plant level. Through the experimental work planned as part of this effort, researchers will also develop a better understanding of the chemical interactions of the actinide elements, providing additional data for the development of first-principles based models of the solvent extraction process. The information gathered through these experiments will also add to the database on the UREX+ solvent extraction process, particularly in the offnormal operating regimes.

The research objectives are:

- To evaluate the potential for utilizing UV-Visible and laser fluorescence spectroscopy to determine actinide concentrations under process conditions, including the spectroscopic impact of acid concentration, solvent vs. aqueous product streams, ligand concentrations (TBP, AHA), and chromophoric agents (e.g. iron) from fission products or corrosion/ degradation products.

- To examine what process chemistry information can be extracted from the spectroscopic signals along with the actinide metal concentrations.

- To examine the fundamental chemistry underlying the spectroscopic behavior under process conditions in support of process chemistry modeling activities.

\section{RESEARCH ACCOMPLISHMENTS}

To evaluate the potential application of optical spectroscopy techniques for the determination of uranium in the aqueous process streams of the UREX process, the impact of process chemistry on the absorbance and fluorescence behavior of the uranyl ion was examined. For the UREX flowsheet, the potential areas for deployment of these techniques was divided into four categories, based on the chemical environment, each represented by a feed or product stream: the process feed, the raffinate (actinide/fission product) stream, the technetium product stream, and the uranium product stream. These process ranges also allowed researchers to examine the potential application of these technologies to a PUREX-based flow sheet as well. 
The UREX feed stream and uranium product will both have molar quantities of uranium present. The concentration of uranium in these streams is expected to exceed the linear range of detection for a $1 \mathrm{~cm}$ path length cell. To measure these high concentration streams by UV/Vis, plant designers would need to either insert a reduced path-length slip stream or add the capability for a fixed mass dilution in the slip stream. Either of these options, or more realistically the combination of the two, could reduce the absorbance in the system back to within the linear response range of the technique.

The raffinate and technetium streams are expected to have significantly lower concentrations of uranium. For the UREX process, the raffinate stream will also contain the AHA from the process. Based on the measured molar extinction coefficients for uranium under the chemical environments expected for these streams, the expected uranium concentrations will likely fall below the detection limits observed for a $1 \mathrm{~cm}$ optical path. While the limits of detection may be able to be extended with a longer path length, scattering and other phenomena would likely only limit this to an order of magnitude reduction in the detection limit. Even with these limitations, the technique could still be used to establish a threshold value for uranium, which may be useful in detecting changes in process chemistry. UV/Vis spectroscopy, combined with titration by a fixed mass of a caustic stream, can also be used to probe for the presence of AHA in the raffinate stream, allowing for independent confirmation that the plant is running the UREX flowsheet and has not switched to a plutonium extraction process (such as PUREX).

\section{Laser Fluorescence Spectroscopy}

The primary focus of the year two work on the project was the evaluation of Time Resolved Laser-induced Fluorescence Spectroscopy (TRLFS) techniques for the determination of uranium under process conditions. The impact of process chemistry on the observed lifetime and fluorescence yield of uranium in the aqueous process streams was investigated. TRLFS was determined to be significantly more sensitive for the detection of uranium, so much so that the signals in the feed and uranium product streams would easily saturate the detection systems. This sensitivity, however, may make the technique ideal for observing streams where the uranium concentration is expected to be very low, such as the technetium product stream and the raffinate stream. The detection limits and linear response regimes for both these process streams have been examined.

\section{ACADEMIC YEAR HIGHLIGHTS}

- N.A. Smith, G.S. Cerefice, and K.R. Czerwinski, “Application of Optical Techniques for On-Line Materials Accountability in the UREX Solvent Extraction Process," Proceedings, $47^{\text {th }}$ Annual Institute for Nuclear Materials Management Annual Meeting, Nashville, TN, July 16-20, 2006.

- N.A. Smith, G.S. Cerefice, and K.R. Czerwinski, "Use of UVVis spectroscopy and TRLFS for material accountability in solvent extraction processes," $233^{\text {rd }}$ National Meeting of the American Chemical Society, Chicago, Il, March 27, 2007.

\section{FUTURE WORK}

For the final project year, work will continue to apply the spectroscopy techniques to expand the fundamental understanding of the chemistry of uranium under process conditions, with the goal of providing the theoretical basis to allow a better interrogation of the observed spectra to confirm process chemistry conditions. Research will also examine the potential spectral interferences on the determination of uranium due to dissolved iron (and other corrosion products), fission products, and other actinide elements.

In parallel, the application of these techniques to the organic process streams will be examined. Initial TRLFS experiments on uranium samples extracted into the organic phase have showed no fluorescence under laser irradiation. The reason for this is being investigated, but the leading hypothesis is that the $\mathrm{C}-\mathrm{H}$ oscillators of the organic matrix are acting as quenching agents in much the same way that $\mathrm{O}-\mathrm{H}$ oscillators do in a water based system. As a result, it is unlikely that TRLFS will be useful for determination of uranium concentrations in the organic streams. Initial experiments suggest that UV-Visible spectroscopy, however, appears to be a viable alternative technique for these organic process streams.

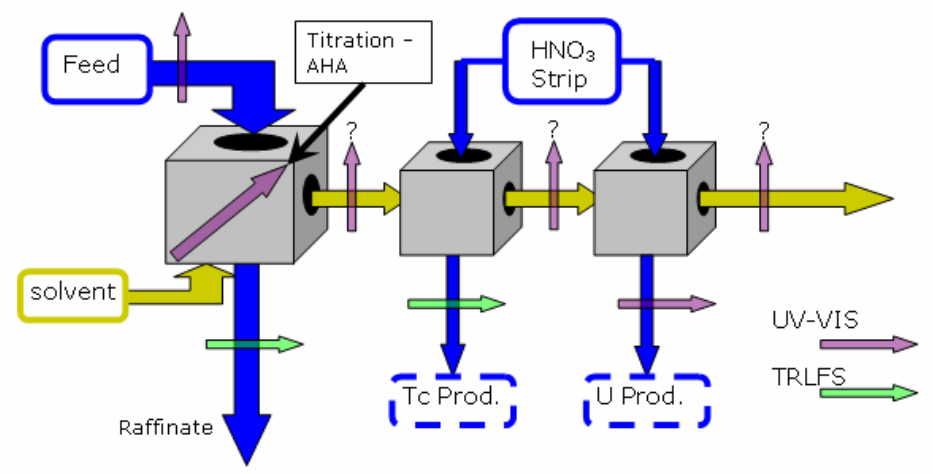

Potential Application Locations for Optical Spectroscopy in the UREX Flowsheet

Research Staff

Gary Cerefice (PI), Asst. Research Professor, UNLV Radiochemistry Ph.D. Program

Ken Czerwinski, Assc. Professor, UNLV Chemistry Department, Director - UNLV Radiochemistry Ph.D. Program

Students

Nicholas Smith, Graduate Student, UNLV Radiochemistry Ph.D. Program

Jeremy Maute, Undergraduate Student, Chemistry

George Vandergrift, Argonne National Laboratory 


\title{
Combined Radiation Detection Methods for Assay of Higher Actinides in Separation Processes (AFCl)
}

\author{
D. Beller and W. Kernan
}

\section{BACKGROUND}

Monitoring of higher actinides (HA-includes neptunium, plutonium, americium, and curium) during the separation of used nuclear fuel has been identified as a critical research area in the U.S. Advanced Fuel Cycle Initiative (AFCI). Recycling of used fuel by chemically separating it into uranium, fission products, and HA would be the first step in this new fuel cycle. Material Protection, Accounting, and Control (MPAC) is necessary for materials accounting, criticality monitoring, and assurance of proliferation resistance.

In the MPAC project, faculty and students are investigating the potential to use combined neutron and gamma-ray detector systems to measure quantities and isotopic constituents contained during separations and intermediate storage. This will require knowledge of the nuclear and decay characteristics of materials during processing, the development of conceptual designs of monitoring systems, radiation transport studies to develop an understanding of operational regimes, and experiments to confirm performance. In addition, both passive and active concepts will be investigated, including collaborations with the Idaho Accelerator Center at Idaho State University (ISU) to use electron linear accelerators for producing photoneutrons in situ, for photon activation of HA, or for stimulating emissions processes (e.g. x-ray fluorescence).

\section{RESEARCH OBJECTIVES AND METHODS}

The ultimate objective of this project is to develop technology to detect and accurately measure quantities of higher actinides in processing systems without taking frequent samples. These systems include used fuel receipt, separations batches, and pipelines. A variety of measurements may be combined to calculate flow rates of actinide elements with a to-be-determined precision. Nuclear and decay characteristics of materials during processing will be acquired, conceptual designs of monitoring systems will be developed, radiation transport studies will be conducted to develop an understanding of operational regimes, and experiments will be performed to confirm performance. Radiation transport and scoping studies will be conducted to investigate combined gamma-ray, neutron, and active and passive detection techniques to measure quantities and isotopic constituents contained during separations and intermediate storage. Scoping and design studies will first be performed using validated data sets (decay properties and reaction cross sections) and the radiation transport code MCNPX. Basic measurements will then be performed and compared to predictions. Experiments to be conducted in subsequent work are to be determined, but may include small quantities of radioactive actinides at UNLV in addition to accelerator-coupled experiments at ISU.

\section{RESEARCH ACCOMPLISHMENTS}

Students continued to develop concepts and models for use of the ${ }^{3} \mathrm{He}$ Neutron Multiplicity Detector System (NMDS, which was developed as part of Task 6) for MPAC. Technology for assaying fuel rods and/or complete assemblies, and the use of the NMDS and other techniques to assay dilute quantities of HA in waste and other process streams were investigated.

\section{Lead and Carbon-based Slowing Down Spectrometers}

Neutron slowing down spectrometers (SDSs) were modeled and plans were developed to conduct experiments at ISU with their carbon-based SDS. This work will be used to investigate technology for assaying fuel rods and/or complete assemblies. In preparation for these experiments, MCNPX was used to model neutron transport characteristics in lead and carbon-based SDSs. The energy of neutrons measured in a neutron detector with an SDS can be characterized by the equation $\mathrm{E}=\mathrm{K} /\left(\mathrm{t}+\mathrm{t}_{0}\right)^{2}$, where $\mathrm{E}$ is the energy of the neutron when it was created at the source (not its energy when detected), $\mathrm{t}$ is the time of the radiation detection (count) after a source event, and $\mathrm{K}$ and $\mathrm{t}_{0}$ are characteristics of the particular SDS. Thus, if an accelerator pulse is used to generate neutrons which then initiate fission, the time history of the spectrum can be de-convolved to yield the energy spectrum. In addition, the neutron multiplicity can simultaneously be measured by the NMDS.

However, the detector system must be able to resolve the time dependence of the neutron signal. Because ${ }^{3} \mathrm{He}$ detectors, such as those contained in the NMDS, have a slow response, the SDS configurations must be studied before conducting experiments. Those studies are currently ongoing, beginning with benchmarking computational methods. A Los Alamos lead SDS was mod-
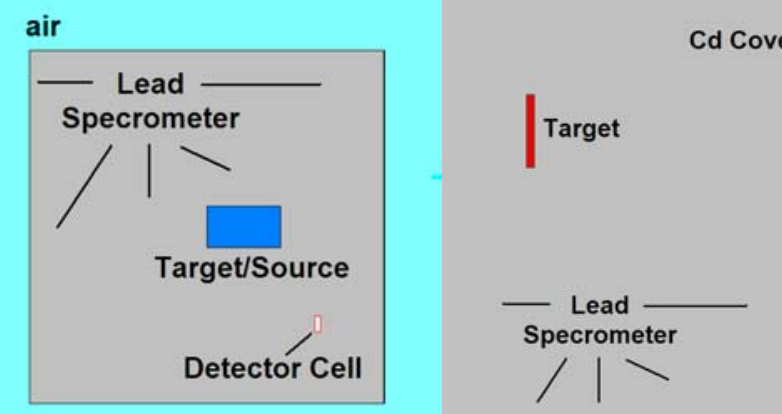

Cross sections of the UNLV benchmark of the LANL lead SDS taken from MXNPX models. (Left) The overall geometry, (Right) A close-up of a cross section of the thin target. The response to neutrons of various energies (time constants) is influenced by the position and isotopic composition of the detector. 
eled to benchmark computational methods for determining energy-time correlation constants, and energy-time correlation constants are now close to those obtained in LANL experiments. The next step will be to use the MCNPX code to design an experiment using the ISU carbon-based SDS and electron linac, followed by experiments conducted at ISU in the next year. During this period, plans were developed to conduct experiments at ISU with the carbon-based SDS to develop technology for assaying fuel rods and/or assemblies.

\section{MPAC for UREX+ Processes}

Another application of NMDS to MPAC might utilize the measurement of both passive and active neutron multiplicity in very dilute concentrations of higher actinides, such as in a non-actinide waste stream. This is being investigated since it may be more feasible to monitor where actinides are not supposed to be than where they are. The NMDS will be used to assay actinides in pipes, tanks, etc. in a UREX+ fuel separations plant to measure quantities and isotopic constituents in such a stream. Sources and configurations were investigated to simulate a waste pipe that contains residual higher actinides from UREX-plus for use in upcoming experiments.

\section{$\underline{\text { Neutron Multiplicity Detector System }}$}

Several programming and maintenance issues with the NMDS that were revealed during testing in December were repaired or resolved. New detector wiring that was installed on one detector group of NMDS significantly reduced background count rates (noise). As a result, all of the of standard cables were replaced with coaxial cables. In addition, as a result of differences in detector response between the original Russian data acquisition system and the new LabView-based system, detector response is being re-mapped with the data collection and analysis software. These improvements are expected to significantly improve the performance of the NMDS.

\begin{tabular}{|c|c|c|c|}
\hline Isotope & $\begin{array}{l}\text { Resonance } \\
\text { energy (ev) }\end{array}$ & $\begin{array}{c}\mathrm{K}\left(\mathrm{keV}^{*} \mu \mathrm{sec}^{2}\right) \\
\text { LANL }\end{array}$ & $\begin{array}{c}\left.\text { K (keV* } \mu \sec ^{2}\right) \\
\text { UNLV }\end{array}$ \\
\hline $\ln -115$ & 1.5 & 164 & \\
\hline Ta-181 & 4.3 & 161 & 148 \\
\hline Au-197 & 4.9 & 158 & 194 \\
\hline $\mathrm{Ag}-109$ & 5.2 & 161.5 & 191 \\
\hline Ta-181 & 10.4 & 162 & 153 \\
\hline $\mathrm{Ag}-107$ & 16.3 & 162.5 & 166 \\
\hline $\mathrm{Cd}-111$ & 27.5 & 163 & 167 \\
\hline Au-197 & 59 & 159 & 174 \\
\hline
\end{tabular}

Comparison of UNLV MCNPX computed time constants versus LANL's values for the LANL LSDS benchmark.

\section{ACADEMIC YEAR HIGHLIGHTS}

- D. Beller, W. Kernan, M. Schanfein, T. Ward, A. RimskyKorsakov, F. Harmon, Q. Newell, L. Lakeotes, P. Attur, T. Beller, and R. LeCounte, "Combined Radiation Detection Methods for AFCI MPAC Project,” Proceedings, 47th Annual Meeting of the Institute of Nuclear Materials Management, Nashville, TN, July 16-20, 2006.

- A collaboration with the V. G. Khlopin Radium Institute was developed for an upgrade to and maintenance on the Neutron Multiplicity Detector System.

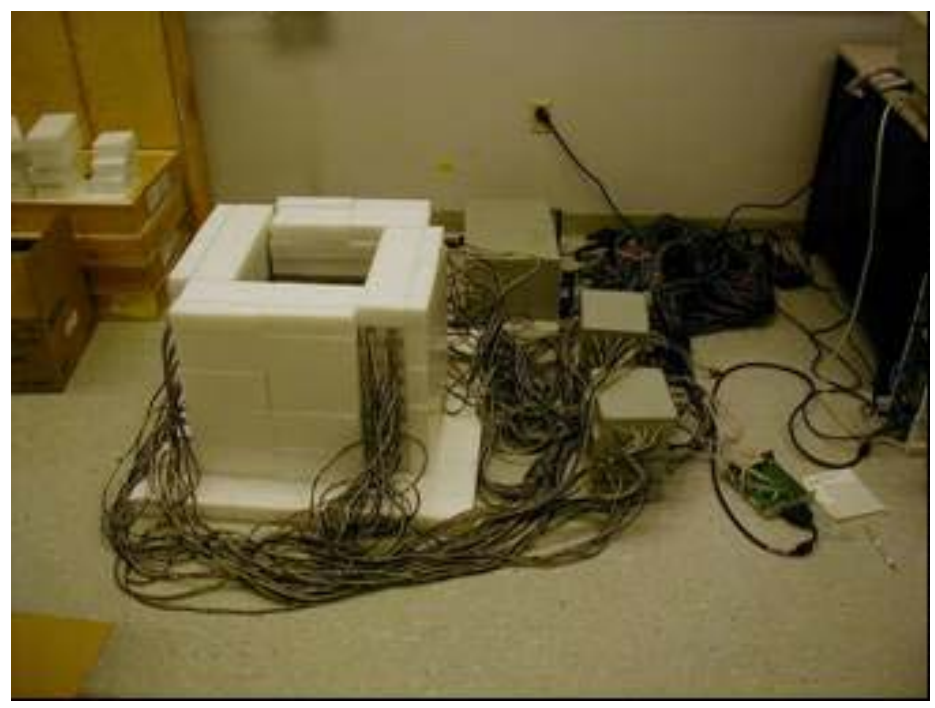

Neutron Multiplicity Detector System configured in a cubic geometry for background and source counting.

\section{FUTURE WORK}

In the final year of this project modeling will be completed, the NMDS will be tested further, and it will be employed in two separate experiments. One is with a carbon-based neutron slowing down spectrometer to develop LSDS technology to assay fuel assemblies upon receipt for separations, and the other is to assay a process pipe containing dilute concentrations of separated higher actinides. The CSDS has been constructed at the Idaho Accelerator Center. Actinides for the pipe assay experiments are available at UNLV, how they will be used in these studies is yet to be determined.

Research Staff

Dr. Denis Beller, Principal Investigator, Research Professor, Mechanical Engineering Department

Dr. Warnick Kernan, UNLV Instructor, Physics Department; Principal Scientist, Remote Sensing Laboratory (RSL)

Students

Quinten Newell, Lawrence Lakeotes, and Timothy Beller, Graduate Students, Mechanical Engineering Department

Collaborators

Dr. Mark Schanfein, Safeguards and Security Group, Los Alamos National Laboratory

Dr. James Laidler, National Technical Director for Separations and Waste, Argonne National Laboratory

Dr. Thomas Ward, UNLV Science Adviser for Russian Collaborations, TechSource, Inc. 


\section{Deep Burn \\ Deep Burn Separation and Repository Performance (UNLV) \\ K. Czerwinski and G. Cerefice}

\section{BACKGROUND}

This task is part of a larger national program to develop and demonstrate the science and technology required for the integration of tri-isotropic (TRISO) fuel for gas reactors into the current and future nuclear fuel cycles. This includes the fabrication of transuranic actinide-bearing kernels, the recycling and partitioning of TRISO fuels, and the performance of TRISO particles in a waste repository.

\section{RESEARCH OBJECTIVES AND METHODS}

Deep burn separation and repository studies was performed by a collaborative comprising UNLV, Savannah River National Laboratory (SRNL), and the University of Iowa. The UNLV team evaluated the treatment of TRISO fuel in a fluidized bed as a reprocessing step. Repository behavior of fuels was also performed.

The SRNL assisted in the development of X-ray absorption finestructure (XAFS) spectroscopic studies to provide information on the average coordination environment of specific elements of interest. This technique which reveals information on local structure can be conducted with amorphous as well as crystalline materials. Working with radioactive samples at synchrotron facilities and the acquisition of XAFS spectroscopic data from radioactive samples poses challenges for researchers. The purpose of this work was to mentor students in the area of XAFS data acquisition with radioactive samples in an X-ray user facility at a national laboratory. SRNL researchers arranged the user time, met the safety guidelines required for the work at the user facility, determined detector needs, assisted with the handling/manipulation of the samples at the user facility and X-ray beam line set-up, helped the UNLV students with the acquisition of quality XAFS spectra, and answered questions regarding XAFS analyses.

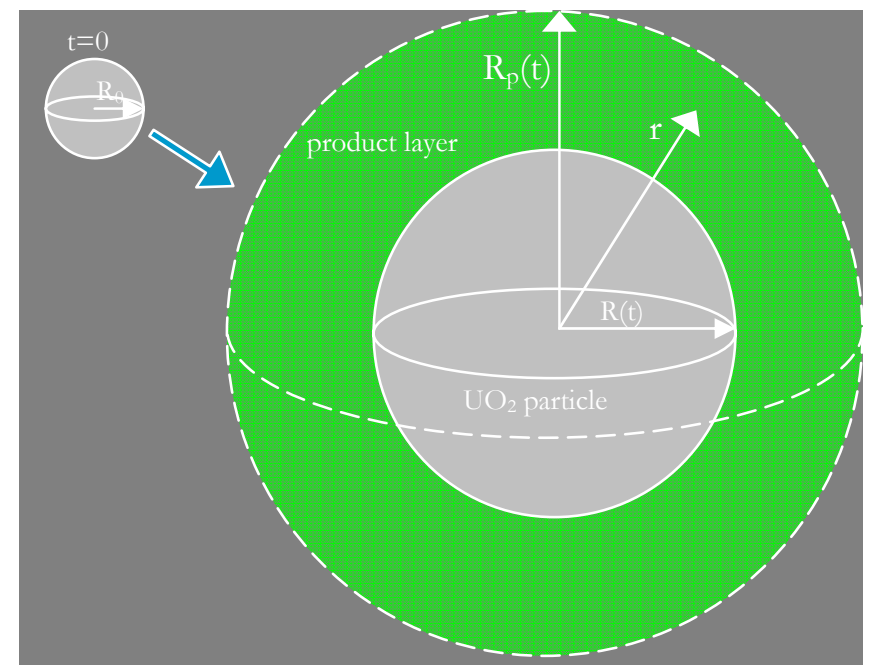

Graphical Representation of a Model Shrinking Sphere.

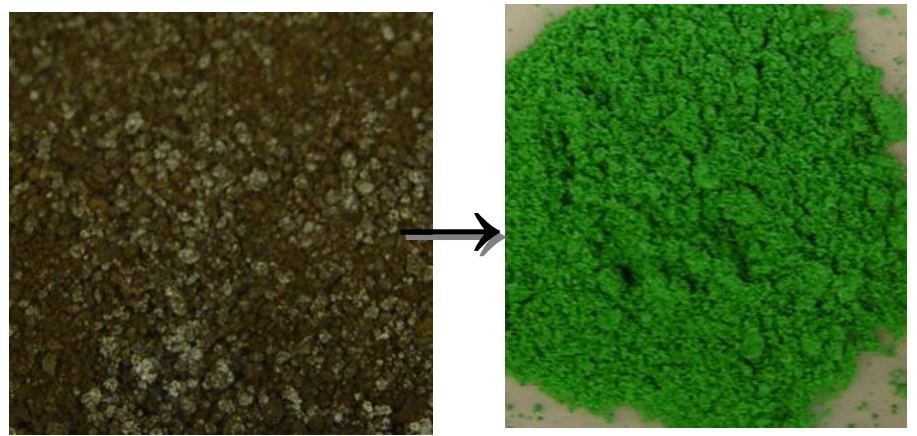

Mixed Ammonium Bifluoride and Uranium Dioxide Before (left) and After (right) Ball Milling at $25^{\circ} \mathrm{C}$.

The University of Iowa partner synthesized ligands for the separation of lanthanides from actinides and actinides from other actinides. The goal of this research was to develop a rational, scalable method to separate americium from curium using ligands that take advantage of coordination preferences and size selectivity within $\mathrm{Am}$ and $\mathrm{Cm}$ coordination spheres. Specifically the following aims were addressed:

- Development of new ligands for the separation of $\mathrm{Am}^{3+}$ from $\mathrm{Cm}^{3+}$. The proposed ligand groups exploit the principle inner-sphere coordination preferences of the actinides. These ligands are attached to rigid architectural groups that also enforce size discrimination.

- Determination of the ligand affinities for the lanthanide and members of the actinide series. The affinity was thermodynamically and kinetically quantified. The data was incorporated into models to evaluate trivalent actinide separations under varying conditions.

\section{RESEARCH ACCOMPLISHMENTS}

\section{Fuel Treatment by Fluorination}

Ammonium bifluoride was investigated as a chemical deconstruction agent for TRISO-coated fuels. Solid-solid reactions were observed between ammonium bifluoride and oxides of vanadium, zirconium, thorium, uranium, and plutonium. Fundamental information is needed on reaction mechanisms and rates of ammonium bifluoride with uranium dioxide, silicon carbide, and pyrolytic carbon in order to incorporate into a shrinking-sphere model (see figure, left) of a TRISO-coated particle. This model was needed for process design. In a hypothetical end-of-cycle processing scheme, a chemical deconstruction may prove a viable alternative to physical methods now being considered.

Chemical compounds in the ammonium uranium fluoride system are $\left(\mathrm{NH}_{4}\right)_{\mathrm{x}} \mathrm{UF}_{4+\mathrm{x}} \cdot \mathrm{yH}_{2} \mathrm{O}$

$$
\mathrm{x}: 4,2,7 / 6,1 \text {, or } 1 / 3 \text {. }
$$

$\mathrm{y}$ : 0 when $\mathrm{x} \neq 4$ continuous up to 2 when $x=4$ 
Ammonium bifluoride will fluorinate uranium dioxide at $25^{\circ} \mathrm{C}$ when the reagents are maintained in good physical contact with some interstitial pore volume. Experiments were conducted in a mechanical ball mill with $\sim 10 \mathrm{~g}$ charges of ammonium bifluoride and uranium dioxide (see figure on opposite page, above). The initial product upon milling for 20 minutes was a mixture of ammonium uranium fluoride compounds, including $\left(\mathrm{NH}_{4}\right)_{4} \mathrm{UF}_{8}, \gamma$ $\left(\mathrm{NH}_{4}\right)_{2} \mathrm{UF}_{6}$, and $\alpha-\left(\mathrm{NH}_{4}\right)_{2} \mathrm{UF}_{6}$. After one month in air with no additional mechanical agitation, the product was determine by its powder X-ray diffraction pattern to be pure $\left(\mathrm{NH}_{4}\right)_{4} \mathrm{UF}_{8}$.

Decomposition studies on the ball mill product were performed using a thermogravimetric analyzer (TGA). The decomposition product at $150^{\circ} \mathrm{C}$ in argon was determined to be $\beta-\left(\mathrm{NH}_{4}\right) \mathrm{UF}_{5}$. The decomposition product at $425^{\circ} \mathrm{C}$ in argon was determined to be $\mathrm{UF}_{4}$.

The fluorination studies on $\mathrm{SiC}$ with $\mathrm{NH}_{4} \mathrm{FHF}$ were performed by the UNLV team. No degradation of the SiC was observed. Work was initiated on $\mathrm{SiC}$ interactions with $\mathrm{U}$ and cloud point extraction experiments for Eu-Cm separations. The phase of the $\mathrm{SiC}$ was studied and surface analysis performed

\section{X-ray Absorption Fine-Structure Studies}

The SRNL team arranged for the safety aspects and assisted with the experiments at the Advanced Photon Source (APS) at Argonne National Laboratory. Actinide Sample Boxes were developed and produced for XAFS experiments The UNLV team performed further data analysis from the XAFS experiments. The SRNL team provided a final report on its activities.

\section{Ligand Development}

Acid-base titrations of the sodium salt of per-6-thiopropionate- $\beta$ cyclodextrin with the lanthanides were completed. The $\log \beta_{110}$ for the ligand with each lanthanide are shown in the graphs to the right. For comparison to the sodium salt of per-6-thiopropionate$\beta$-cyclodextrin, the data for the sodium salt of per-6thiopropionate- $\beta$-cyclodextrin is shown in the lower graph.

Synthesis of a mono- and tri-functionalized DTPA per-6ethyldiamino- $\beta$-cyclodextrin was accomplished $(\mathrm{m} / \mathrm{z} 1785.6$ and 2142.2 , respectively). The purification of these derivatives from unreacted per-6-ethylenediamino- $\beta$-cyclodextrin and hydrolyzed DTPA dianhydride was partially accomplished through Sephadex LH-20 column chromatography under basic conditions.
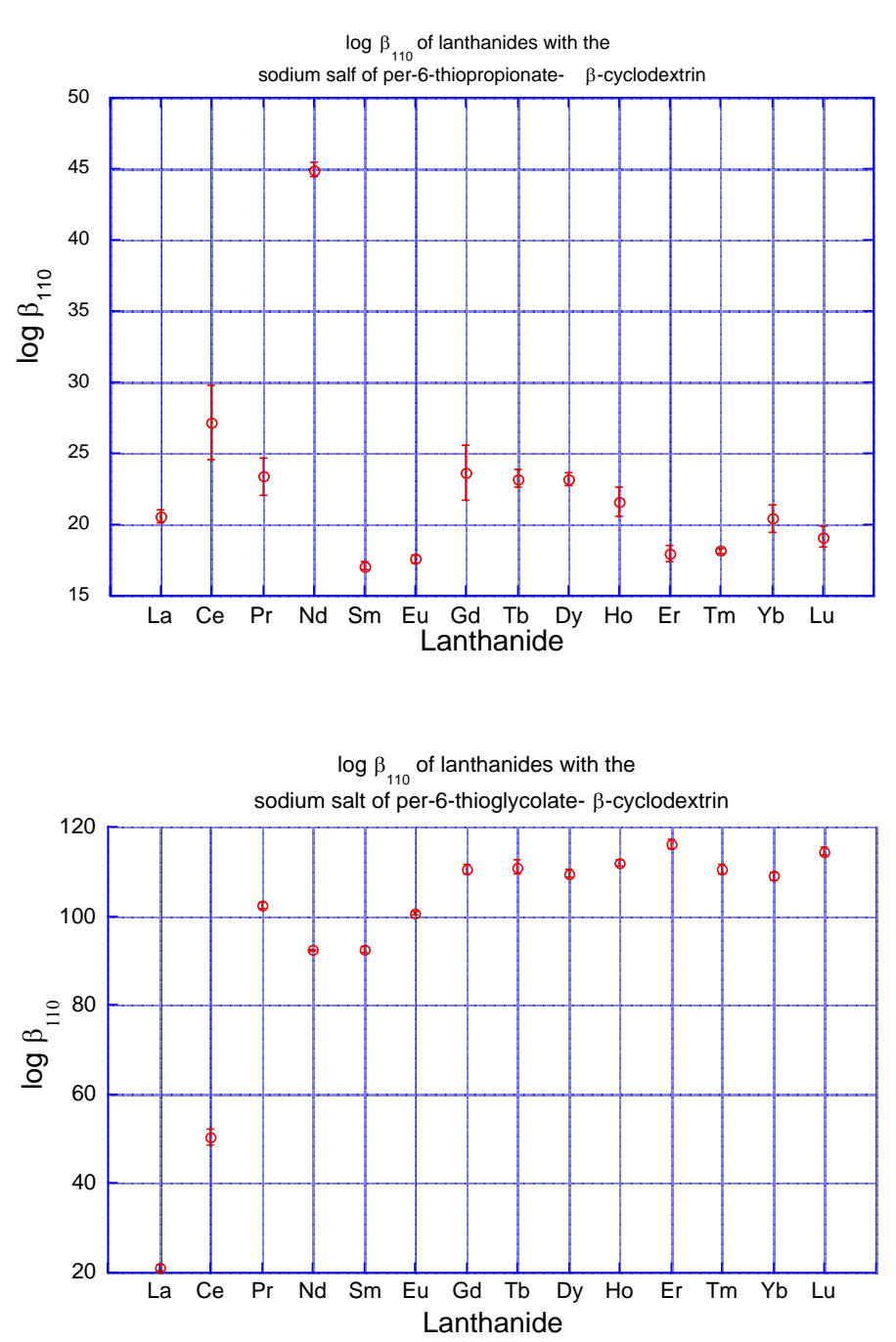

The 1:1 complex of $\mathrm{Tb}^{3+}$ and per-6-thiopropionate- $\beta$-cyclodextrin complex was detected by mass spectroscopy (m/z: 1957.4). This mass includes the complex, plus a water molecule that is most likely bound to the $\mathrm{Tb}$ and a methanol molecule that is thought to be included in the cavity. The 1:1 complex of $\mathrm{Eu}^{3+}$ and per-6thiopropionate- $\beta$-cyclodextrin complex was detected by mass spectroscopy (m/z: 1833.1). This mass includes the complex and a methanol molecule that is thought to be included in the cavity. Synthesis of a mono-6-tosyl- $\beta$-cyclodextrin $(\mathrm{m} / \mathrm{z}$ of 1310.5 for the $\mathrm{Na}^{+}$adduct) has been accomplished using literature methodology. Complete purification and optimization is underway.

Research Staff

Ken Czerwinski, Principal Investigator, Associate Professor, Department of Chemistry

Gary Cerefice, Assistant Research Professor, Harry Reid Center for Environmental Studies

\section{Students}

Troy Robinson and Richard Gostic, Graduate Students, Department of Chemistry (Radiochemistry Ph.D. Program)

Charles Yeamans, Graduate Student, Department of Nuclear Engineering, University of California, Berkeley

\section{Collaborators}

Martine Duff, Keisha Martin, and Doug Hunter, Savannah River National Laboratory

Jason Telford, Department of Chemistry, University of lowa 